\title{
Substrate metabolism in type 2 diabetes : an exercise and pharmacological approach
}

Citation for published version (APA):

Boon, H. (2009). Substrate metabolism in type 2 diabetes : an exercise and pharmacological approach. [Doctoral Thesis, Maastricht University]. https://doi.org/10.26481/dis.20091014hb

Document status and date:

Published: 01/01/2009

DOI:

10.26481/dis.20091014hb

Document Version:

Publisher's PDF, also known as Version of record

\section{Please check the document version of this publication:}

- A submitted manuscript is the version of the article upon submission and before peer-review. There can be important differences between the submitted version and the official published version of record.

People interested in the research are advised to contact the author for the final version of the publication, or visit the DOI to the publisher's website.

- The final author version and the galley proof are versions of the publication after peer review.

- The final published version features the final layout of the paper including the volume, issue and page numbers.

Link to publication

\footnotetext{
General rights rights.

- You may freely distribute the URL identifying the publication in the public portal. please follow below link for the End User Agreement:

www.umlib.nl/taverne-license

Take down policy

If you believe that this document breaches copyright please contact us at:

repository@maastrichtuniversity.nl

providing details and we will investigate your claim.
}

Copyright and moral rights for the publications made accessible in the public portal are retained by the authors and/or other copyright owners and it is a condition of accessing publications that users recognise and abide by the legal requirements associated with these

- Users may download and print one copy of any publication from the public portal for the purpose of private study or research.

- You may not further distribute the material or use it for any profit-making activity or commercial gain

If the publication is distributed under the terms of Article $25 \mathrm{fa}$ of the Dutch Copyright Act, indicated by the "Taverne" license above, 


\section{Substrate metabolism in type 2 diabetes}

An exercise and pharmacological approach 


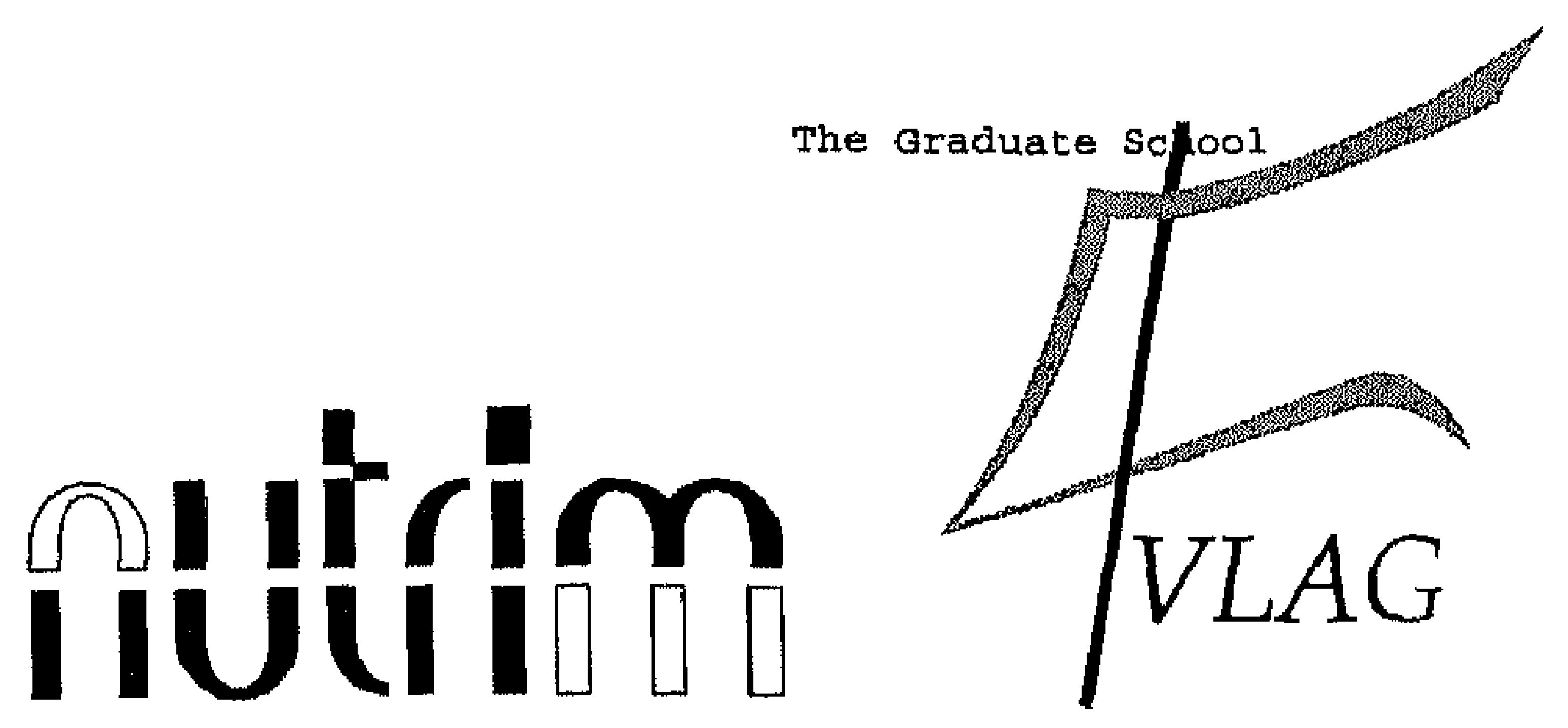

The studies presented in this thesis were performed at the Nutrition and Toxicology Research Institute Maastricht (NUTRIM), which participates in the graduate school VLAG (Food Technology, Agrobiotechnology, Nutrition and Health Sciences), accredited by the Royal Netherlands Academy of Arts and Sciences.

$\begin{array}{ll}\text { Cover design: } & \text { Ridderprint and Hanneke Boon } \\ \text { Layout: } & \text { Miranda de Haas } \\ \text { Printed by: } & \text { Ridderprint }\end{array}$

(C) Hanneke Boon, Maastricht, september 2009

ISBN 978-90-5335-210-6 


\section{Substrate metabolism in type 2 diabetes}

An exercise and pharmacological approach

\section{PROEFSCHRIFT}

ter verkrijging van de graad van doctor

aan de Universiteit Maastricht

op gezag van de Rector Magnificus

Prof.mr G.P.M.F. Mols

volgens het besluit van het College van Decanen

in het openbaar te verdedigen

op

woensdag 14 oktober 2009 om 16.00u

door

Hanneke Boon

geboren te Rotterdam op 24 juli 1981 


\title{
Promotores
}

Prof. Dr. E.E. Blaak

Prof. Dr. C.J. Tack

\section{Co-promotor \\ Dr. L.J.C. van Loon}

\author{
Beoordelingscommissie \\ Prof. Dr. C.D. Stehouwer \\ Prof. Dr. H. Kuipers \\ Prof. Dr. J.R. Zierath (Karolinska Institutet, Stockholm, Zweden) \\ Prof. Dr. M. Diamant (VUMC, Amsterdam) \\ Dr. P. Schrauwen
}

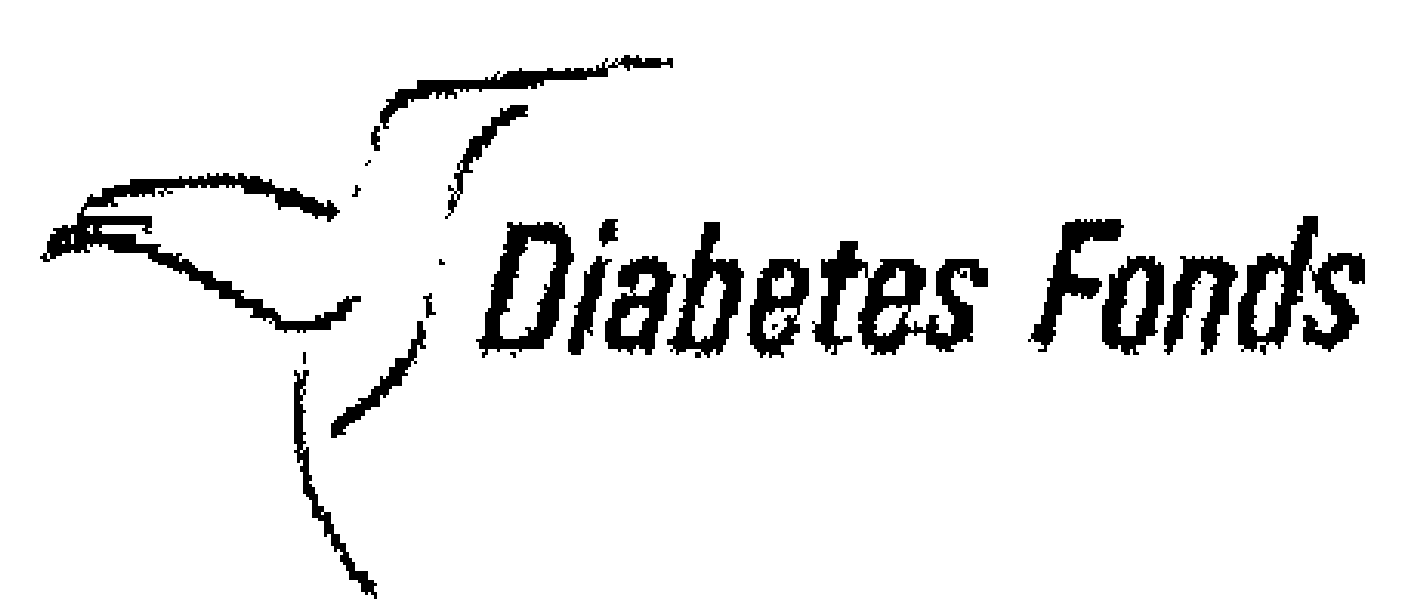

The research described in this thesis was supported by a project grant of the Dutch Diabetes Research Foundation (DFN 2002.00.04).

Printing of this thesis was financially supported by the Dutch Diabetes Research Foundation, which is gratefully acknowledged by the author. 


\section{CONTENTS}

\section{Chapter 1}

General Introduction

\section{Chapter 2}

Substrate source utilisation in long-term diagnosed type 2 diabetes patients at rest, during exercise and subsequent recovery

\section{Chapter 3}

Substrate source use in older, trained males after decades of endurance training

\section{Chapter 4}

Intra-arterial AICA-riboside administration induces NO-dependent vasodilation in vivo in human skeletal muscle

\section{Chapter 5}

Intravenous AICAR administration reduces hepatic glucose output and inhibits whole body lipolysis in type 2 diabetic patients

\section{Chapter 6}

General Discussion

Summary / Samenvatting

Dankwoord

Curriculum vitae

List of publications 
General Introduction

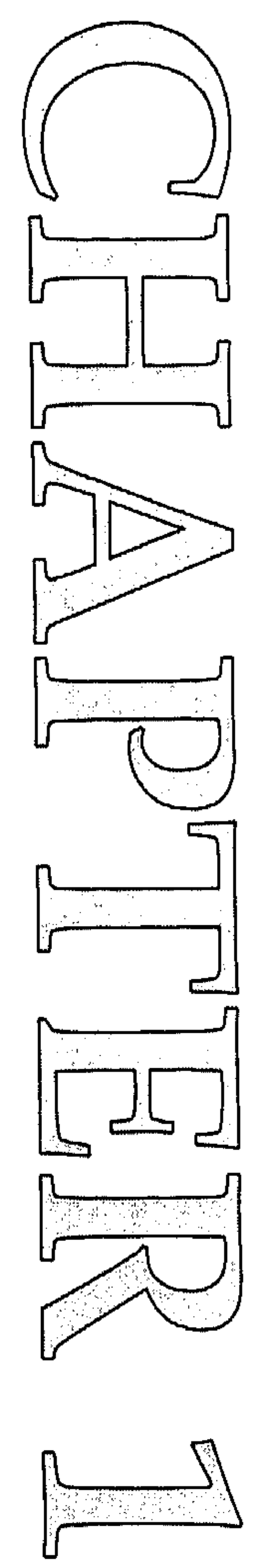


Ectopic lipid accumulation: linking diabetes, obesity and physical inactivity

Disturbances in carbohydrate metabolism in type 2 diabetes

Uptake, oxidation and storage of glucose in skeletal muscle

Disturbances in fatty acid metabolism in type 2 diabetes

Uptake of FA in skeletal muscle

Oxidation of FA in skeletal muscle

An exercise approach to disturbances in substrate metabolism

A pharmacological approach to disturbances in substrate metabolism

Outline of the thesis 
Type 2 diabetes mellitus (T2DM) is a disease characterised by severe metabolic disturbances, and diagnosed by abnormal high plasma glucose levels. It is generally acknowledged that environmental factors, in particular obesity and lack of physical activity, play a crucial role in the pathogenesis of T2DM. Genetic predisposition can interact with these environmental factors in producing the phenotypic expression of the disease. This combination of genes and environment has triggered a worldwide epidemic in overweight and obesity, affecting 1.1 billion adults and causing an impressive number of more than 171 million T2DM patients today [1]. Historically, T2DM was seen as a disease of disturbed carbohydrate metabolism [2]. It is now evident that disturbances are present in protein, carbohydrate and fat metabolism. In particular, disturbances in fat metabolism have become a major topic of interest, as they may explain the link between obesity, physical inactivity and the development of insulin resistance and/or type 2 diabetes. The focus of the research described in this thesis is therefore on alterations in fat and carbohydrate metabolism in type 2 diabetes and on possible approaches for prevention and/or correction of these disturbances. These approaches include exercise and pharmacological targeting of the insulin-independent AMPK pathway. The latter is a pathway that is - at least in part - involved in inducing the effects of exercise on substrate metabolism. It is therefore not only an interesting target for the study of metabolic regulation in response to exercise, but also for pharmacological intervention. The introduction of this thesis will first propose a theory to explain the link between diabetes, obesity and physical inactivity and will summarize the current knowledge on disturbances in fat and carbohydrate metabolism in T2DM. Next, it will discuss the effects of both acute exercise and exercise training on these disturbances in substrate metabolism. Finally, the AMPK pathway, its role in the regulation of substrate metabolism and its potential as a novel approach to prevent and/or treat the metabolic disturbances will be discussed.

\section{Ectopic lipid accumulation: linking diabetes, obesity and physical inactivity}

Research in the last few decades has shown that disturbances in fatty acid (FA) metabolism are not only present in adipose tissue but also in skeletal muscle and liver, and in the crosstalk between these tissues (for excellent reviews see [3-8]). An important hypothesis that has been derived from these insights links the accumulation of lipids in non-adipose tissue (i.e. ectopic fat accumulation) to the development and/or progression of insulin resistance. This theory states that an increased flow of FFA and triacylglycerol (TG) from enlarged dysfunctional adipose tissue to the skeletal muscle and other non-adipose tissues will lead to 
lipid accumulation in these tissues and subsequently, to insulin resistance. More precisely, this is thought to occur as follows (Figure 1 and 2). Enlargement of adipose tissue, caused by energy intake exceeding energy expenditure, might result in a dysfunction in its capacity to buffer $F A$, i.e. to minimize excursions in FA in the postprandial period by changing FA uptake and release $[9,10]$. This impairment is possibly initiated by a defect in the capacity of adipocytes to differentiate upon increased demand for FA storage and expanding fat mass. Due to this defect, an enlargement of adipocytes occurs rather than an increase in the number of adipocytes, and an enlarged adipocyte size is associated with impaired buffering capacity [11]. For one, this results in increased release of FA from adipose tissue lipolysis. In addition, according to recent insights, impaired

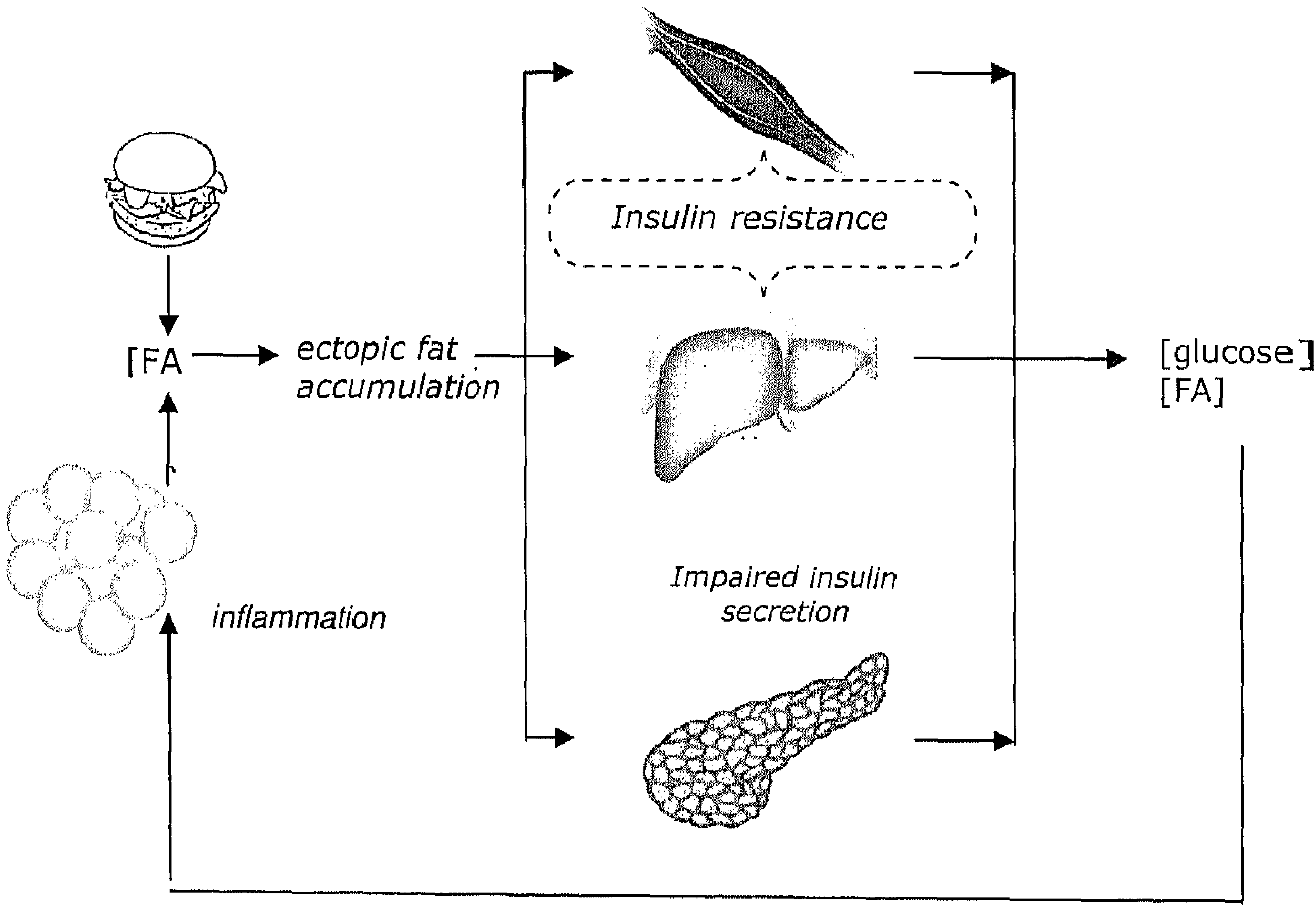

Figure 1. The relationship between FFA supply, ectopic fat accumulation and insulin resistance. An overflow of FFA from enlarged adipose tissue to non-adipose tissues will lead to ectopic fat accumulation, which results in insulin resistance and impaired insulin secretion. A primary or secondary defect in tissue FA oxidation can cause a further imbalance between supply and oxidation of FA and thus increase further lipid accumulation. Together, this will in turn increase plasma levels of FFA and glucose, which, in a downward spiral, will further stimulate ectopic lipid accumulation. In addition, high adipose tissue mass and high circulation levels of FFA and glucose are associated with increased inflammation in adipose tissue, which can both increase lipid flow from the adipose tissue as well as affect skeletal muscle fat oxidation. 
adipocyte uptake of FA released from plasma TG in the postprandial period by lipoprotein lipase (LPL) contributes importantly to an excessive lipid flux to the plasma and non-adipose tissues in the obese state [12-16]. In addition, skeletal muscle in the sedentary and/or obese state may lack an adequate capacity to increase fatty acid uptake and oxidation concomitantly with this increased plasma lipid flux. One of the underlying causes may be a low level of habitual physical activity in the sedentary and/or obese state, which minimizes daily energy expenditure and fatty acid oxidative capacity. Physical inactivity thus contributes significantly to an imbalance between FA supply and FA oxidation. As a consequence, the greater FA supply is not readily compensated for by an increase in FA oxidation, a state which is referred to as metabolic inflexibility. Together, the high FA flux and low FA oxidative capacity may lead to ectopic accumulation of FA and FA intermediates (such as diacylglycerol and ceramides) and disruption of the insulin-mediated pathway of glucose uptake, particularly in skeletal muscle but also in liver and pancreas (also referred to as lipotoxicity) [3, 17-22]. This lipotoxicity leads to increased liver glucose production, impaired insulin secretion and impaired glucose tolerance, eventually resulting in hyperglycemia and hyperlipidemia and leading to and/or aggravating the increased flow of FA and glucose to adipose and non-adipose tissues [23] (Figure 1 and 2).

Figure 2. Proposed mechanism for fatty acid induced insulin resistance in human skeletal muscle. An imbalance between the supply, uptake and/or a oxidation of fatty acids will lead to accumulation of lipids and consequently, of intracellular fatty acid metabolites, such as diacylglycerol (DAG) and ceramides.These metabolites

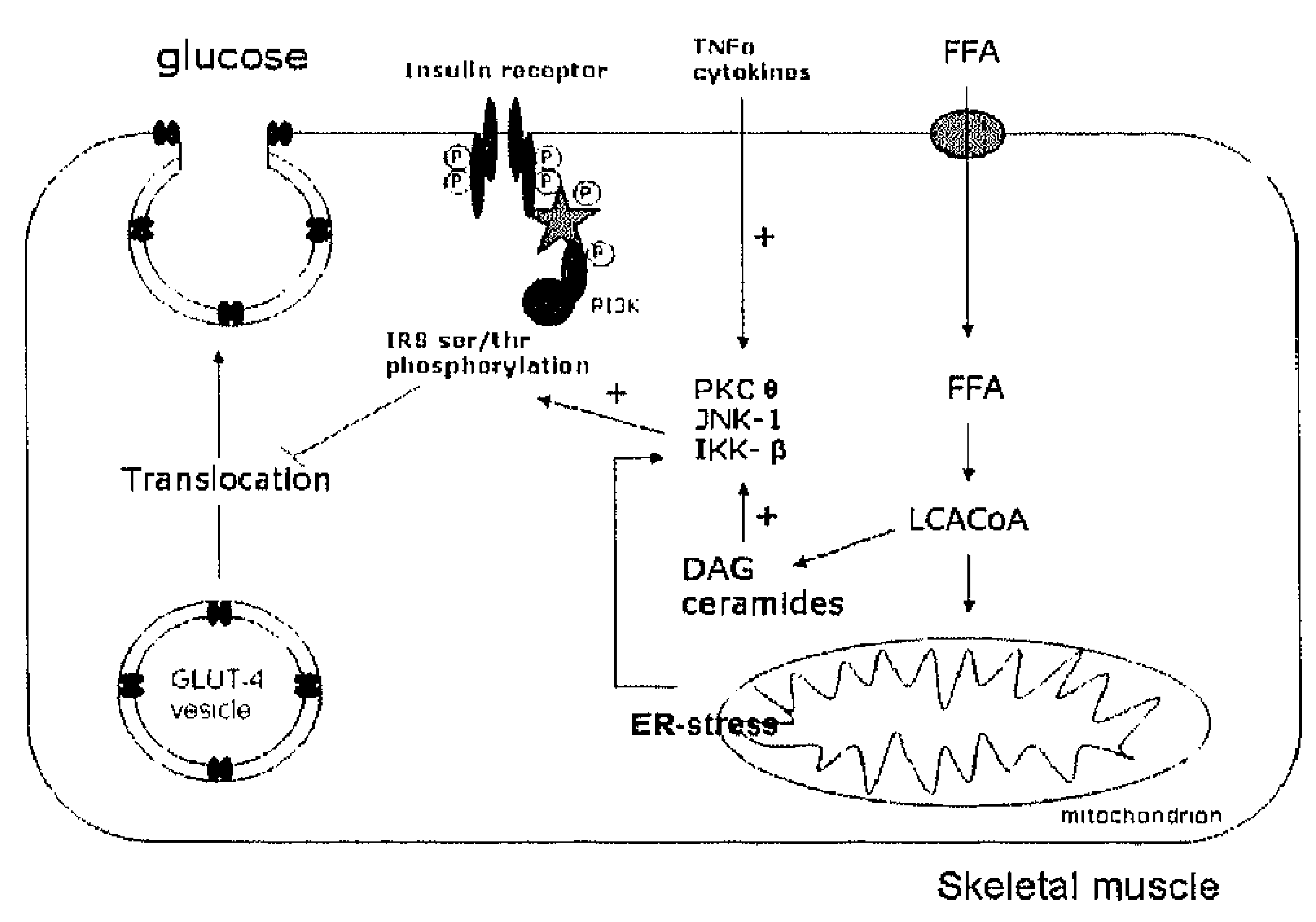

activate a serine/threonine kinase cascade through activation of PKC, IKK-B and JNK and phosphorylation of serine/threonine sites of the insulin receptor substrates 1 and 2 (IRS-1 and IRS-2). This in turn reduces the ability of IRS to activate PI3-kinase, which inhibits translocation of GLUT-4 vesicles to the sarcolemma, as well as other events downstream of insulin receptor signalling. Adapted from: Kraegen and Cooney, Curr Opin Lipidol 2008 [7]. 
Obviously, this theory of ectopic lipid accumulation does not solely explain the development of type 2 diabetes. The contribution of other factors associated with adipose tissue and/or skeletal muscle dysfunction should not be disregarded. These include changes in adipose tissue secretion of adipokines and/or pro- and anti-inflammatory factors [24-27], skeletal muscle mitochondrial dysfunction [28] and endoplasmatic reticulum (ER) stress [29-31]. It is interesting that these factors may also interact with the mechanism of ectopic lipid accumulation. For example, ER stress and mitochondrial dysfunction have been shown to induce ectopic lipid accumulation $[28,29]$.

\section{Disturbances in carbohydrate metabolism in type 2 diabetes}

Type 2 diabetes mellitus has long been viewed from a glucose-centered perspective only [32]. This is most likely because glucose, in contrast to FFA, is essential for direct survival, as apparent from the pathophysiology of type 1 diabetes. Glucose metabolism should be so tightly regulated to ensure glucose availability for the central nervous system, which almost entirely depends on glucose for its fuel [33]. However, an impairment in insulin-mediated glucose uptake will affect FA metabolism (and vice versa), as the biochemical pathways of glucose and FA metabolism are fully integrated [19, 20,34-36]. To unravel the pathophysiology of type 2 diabetes, it is therefore important to understand the disturbances in uptake, oxidation, storage and/or production of glucose.

\section{Uptake, oxidation and storage of glucose in skeletal muscle}

Skeletal muscle is responsible for the major part $(>80 \%)$ of insulin-stimulated whole body glucose disposal [37], which is facilitated primarily by the glucose transporter 4 (GLUT-4) protein. However, in type 2 diabetes, this insulinmediated glucose uptake, oxidation and storage by skeletal muscle is severely impaired [37-39]. As mentioned earlier, a currently widely accepted hypothesis states that this is caused by increased amounts of intramyocellular lipid species such as diacylglycerol and ceramides, derived from accumulated lipids, which interfere with GLUT-4 translocation via the inhibition of the insulin receptor substrate (IRS-1) and other downstream targets [7] (Figure 1 and 2). There is considerable evidence that the impaired insulin-mediated glucose transport may be the cause of the downstream impairments in both insulin-mediated glucose oxidation and/or glycogen storage [40,41]. Under postprandial (hyperglycemic, hyperinsulinemic) conditions, muscle glycogen synthesis is the major pathway for glucose metabolism, and muscle glycogen synthesis rate is approximately $50 \%$ lower in T2DM patients as compared with healthy subjects [37]. An elegant series of experiments by Shulman and colleagues using ${ }^{13} \mathrm{C}$ - and ${ }^{13 P}$ - NMR have 
demonstrated that defects in glucose transport are the main cause for decreased insulin-stimulated glycogen synthesis in type 2 diabetes, thus pointing at a primary defect in glucose uptake $[37,39,41,42]$. Taken together, both oxidation of glucose and its storage as glycogen are processes affected by predominant upstream disturbances in insulin-stimulated glucose uptake.

Carbohydrate metabolism in the insulin resistant type 2 diabetic state is not only characterized by an impaired insulin-mediated glucose uptake, oxidation and storage, but also by a defective adaptation of fuel selection to fuel availability [20, 40, 43-45]. Thus, in the fasting type 2 diabetic versus lean insulin-sensitive state, skeletal muscle glucose oxidation is increased and fatty acid oxidation is low, whereas under insulin-stimulated conditions, fatty acid oxidation is not sufficiently suppressed and glucose oxidation is hardly increased. This is reflected by a less significant change in respiratory quotient (RQ) when switching from the fasting to the insulin-stimulated condition in the insulin resistant and/or T2DM state as compared to insulin sensitive controls [20,38, 39, 46, 47]. This adaptation of fuel selection to fuel availability (also called metabolic flexibility) is strongly affected by a low level of habitual physical activity. The latter minimizes daily energy expenditure, (skeletal muscle) fat oxidation and skeletal muscle FA oxidative capacity. Altogether, this will prevent depletion of skeletal muscle lipid storage and stimulate ectopic lipid accumulation.

\section{Hepatic glucose production}

Another organ involved in the metabolic disturbances of type 2 diabetes is the liver. In T2DM, hepatic glucose production is increased in both the fasting and insulin-stimulated state $[9,48,49]$. This is partly due to insulin resistance of the liver, but is also the consequence of a disturbance in adipose tissue and pancreas function, as elevated FFA levels and insufficient insulin secretion dysregulate hepatic glucose production [50]. Insulin inhibits hepatic glucose production, whereas FFA stimulate hepatic glucose production. Basal FFA levels are often increased in the T2DM state [14-16], which is mainly due to increased FA release by dysfunctional (enlarged) adipose tissue. This results in increased lipid flow to the liver and, consequently, increased hepatic FFA oxidation. The latter will increase basal gluconeogenesis through accumulation of acetyl-CoA and subsequent activation of enzymes controlling hepatic gluconeogenesis. Suppression of hepatic glucose production is also impaired in the insulinstimulated T2DM state. This is thought to occur via two pathways. First, plasma FFA levels are insufficiently suppressed in the postprandial insulin-stimulated state due to an increased FFA release by adipose tissue [12]. As in the fasting 
state, this results in increased lipid supply to the liver, increased hepatic FFA oxidation and consequently, increased hepatic gluconeogenesis [23]. Secondly, lipid (intermediate) accumulation in the liver inhibits the insulin signalling pathway directly, impairing insulin-stimulated glucose uptake and increasing hepatic glucose output $[51,52]$. Basal hepatic glucose production is thus increased via increased plasma FFA concentrations, insufficient insulin secretion and intrinsic liver insulin resistance due to lipid accumulation.

Taken together, glucose metabolism in T2DM is characterized by impaired hepatic glucose production, skeletal muscle glucose uptake, storage and oxidation. This impaired regulation of glucose metabolism in both liver and skeletal muscle is, at least partly, the result of ectopic lipid accumulation and insulin resistance in these tissues, which in turn may be the consequence of disturbances in fatty acid metabolism. These will be described next.

\section{Disturbances in fatty acid metabolism in type 2 diabetes}

The biochemical pathways of carbohydrate and fatty acid metabolism are fully integrated [19, 20, 34-36]. An overflow of FA which is not compensated by increased FA oxidation can result in ectopic lipid accumulation and insulin resistance of glucose metabolism in skeletal muscle, liver and pancreas. Consequently, this causes dysregulation of glucose uptake, oxidation and storage (Figure 1). The main disturbances in FA metabolism in T2DM are an increased release of FA from adipose tissue, impaired uptake of TG by adipose tissue and impaired skeletal muscle FFA uptake and/or oxidation.

\section{Release of $F A$ from the adipose tissue}

A greater supply of FA, either as FFA or TG, from the plasma will flood the skeletal muscle and other organs with FA. Lipids and lipid intermediates may accumulate in non-adipose tissues if this increased flow is not compensated by increased FA oxidation in these tissues. The flow of FA to skeletal muscle and other organs is determined by lipolysis and clearance of postprandial plasma lipids by adipose tissue. In the obese in vivo state, after an overnight fast, rate of lipolysis is normal when related to body mass [53], whereas lower rates are found when related to fat mass [53-55]. Using microdialysis, in situ no differences in fasting lipolysis rate exist when related to fat mass, but total adipose tissue glycerol concentrations were found to be increased in obese versus lean subjects [56]. These data indicate that a down-regulation of adipose tissue lipolysis occurs to restrict FFA release. This can possibly be explained by inhibition of lipolysis induced by hyperinsulinemia [53]. Despite a reduced or similar lipolysis per unit 
fat mass, the mass effect of enlarged adipose tissue in obesity can result in an increased total rate of basal FFA turnover and thus, in increased FFA supply to the circulation in obesity versus normal-weight [14]. Indeed, the obese [14-16] and type 2 diabetic [57] state are often, though not consistently [53], associated with elevated fasting and postprandial plasma FA concentrations. In the obese, insulin-resistant and/or type 2 diabetic states, adipose tissue may thus lose its capacity to buffer the FA flux, i.e. to minimize excursions in FA in the postprandial period $[9,10]$. This buffering capacity of the adipose tissue does not only involve a restriction of the release of FFA from adipose tissue. Evidence suggests that impaired adipocyte uptake of FA released from plasma TG by lipoprotein lipase (LPL) in the postprandial state might play a key role in the loss of buffering capacity of adipose tissue in the obese and/or diabetic state $[12,58$ 60]. The reason why adipose tissue loses its buffering capacity is not entirely clear. As mentioned earlier, a current hypothesis is, that a lack of potential to differentiate new adipocytes upon increased fat storage leads instead to enlarged adipocytes, and these have a reduced efficiency to buffer FA.

\section{Uptake of FA in skeletal muscle}

FA uptake is another important factor in the balance between plasma FA availability, muscle FA uptake and muscle FA oxidation, which determines accumulation of ectopic lipids. FA uptake is determined by FFA and TG plasma concentrations, intracellular FFA concentrations and the facilitation of diffusion by FA transporters. The type 2 diabetic state has been associated with a reduced fasting FA uptake [47, 61, 62] but greater insulin-stimulated FA uptake as compared to lean and/or obese controls [47, 63]. In obese T2DM subjects, arteriovenous differences of plasma FFA concentrations over the leg or arm display reduced fasting plasma FFA uptake into skeletal muscle when compared to normoglycemic lean and/or obese controls [47, 61,62]. This might be caused by several factors. An increased basal skeletal muscle lipolysis can decrease the blood-tissue FFA concentration gradient and is a strong determinant of skeletal muscle FA uptake [61, 64]. Furthermore, uptake of FFA into skeletal muscle occurs not only via diffusion $[65,66]$ but also via protein-mediated transport [6569]. A number of fatty acid transporter proteins have been identified, including fatty acid translocase/CD36 (FAT/CD36), membrane-bound and cytosolic fatty acid binding protein (FABPpm and $\mathrm{FABPC}$, respectively) and fatty acid transporter protein (FATP) [65]. An increased FA transporter mRNA and/or protein expression may be instrumental to allow greater FA oxidation rates [70], and a decreased expression of CD36 and FABPc has been associated with type 2 diabetes and low muscle plasma FA uptake $[61,71]$. However, data on fatty acid 
transporters are not conclusive, as some other studies find an increased level or $i_{n}$ vitro redistribution of fatty acid transporter proteins to the sarcolemma in the insulin resistant $[72,73]$ or T2DM [74-76] state. The discrepancy between findings may be explained by differences in applied techniques, species studied $\mathrm{o}_{\mathrm{N}}$ subjects' characteristics, but this remains to be fullyy elucidated. Obviously, reduced FFA uptake by skeletal muscle in the fasting state cannot explain an increased skeletal muscle lipid accumulation. Therefore, an interesting finding is that in postprandial insulin-stimulated conditions, adipose tissue lipolysis was not sufficiently suppressed in the type 2 diabetes state, resulting in greater skeletal muscle FFA uptake [47]. Thus, in diabetes patients relative to healthy lean controls, the fasting FFA uptake into skeletal muscle was reduced, whereas the insulin-stimulated suppression of FFA uptake was blunted. The latter might provide, at least in part, a possible explanation for increased lipid accumulation in the T2DM state. This idea was confirmed by Ravikumar et al., who demonstrated that a greater postprandial FA uptake in diabetes patients versus overweight controls, and a concomitant higher TG accumulation in skeletal muscle [63]. Additionally, it is important to stress that accumulation of lipids in. skeletal muscle is determined not only by FA uptake, but merely by the balance between FA uptake and FA oxidation in skeletal muscle. Only when FA uptake exceeds FA oxidation, will this balance be positive and will lipid accumulation occur. In this respect, an interesting finding is reported by Blaak and Wagenmakers, who demonstrated that in T2DM patients, a smaller fraction of FA taken up by skeletal muscle is oxidized as compared with lean age-matched controls [77]. Taken together, data from in vivo studies in T2DM patients have demonstrated decreased FFA uptake by skeletal muscle in the fasting state, whereas FFA uptake has been reported to be increased in the postprandial T2DM condition relative to healthy controls. Measurements of the cellular FA transporter protein content do not provide a conclusive explanation for the differences between the healthy and diabetic state. Though this should be an area of further investigation, the explanation for the alterations in skeletal muscle FA uptake in the T2DM state is likely also to be found in other factors that may influence FA uptake, e.g. plasma FA levels (fasting and postprandial) and rates of FA oxidation.

\section{Oxidation of FA in skeletal muscle}

Lower fasting skeletal muscle fat oxidation rates have been reported in obes $e$ T2DM patients versus obese normoglycemic controls [46, 47, 78]. However, during insulin-stimulated conditions, lipid oxidation is less suppressed and therefore higher in T2DM patients compared to normoglycemic controls' 
indicating that the capacity to switch between FFA and carbohydrate as a fuel from the fasting to the postprandial state is reduced in the insulin resistant state [20]. This 'metabolic inflexibility' has been related to the accumulation of lipids and consequently, of lipid intermediates in insulin-resistant muscle [20, 40, 79-81]. However, much less is known on disturbances in the oxidation of specific fatty acid substrate sources and on how these disturbances in fat and carbohydrate metabolism may lead to lipid (intermediate) accumulation. Skeletal muscle FA oxidation can be accounted for by either plasma-derived FA, or by lipids stored within the muscle itself (intramyocellular triacylglycerol or IMTG). A disturbance in the oxidation of either FA source may disturb the balance between skeletal muscle supply, storage and oxidation of FA, resulting in increased lipid storage and insulin resistance. An impaired IMTG oxidation may directly increase storage of IMTG. A review of the literature on the use of IMTG suggests that type 2 diabetes patients have a reduced capacity to mobilize and/or oxidize the intramyocellular lipid stores [82]. On the other hand, an impaired oxidation of plasma FFA has also been reported in obese T2DM patients versus obese controls [78]. This might stimulate lipid accumulation indirectly, if plasma FFA are taken up into skeletal muscle but not oxidized, as reported by Blaak and Wagenmakers [77]. The cause of these different findings on impairments of specific substrate source oxidation (i.e. in either plasma FFA or IMTG, or both) is not entirely known. It is likely that differences in FA supply and disposal can account for at least part of this, as an impaired FFA rate of appearance and rate of disappearance has been associated with impairments in FFA oxidation [78]. This view is supported by evidence that pharmacological inhibition of adipose tissue lipolysis, resulting in lower plasma FFA rate of appearance and thus, lower plasma FFA availability, decreases FFA disposal and oxidation and increases IMTG oxidation [83, 84].

The inverse relationship between IMTG content and insulin sensitivity disappears with the inclusion of endurance-trained athletes, as these have increased IMTG but also an increased insulin sensitivity $[85,86]$. This so-called 'athletes paradox' may be explained by indications that not the IMTG itself, but merely an accumulation of lipid intermediates such as DAG and ceramides actually inhibit the insulin-mediated pathway [85]. Athletes might store increased amounts of TG intramyocellularly in response to increased energy demands, and lipid intermediates will only accumulate when IMTG stores are not frequently emptied (i.e. oxidized) and replenished. The latter is more likely to occur in a sedentary state in which daily energy expenditure is low, than in an active athlete. In any way, an inability to use fatty acids, derived from either plasma FFA or IMTG, might add to excessive deposition of lipids in the muscle. 


\section{An exercise approach to disturbances in substrate metabolism}

A lack of exercise or physical activity is an independent cause of obesity and type 2 diabetes. Some have fiercely proposed a lifetime of physical activity to be the ideal environment for the human 'Paleolithic' genome, which was developed in times when hunting and gathering required large amounts of physical activity $[87,88]$. Regular exercise training diminishes the risk for ectopic lipid accumulation and T2DM through several factors, including an increase in fat oxidation [89-93], in skeletal muscle fat oxidative capacity [89-92, 94, 95] and in insulin sensitivity [95]. Furthermore, regular exercise can increase total daily energy expenditure, thereby promoting a negative energy balance and body weight control. Despite this, research on disturbances in glucose and/or fatty acid metabolism in type 2 diabetes thus far has not posed a major focus on the acute exercise and/or the post-exercise state. It is thus not entirely clear whether the disturbances in release, uptake and/or oxidation of glucose or fatty acids during fasting and/or postprandial conditions, as described earlier, are extended to the exercise situation in a type 2 diabetic state. However, when a low FA oxidation, high FA uptake and/or high plasma FA concentrations is also present during exercise in type 2 diabetes patients, this would imply that FA supply exceeds FA oxidation during most part of the day, which will greatly stimulate ectopic lipid accumulation. On the other hand, an absence or improvement of these metabolic disturbances in response to acute and/or chronic exercise would provide a physiological rationale to promote exercise as a means to prevent and/or treat disturbances in metabolism of type 2 diabetes. Thus, more specifically, it is important to identify whether acute and/or chronic exercise training can reduce lipid overflow and improve muscle fat oxidation, thereby potentially reducing lipid (intermediate) accumulation and insulin resistance.

So, what is currently known on disturbances in substrate source metabolism in type 2 diabetes during acute exercise and in response to exercise training? Studies on substrate metabolism in acute exercise in T2DM have investigated release, uptake and/or oxidation of glucose and fatty acids during moderate and highintensity exercise. Most controversy exists with regard to alterations in fat and FA substrate source (i.e. IMTG and/or plasma-derived FFA) mobilization and/or oxidation in T2DM. Some studies show no differences in total fat oxidation during exercise $[78,96]$, while another study found a decreased exercise-induced fat oxidation in T2DM as compared with healthy controls [97]. Despite the equal whole-body $R Q$, Blaak et al. found a decreased oxidation of plasma-derived FFA and increased oxidation of TG-derived FA in obese T2DM patients compared with healthy obese controls during exercise [78]. However, Borghouts et al. 
showed no differences in substrate source oxidation during exercise between overweight T2DM patients and overweight control subjects [96]. This discrepancy can likely be explained by differences in subjects' characteristics between studies, such as BMI, physical fitness, disease duration and/or use of medication in the study populations, but these contradictory findings clearly need more study. In contrast, studies are quite consistent with respect to the effects of acute exercise on glucose metabolism in T2DM. It is generally accepted that during acute moderate-intensity exercise in T2DM patients, plasma glucose oxidation rates are increased, whereas muscle glycogen oxidation seems to be lower when compared with healthy matched controls. Consequently, plasma glucose levels generally decline during moderate-intensity exercise in T2DM patients [78, 96-99], which is mainly attributed to an increased uptake and oxidation of plasma glucose [96-98].

As described above, acute moderate-intensity exercise positively affects the supply, uptake and oxidation of glucose and FA, which are important determinants of ectopic lipid accumulation. However, exercise is likely to be most effective on these parameters if performed regularly, as in an endurance training program. Indeed, studies in type 2 diabetes patients show the benefits of an exercise training program on body composition [100], energy balance [100], fat oxidation during exercise [101], skeletal muscle FA oxidative capacity [101], endothelial function [102] and inflammatory status [103, 104]. All of these effects might contribute to the improvement in insulin sensitivity and glucose homeostasis [105-107]. The mechanisms underlying these metabolic improvements are not fully elucidated, but a reduction of ectopic lipid accumulation and a relieved inhibition of the insulin signaling pathway is a likely candidate to explain part of these improvements [108].

However, short-term interventions studies might not have the same effects as a lifetime of physical activity. Despite this, studies that accurately describe substrate source metabolism in subjects that have a lifelong history of endurancetraining are scarce [109]. It is not established whether endurance exercise training throughout life has significant positive effects on supply, uptake and oxidation of glucose and FA, and whether these effects are still present at middle-age (50-60y), when T2DM usually develops.

\section{A pharmacological approach to disturbances in substrate metabolism}

The obvious question arises as to what mechanism(s) underlie the effects of acute and regular exercise on supply, uptake and/or oxidation of glucose and FA. Furthermore, an interesting approach for patients unwilling or unable to perform regular exercise would be to pharmacologically target the biochemical pathways 
involved in exercise effects on substrate metabolism. A possible mechanism underlying the effects of exercise is an insulin-indepent signaling pathway that is activated upon exercise and is, at least in part, mediated by the AMP-activated protein kinase (AMPK). AMPK is a key enzyme in the regulation of energy metabolism (Figure 3) [110-112]. It acts as a cellular energy sensor, and is activated by metabolic stress, including muscle contraction [113-118]. AMPK is most known for its insulin-independent control of glucose uptake in skeletal muscle [119-122], but is also known to increase fat oxidation [120, 123] and decrease hepatic glucose output [124]. The AMPK pathway appears largely intact in obese and/or type 2 diabetic rodents [125-129] and in several human studies $[113,124,130-134]$. Consequently, AMPK is regarded as a potential target to bypass the reduced insulin-mediated glucose uptake and reduce ectopic lipid accumulation through a decrease in adipose tissue lipolysis and an increase in skeletal muscle FA oxidation. As mentioned, AMPK activation can be induced by exercise. However, the AMPK enzyme can also be activated, at least in animal studies and human in vitro studies, via pharmacological AMPK activation by 5aminoimidazole-4-carboxamide-riboside (AICAR). AICAR is therefore an interesting substance, both as a research tool and for therapeutic purposes. However, until now, artificial AMPK activation by AICAR has mainly been studied in animal studies and human in vitro studies. From these studies, it is clear that AICAR induces AMPK activation in skeletal muscle [119-122, 124-129], decreases plasma glucose concentrations $[127,128]$, increases GLUT4 translocation to the plasma membrane $[122,130]$ and increases skeletal muscle glucose uptake $[119,120,124,135,136]$, even in type 2 diabetic animals [124-129] and/or tissue from obese and/or T2DM subjects [130]. Despite these promising results, the metabolic effects of AICAR have only been studied once in a human in vivo setting. In this study in healthy subjects, only a minor increase in glucose uptake was reported and no significant activation of skeletal muscle AMPK was found [137]. This implies a difference between the in vivo and in vitro situation as well as possible species differences between rodents and humans. Indeed, it has been reported that human skeletal muscle only expresses the $\beta_{2}$-subunit of the AMPK enzyme [138], whereas rodent skeletal muscle also express the $\beta_{1}$-subunit [139]. It would therefore be interesting to study the effects of artificial AMPK activation by AICAR in humans in vivo. 


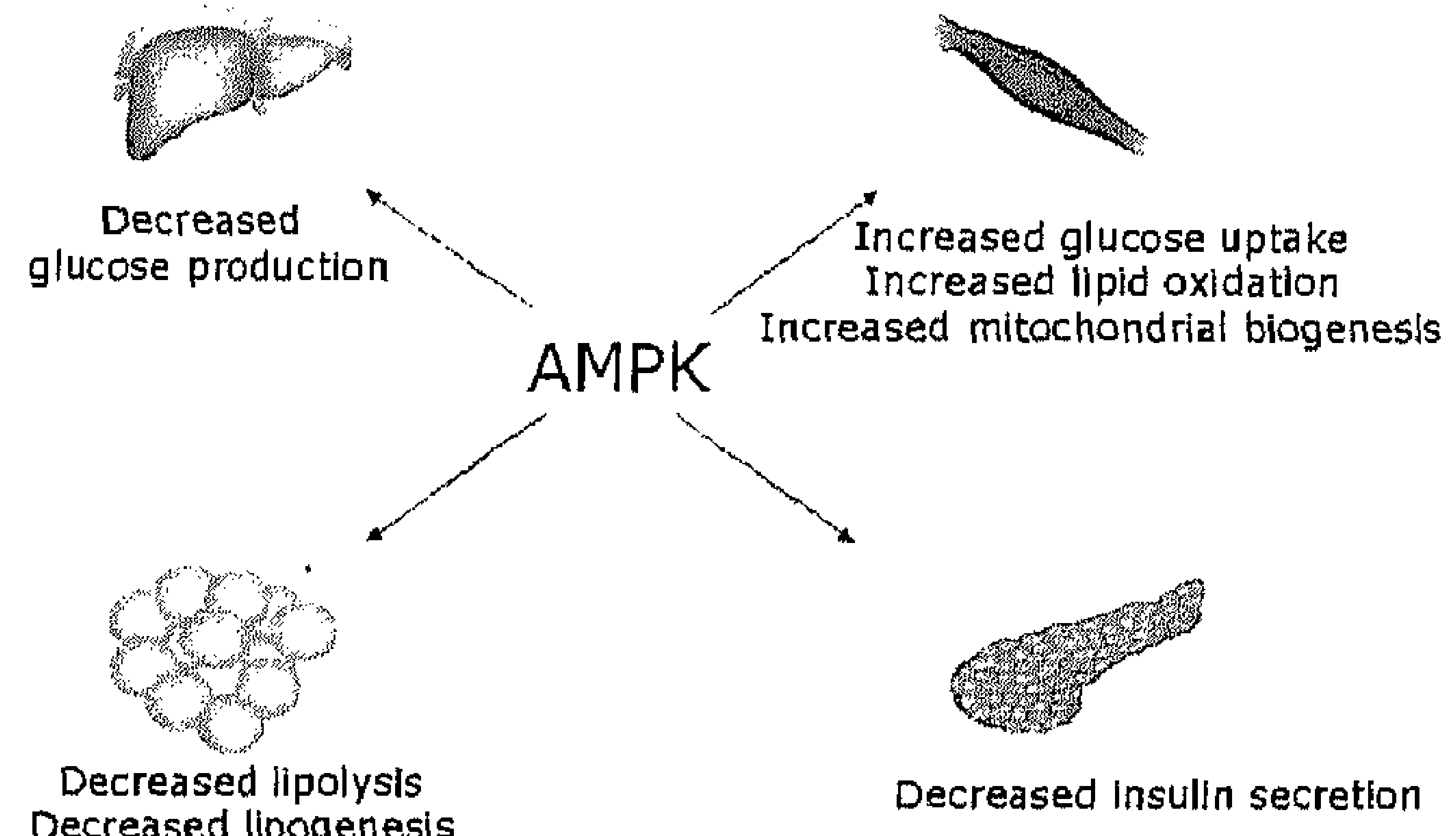

Decreased lipogenesis

Decreased [glucose] and [FFA]

Decreased ectopic lipid accumulation

Increased insulin sensitivity

Figure 3. Role of AMPK in the regulation of whole-body glucose homeostasis. Activation of AMPK turns on ATP-generating processes, while switching off ATP-consuming processes. Collectively, activation of AMPK in skeletal muscle, liver, and adipose tissue results in a favorable metabolic milieu for the prevention or treatment of T2D, i.e. decreased plasma glucose, reduced plasma FFA and ectopic fat accumulation, as well as increased insulin sensitivity. Adapted from Long and Zierath JCI 2006 [140].

\section{Outline of the thesis}

The focus of this thesis is on alterations in fatty acid and glucose metabolism in type 2 diabetes. A thorough investigation of glucose and FA substrate source metabolism in type 2 diabetes will improve our insight in the nature and extent of the alterations in substrate source metabolism in type 2 diabetes versus the healthy lean and/or obese state. To accomplish this, it is important to have a detailed characterization of the subjects, as BMI, age, level of physical fitness, disease duration and/or the use of medication significantly affect substrate source metabolism and can strongly modulate differences observed between study groups. Therefore, the first study of this thesis investigates differences in substrate source use between long-standing type 2 diabetes patients and a wellcharacterized control group at rest, during exercise and subsequent post-exercise recovery (chapter 2), [U-13 C]palmitate and [6,6-2 $\left.\mathrm{H}_{2}\right]$ glucose tracers were used to assess plasma FA and glucose oxidation rates and to estimate the use of muscleand/or lipoprotein-derived triacylglycerol and muscle glycogen. Exercise and/or 
an active lifestyle are of utmost importance for metabolic health. Training studies are relatively short and cannot mimic a situation of life-long (>25y) exercise. Therefore, chapter 3 of this thesis describes the metabolic differences between middle-aged athletes with $>25 y$ of training background and sedentary, agematched controls. Again, stable isotope tracers were applied to investigate substrate source utilisation.

An enzyme that is particularly interesting in the beneficial effects of exercise is AMPK. As described earlier, AMPK is regarded as a 'metabolic master switch' and is an insulin-independent enzyme that seems to play an important role in the regulation of substrate metabolism during exercise. It is therefore an interesting target for the treatment and prevention of type 2 diabetes. In a proof-of-principle study, we investigated the effects of the AMPK-activator AICAR on plasma substrate levels in healthy, young subjects (chapter 4). Next, we administered AICAR in type 2 diabetes patients, again applying glucose and FA stable isotope tracers to determine substrate turnover rates (chapter 5). In chapter 6 of this thesis, we combine the major findings of the results described in chapter 2-5 and propose a broader perspective on the nature of the disturbances in substrate source metabolism, their underlying mechanisms and consequences for the prevention and/or treatment of type 2 diabetes. 


\section{REFERENCES}

1. Hossain P, Kawar B, El Nahas M (2007) Obesity and diabetes in the developing world--a growing challenge. $\mathrm{N}$ Engl J Med 356: 213-215

2. McGarry JD (1992) What if Minkowski had been ageusic? An alternative angle on diabetes. Science 258: 766-770

3. Savage DB, Petersen KF, Shulman GI (2005) Mechanisms of insulin resistance in humans and possible links with inflammation. Hypertension 45: 828-833

4. Schenk S, Saberi M, Olefsky JM (2008) Insulin sensitivity: modulation by nutrients and inflammation. J Clin Invest 118: 2992-3002

5. Wellen KE, Hotamisligil GS (2005) Inflammation, stress, and diabetes. J Clin Invest 115: $1111-1119$

6. Arner $P$ (2002) Insulin resistance in type 2 diabetes: role of fatty acids. Diabetes Metab Res Rev 18 Suppl 2: S5-9

7. Kraegen EW, Cooney GJ (2008) Free fatty acids and skeletal muscle insulin resistance. Curr Opin Lipidol 19: 235-241

8. Lewis GF, Carpentier A, Adeli K, Giacca A (2002) Disordered fat storage and mobilization in the pathogenesis of insulin resistance and type 2 diabetes. Endocr Rev 23: $201-229$

9. Groop LC, Bonadonna RC, DelPrato S, et al. (1989) Glucose and free fatty acid metabolism in non-insulin-dependent diabetes mellitus. Evidence for multiple sites of insulin resistance. J Clin Invest 84: 205-213

10. Groop LC, Saloranta C, Shank M, Bonadonna RC, Ferrannini E, DeFronzo RA (1991) The role of free fatty acid metabolism in the pathogenesis of insulin resistance in obesity and noninsulin-dependent diabetes mellitus. J Clin Endocrinol Metab 72: 96-107

11. Danforth E, Jr. (2000) Failure of adipocyte differentiation causes type II diabetes mellitus? Nat Genet 26: 13

12. Frayn KN (2002) Adipose tissue as a buffer for daily lipid flux. Diabetologia 45: 12011210

13. Goossens GH (2008) The role of adipose tissue dysfunction in the pathogenesis of obesity-related insulin resistance. Physiol Behav 94: 206-218

14. Groop LC, Bonadonna RC, Simonson DC, Petrides AS, Shank M, DeFronzo RA (1992) Effect of insulin on oxidative and nonoxidative pathways of free fatty acid metabolism in human obesity. Am J Physiol 263: E79-84

15. Opie LH, Walfish PG (1963) Plasma free fatty acid concentrations in obesity. N Engl J Med 268: 757-760

16. Baldeweg SE, Golay A, Natali A, Balkau B, Del Prato S, Coppack SW (2000) Insulin resistance, lipid and fatty acid concentrations in 867 healthy Europeans. European Group for the Study of Insulin Resistance (EGIR). Eur J Clin Invest 30: 45-52

17. Itani SI, Ruderman NB, Schmieder F, Boden G (2002) Lipid-induced insulin resistance in human muscle is associated with changes in diacylglycerol, protein kinase $\mathrm{C}$, and IkappaB-alpha. Diabetes 51: 2005-2011

18. Roden M, Price TB, Perseghin G, et al. (1996) Mechanism of free fatty acid-induced insulin resistance. J Clin Invest 97: 2859-2865

19. Shulman GI (2000) Cellular mechanisms of insulin resistance. J Clin Invest 106: 171-176

20. Kelley DE, Mandarino LJ (2000) Fuel selection in human skeletal muscle in insulin resistance. Diabetes 49: 677-683 
21. Yu C, Chen Y, Cline GW, et al. (2002) Mechanism by which fatty acids inhibit insulin activation of insulin receptor substrate-1 (IRS-1)-associated phosphatidylinositol 3kinase activity in muscle. J Biol Chem 277: 50230-50236

22. Holland WL, Brozinick JT, Wang LP, et al. (2007) Inhibition of ceramide synthesis ameliorates glucocorticoid-, saturated-fat-, and obesity-induced insulin resistance. Cell Metab 5: 167-179

23. Bays H, Mandarino L, DeFronzo RA (2004) Role of the adipocyte, free fatty acids, and ectopic fat in pathogenesis of type 2 diabetes mellitus: peroxisomal proliferatoractivated receptor agonists provide a rational therapeutic approach. J Clin Endocrinol Metab 89: 463-478

24. Bastard JP, Maachi M, Lagathu C, et al. (2006) Recent advances in the relationship between obesity, inflammation, and insulin resistance. Eur Cytokine Netw 17: 4-12

25. Bruun JM, Lihn AS, Verdich C, el al. (2003) Regulation of adiponectin by adipose tissuederived cytokines: in vivo and in vitro investigations in humans. Am J Physiol Endocrinol Metab 285: E527-533

26. Hotamisligil GS, Arner P, Caro JF, Atkinson RL, Spiegelman BM (1995) Increased adipose tissue expression of tumor necrosis factor-alpha in human obesity and insulin resistance. J Clin Invest 95: 2409-2415

Hotamisligil GS, Spiegelman BM (1994) Tumor necrosis factor alpha: a key component of the obesity-diabetes link. Diabetes 43: 1271-1278

Schrauwen P, Hesselink MKC (2004) Oxidative capacity, lipotoxicity, and mitochondrial damage in type 2 diabetes. Diabetes 53: 1412-1417

29. Hotamisligil GS (2008) Inflammation and endoplasmic reticulum stress in obesity and diabetes. Int J Obes (Lond) 32 Suppl 7: S52-54

30. Ozcan U, Cao Q, Yilmaz E, et al. (2004) Endoplasmic reticulum stress links obesity, insulin action, and type 2 diabetes. Science 306: 457-461

31. Eizirik DL, Cardozo AK, Cnop M (2008) The role for endoplasmic reticultum stress in diabetes mellitus. Endocr Rev 29: 42-61

Shafrir E, Raz I (2003) Diabetes: mellitus or lipidus? Diabetologia 46: 433-440

Amiel SA (1995) Organ fuel selection: brain. Proc Nutr Soc 54: 151-155

Ruderman NB, Saha AK, Kraegen EW (2003) Malonyl-CoA, AMP-activated protein kinase, and adiposity. Endocrinology 144: 5166-5171

35. Randle PJ (1998) Regulatory interactions between lipids and carbohydrates: the glucose fatty acid cycle after 35 years. Diabetes Metab Rev 14: 263-283

36. Randle PJ, Garland PB, Hales CN, Newsholme EA (1963) The glucose fatty-acid cycle. Its role in insulin sensitivity and the metabolic disturbances of diabetes mellitus. Lancet 1: $785-789$

Shulman GI, Rothman DL, Jue T, Stein P, DeFronzo RA, Shulman RG (1990) Quantitation of muscle glycogen synthesis in normal subjects and subjects with noninsulin-dependent diabetes by $13 \mathrm{C}$ nuclear magnetic resonance spectroscopy. $\mathrm{N}$ Engl J Med 322: 223-228

38. Kelley DE, Mokan M, Mandarino LJ (1992) Intracellular defects in glucose metabolism in obese patients with NIDDM. Diabetes 41: 698-706

39. Rothman DL, Magnusson I, Cline G, et al. (1995) Decreased muscle glucose transport/phosphorylation is an early defect in the pathogenesis of non-insulindependent diabetes mellitus. Proc Natl Acad Sci U S A 92: 983-987

40. Galgani JE, Moro $C_{f}$ Ravussin E (2008) Metabolic flexibility and insulin resistance. Am J Physiol Endocrinol Metab 295: E1009-1017 
41.

Cline GW, Petersen KF, Krssak M, et al. (1999) Impaired glucose transport as a cause of decreased insulin-stimulated muscle glycogen synthesis in type 2 diabetes. $N$ Engl J Med 341: 240-246

Rothman DL, Shulman RG, Shulman GI (1992) 31P nuclear magnetic resonance measurements of muscle glucose-6-phosphate. Evidence for reduced insulin-dependent muscle glucose transport or phosphorylation activity in non-insulin-dependent diabetes mellitus. J Clin Invest 89: 1069-1075

Mandarino LJ, Consoli A, Jain A, Kelley DE (1996) Interaction of carbohydrate and fat fuels in human skeletal muscle: impact of obesity and NIDDM. Am J Physiol 270: E463470

Corpeleijn E, Saris WH, Blaak EE (2009) Metabolic flexibility in the development of insulin resistance and type 2 diabetes: effects of lifestyle. Obes Rev 10: 178-193

Corpeleijn E, Mensink M, Kooi ME, Roekaerts PM, Saris WH, Blaak EE (2008) Impaired skeletal muscle substrate oxidation in glucose-intolerant men improves after weight loss. Obesity (Silver Spring) 16:1025-1032

Kelley DE, Mandarino LJ (1990) Hyperglycemia normalizes insulin-stimulated skeletal muscle glucose oxidation and storage in noninsulin-dependent diabetes mellitus. J Clin Invest 86: 1999-2007

Kelley DE, Simoneau J-A (1994) Impaired free fatty acid utilization by skeletal muscle in non-insulin dependent diabetes mellitus. J Clin Invest 94: 2349-2356

DeFronzo RA, Ferrannini E, Simonson DC (1989) Fasting hyperglycemia in non-insulindependent diabetes mellitus: contributions of excessive hepatic glucose production and impaired tissue glucose uptake. Metabolism 38: 387-395

Golay A, Swislocki AL, Chen YD, Reaven GM (1987) Relationships between plasma-free fatty acid concentration, endogenous glucose production, and fasting hyperglycemia in normal and non-insulin-dependent diabetic individuals. Metabolism 36: 692-696

DeFronzo RA (1988) Lilly lecture 1987. The triumvirate: beta-cell, muscle, liver, A collusion responsible for NIDDM. Diabetes 37: 667-687

Lam TK, Carpentier A, Lewis GF, van de Werve G, Fantus IG, Giacca A (2003) Mechanisms of the free fatty acid-induced increase in hepatic glucose production. Am J Physiol Endocrinol Metab 284: E863-873

Seppala-Lindroos A, Vehkavaara S, Hakkinen AM, et al. (2002) Fat accumulation in the liver is associated with defects in insulin suppression of glucose production and serum free fatty acids independent of obesity in normal men. J Clin Endocrinol Metab 87: 30233028

Bickerton AS, Roberts R, Fielding BA, et al. (2008) Adipose tissue fatly acid metabolism in insulin-resistant men. Diabetologia 51: 1466-1474

Jocken JW, Goossens GH, van Hees AM, et al. (2008) Effect of beta-adrenergic stimulation on whole-body and abdominal subcutaneous adipose tissue lipolysis in lean and obese men. Diabetologia 51:320-327

Campbell PJ, Carlson MG, Nurjhan N (1994) Fat metabolism in human obesity. Am J Physiol 266: E600-605

Jansson PA, Larsson A, Smith U, Lonnroth P (1992) Glycerol production in subcutaneous adipose tissue in lean and obese humans. J Clin Invest 89: 1610-1617

Reaven GM, Hollenbeck C, Jeng CY, Wu MS, Chen YD (1988) Measurement of plasma glucose, free fatty acid, lactate, and insulin for $24 \mathrm{~h}$ in patients with NIDDM. Diabetes 37: 1020-1024

Coppack SW, Evans RD, Fisher RM, et al. (1992) Adipose tissue metabolism in obesity: lipase action in vivo before and after a mixed meal. Metabolism 41: 264-272 
Riemens SC, Sluiter WJ, Dullaart RP (2000) Enhanced escape of non-esterified fatty acids from tissue uptake: its role in impaired insulin-induced lowering of total rate of appearance in obesity and Type II diabetes mellitus. Diabetologia 43: 416-426

Potts JL, Coppack SW, Fisher RM, Humphreys SM, Gibbons GF, Frayn KN (1995) Impaired postprandial clearance of triacylglycerol-rich lipoproteins in adipose tissue in obese subjects. Am J Physiol Endocrinol Metab 268: E:588-594

Blaak EE, Wagenmakers AJM, Glatz JFC, et al. (2000) Plasma FFA utilization and fatty acid-binding protein content are diminished in type 2 diabetic muscle. Am J Physiol Endocrinol Metab 279: E146-E154

Colberg SR, Simoneau JA, Thaete FL, Kelley DE (1995) Skeletal muscle utilization of free fatty acids in women with visceral obesity. J Clin Invest 95: 1846-1853

Ravikumar B, Carey PE, Snaar JE, et al. (2005) Real-time assessment of postprandial fat storage in liver and skeletal muscie in health and type 2 diabetes. Am J Physiol Endocrinol Metab 288: E789-797

van der Vusse GJ, van Bilsen M, Glatz JF, Hasselbaink DM, Luiken JJ (2002) Critical steps in cellular fatty acid uptake and utilization. Mol Cell Biochem 239: 9-15

Glatz JF, Luiken JJ, Bonen A (2001) Involvement of membrane-associated proteins in the acute regulation of cellular fatty acid uptake. J Mol Neurosci 16: 123-132; discussion 151127

Glatz JF, Storch J (2001) Unravelling the significance of cellular fatty acid-binding proteins. Curr Opin Lipidol 12: 267-274

Abumrad N, Coburn C, Ibrahimi A (1999) Membrane proteins implicated in long-chain fatty acid uptake by mammalian cells: CD36, FATP and FABPm. Biochim Biophys Acta 1441: $4-13$

Bonen A, Dyck DJ, Ibrahimi A, Abumrad NA (1999) Muscle contractile activity increases fatty acid metabolism and transport and FAT/CD36. Am J Physiol 276: E642649

Bonen A, Miskovic D, Kiens B (1999) Fatty acid transporters (FABPpm, FAT, FATP) in human muscle. Can J Appl Physiol 24: 515-523

Pelsers MM, Tsintzas $\mathrm{K}$, Boon $\mathrm{H}$, et al. (2007) Skeletal muscle fatty acid transporter protein expression in type 2 diabetes patients compared with overweight, sedentary men and age-matched, endurance-trained cyclists. Acta Physiol (Oxf) 190: 209-219

Wilmsen HM, Ciaraldi TP, Carter L, Reehman N, Mudaliar SR, Henry RR (2003) Thiazolidinediones upregulate impaired fatty acid uptake in skeletal muscle of type 2 diabetic subjects. Am J Physiol Endocrinol Metab 285: E354-362

Hegarty BD, Cooney GJ, Kraegen EW, Furler SM (2002) Increased efficiency of fatty acid uptake contributes to lipid accumulation in skeletal muscle of high fat-fed insulinresistant rats. Diabetes 51: 1477-1484

Simoneau JA, Veerkamp JHI, Turcotte LP, Kelley DE (1999) Markers of capacity to utilize fatty acids in human skeletal muscle: relation to insulin resistance and obesity and effects of weight loss. FASEB J 13: 2051-2060

Bonen A, Parolin ML, Steinberg GR, et al. (2004) Triacylglycerol accumulation in human obesity and type 2 diabetes is associated with increased rates of skeletal muscle fatty acid transport and increased sarcolemmal FAT/CD36. FASEB J 18: 1144-1146

Chabowski A, Chatham JC, Tandon NN, et al. (2006) Fatty acid transport and FAT/CD36 are increased in red but not in white skeletal muscle of ZDF rats. Am J Physiol Endocrinol Metab 291: E675-682

6. Bruce CR, Anderson MJ, Carey AL, et al. (2003) Muscle oxidative capacity is a better predictor of insulin sensitivity than lipid status. J Clin Endocrinol Metab 88: 5444-5451 
Blaak EE, Wagenmakers AJ (2002) The fate of [U-(13)Clpalmitate extracted by skeletal muscle in subjects with type 2 diabetes and control subjects. Diabetes 51: 784-789

Blaak EE, van Aggel-Leijssen DPC, Wagenmakers AJM, Saris WHM, van Baak MA (2000) Impaired oxidation of plasma-derived fatty acids in type 2 diabetic subjects during moderate-intensity exercise. Diabetes 49: 2102-2107

Krssak M, Petersen KF, Dresner A, et al. (1999) Intramyocellular lipid concentrations are correlated with insulin sensitivity in humans: a $1 \mathrm{H}-\mathrm{MRS}$ spectoscropy study. Diabetologia 42: 113-116

80. Phillips SM, Green HJ, Tarnopolsky MA, Heigenhauser GF, Hill RE, Grant SM (1996) Effects of training duration on substrate turnover and oxidation during exercise. J Appl Physiol 81: 2182-2191

81. Pan DA, Lillioja S, Kriketos AD, et al. (1997) Skeletal muscle triglyceride levels are inversely related to insulin action. Diabetes 46: 983-988 van Loon LJC (2004) Use of intramuscular triacylglycerol as a substrate source during exercise in humans. J Appl Physiol 97: 1170-1187 van Loon LJ, Manders RJ, Koopman R, et al. (2005) Inhibition of adipose tissue lipolysis increases intramuscular lipid use in type 2 diabetic patients. Diabetologia 48: 2097-2107 adipose tissue lipolysis increases intramuscular lipid and glycogen use in vivo in humans. Am J Physiol Endocrinol Metab 289: E482-493

Goodpaster BH, He J, Watkins S, Kelley DE (2001) Skeletal muscle lipid content and insulin resistance: evidence for a paradox in endurance-trained athletes. J Clin Endocrinol Metab 86: 5755-5761

Thamer C, Machann J, Bachmann O, et al. (2003) Intramyocellular lipids: anthropometric determinants and relationships with maximal aerobic capacity and insulin sensitivity. J Clin Endocrinol Metab 88: 1785-1791 Booth FW, Chakravarthy MV, Spangenburg EE (2002) Exercise and gene expression: physiological regulation of the human genome through physical activity. J Physiol 543: 399-411

.

Booth FW, Gordon SE, Carlson CJ, Hamilton MT (2000) Waging war on modern chronic diseases: primary prevention through exercise biology. J Appl Physiol 88: 774-787 exercise in men and women after endurance training. Am J Physiol Endocrinol Metab 280: E898-907 endurance-trained and untrained men. Am J Physiol 267: E934-940

Manetta J, Brun JF, Prefaut C, Mercier J (2005) Substrate oxidation during exercise at moderate and hard intensity in middle-aged and young athletes vs sedentary men. Metabolism 54: 1411-1419

Martin WH, 3rd, Dalsky GP, Hurley BF, et al. (1993) Effect of endurance training on plasma free fatty acid turnover and oxidation during exercise. Am J Physiol 265: E708714

van Loon LJ, Jeukendrup AE, Saris WH, Wagenmakers AJ (1999) Effect of training status on fuel selection during submaximal exercise with glucose ingestion. J Appl Physiol 87: 1413-1420

Pruchnic R, Katsiaras A, He J, Kelley DE, Winters C, Goodpaster BH (2004) Exercise training increases intramyocellular lipid and oxidative capacity in older adults. Am J Physiol Endocrinol Metab 287: E857-862 
95. Rimbert V, Boirie Y, Bedu M, Hocquette JF, Ritz P, Morio B (2004) Muscle fat oxiclative capacity is not impaired by age but by physical inactivity: association with insulin sensitivity. Faseb J 18: 737-739

96. Borghouts LB, Wagenmakers AJM, Goyens PLL, Keizer HA (2002) Substrate utilization in non-obese type II diabetic patients at rest and during exercise. Clinical Science 103: $559-566$

97. Martin IK, Katz A, Wahren J (1995) Splanchnic and muscle metabolism during exercise in NIDDM patients. Am J Physiol 269: E583-590

98. Colberg SR, Hagberg JM, McCole SD, Zmuda JM, Thompson PD, Kelley DE (1996) Utilization of glycogen but not plasma glucose is reduced in individuals with NIDDM during mild-intensity exercise. J Appl Physiol 81: 2027-2033

99. Kang J, Kelley DE, Robertson RJ, et al. (1999) Substrate utilization and glucose turnover during exercise of varying intensities in individuals with NIDDM. Med Sci Sports Exerc 31: $82-89$

100. Schwartz RS, Shuman WP, Larson V, et al. (1991) The effect of intensive endurance exercise training on body fat distribution in young and older men. Metabolism 40: 545551

101. Bruce CR, Hawley JA (2004) Improvements in insulin resistance with aerobic exercise training: a lipocentric approach. Med Sci Sports Exerc 36: 1196-1201

102. Maiorana A, O'Driscoll G, Cheetham C, et al. (2001) The effect of combined aerobic and resistance exercise training on vascular function in type 2 diabetes. J Am Coll Cardiol 38: 860-866

103. Herder C, Peltonen M, Koenig W, et al. (2009) Anti-inflammatory effect of lifestyle changes in the Finnish Diabetes Prevention Study. Diabetologia 52: 433-442

104. Mathur N, Pedersen BK (2008) Exercise as a mean to control low-grade systemic inflammation. Mediators Inflamm 2008: 109502 Bogardus C, Ravussin E, Robbins DC, Wolfe RR, Horton ES, Sims EA (1984) Effects of physical training and diet therapy on carbohydrate metabolism in patients with glucose intolerance and non-insulin-dependent diabetes mellitus. Diabetes 33: 311-318

Bruce CR, Kriketos AD, Cooney G], Hawley JA (2004) Disassociation of muscle triglyceride content and insulin sensitivity after exercise training in palients with Type 2 diabetes. Diabetologia 47: 23-30

De Feyter HM, Praet SF, van den Broek NM, et al. (2007) Exercise training improves glycemic control in long-standing instlin-treated type 2 diabetic patients. Diabetes Care 30: 2511-2513

Turcotte LP, Fisher JS (2008) Skeletal muscle insulin resistance: roles of fatty acid metabolism and exercise. Phys Ther 88: 1279-1296

Coggan AR, Spina RJ, Rogers MA, et al. (1990) Histochemical and enzymatic characteristics of skeletal muscle in master athletes. J Appl Physiol 68: 1896-1901

Hardie DG (2004) AMP-activated protein kinase: a key system mediating metabolic responses to exercise. Med Sci Sports Exerc 36: 28-34

111. Hardie DG, Carling D, Carlson M (1998) The AMP-activated/SNF1 protein kinase subfamily: metabolic sensors of the eukaryotic cell? Annu Rev Biochem 67: 821-855

112. Hardie DG, Salt IP, Davies SP (2000) Analysis of the role of the AMP-activated protein kinase in the response to cellular stress. Methods in molecular biology 99: 63-74 , activated in muscle of subjects with type 2 diabetes during exercise. Diabetes 50: 921-927

114. Wojtaszewski JF, Hansen BF, Gade, et al. (2000) Insulin signaling and insulin sensitivity after exercise in human skeletal muscle. Diabetes 49: 325-331 
115.

116.

118.

119

131.

Wojtaszewski JF, Jorgensen SB, Frosig C, MacDonald C, Birk JB, Richter EA (2003) Insulin signalling: effects of prior exercise. Acta Physiol Scand 178: 321-328

Wojtaszewski JF, MacDonald C, Nielsen JN, et al. (2003) Regulation of 5 'AMP-activated protein kinase activity and substrate utilization in exercising human skeletal muscle. Am J Physiol Endocrinol Metab 284: E813-822

Wojtaszewski JF, Nielsen P, Hansen BF, Richter EA, Kiens B (2000) Isoform-specific and exercise intensity-dependent activation of 5'-AMP-activated protein kinase in human skeletal muscle. J Physiol 528 Pt 1: 221-226

Sakamoto K, McCarthy A, Smith D, et al. (2005) Deficiency of LKB1 in skeletal muscle prevents AMPK activation and glucose uptake during contraction. EMBO J 24: 18101820

Bergeron R, Russell RR, 3rd, Young LH, et al. (1999) Effect of AMPK activation on muscle glucose metabolism in conscious rats. Am J Physiol 276: E938-944

Merrill GF, Kurth EJ, Hardie DG, Winder WW (1997) AICA riboside increases AMPactivated protein kinase, fatty acid oxidation, and glucose uptake in rat muscle. Am J Physiol 273: E1107-1112

Hayashi T, Hirshman MF, Kurth EJ, Winder WW, Goodyear LJ (1998) Evidence for 5' AMP-activated protein kinase mediation of the effect of muscle contraction on glucose transport. Diabetes 47: 1369-1373

Kurth-Kraczek EJ, Hirshman MF, Goodyear LJ, Winder WW (1999) 5' AMP-activated protein kinase activation causes GLUT4 translocation in skeletal muscle. Diabetes 48 : 1667-1671

Hardie DG, Pan DA (2002) Regulation of fatty acid synthesis and oxidation by the AMP-activated protein kinase. Biochem Soc Trans 30: 1064-1070

Bergeron R, Previs SF, Cline GW, et al. (2001) Effect of 5-aminoimidazole-4carboxamide-1-beta-D-ribofuranoside infusion on in vivo glucose and lipid metabolism in lean and obese Zucker rats. Diabetes 50: 1076-1082

Iglesias MA, Furler SM, Cooncy GJ, Kraegen EW, Ye J-M (2004) AMP-activated protein kinase activation by AICAR increases both muscle fatty acid and glucose uptake in white muscle of insulin-resistant rats in vivo. Diabetes 53: 1649-1654

Iglesias MA, Ye JM, Frangioudakis $G$, et al. (2002) AICAR administration causes an apparent enhancement of muscle and liver insulin action in insulin-resistant high-fatfed rats. Diabetes 51: 2886-2894

Song XM, Fiedler M, Galuska D, et al. (2002) 5-Aminoimidazole-4-carboxamide ribonucleoside treatment improves glucose homeostasis in insulin-resistant diabetic (ob/ob) mice. Diabetologia 45: 56-65

Pold R, Jensen LS, Jessen N, et al. (2005) Long-Term AICAR Administration and

Exercise Prevents Diabetes in ZDF Rats. Diabetes 54: 928-934

Buhl ES, Jessen N, Pold R, et al. (2002) Long-term AICAR administration reduces metabolic disturbances and lowers blood pressure in rats displaying features of the

insulin resistance syndrome. Diabetes 51: 2199-2206
Koistinen HA, Galuska D, Chibalin AV, el al. (2003) 5-amino-imidazole carboxamide riboside increases glucose transport and cell-surface GLUT4 content in skeletal muscle

from subjects with type 2 diabetes. Diabetes 52: 1066-1072
Steinberg GR, Smith AC, Van Denderen BJ, et al. (2004) AMP-activated protein kinase is not down-regulated in human skeletal muscle of obese females. J Clin Endocrinol Metab $89: 4575-4580$ 
Sriwijitkamol A, Coletta DK, Wajcberg E, et al. (2007) Effect of acute exercise on AMPK signaling in skeletal muscle of subjects with type 2 diabetes: a time-course and doseresponse study. Diabetes 56: 836-848

133. Musi N, Hirshman MF, Nygren J, et al. (2002) Metformin increases AMP-activated protein kinase activity in skeletal muscle of subjects with type 2 diabetes. Diabetes 51 : 2074-2081

134. Hojlund K, Mustard KJ, Staehr P, et al. (2004) AMPK activity and isoform protein expression are similar in muscle of obese subjects with and without type 2 diabetes. Am J Physiol Endocrinol Metab 286: E239-244

135. Fryer LG, Hajduch E, Rencurel F, et al. (2000) Activation of glucose transport by AMPactivated protein kinase via stimulation of nitric oxide synthase. Diabetes 49: 1978-1985

136. Fujii N, Aschenbach WG, Musi N, Hirshman MF, Goodyear LJ (2004) Regulation of glucose transport by the AMP-activated protein kinase. Proceedings of the Nutrition Society 63: 205-210

137. Cuthbertson DJ, Babraj JA, Mustard KJ, et al. (2007) 5-aminoimidazole-4-carboxamide 1beta-D-ribofuranoside acutely stimulates skeletal muscle 2-deoxyglucose uptake in healthy men. Diabetes 56: 2078-2084

138. Birk JB, Wojtaszewski JF (2006) Predominant alpha2/beta2/gamma3 AMPK activation during exercise in human skeletal muscle. J Physiol 577: 1021-1032

139. Winder WW, Hardie DG, Mustard KJ, et al. (2003) Long-term regulation of AMPactivated protein kinase and acetyl-CoA carboxylase in skeletal muscle. Biochem Soc Trans 31: 182-185

140. Long YC, Zierath JR (2006) AMP-activated protein kinase signaling in metabolic regulation. J Clin Invest 116: 1776-1783 


\section{Substrate source utilisation in long-term diagnosed type 2 diabetes patients at rest, during exercise and subsequent recovery}

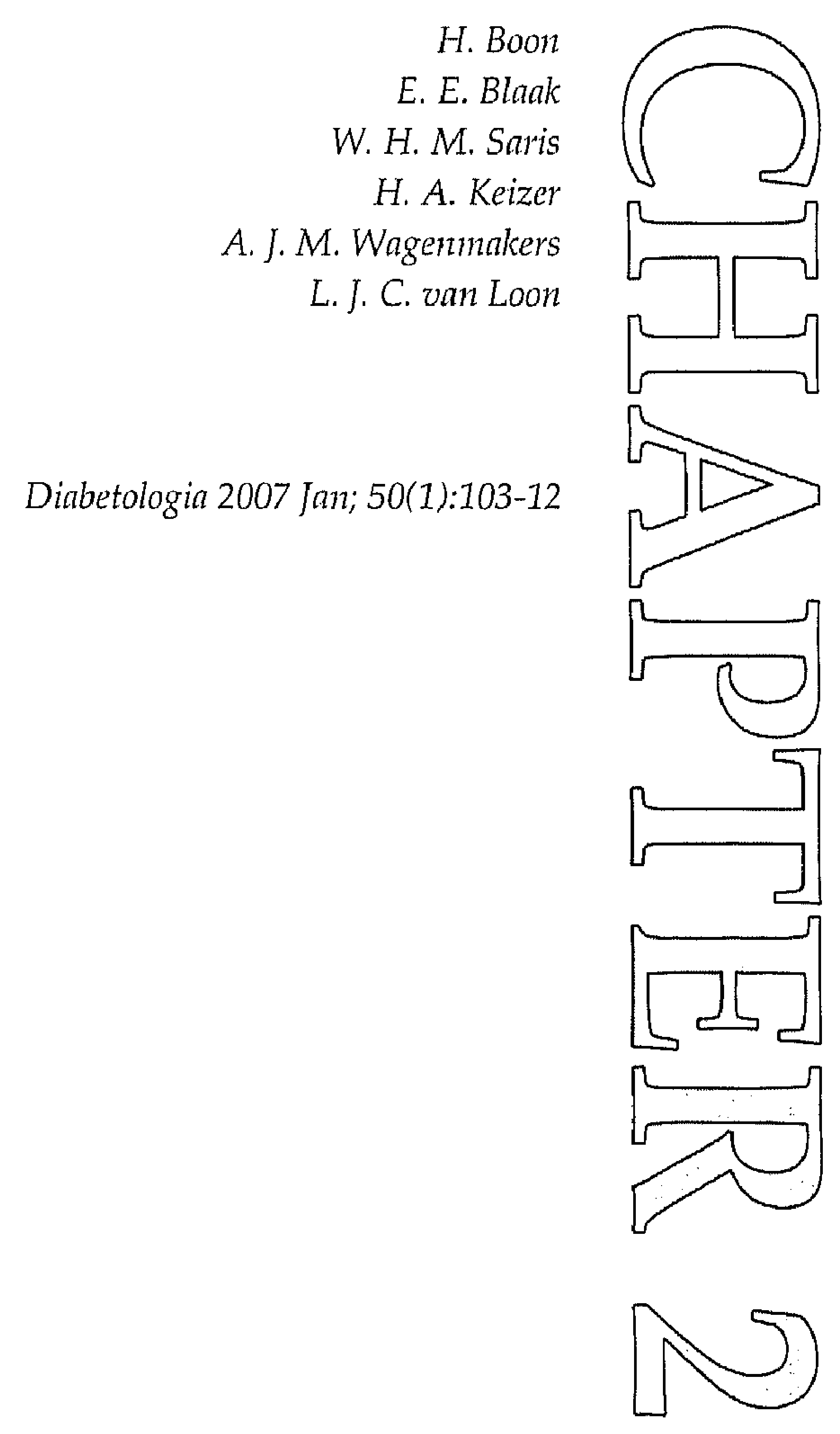




\section{ABSTRACT}

\section{Aims/hypothesis}

Disturbances in substrate source metabolism and, more particularly, in fatty acid metabolism, play an important role in the aetiology and progression of type 2 diabetes. However, data on substrate source utilisation in type 2 diabetes are inconclusive.

\section{Methods}

[U-13 C]palmitate and $\left[6,6-{ }^{2} \mathrm{H}_{2}\right]$ glucose tracers were used to assess plasma NEFA and glucose oxidation rates and to estimate the use of muscle- and/or lipoprotein-derived triacylglycerol and muscle glycogen. Subjects were ten male patients who had a long-term ( $7 \pm 1$ years) diagnosis of type 2 diabetes and were overweight, and ten matched healthy, male control subjects. Muscle biopsy samples were collected before and after exercise to assess muscle fibre type-specific intramyocellular lipid and glycogen content.

\section{Results}

At rest and during exercise, the diabetes patients had greater values than the controls for palmitate rate of appearance (Ra) (rest, $2.46 \pm 0.18$ and $1.85 \pm 0.20$ respectively; exercise, $3.71 \pm 0.36$ and $\left.2.84 \pm 0.20 \mu \mathrm{mol} \mathrm{kg}^{-1} \mathrm{~min}^{-1}\right)$ and rate of disappearance (Rd) (rest, 2.45 \pm 0.18 and 1.83 \pm 0.20 ; exercise, $3.64 \pm 0.35$ and $2.80 \pm 0.20 \mu \mathrm{mol} \mathrm{kg}^{-1} \mathrm{~min}^{-1}$ respectively). This was accompanied by significantly higher fat oxidation rates at rest and during recovery in the diabetes patients (rest, $0.11 \pm 0.01$ in diabetes patients and $0.09 \pm 0.01$ in controls; recovery, $0.13 \pm 0.01$ and $0.11 \pm 0.01 \mathrm{~g} / \mathrm{min}$ respectively), despite significantly greater plasma glucose $\mathrm{Ra}, \mathrm{Rd}$ and circulating plasma glucose concentrations. Furthermore, exercise significantly lowered plasma glucose concentrations in the diabetes patients, as a result of increased blood glucose disposal.

\section{Conclusion}

This study demonstrates that substrate source utilisation in long-term diagnosed type 2 diabetes patients, in whom compensatory hyperinsulinaemia is no longer present, shifts towards an increase in whole-body fat oxidation rate and is accompanied by disturbances in fat and carbohydrate handling. 


\section{INTRODUCTION}

Disturbances in fatty acid metabolism, as found in sedentary, obese and/or type 2 diabetes patients, are an important factor in the development of skeletal muscle insulin resistance [1-3]. Elevated fatty acid delivery and/or impaired fatty acid oxidation result in net intramyocellular accumulation of triacylglycerol and fatty acid metabolites (such as fatty acyl-CoA, ceramides and diacylglycerol). The latter are likely to induce defects in the insulin signalling cascade, thus causing insulin resistance [4-10] in skeletal muscle. On a whole-body level, conflicting data exist on the proposed disturbances in substrate metabolism in type 2 diabetes patients. In these patients, basal oxidation rates of whole-body total fat have been reported to be both increased [11-13] and similar [14-19] compared with lean [11-13] and overweight/obese [14-19] controls respectively. Whole-body plasma NEFA uptake and/or oxidation rates at rest have been reported to be either similar $[17,18]$ or decreased [16] in the type 2 diabetes patient. However, data on arteriovenous differences in plasma NEFA concentrations over the leg or arm have more consistently displayed reduced fasting plasma NEFA uptake and/or oxidation in type 2 diabetes patients when compared with normoglycaemic controls [11, 14, 20], despite elevated systemic plasma NEFA and glucose levels [14, 20]. During exercise, the uptake and oxidation of plasma NEFA and other lipid sources have been shown to be either similar $[17,18]$ or decreased $[16,21]$ in both the prediabetic and the type 2 diabetes state. A cross-sectional review of the literature on the use of lipoprotein and/or muscle-derived triacylglycerol suggests that type 2 diabetes patients have a reduced capacity to mobilise and/or oxidise the intramyocellular lipid stores [22]. However, a direct comparison of intramyocellular triacylglycerol (IMTG) use between diabetes patients and matched controls has not yet been made. Exercise can lower plasma glucose concentrations in type 2 diabetes patients. This can be attributed to a blunted increase in hepatic glucose output [23] and/or an increase in wholebody glucose uptake rate $[15,17,18,24]$. The latter has been shown to result in greater carbohydrate oxidation rates during exercise in type 2 diabetes patients in some [24] but not all studies [15-18]. Data on differences in substrate source utilisation during post-exercise recovery between diabetes patients and healthy, normoglycaemic controls are entirely lacking in the literature. The apparently inconsistent findings on aberrations in whole-body substrate utilisation in the type 2 diabetes state can be explained by differences in the methods used and in the selected subpopulations of type 2 diabetes patients and controls. These equivocal data restrict conclusive insight into the exact nature and extent of the metabolic disturbances that play a key role in the aetiology and progression of 
type 2 diabetes. In the present study, we investigated the disturbances in wholebody substrate source utilisation in long-standing type 2 diabetes at rest, during exercise and subsequent recovery by using contemporary stable isotope methods combined with skeletal muscle biopsy sampling. Patients with longstanding type 2 diabetes were selected to assess the metabolic disturbances when compensatory hyperinsulinaemia is no longer present. Careful matching of the type 2 diabetes patients with normoglycaemic controls was performed to be able to determine the effect of type 2 diabetes on substrate use independently of age, body composition and aerobic capacity. The present study is the first to provide a complete overview of substrate source utilisation rates at rest, during exercise and post-exercise recovery in overweight patients with long-standing type 2 diabetes, in whom compensatory hyperinsulinaemia is no longer present.

\section{SUBJECTS AND METHODS}

\section{Subjects}

Ten male, sedentary, overweight type 2 diabetes patients and ten male, sedentary, weight-matched healthy controls (Table 1) participated in this study. All patients were using metformin with $(n=7)$ or without $(n=3)$ sulphonylurea derivatives (gliclazide, glimepiride or tolbutamide). Exclusion criteria were impaired liver function, renal failure and/or a history of severe cardiovascular problems. Diabetic status was verified with an OGTT according to WHO criteria [25]. Medication was withheld for $24 \mathrm{~h}$ prior to the trials. Subjects were informed about the nature and risks of the experimental procedures before their written informed consent was obtained. The study was performed according to the principles of the Declaration of Helsinki and was approved by the local medical ethical committee.

\section{Pretesting}

Maximal power output $\left(\mathrm{W}_{\max }\right)$ and maximal oxygen uptake capacity $\left(\mathrm{VO}_{2 \mathrm{max}}\right)$ were determined with an electronically braked cycle ergometer (Excalibur; Lode Groningen, the Netherlands) during an incremental exhaustive exercise test 2 weeks prior to the first trial [17]. Oxygen uptake $\left(V \mathrm{O}_{2}\right)$ and carbon dioxide production $\left(\mathrm{VCO}_{2}\right)$ were measured with an Oxycon $\beta$ (Mijnhart, Breda, the Netherlands). Body composition was assessed using the hydrostatic weighing method. Body fat percentage was calculated using Siri's equation [26]. 


\section{Diet and physical activity prior to testing}

All subjects were instructed to refrain from strenuous physical activity for 2 days prior to each trial. In addition, they recorded dietary intake during 2 days prior to the first trial and repeated this diet prior to the second trial. The evening before each trial, all subjects received the same standardised meal

\section{Table 1 Subjects' characteristics}

\begin{tabular}{lll}
\hline & $\begin{array}{l}\text { Control group } \\
(\mathbf{n}=10)\end{array}$ & $\begin{array}{l}\text { Diabetes group } \\
(\mathrm{n}=10)\end{array}$ \\
\hline Age (years) & $60 \pm 2$ & $60 \pm 2$ \\
Height $(\mathrm{m})$ & $1.76 \pm 0.01$ & $1.79 \pm 0.02$ \\
Body mass $(\mathrm{kg})$ & $87 \pm 2$ & $91 \pm 4$ \\
BMI $\left(\mathrm{kg} / \mathrm{m}^{2}\right)$ & $28 \pm 0$ & $28 \pm 1$ \\
Body fat $(\%)$ & $29 \pm 1$ & $29 \pm 2$ \\
Fat-free mass (kg) & $61 \pm 1$ & $64 \pm 2$ \\
Basal plasma glucose (mmol/l) & $5.56 \pm 0.14$ & $9.44 \pm 0.59^{\mathrm{a}}$ \\
Plasma glucose120min (mmol/l) $\mathrm{b}$ & $5.55 \pm 0.5$ & $16.7 \pm 1.2^{\mathrm{a}}$ \\
Basal plasma insulin (pmol/l) & $47.16 \pm 9.48$ & $52.20 \pm 6.06$ \\
Plasma insulin120min (pmol/1) ${ }^{\mathrm{b}}$ & $290.40 \pm 48.24$ & $270.06 \pm 46.50$ \\
HbA1c (\%) & $5.83 \pm 0.2$ & $7.30 \pm 0.3^{\mathrm{a}}$ \\
VO2max (1/min) & $3.2 \pm 0.2$ & $2.9 \pm 0.2$ \\
Wmax (W) & $203 \pm 16$ & $200 \pm 15$ \\
Maximal heart rate (beats/min) & $164 \pm 7$ & $161 \pm 4$ \\
Diagnosed with diabetes (years) & - & $7 \pm 1^{\mathrm{a}}$ \\
\hline
\end{tabular}

Data are mean \pm SEM

VO2max, maximal oxygen uptake capacity; Wmax, maximal workload capacity

aSignificantly different from control group $(\mathrm{p}<0.05)$

bConcentrations at $\mathrm{t}=120 \mathrm{~min}$ during OGTT

(42 kJ [10 kcal] $/ \mathrm{kg}$; consisting of $61 \%$ of energy as carbohydrate, $24 \%$ as fat and $15 \%$ as protein). There were no differences between groups in daily energy intake and macronutrient composition of the diet.

\section{Experimental trials}

Each subject performed one main trial and an additional test to determine the acetate recovery factor. Both tests were separated by at least 1 week. Each trial consisted of $120 \mathrm{~min}$ of resting measurements followed by $60 \mathrm{~min}$ of cycling exercise at an exercise intensity set at $50 \% \mathrm{~W}_{\max }$, and a subsequent $120 \mathrm{~min}$ recovery period. In the main trial, a $\left[\mathrm{U}_{-13}{ }^{13} \mathrm{C}\right]$ palmitate and $\left[6,6-{ }^{2} \mathrm{H} 2\right]$ glucose tracer 
was infused and breath, blood and muscle samples were collected at regular intervals. The acetate test was identical with the exception of the infusion of $\left[1,2-{ }^{13} \mathrm{C}\right]$ acetate and the collection of breath samples only [27].

\section{Protocol}

After an overnight fast, subjects arrived at the laboratory at 08.00 hours by car or public transport. After $30 \mathrm{~min}$ of supine rest, a percutaneous muscle biopsy [28] was taken from the vastus lateralis muscle. A Teflon catheter (Baxter, Utrecht, the Netherlands) was inserted into an antecubital vein of one arm for blood sampling and another catheter was inserted in the contralateral arm for isotope infusion. Subsequently, subjects were administered a single intravenous dose of $\mathrm{NaH}^{13} \mathrm{CO}_{3}(0.06375 \mathrm{mg} / \mathrm{kg})$, followed by a $\left[6,6-{ }^{2} \mathrm{H}_{2}\right]$ glucose prime $(13.5 \mu \mathrm{mol} / \mathrm{kg})$. Thereafter, a continuous infusion of $\left[6,6-{ }^{2} \mathrm{H}_{2}\right]$ glucose

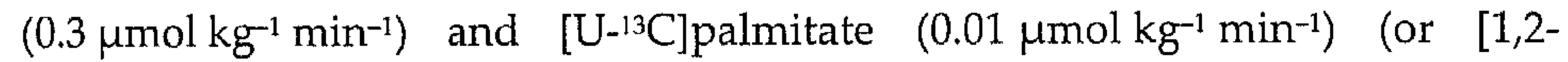
${ }^{13} \mathrm{C}$ ]acetate) was started ( $t=0 \mathrm{~min}$ ) via a calibrated IVAC pump (IVAC 560; Ivac, San Diego, CA, USA). At $t=120$ min subjects started to exercise on a cycle ergometer at $50 \% \mathrm{~W}_{\max }$ for a $60 \mathrm{~min}$ period. Whilst the subject was at rest, $\mathrm{VO}_{2}$ and $V \mathrm{CO}_{2}$ were measured from $t=60$ to $120 \mathrm{~min}$ (Oxycon- $\beta$; Mijnhart), during exercise $V \mathrm{O}_{2}$ and $V \mathrm{CO}_{2}$ were measured for $5 \mathrm{~min}$ every $15 \mathrm{~min}$ prior to sampling of blood and expired breath. Immediately after cessation of exercise, a second muscle biopsy was taken, after which the subject rested supine for $2 \mathrm{~h}$. $V \mathrm{O}_{2}$ and $V \mathrm{CO}_{2}$ were measured during recovery from $t=210$ to $270 \mathrm{~min}$.

\section{Blood and breath samples}

Blood samples $(7 \mathrm{ml})$ were collected in EDTA-containing tubes and centrifuged at $1000 \mathrm{~g}$ for $10 \mathrm{~min}$ at $4^{\circ} \mathrm{C}$. Aliquots of plasma were frozen immediately in liquid nitrogen and stored at $-80^{\circ} \mathrm{C}$. Plasma concentrations of glucose (Roche, Basel, Switzerland), lactate, NEFA (Wako Chemicals, Neuss, Germany), glycerol (Roche Diagnostics, Indianapolis, IN, USA) and triacylglycerol (Sigma Diagnostics, St Louis, MO, USA) were analysed with a COBAS semi-automatic analyser (Roche). Plasma insulin was measured by radioimmunoassay (Linco, St Charles, MO, USA). Blood HbA1c content was analysed by high-performance liquid chromatography (Bio-Rad Diamat, Munich, Germany). Expired breath samples were analysed for ${ }^{13} \mathrm{C} /{ }^{12} \mathrm{C}$ ratio using a gas chromatograph-isotope ratio mass spectrometer system (GC-IRMS; Finnigan MAT 252, Bremen, Germany). For determination of plasma palmitate and NEFA kinetics, NEFA were extracted, isolated by thin-layer chromatography and derivatised to their methyl esters. Palmitate concentration was determined on an analytical GC with flame ionisation detection using heptadecanoic acid as internal standard, 
and constituted $21.3 \pm 0.7 \%$ of total NEFA. The isotope tracer/tracee ratio (TTR) of [U-13C]palmitate was determined using GC combustion isotope ratio MS (Finnigan MAT 252). Following derivatisation, plasma $\left[6,6-{ }^{2} \mathrm{H}_{2}\right]$ glucose enrichment was determined by electron ionisation GC-MS (Finnigan). Palmitate, glucose and acetate tracer concentrations in the infusates averaged $1.05 \pm 0.01,34.4 \pm 0.9$ and $4.92 \pm 0.03 \mathrm{mmol} / 1$ respectively. Therefore, the exact tracer infusion rates averaged $9.1 \pm 0.1,277 \pm 2$ and $75 \pm 1 \mathrm{nmol} \mathrm{kg}^{-1} \mathrm{~min}^{-1}$ respectively.

\section{Calculations}

From respiratory measurements, total fat and carbohydrate oxidation rates were calculated using the non-protein respiratory quotient [29]:

$$
\begin{aligned}
& \text { fat oxidation rate }=1.695 \mathrm{VO}_{2}-1.701 \mathrm{VCO}_{2} \\
& \text { carbohydrate oxidation rate }=4.585 \mathrm{VCO}_{2}-3.226 \mathrm{VO}_{2}
\end{aligned}
$$

where $V \mathrm{O}_{2}$ and $V \mathrm{VO}_{2}$ are in litres/min and oxidation rates in $\mathrm{g} / \mathrm{min}$. Rate of appearance $(\mathrm{Ra})$ and rate of disappearance $(\mathrm{Rd})$ of palmitate and glucose were calculated using the single-pool non-steady state Steele equations adapted for stable isotope methodology [30]:

$$
\begin{aligned}
& \mathrm{Ra}=\frac{\mathrm{F}-\mathrm{V}\left[\left(\mathrm{C}_{2}+\mathrm{C}_{1}\right) / 2\right]\left[\left(\mathrm{E}_{2}-\mathrm{E}_{1}\right) /\left(\mathrm{t}_{2}-\mathrm{t}_{1}\right)\right]}{\left(\mathrm{E}_{2}+\mathrm{E}_{1}\right) / 2} \\
& \mathrm{Rd}=\mathrm{Ra}-\mathrm{V} \cdot\left(\frac{\mathrm{C}_{2}-\mathrm{C}_{1}}{\mathrm{t}_{2}-\mathrm{t}_{1}}\right)
\end{aligned}
$$

where $F$ is the infusion rate $\left(\mu \mathrm{mol} \mathrm{kg}{ }^{-1} \mathrm{~min}^{-1}\right), V$ is the distribution volume for palmitate or glucose (40 and $160 \mathrm{ml} / \mathrm{kg}$, respectively), $C_{1}$ and $C_{2}$ are palmitate or glucose concentrations ( $\mathrm{mmol} / \mathrm{l})$ at times $1\left(t_{1}\right)$ and $2\left(t_{2}\right)$ respectively, and $E_{2}$ and $E_{1}$ are the plasma palmitate or glucose enrichments (TTR) at times 2 and 1, respectively. Production of ${ }^{13} \mathrm{CO}_{2}\left(\mathrm{Pr}^{13} \mathrm{CO}_{2} ; \mathrm{mol} / \mathrm{min}\right)$ from the infused palmitate tracer was calculated as:

$$
\operatorname{Pr}^{13} \mathrm{CO}_{2}=\left(\mathrm{TTRCO}_{2} \times V \mathrm{CO}_{2}\right) /(\mathrm{k} \times A r)
$$

where $\mathrm{TTRCO}_{2}$ is the breath ${ }^{13} \mathrm{C} /{ }^{12} \mathrm{C}$ ratio at a given time point, $V \mathrm{CO}_{2}$ is carbon dioxide production $(1 / \mathrm{min}), \mathrm{k}$ is the volume of 1 mole of $\mathrm{CO}_{2}(22.4 \mathrm{litres} / \mathrm{mol})$, 
and $\mathrm{Ar}$ is the fractional ${ }^{13} \mathrm{C}$ label recovery in breath $\mathrm{CO}_{2}$ observed after the infusion of labelled acetate [27, 31, 32], calculated as:

$$
\mathrm{Ar}=\left(\left(\mathrm{TTRCO}_{2} \times \mathrm{VCO}_{2}\right) /(\mathrm{k} \times 2 \mathrm{~F})\right)
$$

where $F$ is the infusion rate of $\left[1,2-{ }^{13} \mathrm{C}\right]$ acetate $(\mathrm{mol} / \mathrm{min})$. Plasma palmitate oxidation (Rox) ( $\mathrm{mol} / \mathrm{min}$ ) can subsequently be calculated as:

$$
\text { Rox palmitate }=\text { Rd palmitate } \times\left(\operatorname{Pr}^{13} \mathrm{CO}_{2} / F \times 16\right)
$$

where $\mathrm{Rd}$ palmitate is the rate of disappearance of palmitate $(\mathrm{mol} / \mathrm{min}), F$ is the palmitate infusion rate ( $\mathrm{mol} / \mathrm{min}$ ) and 16 is the number of labelled carbon atoms in palmitate. Total plasma NEFA oxidation was calculated by dividing palmitate oxidation rates by the fractional contribution of plasma palmitate to total plasma NEFA concentration. The contribution of fat sources other than plasma NEFA was calculated by subtracting plasma NEFA oxidation from total fat oxidation.

In a previous study it has been shown that during exercise $\left(50 \% \mathrm{~W}_{\max }\right)$ plasma glucose Rd equals its Rox (96-100\%) [33]. Therefore, plasma glucose oxidation rate during exercise was estimated as:

\section{Rox plasma glucose $=$ Rd plasma glucose}

Whole-body muscle glycogen use was calculated by subtracting plasma glucose oxidation from total carbohydrate oxidation. As plasma glucose $\mathrm{Rd}$ does not match Rox during resting conditions [34], plasma glucose oxidation rates cannot be calculated accurately at rest when using a $\left[6,6{ }^{2} \mathrm{H}_{2}\right]$ glucose tracer.

\section{Muscle sample analysis}

Muscle samples were dissected, freed from any visible non-muscle material, frozen in nitrogen-cooled isopentane and embedded in Tissue-Tek (Sakura, Zoeterwoude, the Netherlands). Multiple serial sections $(5 \mu \mathrm{m})$ were thawmounted together on uncoated, precleaned glass slides for each subject. To determine muscle fibre type-specific IMTG content, cross-sections were stained with Oil red $O$ together with immunolabelled cellular constituents using a protocol described before [2]. For each muscle biopsy a total of $58 \pm 7$ and $49 \pm 4$ muscle fibres were analysed for lipid content for diabetes patients and control subjects respectively. To permit quantification of intramyocellular glycogen we used the modified PAS stain [35]. For each muscle biopsy, $148 \pm 15$ and $157 \pm 13$ 
muscle fibres were analysed for glycogen content in diabetes and control subjects respectively. Large overviews containing $167 \pm 24$ and $174 \pm 20$ fibres per subject (diabetes and control subjects respectively) were used to determine muscle fibre type composition.

\section{Statistics}

All data are expressed as mean \pm SEM. To compare tracer kinetics, substrate utilisation rates, IMTG contents and/or plasma metabolite concentrations over time, repeated measures ANOVA was applied. A Scheffé post hoc test was applied in case of a significant $F$ ratio, to locate specific differences. To determine differences between diabetes patients and control subjects, Student's $t$ test for unpaired observations was used. Simple linear regression was used to investigate specific correlations. Significance was set at the 0.05 level of confidence.

\section{RESULTS}

\section{Tracer kinetics}

Plasma palmitate and glucose $\mathrm{Ra}, \mathrm{Rd}$ and Rox are shown in Fig. 1 and Table 2. As plasma palmitate and glucose concentrations were subject to changes throughout rest, exercise and/or recovery (Fig. 2), non-steady-state Steele equations were applied. Table 3 shows breath ${ }^{13} \mathrm{CO}_{2}$ enrichment and plasma palmitate and glucose enrichment throughout the test. At rest, plasma palmitate $\mathrm{Ra}, \mathrm{Rd}$ and Rox were stable, and significantly higher in the diabetes patients compared with the controls ( $\mathrm{Ra}$ and $\mathrm{Rd}, p<0.05$; Rox, $p=0.07$ ). During exercise, plasma palmitate $\mathrm{Ra}, \mathrm{Rd}$ and Rox increased over time in both groups $(p<0.01)$ and were higher in the diabetes compared with the control group ( $\mathrm{Ra}$ and $\mathrm{Rd}$, $p<0.05$; Rox, $p=0.08$ ). During post-exercise recovery, plasma palmitate $\mathrm{Ra}, \mathrm{Rd}$ and Rox were similar between groups. Acetate recovery factors in the diabetes and control groups respectively averaged $0.11 \pm 0.00$ and $0.13 \pm 0.00$ at rest, $0.87 \pm 0.00$ and $0.91 \pm 0.00$ during exercise, and $0.24 \pm 0.00$ and $0.26 \pm 0.00$ during subsequent recovery (no significant difference between groups). At rest, plasma glucose $\mathrm{Ra}$ and $\mathrm{Rd}$ were stable, and significantly higher in the diabetes patients $(p<0.05)$. During exercise, plasma glucose $\mathrm{Ra}$ and $\mathrm{Rd}$ increased over time in both groups $(p<0.01)$ and were similar between groups. During post-exercise recovery, plasma glucose $\mathrm{Ra}$ and $\mathrm{Rd}$ were higher in the diabetes patients $(p<0.05)$. No changes over time in plasma glucose $\mathrm{Ra}$ or $\mathrm{Rd}$ were observed. In the diabetes patients, the percentage of plasma glucose Ra that disappeared 
(\%Ra/Rd) was significantly greater during exercise when compared with resting conditions. Furthermore, during exercise, $\% \mathrm{Ra} / \mathrm{Rd}$ was significantly greater in the diabetes group compared with the controls.

Table 2 Tracer kinetics

\begin{tabular}{|c|c|c|}
\hline & $\begin{array}{l}\text { Control } \\
(n=10)\end{array}$ & $\begin{array}{l}\text { Diabetes } \\
(n=10)\end{array}$ \\
\hline \multicolumn{3}{|l|}{ Rest } \\
\hline Ra palmitate & $1.85 \pm 0.20$ & $2.46 \pm 0.18 a$ \\
\hline Rd palmitate & $1.83 \pm 0.20$ & $2.45 \pm 0.18 a$ \\
\hline Rox palmitate & $0.73 \pm 0.10$ & $1.01 \pm 0.10$ \\
\hline$\%$ Rd ox palmitate & $39.9 \pm 2.0$ & $40.9 \pm 1.9$ \\
\hline Ra glucose & $10.77 \pm 0.42$ & $15.53 \pm 0.84$ \\
\hline Rd glucose & $10.91 \pm 0.33$ & $16.46 \pm 0.76^{a}$ \\
\hline$\%$ Ra Rd glucose & $101 \pm 2$ & $105 \pm 3$ \\
\hline \multicolumn{3}{|l|}{ Exercise } \\
\hline Ra palmitate & $2.84 \pm 0.20^{b}$ & $3.71 \pm 0.36 \mathrm{a}, \mathrm{b}$ \\
\hline Rd palmitate & $2.80 \pm 0.20^{b}$ & $3.64 \pm 0.35 a, b$ \\
\hline Rox palmitate & $2.26 \pm 0.20^{\mathrm{b}}$ & $2.82 \pm 0.22^{b}$ \\
\hline$\%$ Rd ox palmitate & $80.8 \pm 3.70^{b}$ & $79.2 \pm 3.9^{b}$ \\
\hline Ra glucose & $20.51 \pm 0.91^{b}$ & $18.69 \pm 0.98^{b}$ \\
\hline Rd glucose & $20.11 \pm 1.06^{\mathrm{b}}$ & $21.52 \pm 1.21^{b}$ \\
\hline$\%$ Ra Rd glucose & $99 \pm 4$ & $118 \pm 6^{a, b}$ \\
\hline \multicolumn{3}{|l|}{ Recovery } \\
\hline Ra palmitate & $2.01 \pm 0.14^{\mathrm{c}}$ & $2.23 \pm 0.15^{c}$ \\
\hline Rd palmitate & $2.00 \pm 0.14^{\mathrm{c}}$ & $2.24 \pm 0.15^{c}$ \\
\hline Rox palmitate & $0.86 \pm 0.08^{\mathfrak{c}}$ & $1.04 \pm 0.08^{c}$ \\
\hline$\%$ Rd ox palmitate & $43.2 \pm 2.6^{\mathrm{c}}$ & $46.5 \pm 1.6^{\mathrm{b}, \mathrm{c}}$ \\
\hline Ra glucose & $8.63 \pm 0.48^{b, c}$ & $10.14 \pm 0.47^{a, c}$ \\
\hline Rd glucose & $9.57 \pm 0.45^{b, c}$ & $11.59 \pm 0.76 \mathrm{a}, \mathrm{c}$ \\
\hline$\%$ Ra Rd glucose & $106 \pm 6$ & $114 \pm 4$ \\
\hline
\end{tabular}

Tracer kinetics were determined at rest and during exercise (50\% Wmax) and subsequent recovery. Ra rate of appearance; Rd rate of disappearance; Rox rate of oxidation $\left(\mu \mathrm{mol} \mathrm{kg}{ }^{-1} \mathrm{~min}^{-1}\right) ; \% \mathrm{Rd}$ ox percentage of Rd oxidised (\%); \% Ra Rd percentage of Ra that disappeared. Values are mean \pm SEM $(2 n=20)$. aSignificantly different from control group ( $p<0.05)$. bSignificantly different from resting values $(\mathrm{p}<0.01)$. 'Significantly different from exercise values $(\mathrm{p}<0.01)$. 


\section{Substrate utilisation}

Total energy expenditure and substrate source utilisation rates are illustrated in Fig. 3. Energy expenditure averaged $5.75 \pm 0.22$ and $5.28 \pm 0.16 \mathrm{~kJ} / \mathrm{min}$ in the diabetes and control group respectively. Total fat oxidation rates $(\mathrm{g} / \mathrm{min})$ at rest were significantly higher in the diabetes group than in the control group $(0.11 \pm 0.01$ and $0.09 \pm 0.01 \mathrm{~g} / \mathrm{min}$ respectively), contributing $77 \pm 2$ and $67 \pm 3 \%$ to
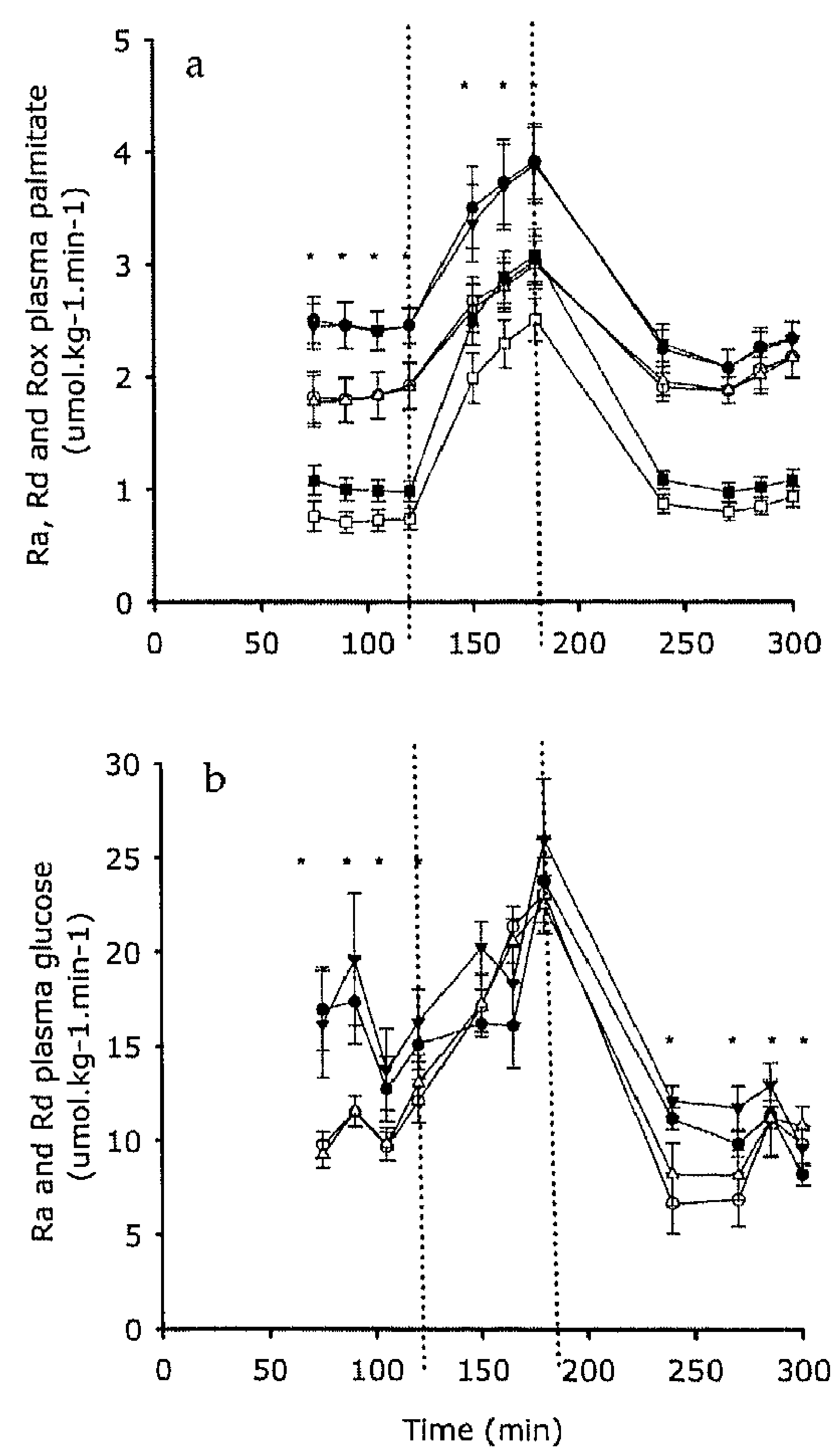

Figure 1. a Plasma rates of appearance (Ra), disappearance (Rd) and oxidation (Rox) of palmitate at rest and during exercise and post-exercise recovery $\left(\mu \mathrm{mol} \mathrm{kg}^{-1} \mathrm{~min}^{-1}\right)$ in the diabetes group (closed symbols) and the control group (open symbols). Circles, Ra; triangles, Rd; squares, Rox. b Plasma glucose rates of appearance $(\mathrm{Ra})$, disappearance ( $\mathrm{Rd}$ ) and oxidation (Rox) at rest and during exercise and post-exercise recovery $\left(\mu \mathrm{mol} \mathrm{kg}{ }^{-1} \mathrm{~min}^{-1}\right)$. Data are mean $\pm \mathrm{SEM}(\mathrm{n}=20)$. ${ }^{*} \mathrm{Ra}$ and $\mathrm{Rd}$ significantly different from control group $(p<0.05)$. 

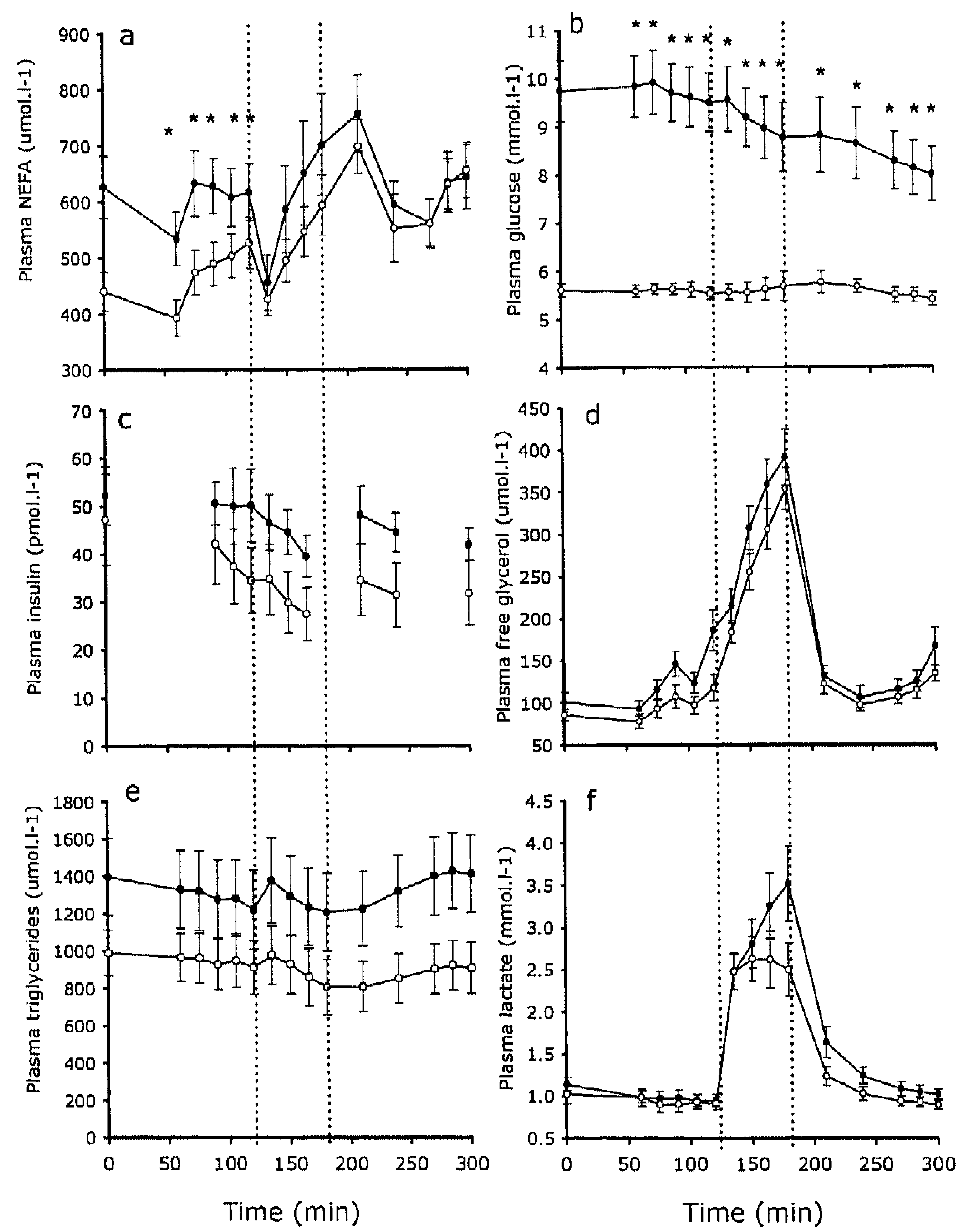

Figure 2. Plasma concentrations of NEFA (a), glucose (b), insulin (c), free glycerol (d), triglycerides (e) and lactate (f) in the diabetes (closed circles) and control group (open circles). Values are mean \pm SEM. *Significantly different from control group $(\mathrm{p}<0.05)$.

total energy expenditure $(p<0.01)$. The difference in fat oxidation rate was attributed to a significantly higher NEFA oxidation rate in the diabetes group $(p<0.05)$, with no differences in muscle and/or lipoprotein-derived triacylglycerol utilisation. The latter contributed only $-2 \pm 7$ and $6 \pm 7 \%$ to total energy expenditure in the diabetes and control groups respectively. Exercise 
was performed at a 50\% Wmax workload, which resulted in an absolute workload set at $100 \pm 7$ and $101 \pm 8 \mathrm{~W}$ (NS) or a relative workload of $63 \pm 2 \%$ and $54 \pm 2$ of $\mathrm{VO}_{2} \max (p<0.05)$ in the diabetes and control groups respectively. Energy expenditure during exercise averaged $39 \pm 2$ and $36 \pm 2 \mathrm{~kJ} / \mathrm{min}$ respectively. Fat oxidation contributed $42 \pm 3(0.40 \pm 0.04 \mathrm{~g} / \mathrm{min})$ and $39 \pm 3 \%(0.35 \pm 0.03 \mathrm{~g} / \mathrm{min})$ to total energy expenditure in the diabetes and control group respectively. Muscle and/or lipoprotein-derived triacylglycerol use increased significantly during exercise conditions to $0.09 \pm 0.03$ and $0.10 \pm 0.02 \mathrm{~g} / \mathrm{min}$ in the diabetes and control group respectively, contributing $8 \pm 3$ and $11 \pm 3 \%$ respectively. Total carbohydrate oxidation rates during exercise averaged $1.37 \pm 0.09$ and $1.37 \pm 0.08$ $\mathrm{g} / \mathrm{min}$ in the diabetes and control group respectively, contributing $58 \pm 3$ and $61 \pm 3 \%$ to total energy expenditure. In the diabetes and control group, plasma glucose oxidation averaged $0.35 \pm 0.03$ and $0.32 \pm 0.02 \mathrm{~g} / \mathrm{min}$ respectively, contributing $15 \pm 1$ and $14 \pm 1 \%$ to total energy expenditure, with muscle glycogen contributing $43 \pm 3$ and $46 \pm 3 \%$ to energy expenditure. Aside from a tendency to greater plasma NEFA oxidation rates in the diabetes group $(p=0.08)$, no significant differences in substrate source utilisation rates were observed between groups. During post-exercise recovery, energy expenditure averaged $5.9 \pm 0.2$ in the diabetes group and $5.5 \pm 0.2 \mathrm{~kJ} / \mathrm{min}$ in the control group, fat oxidation contributing $90 \pm 2 \%(0.13 \pm 0.01 \mathrm{~g} / \mathrm{min})$ and $80 \pm 3 \%(0.11 \pm 0.01 \mathrm{~g} / \mathrm{min}$; $p<0.05)$ to total energy expenditure, respectively. The greater fat oxidation rate in the diabetes group was attributed mainly to a greater plasma NEFA oxidation rate in the diabetes group $(p=0.10)$, whereas no differences were observed in muscle- and/or lipoprotein-derived triacylglycerol. The greater fat oxidation rates were matched by lower total carbohydrate oxidation rates.

Table 3 Palmitate and glucose enrichments

\begin{tabular}{|c|c|c|c|c|c|}
\hline & \multicolumn{2}{|c|}{${ }^{13} \mathrm{C}$ breath enrichment } & \multicolumn{2}{|c|}{${ }^{13} \mathrm{C}$ palmitate enrichment } & \multirow{2}{*}{$\begin{array}{l}{ }^{2} \mathrm{H} \text { glucose enrichment } \\
\text { (TTR 10-3) }\end{array}$} \\
\hline & (TTR 10-5) & & (TTR 10-3 & & \\
\hline & $\mathrm{D}$ & C & $\mathrm{D}$ & $\mathrm{C}$ & $\mathrm{D}$ \\
\hline Rest & $6.39 \pm 0.74$ & $6.88 \pm 0.87$ & $3.92 \pm 0.0^{\mathrm{a}}$ & $5.59 \pm 0.10$ & $11.13 \pm 0.76^{\mathrm{a}} 18.44 \pm 0.92$ \\
\hline Exercise & $12.07 \pm 0.18$ & $12.84 \pm 0.38$ & $2.78 \pm 0.12^{\mathrm{a}}$ & $3.43 \pm 0.16$ & $14.87 \pm 0.17^{\mathrm{a}} 18.94 \pm 1.18$ \\
\hline Recovery & $15.42 \pm 1.03$ & $15.68 \pm 0.98$ & $4.24 \pm 0.18$ & $4.69 \pm 0.16$ & $19.49 \pm 0.10 \quad 22.41 \pm 0.10$ \\
\hline
\end{tabular}

${ }^{13} \mathrm{C}$ breath, ${ }^{13} \mathrm{C}$ palmitate and $\left[6,6-{ }^{2} \mathrm{H}_{2}\right]$ glucose enrichments (tracer/tracee ratio, TTR) during rest,

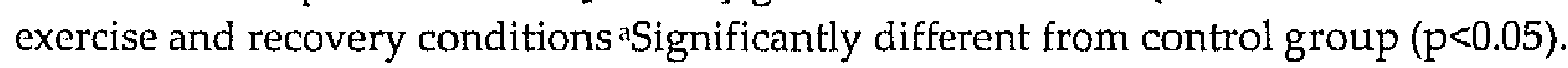




\section{Plasma metabolite concentrations}

Plasma metabolite concentrations are shown in Fig. 2. Plasma glucose concentrations were significantly higher in the diabetes group throughout the experiment. During exercise, there was a significant decline in plasma glucose concentration in the diabetes group only. Plasma NEFA concentrations at rest were higher in the diabetes group compared with the control group. No

differences in plasma NEFA between groups were

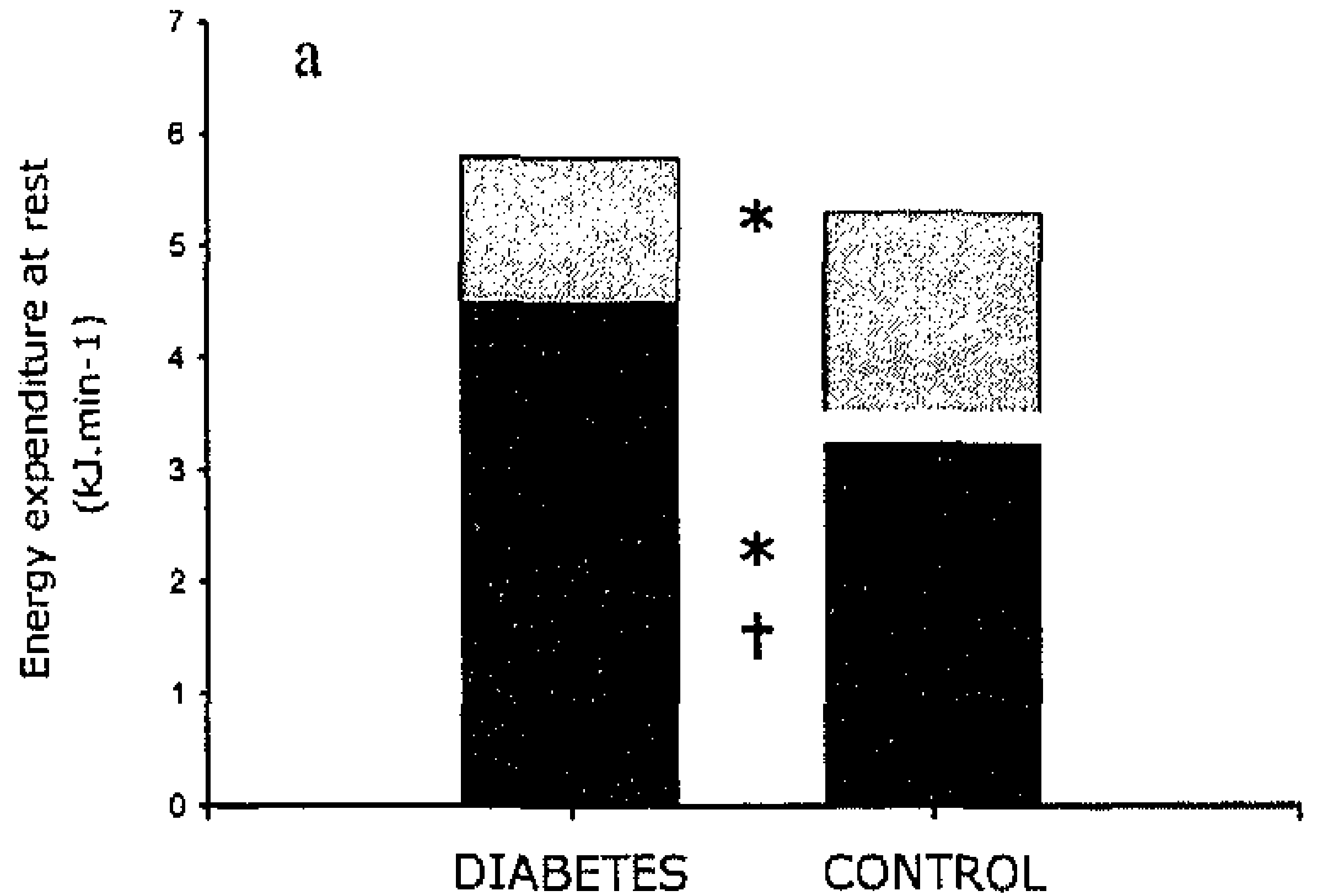
observed during exercise and recovery conditions. Glycerol concentrations increased significantly during rest and exercise and decreased during recovery. Free glycerol concentration tended to be higher in the diabetes group $(p=0.06)$. Plasma triglycerol concentrations declined

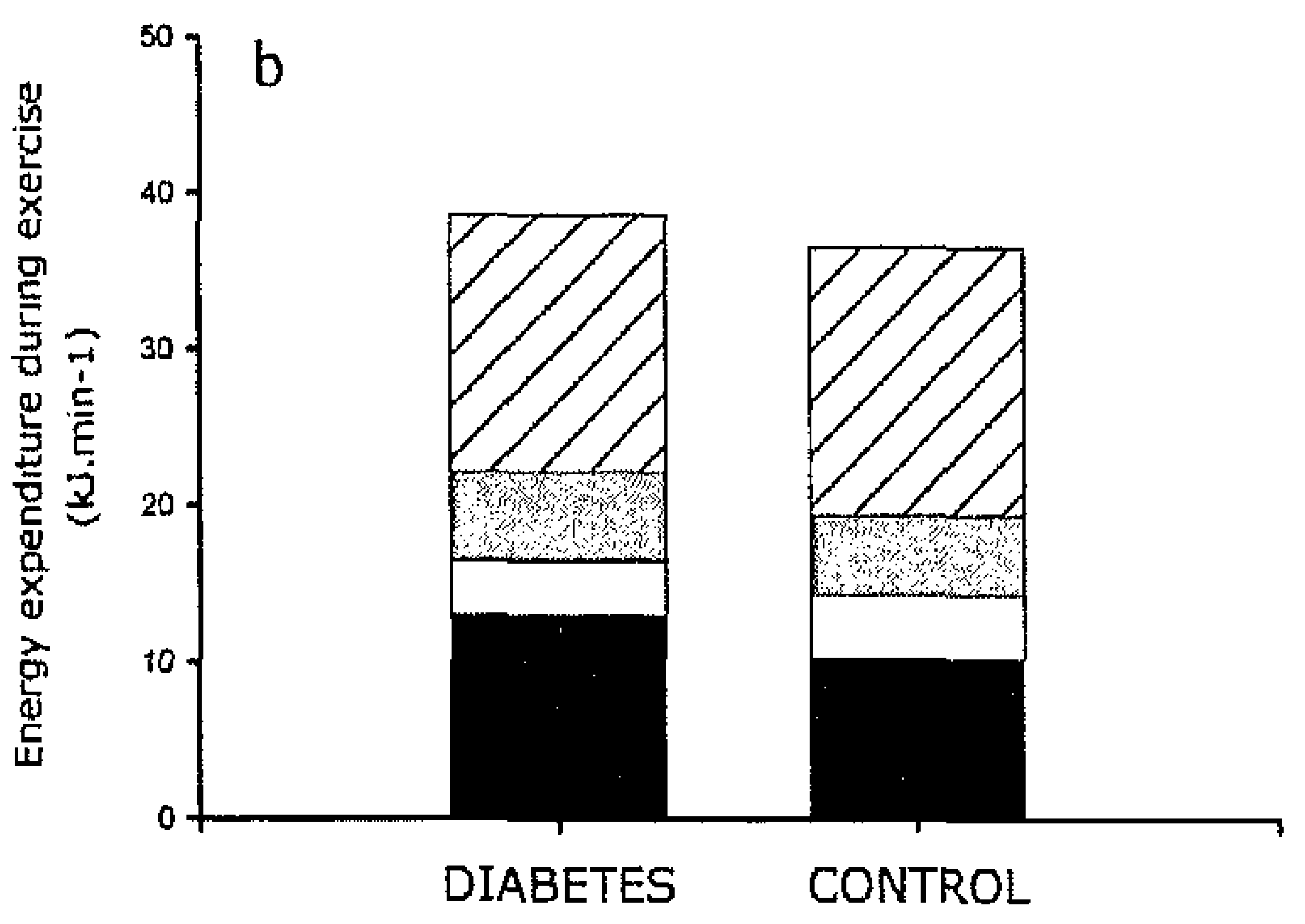
significantly at rest and during exercise in the diabetes patients, but were stable in control subjects.

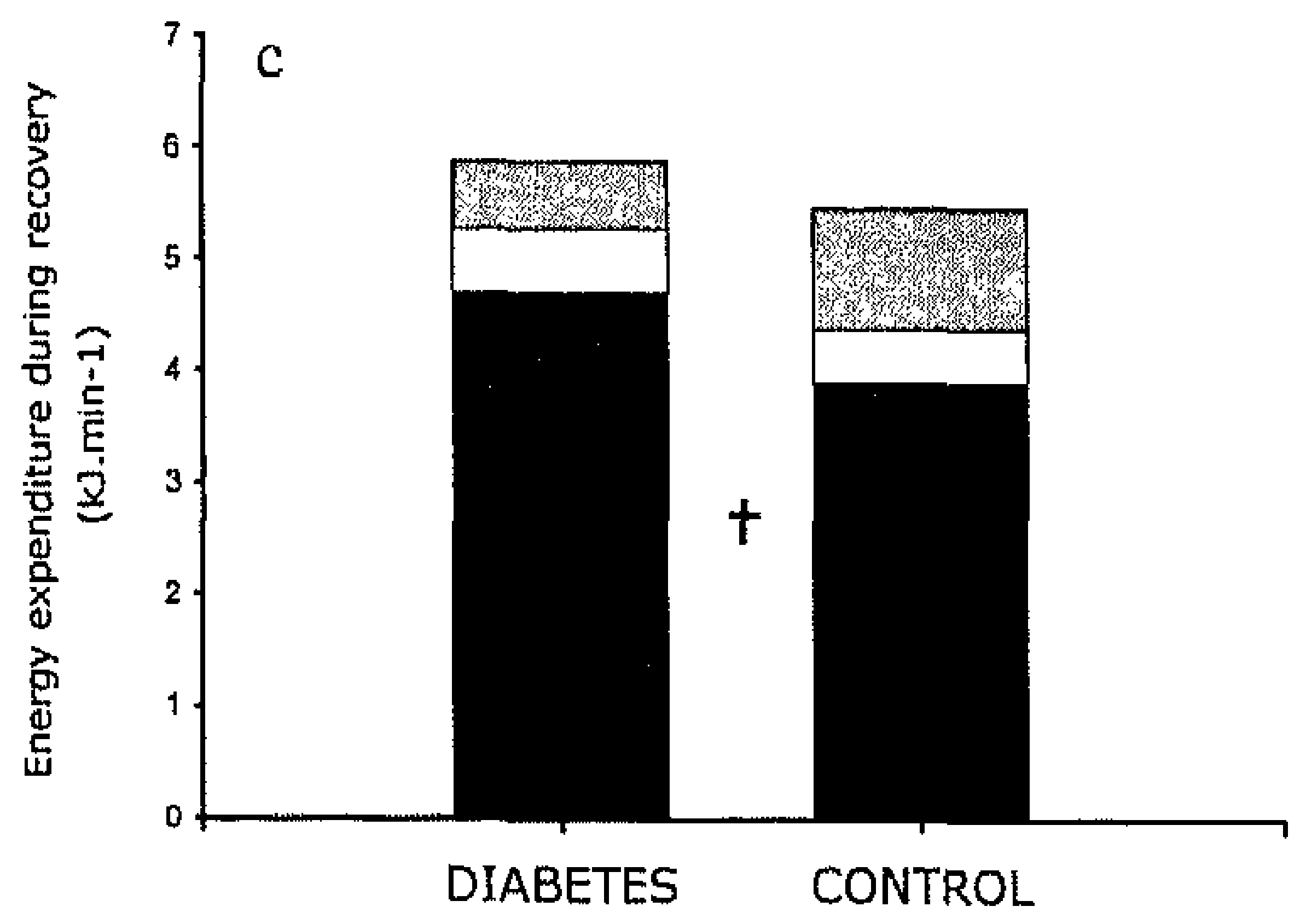

Figure 3 . Whole-body substrate source utilisation at rest (a), during exercise (b) and post-exercise recovery (c).

Black (a-c), plasma NEFA; white $(a-c)$, muscle and lipoprotein-derived triacylglycerol; grey, carbohydrate in a and c, plasma glucose in b; hatching (b), muscle glycogen. *Substrate source oxidation significantly different from control group $(p<0.05)$; t total fat oxidation significantly different from control group $(\mathrm{p}<0.05)$. 
Plasma insulin levels declined during exercise in both groups $(p<0.01)$, resulting in significantly lower insulin concentrations during recovery compared with resting levels. No significant differences in plasma insulin concentrations were observed between groups.

\section{Muscle tissue analysis}

Muscle fibre type analysis showed $46 \pm 3 \%$ type I muscle fibres and $54 \pm 3 \%$ type II fibres in the diabetes group, and $49 \pm 4 \%$ type I muscle fibres and $51 \pm 4 \%$ type II fibres in the control group. In both groups, type I fibres contained 2-3 times more IMTG than type II fibres ( $\mathrm{p}<0.005)$. Type I and II muscle fibre lipid content averaged $24 \pm 4$ and $11 \pm 2$ arbitrary units (AU) respectively in the diabetes group and $34 \pm 5$ and $11 \pm 2$ AU respectively in the control group. No significant differences in type I or II muscle fibre lipid content were observed between groups. No significant net changes in type I or type II intramyocellular lipid content were observed following exercise in the diabetes or control group. In the diabetes and control groups, net changes were $8 \pm 4$ and $-6 \pm 6$ AU respectively for type 1 fibres and $4 \pm 3$ and $3 \pm 4$ for type II fibres (all p>0.05), respectively. Type I and II muscle fibre glycogen content averaged $36 \pm 6$ and $32 \pm 4$ AU respectively in the diabetes group and $36 \pm 4$ and $46 \pm 6$ AU in the control group. No significant differences in type I or II muscle fibre glycogen content were observed between groups. After exercise, type II fibres contained significantly more glycogen than type I fibre type in both groups. However, no significant net changes in type I and II muscle fibre glycogen content (type I fibres, $-13 \pm 6 \mathrm{AU}$ in diabetes group and $-6 \pm 3 \mathrm{AU}$ in control group; type II fibres, $9 \pm 6 \mathrm{AU}$ in diabetes group and $-6 \pm 5 \mathrm{AU}$ in control group; all $\mathrm{p}>0.05$ ) were observed following exercise in both groups.

\section{DISCUSSION}

The present study investigated the nature and extent of disturbances in different components of whole-body carbohydrate and fat metabolism in longterm diagnosed type 2 diabetes patients. Using contemporary stable isotope methods, we found that basal whole-body fat oxidation rates were significantly greater in long-standing type 2 diabetes patients when compared with normoglycaemic controls matched for age, body composition and whole-body oxidative capacity (Fig. 3). This is attributed to significantly higher plasma NEFA appearance rates, resulting in greater NEFA uptake and oxidation rates (Fig. 1). In contrast, resting total carbohydrate oxidation rates were reduced in type 2 diabetes patients, despite substantially elevated plasma glucose 
appearance rates and the prevalence of hyperglycaemia. Exercise significantly reduces plasma glucose concentrations in type 2 diabetes patients, as glucose disposal exceeds its rate of appearance during exercise conditions.

Fasting whole-body fat oxidation rates were greater in the diabetes patients. This seems to be in contrast to some [14-19], but not all [12, 13, 36], previous studies, which describe normal and/or decreased basal whole-body fatty acid oxidation rates in the type 2 diabetic state [14-19]. These apparently contradictory findings are explained by the fact that long-term diagnosed diabetes patients were selected to participate in the present study. These patients differ significantly in metabolic profile from their recently diagnosed counterparts in that they no longer show any compensatory hyperinsulinaemia (Fig. 2, Table 1). As a consequence, plasma insulin levels do not compensate for the adipose tissue insulin resistance present in type 2 diabetes [37-40] and fail to inhibit adipose tissue lipolysis. This explains the greater plasma NEFA appearance rates and elevated plasma NEFA availability observed in the diabetes patients (Figs 1 and 2). The elevated plasma NEFA availability drives a greater NEFA uptake rate and subsequently augments plasma NEFA oxidation in the diabetes patients. The higher basal plasma NEFA turnover and fat oxidation in the diabetes patients were accompanied by a lower carbohydrate oxidation rate (Fig. 3), despite substantially greater hepatic glucose output (Ra glucose) and the presence of marked hyperglycaemia. This clearly demonstrates that carbohydrate metabolism is significantly impaired in the long-term diagnosed type 2 diabetes patient, and suggests that this might (in part) be attributed to the increased fat oxidation. Interestingly, despite previous studies suggesting substantial differences in the use of plasma glucose, glycogen, NEFA and/or IMTG as a substrate source during exercise conditions in type 2 diabetes patients and normoglycaemic controls [16-18, 24], substrate source utilisation rates were remarkably similar between type 2 diabetes patients and normoglycaemic controls (Fig. 3). However, it should be noted that in the type 2 diabetic state, such apparently normal substrate utilisation rates are observed in the presence of a significantly greater NEFA turnover. Exercise significantly lowered blood glucose concentrations in type 2 diabetes patients. Though this has been observed before $[15,17,18,23,41]$, the present study shows that this can be attributed to an improved plasma glucose disposal rate, with plasma glucose $\mathrm{Rd}$ representing $118 \pm 6 \%$ of its Ra during exercise (Table 2). The exercise-induced decline in blood glucose concentrations continued during subsequent recovery, blood glucose Rd remaining well above its Ra (114 $1 \%$ ). These data extend the observations made in previous studies [17, 23, 24, 42] and demonstrate that exercise forms a potent strategy to acutely improve glycaemic 
control in type 2 diabetes. Our data do not support the hypothesis that the capacity to mobilise and/or oxidise the IMTG pool is substantially impaired in type 2 diabetes patients when compared with normoglycaemic controls, as suggested previously $[2,43,44]$. Tracer kinetic data (Fig. 1, Table 2) as well as histochemical analysis indicate that muscle- (and/or lipoprotein-)derived triglycerol play only a relatively minor (quantitative) role as a substrate source at rest and/or during exercise conditions in both sedentary type 2 diabetes patients and healthy sedentary men. During post-exercise recovery, total fat oxidation rates were elevated compared with pre-exercise resting values in both the type 2 diabetes patients and the normoglycaemic controls (Fig. 3). Furthermore, total fat oxidation rates were greater in the type 2 diabetes patients compared with controls. In contrast, carbohydrate oxidation rates were reduced, which was accompanied by a decreased plasma glucose Ra and Rd. The present data are not necessarily in contrast to previous findings, which generally show reduced NEFA uptake and/or oxidation rates over the leg or arm in recently diagnosed type 2 diabetes patients $[11,14,16,20,45]$. The greater whole-body NEFA turnover rate in long-term diagnosed type 2 diabetes patients observed in the present study is most likely attributable to the presence of adipose tissue insulin resistance and the absence of compensating hyperinsulinaemia in the selected patient group. Disturbances in whole-body NEFA metabolism remain evident, since the higher total fat oxidation rates occurred under conditions of disproportional elevated plasma NEFA appearance rates and concomitantly elevated plasma NEFA concentrations. Disturbances in glucose handling in these long-standing diabetes patients are more clearly visible, as total glucose oxidation rates are reduced, despite major upregulation of plasma glucose $\mathrm{Ra}, \mathrm{Rd}$ and the concomitant hyperglycaemic state. Gaining more insight into the differences in disturbances of substrate utilisation between subpopulations of type 2 diabetes patients (i.e. recently or long-term diagnosed) will be of great importance to our understanding of the aetiology and progression of the disease.

In conclusion, fasting whole-body fat oxidation rates are elevated in long-term diagnosed type 2 diabetes patients, which is attributed to greater plasma NEFA appearance rates, elevated plasma NEFA availability, and increased plasma NEFA disappearance and oxidation rates. The greater plasma NEFA appearance rate is most likely attributable to disinhibition of adipose tissue lipolysis, secondary to adipose tissue insulin resistance and the absence of compensatory hyperinsulinaemia. Furthermore, hyperglycaemia in longstanding type 2 diabetes patients is associated with elevated plasma glucose appearance and disappearance rates, but is not accompanied by elevated 
carbohydrate oxidation rates. Moderate-intensity exercise improves plasma glucose disposal in long-standing type 2 diabetes patients, thereby effectively reducing blood glucose concentrations.

\section{ACKNOWLEDGEMENTS}

We gratefully acknowledge the expert analytical assistance of J. Stegen, J. Senden, M. Meers, H. Vandereyt and A. Gijsen, and the enthusiastic participation of the volunteers in these trials. 


\section{REFERENCES}

1. Goodpaster BH, Kelley DE, Wing RR, Meier A, Thaete FL (1999) Effects of weight loss on regional fat distribution and insulin sensitivity in obesity. Diabetes 48:839-847

2. van Loon LJC, Koopman R, Manders R, van der Weegen W, van Kranenburg GP, Keizer HA (2004) Intramyocellular lipid content in type 2 diabetes patients compared to overweight sedentary men and highly trained endurance athletes. Am J Physiol Endocrinol Metab 287:E558-EE565

3. Thamer C, Machann J, Bachmann $\mathrm{O}$ et al (2003) Intramyocellular lipids: anthropometric determinants and relationships with maximal aerobic capacity and insulin sensitivity. J Clin Endocrinol Metab 88:1785-1791

4. Yu C, Chen Y, Cline GW et al (2002) Mechanism by which fatty acids inhibit insulin activation of insulin receptor substrate-1 (IRS-1)-associated phosphatidylinositol 3-kinase activity in muscle. J Biol Chem 277:50230-50236

5. Shulman GI (2000) Cellular mechanisms of insulin resistance. J Clin Invest 106:171-176

6. Roden M, Price TB, Perseghin G et al (1996) Mechanism of free fatty acid-induced insulin resistance. J Clin Invest 97:2859-2865

7. Russell AP, Gastaldi G, Bobbioni-Harsch E et al (2003) Lipid peroxidation in skeletal muscle of obese as compared to endurance-trained humans: a case of good vs. bad lipids? FEBS Lett 551:104-106

8. Adams JM 2nd, Pratipanawatr T, Berria $R$ et al (2004) Ceramide content is increased in skeletal muscle from obese insulin-resistant humans. Diabetes 53:25-31

9. Ellis BA, Poynten A, Lowy AJ et al (2000) Long-chain acyl-CoA esters as indicators of lipid metabolism and insulin sensitivity in rat and human muscle. Am J Physiol Endocrinol Metab 279:E554-E560

10. Itani SI, a NB, Schmieder F, Boden G (2002) Lipid-induced insulin resistance in human

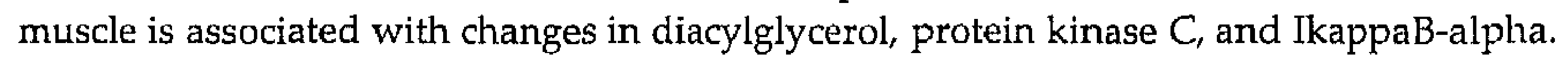
Diabetes 51:2005-2011

11. Blaak EE, Wagenmakers AJM, Glatz JFC et al (2000) Plasma FFA utilization and fatty acid-binding protein content are diminished in type 2 diabetic muscle. Am J Physiol Endocrinol Metab 279:E146-E154

12. Felber JP, Ferrannini E, Golay A et al (1987) Role of lipid oxidation in pathogenesis of insulin resistance of obesity and type II diabetes. Diabetes 36:1341-1350

13. Golay A, Felber JP, Meyer HU, Curchod B, Maeder E, Jequier E (1984) Study on Iipid metabolism in obesity diabetes. Metabolism 33:111-116

14. Kelley DE, Simoneau J-A (1994) Impaired free fatty acid utilization by skeletal muscle in non-insulin dependent diabetes mellitus. J Clin Invest 94:2349-2356

15. Kang J, Kelley DE, Robertson RJ et al (1999) Substrate utilization and glucose turnover during exercise of varying intensities in individuals with NIDDM. Med Sci Sports Exerc 31:82-89

16. Blaak EE, van Aggel-Leijssen DPC, Wagenmakers AJM, Saris WHM, van Baak MA (2000) Impaired oxidation of plasma-derived fatty acids in type 2 diabetic subjects during moderate-intensity exercise. Diabetes 4:9:2102-2107

17. Borghouts LB, Wagenmakers AJM, Goyens PLL, Keizer HA (2002) Substrate utilization in non-obese type II diabetic patients at rest and during exercise. Clin Sci 103:559-566

18. Colberg SR, Hagberg JM, McCole SD, Zmuda JM, Thompson PD, Kelley DE (1996) Utilization of glycogen but not plasma glucose is reduced in individuals with NIDDM during mild-intensity exercise. J Appl Physiol 81:2027-2033 
19. Taskinen MR, Bogardus C, Kennedy A, Howard BV (1985) Multiple disturbances of free fatty acid metabolism in noninsulin-dependent diabetes. Effect of oral hypoglycemic therapy. J Clin Invest 76:637-644

20. Kelley DE, Mandarino LJ (1990) Hyperglycemia normalizes insulin-stimulated skeletal muscle glucose oxidation and storage in noninsulin-dependent diabetes mellitus. J Clin Invest 86:1999-2007

21. Mensink M, Blaak EE, van Baak MA, Wagenmakers AJM, Saris WHM (2001) Plasma free fatty acid uptake and oxidation are already diminished in subjects at high risk for developing type 2 diabetes. Diabetes 50:2548-2554

22. van Loon LJC (2004) Use of intramuscular triacylglycerol as a substrate source during exercise in humans. J Appl Physiol 97:1170-1187

23. Minuk HL, Vranic M, Marliss EB, Hanna AK, Albisser AM, Zinman B (1981) Glucoregulatory and metabolic response to exercise in obese noninsulin-dependent diabetes. Am J Physiol 240:E458-E464

24. Martin IK, Katz A, Wahren J (1995) Splanchnic and muscle metabolism during exercise in NIDDM patients. Am J Physiol 269:E583-E590

25. Alberti KG, Zimmet PZ (1998) Definition, diagnosis and classification of diabetes mellitus and its complications. Part 1: diagnosis and classification of diabetes mellitus provisional report of a WHO consultation. Diabet Med 15:539-553

26. Siri WE (1956) The gross composition of the body. Adv Biol Med Phys 4:239-280

27. van Loon LJC, Koopman R, Schrauwen P, Stegen J, Wagenmakers AJM (2003) The use of the $[1,2-13 \mathrm{C}]$ acetate recovery factor in metabolic research. Eur J Appl Physiol 89:377-383

28. Bergstrom J (1975) Percutaneous needle biopsy of skeletal muscle in physiological and clinical research. Scand J Clin Lab Invest 35:609-616

29. Peronnet F, Massicotte D (1991) Table of nonprotein respiratory quotient: an update. Can J Sport Sci 16:23-29

30. Wolfe RR, Jahoor F (1990) Recovery of labeled CO2 during the infusion of C-1- vs C-2labeled acetate: implications for tracer studies of substrate oxidation. Am J Clin Nutr 51:248-252

31. Sidossis LS, Coggan AR, Gastaldelli A, Wolfe RR (1995) A new correction factor for use in tracer estimations of plasma fatty acid oxidation. Am J Physiol 269:E649-E656

32. Schrauwen $P$, van Aggel-Leijssen DPC, van Marken Lichtenbelt WD, van Baak MA, Gijsen AP, Wagenmakers AJM (1998) Validation of the [1,2-13C] acetate recovery factor for correction of [U-13C] palmitate oxidation rates in humans. J Physiol 513:215-223

33. Jeukendrup AE, Raben A, Gijsen A et al (1999) Glucose kinetics during prolonged exercise in highly trained human subjects: effect of glucose ingestion. J Physiol 515:579589

34. Trimmer JK, Casazza GA, Horning MA, Brooks GA (2001) Recovery of (13)CO2 during rest and exercise after [1-(13)Clacetate, [2-(13)C]acetate, and $\mathrm{NaH}(13) \mathrm{CO} 3$ infusions. Am J Physiol Endocrinol Metab 281:E683-E692

35. Schaart G, Hesselink RP, Keizer HA, van Kranenburg G, Drost MR, Hesselink MK (2004) A modified PAS stain combined with immunofluorescence for quantitative analyses of glycogen in muscle sections. Histochem Cell Biol 122:161-169

36. Sacchetti $M$, Olsen DB, Saltin B, van Hall G (2005) Heterogeneity in limb fatty acid kinetics in type 2 diabetes. Diabetologia 48:938-945

37. Campbell PJ, Carlson MG, Nurjhan N (1994) Fat metabolism in human obesity. Am J Physiol 266:E600-E605 
38. Eriksson JW, Smith U, Waagstein F, Wysocki M, Jansson PA (1999) Glucose turnover and adipose tissue lipolysis are insulin-resistant in healthy relatives of type 2 diabetes patients: is cellular insulin resistance a secondary phenomenon? Diabetes 48:1572-1578

39. Frayn KN (2005) Obesity and metabolic disease: is adipose tissue the culprit? Proc Nutr Soc 64:7-13

40. Groop LC, Bonadonna RC, DelPrato $S$ et al (1989) Glucose and free fatty acid metabolism in non-insulin-dependent diabetes mellitus. Evidence for multiple sites of insulin resistance. J Clin Invest 84:205-213

41. Martin WH (1997) Effect of endurance training on fatty acid metabolism during whole body exercise. Med Sci Sports Exerc 29:635-639

42. Hayashi T, Wojtaszewski JF, Goodyear LJ (1997) Exercise regulation of glucose transport in skeletal muscle. Am J Physiol 273:E1039-E1051

43. Blaak EE (2003) Fatty acid metabolism in obesity and type 2 diabetes mellitus. Proc Nutr Soc 62:753-760

44. Schrauwen P, Hesselink MKC (2004) Oxidative capacity, lipotoxicity, and mitochondrial damage in type 2 diabetes. Diabetes 53:1412-1417

45. Blaak EE, Wagenmakers AJ (2002) The fate of [U-(13)Clpalmitate extracted by skeletal muscle in subjects with type 2 diabetes and control subjects. Diabetes 51:784-789 


\section{Substrate source use in older, trained males after decades of endurance training}

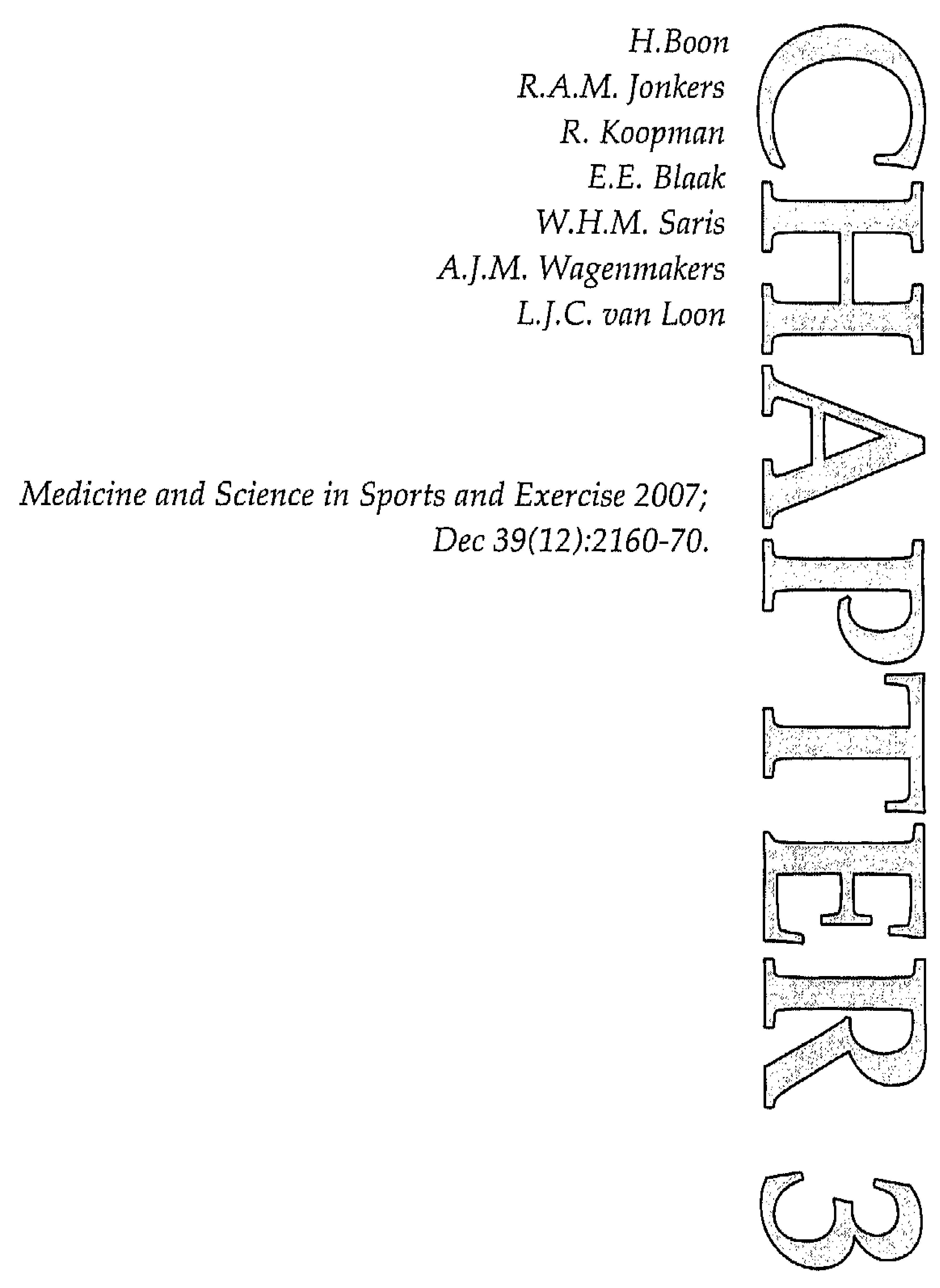




\section{ABSTRACT}

\section{Purpose}

The purpose of this study was to compare substrate source utilization in older, long-term exercising, endurance-trained males with sedentary controls.

\section{Methods}

[U-13C]palmitate and $\left[6,6-2 \mathrm{H}_{2}\right]$ glucose tracers were applied to assess plasma free fatty acid (FFA) and glucose oxidation rates, and to estimate muscle and/or lipoprotein derived triacylglycerol (TG) and muscle glycogen use. Subjects were 10 long-term exercising, endurance-trained males and 10 sedentary controls (age $57 \pm 1$ and $60 \pm 2 \mathrm{y}$, respectively). Muscle biopsy samples were collected before and after exercise to assess muscle fiber type specific intramyocellular lipid and glycogen content.

\section{Results}

During exercise, plasma palmitate $\mathrm{Ra}, \mathrm{Rd}$ and Rox were significantly greater in the trained subjects compared to the controls ( $R a: 0.36 \pm 0.02$ and $0.25 \pm 0.02$; Rd: $0.36 \pm 0.03$ and $0.24 \pm 0.02$; Rox: $0.31 \pm 0.02$ and $0.20 \pm 0.02 \mathrm{mmol} \cdot \mathrm{min}-1$, respectively, $\mathrm{P}<0.01)$. This resulted in greater plasma FFA and total fat oxidation rates in the trained versus sedentary subjects $(\mathrm{P}<0.001)$. Muscle and/or lipoprotein derived TG use contributed $10 \pm 2$ and $11 \pm 3 \%$ in the trained and control group, respectively (NS). No significant net changes in muscle fiber lipid content were observed.

\section{Conclusion}

Older, endurance-trained males oxidize more fat during moderate intensity exercise than sedentary controls. This greater total fat oxidation rate is attributed to a higher plasma FFA release, uptake and oxidation rate. In contrast, intramyocellular triacylglycerol does not seem to represent a major substrate source during $1 \mathrm{~h}$ of moderate intensity exercise in older trained or sedentary men. 


\section{INTRODUCTION}

Endurance exercise elevates skeletal muscle fat oxidative capacity $(2,14,22,27$, $29,33,37,39)$. In accordance, whole-body fat oxidation rates have been reported to be higher during exercise in the endurance-trained versus sedentary state, both at the same absolute $(2,14,22,27,29,33,37,39)$ and relative exercise intensity $(2,4,26)$. Less is known about the impact of training status on the specific use of the different endogenous substrate sources (i.e. plasma glucose, muscle glycogen, plasma free fatty acids and muscle and/or lipoprotein derived triacylglycerol). Some studies applying stable isotope methodology to assess plasma free fatty acid (FFA) uptake and oxidation rates $(2,22,27,29,33,38,40)$, as well as studies quantifying net changes in intramuscular triacylglycerol content (14) suggest that the higher fat oxidation rate during exercise in the endurance-trained state is attributed to a greater utilization of muscle derived triacylglycerol (TG) $(2,4,14,22,27,29,33)$. In contrast, other studies have reported a greater capacity to take up plasma FFA from the circulation $(18,38)$ resulting in higher plasma FFA oxidation rates during exercise in the endurance-trained state (38). The latter findings tend to be in accordance with studies reporting greater skeletal muscle FA transporter protein expression in the endurance-trained state $(19,20)$.

The concomitant reduced reliance on endogenous carbohydrate use, observed both at the same absolute and relative exercise intensity, has been attributed to both a lower plasma glucose appearance (Ra), disappearance (Rd) and oxidation rate $(\operatorname{Rox})(3,5,9,12)$ and less muscle glycogen use $(7,25)$.

The apparent discrepancy in the literature on the effects of endurance training on fat source utilization during exercise is likely due to differences in experimental design and the selected subject population. Data from short-term training interventions $(14,27,29,33)$ suggest that the training-induced increase in whole-body fat oxidation is attributed to a greater muscle (and/or lipoprotein) derived TG use. In contrast, most data from cross-sectional studies comparing substrate use between young endurance-trained athletes and sedentary controls suggest that the greater fat oxidative capacity in the endurance-trained state is attributed to a higher plasma FFA release, uptake and/or oxidation rate $(4,10,11,20,38)$. This discrepancy in the literature implies that large differences may exist in the skeletal muscle adaptive response on substrate use following either short or long-term endurance training. Furthermore, the effects of endurance training on substrate source utilization have generally been studied in healthy, young subjects $(14,22,27,29,33,40)$. Data on the impact of several decades of endurance training (i.e. throughout adulthood) on substrate source utilization are scarce. However, such data are 
warranted to increase our understanding of the impact of physical (in)activity on whole-body and skeletal muscle oxidative capacity, substrate selection, body composition, and the association of these factors with the development of chronic metabolic disease at a more advanced age (1).

In the present study, contemporary stable isotope methodology was applied to quantify whole-body substrate source utilization at rest, during moderateintensity exercise and subsequent post-exercise recovery in 10 older males $(57 \pm 1$ y) following decades of endurance training and 10 male age-matched, sedentary controls $(60 \pm 2 \mathrm{y})$. In addition, skeletal muscle biopsies were collected to determine net changes in muscle fiber type specific lipid and glycogen content. The present study is the first to provide a complete overview on substrate source utilization at rest, during exercise and post-exercise recovery in older, endurance-trained athletes and matched, sedentary controls.

\section{RESEARCH DESIGN AND METHODS}

\section{Subjects}

Ten older, endurance-trained males and 10 age-matched, sedentary controls (Table 1) were selected to participate in this study. Endurance-trained subjects were selected that performed endurance type exercise (cycling) for at least 3 times.week-1, with more than $60 \mathrm{~min}$ per session and had been active in endurance type exercise training for a period of at least $25 \mathrm{y}$. Endurance trained subjects were questioned on their current and past training schedule. Sedentary control subjects had no history of participating in any regular physical activity program. Subjects were informed about the nature and risks of the experimental procedures before their written informed consent was obtained. The study was performed conform the standards set by the Declaration of Helsinki and was approved by the Medical Ethical Committee of Maastricht University.

\section{Pre-testing}

Maximal power output (Wmax) and maximal oxygen uptake capacity (VO2max) were determined on an electronically braked cycle ergometer (Lode Excalibur, Groningen, The Netherlands) during an incremental exhaustive exercise test 2 weeks prior to the first experimental trial. Throughout the test, $\mathrm{VO}_{2}$ and $\mathrm{VCO}_{2}$ were measured with an Oxycon $B$ (Mijnhart, Breda, The Netherlands). Body composition was assessed using the hydrostatic weighing method in the morning after an overnight fast. Simultaneously, residual lung 
volume was measured by the helium-dilution technique using a spirometer (Volugraph 2000, Mijnhardt, Bunnik, The Netherlands). Body weight was measured with a digital balance with an accuracy of $0.001 \mathrm{~kg}$ (E1200, August Sauter $\mathrm{GmbH}$, Albstadt, Germany). Body fat percentage was calculated using Siri's equation. Fat free mass (FFM) was calculated by subtracting fat mass (FM) from total body weight.

\section{Diet and physical activity prior to testing}

All subjects were instructed to refrain from strenuous physical activity for 2 days prior to each trial. In addition, they were asked to record dietary intake during 2 days prior to the first experimental trial and to repeat this diet prior to the second trial. The evening before each trial, all subjects were instructed to consume a standardised meal (42. kJ. kg-1; consisting of 61 Energy\% (En\%) carbohydrate, $24 \mathrm{En} \%$ fat and $15 \mathrm{En} \%$ protein). There were no significant differences in daily energy intake or macronutrient composition of the diet between groups in the days prior to the tests, as assessed by $2 \mathrm{~d}$ food records. Trained subjects ingested 9.8 $\pm 0.8 \mathrm{MJ} \cdot$ day $^{-1}$ with $29 \pm 1$ En\% from fat, $18 \pm 1 \mathrm{En} \%$ from protein and $53 \pm 1$ En\% from carbohydrate. Control subjects ingested 9.1 $\pm 0.3 \mathrm{MJ} \cdot$ day $^{-1}$ with $32 \pm 1 \mathrm{En} \%$ from fat, $15 \pm 1 \mathrm{En} \%$ from protein and $53 \pm 1 \mathrm{En} \%$ from carbohydrate.

\section{Experimental trials}

Each subject performed 2 trials; one main trial and an additional trial to determine the acetate recovery factor. Both trials were separated by at least 1 week. Each trial consisted of 120 min of resting measurements, followed by 60 min of cycling exercise at an exercise intensity set at $50 \% \mathrm{Wmax}$, and a subsequent $120 \mathrm{~min}$ recovery period. In the main trial an [U-13C]palmitate and [6,6-2 $\left.\mathrm{H}_{2}\right]$ glucose tracer were infused with breath and blood samples being collected at regular time intervals. Muscle biopsies from the vastus lateralis were collected before and immediately after cessation of exercise. The acetate recovery test was identical to the main trial with the exception of the infusion of $\left[1,2-{ }^{13} \mathrm{C}\right]$ acetate and the collection of breath samples only. This study is part of a greater research project investigating substrate utilization at rest and during exercise in various (clinical) populations.

\section{Protocol}

After an overnight fast, subjects arrived at the laboratory at $8.00 \mathrm{AM}$ by car or public transportation. After $30 \mathrm{~min}$ of supine rest, a percutaneous muscle 
biopsy was taken from the vastus lateralis muscle. A Teflon catheter (Baxter BV, Utrecht, The Netherlands) was inserted into an antecubital vein of one arm for blood sampling, another catheter was inserted in the contralateral arm for isotope infusion. Subsequently, subjects were administered a single intravenous dose of $\mathrm{NaH}^{13} \mathrm{CO}_{3}\left(0.06375 \mathrm{mg} \cdot \mathrm{kg}^{-1}\right)$, followed by a [6,6-2 $\left.\mathrm{H}_{2}\right]$ glucose prime $(13.5$ $\left.\mu \mathrm{mol} \cdot \mathrm{kg}^{-1}\right)$. Thereafter, a continuous infusion of $\left[6,6-{ }^{-2} \mathrm{H}_{2}\right]$ glucose $(0.3 \mu \mathrm{mol} \cdot \mathrm{kg}$ $\left.1 \cdot \mathrm{min}^{-1}\right)$ and $\left[\mathrm{U}-{ }^{13} \mathrm{C}\right]$ palmitate $\left(0.01 \mu \mathrm{mol} \cdot \mathrm{kg}^{-1} \cdot \mathrm{min}^{-1}\right)$ (or $\left[1,2-{ }^{13} \mathrm{C}\right]$ acetate) was started $(t=0 \mathrm{~min}$ ) via a calibrated IVAC pump (IVAC 560, San Diego, CA). At $t=120$ min subjects started to exercise on a cycle ergometer at $50 \%$ Wmax for a 60 min period. Whilst at rest, $\mathrm{VO}_{2}$ and $\mathrm{VCO}_{2}$ were measured from $\mathrm{t}=60$ to 120 min (Oxycon- $\mathrm{B}$, Mijnhart), during exercise $\mathrm{VO}_{2}$ and $\mathrm{VCO}_{2}$ were measured for 5 min every $15 \mathrm{~min}$ prior to sampling of blood and expired breath. Immediately after cessation of exercise, a second muscle biopsy was taken, after which subjects rested supine for $2 \mathrm{~h} . \mathrm{VO}_{2}$ and $\mathrm{VCO}_{2}$ were measured during recovery from $\mathrm{t}=210$ to $270 \mathrm{~min}$.

\section{Blood and breath sample analysis}

Blood samples $(7 \mathrm{ml})$ were collected in EDTA containing tubes and centrifuged at $1000 . \mathrm{g}$ for $10 \mathrm{~min}$ at $4^{\circ} \mathrm{C}$. Aliquots of plasma were frozen immediately in liquid nitrogen and stored at $-80^{\circ} \mathrm{C}$. Plasma glucose (Roche, Basel, Switzerland), lactate, FFA (Wako Chemicals, Neuss, Germany), glycerol (Roche Diagnostics, Indianapolis, IN, USA) and triacylglycerol (Sigma Diagnostics, St Louis, MO, USA) concentrations were analysed with a COBAS semi-automatic analyser (Roche). Plasma insulin was measured by radioimmunoassay (Linco, St. Charles, MO, USA). Blood HbA1c content was analysed by high-performance liquid chromatography (Bio-Rad Diamat, Munich, Germany). Expired breath samples were analysed for ${ }^{13} \mathrm{C} /{ }^{12} \mathrm{C}$ ratio by GC continuous flow isotope ratio MS (Finnigan MAT 252, Bremen, Germany). For determination of plasma palmitate and FFA kinetics, FFA were extracted, isolated by thin-layer chromatography, and derivatised to their methyl esters. Palmitate concentration was determined on an analytical GC with flame ionisation detection using heptadecanoic acid as internal standard and comprised $21.3 \pm 0.7 \%$ of total FFA. Isotope tracer/tracee ratios (TTR) of [U-13 C]palmitate was determined using GC combustion isotope ratio MS (Finnigan MAT 252). Following derivatization, plasma $\left[6,6-{ }^{2} \mathrm{H}_{2}\right]$ glucose enrichment was determined by electron ionisation GC-MS (Finnigan). Palmitate, glucose and acetate tracer concentrations in the infusates averaged $1.05 \pm 0.01,32.7 \pm 1.0$ and $4.95 \pm 0.04 \mathrm{mmol} \cdot \mathrm{L}^{-1}$, respectively. Therefore, the exact tracer infusion rates averaged $9.1 \pm 0.1,280 \pm 2$, and $76 \pm 1 \mathrm{nmol} \cdot \mathrm{kg}^{-1} \cdot \mathrm{min}^{-1}$, respectively. 


\section{Calculations}

From respiratory measurements, total fat and carbohydrate oxidation rates were calculated using the non-protein respiratory quotient.

$$
\begin{array}{ll}
\text { Fat oxidation rate } & =1.695 \mathrm{VO}_{2}-1.701 \mathrm{VCO}_{2} \\
\text { Carbohydrate oxidation rate } & =4.585 \mathrm{VCO}_{2}-3.226 \mathrm{VO}_{2}
\end{array}
$$

with $\mathrm{VO} 2$ and $\mathrm{VCO} 2$ in $\mathrm{L} \cdot \mathrm{min}^{-1}$ and oxidation rates in $\mathrm{g} \cdot \mathrm{min}^{-1}$. Rate of appearance $(\mathrm{Ra})$ and rate of disappearance (Rd) of palmitate and glucose were calculated using the single-pool non-steady state Steele equations adapted for stable isotope methodology.

$$
\begin{aligned}
& \mathrm{Ra}=\frac{\mathrm{F}-\mathrm{V}\left[\left(\mathrm{C}_{2}+\mathrm{C}_{1}\right) / 2\right]\left[\left(\mathrm{E}_{2}-\mathrm{E}_{1}\right) /\left(\mathrm{t}_{2}-\mathrm{t}_{1}\right)\right]}{\left(\mathrm{E}_{2}+\mathrm{E}_{1}\right) / 2} \\
& \mathrm{Rd}=\mathrm{Ra}-\mathrm{V} \cdot\left(\frac{\mathrm{C}_{2}-\mathrm{C}_{1}}{\mathrm{t}_{2}-\mathrm{t}_{1}}\right)
\end{aligned}
$$

where $\mathrm{F}$ is the infusion rate $\left(\mu \mathrm{mol} \cdot \mathrm{kg}^{-1} \cdot \mathrm{min}^{-1}\right) ; \mathrm{V}=$ distribution volume for palmitate or glucose ( 40 and $160 \mathrm{~mL}^{\mathrm{kg}}{ }^{-1}$, respectively); $\mathrm{C} 1$ and $\mathrm{C} 2$ are palmitate or glucose concentrations (mmol.L-1) at time $1(\mathrm{t} 1)$ and 2(t2), respectively and E2 and E1 are the plasma palmitate or glucose enrichments (TTR) at time 2 and 1, respectively. ${ }^{13} \mathrm{CO}_{2}$ production $\left(\mathrm{Pr}^{13} \mathrm{CO}_{2} ; \mathrm{mol} \cdot \mathrm{min}^{-1}\right)$ from the infused palmitate tracer was calculated as:

$$
\mathrm{Pr}^{13} \mathrm{CO}_{2}=\left(\mathrm{TTRCO} 2, \mathrm{VCO}_{2}\right) /(\mathrm{k} \cdot \mathrm{Ar})
$$

where $\mathrm{TTRCO} 2$ is the breath ${ }^{13} \mathrm{C} /{ }^{12} \mathrm{C}$ ratio at a given time point, $\mathrm{VCO}_{2}$ is the carbon-dioxide production $\left(\mathrm{L} \cdot \mathrm{min}^{-1}\right), \mathrm{k}$ is the volume of $1 \mathrm{~mol}$ of $\mathrm{CO}_{2}(22.4$ $\left.\mathrm{L} \cdot \mathrm{mol}^{-1}\right)$; and $\mathrm{Ar}$ is the fractional ${ }^{13} \mathrm{C}$ label recovery in breath $\mathrm{CO}_{2}$, observed after the infusion of labeled acetate and calculated as:

$$
\mathrm{Ar}=\left(\left(\mathrm{TTRCO} 2, \mathrm{VCO}_{2}\right) /(\mathrm{k} \cdot 2 \mathrm{~F})\right)
$$

where $\mathrm{F}$ is infusion rate of $\left[1,2-{ }^{-13} \mathrm{C}\right]$ acetate $\left(\mathrm{mol} \cdot \mathrm{min}^{-1}\right)$.

Plasma palmitate oxidation (Rox) $\left(\mathrm{mol} \cdot \mathrm{min}^{-1}\right)$ can subsequently be calculated as:

$$
\text { Rox palmitate }=\mathrm{Rd} \text { palmitate } .\left(\operatorname{Pr}^{13} \mathrm{CO}_{2} / \mathrm{F} .16\right)
$$


where $\mathrm{Rd}$ palmitate is the rate of disappearance palmitate $\left(\mathrm{mol} \cdot \mathrm{min}^{-1}\right)$; $\mathrm{F}$ is the palmitate infusion rate $\left(\mathrm{mol} \cdot \mathrm{min}^{-1}\right)$ and 16 is the number of labeled carbon atoms in palmitate. Total plasma FFA oxidation was calculated by dividing palmitate oxidation rates by the fractional contribution of plasma palmitate to total plasma FFA concentration. The contribution of fat sources other than plasma FFA was calculated by subtracting plasma FFA oxidation from total fat oxidation.

In a previous study it has been shown that during exercise ( $50 \%$ Wmax) plasma glucose Rd equals its Rox (96-100\%) (15). Therefore, plasma glucose oxidation rate during exercise was estimated as:

$$
\text { Rox plasma glucose }=\text { Rd plasma glucose }
$$

Whole body muscle glycogen use was calculated by subtracting plasma glucose oxidation from total carbohydrate oxidation. As plasma glucose Rd does not match Rox during resting conditions, plasma glucose oxidation rates can not be accurately calculated at rest when using a $\left[6,6-2 \mathrm{H}_{2}\right]$ glucose tracer.

\section{Muscle sample analysis}

Muscle samples were dissected, freed from any visible non-muscle material, and frozen in nitrogen-cooled isopentane and embedded in Tissue-Tek (Sakura, Zoeterwoude, The Netherlands). Multiple serial sections $(5 \mu \mathrm{m})$ were thaw mounted together on uncoated, pre-cleaned glass slides for each subject. To determine muscle fibre type specific IMTG content, cross-sections were stained with oil red $O$ together with immuno-labelled cellular constituents using the protocol described before (43). From each muscle biopsy a total of $53 \pm 5$ and $49 \pm 4$ muscle fibres were analysed for lipid content in the trained and control group, respectively. To permit quantification of intramyocellular glycogen we applied the modified PAS stain (32). For each muscle biopsy $153 \pm 23$ and $157 \pm 13$ muscle fibres were analysed for glycogen content in the trained and control group, respectively. Muscle fibre type-specific oxidative capacity was assessed by determining succinate dehydrogenase activity (SDH) in skeletal muscle cross-sections using (immuno)histochemical staining analyses as described before (23). For each muscle cross-section $147 \pm 13$ and $111 \pm 8$ muscle fibres were analysed for SDH activity in the trained and control group, respectively. Large overviews containing $146 \pm 26$ and $174 \pm 20$ fibres per subject in the trained and control group, respectively, were used to determine muscle fibre type composition. 


\section{RESULTS}

\section{Subjects' characteristics}

The older, endurance-trained males had been cycling for the greater part of their adulthood $(42 \pm 3 \mathrm{y})$ and were still cycling more than 3 times/week. Current training volume averaged $-275 \mathrm{~km} / \mathrm{wk}$, or approximately $11 \mathrm{~h}$ of exercise per week. Subjects did not participate in other sports except for occasional fitness and/or running $(n=3)$. Sedentary control subjects had no history of participating in any regular physical activity program. Significant differences in body composition, maximal workload and oxygen uptake capacity were observed between groups (Table 1).

\section{Table 1 Subjects' characteristics}

\begin{tabular}{|c|c|c|c|c|c|c|}
\hline \multirow[b]{2}{*}{ Age $(y)$} & \multicolumn{3}{|c|}{$\begin{array}{c}\text { Control } \\
n=10\end{array}$} & \multicolumn{3}{|c|}{$\begin{array}{c}\text { Trained } \\
\mathbf{n}=\mathbf{1 0} \\
\end{array}$} \\
\hline & 60 & \pm & 2 & 57 & \pm & 1 \\
\hline Height (m) & 1.76 & \pm & 0.01 & 1.75 & \pm & 0.01 \\
\hline Body mass $(\mathrm{kg})$ & 87 & \pm & 2 & 78 & \pm & $2^{*}$ \\
\hline $\mathrm{BMI}\left(\mathrm{kg} / \mathrm{m}^{2}\right)$ & 28 & \pm & 0 & 26 & \pm & $1^{*}$ \\
\hline Body fat (\%) & 29 & \pm & 1 & 17 & \pm & $1^{*}$ \\
\hline Fat free mass $(\mathrm{kg})$ & 61 & \pm & 1 & 64 & \pm & 1 \\
\hline Basal plasma glucose $(\mathrm{mM})$ & 5.56 & \pm & 0.14 & 5.65 & \pm & 0.08 \\
\hline Plasma glucose $120 \min (\mathrm{mM})$ & 5.71 & \pm & 0.5 & 5.28 & \pm & 0.4 \\
\hline Basal plasma insulin $\left(\mathrm{mU} \cdot \mathrm{L}^{-1}\right)$ & 7.86 & \pm & 1.58 & 5.13 & \pm & 0.56 \\
\hline Plasma insulin $120 \mathrm{~min}$ & 48.40 & \pm & 8.04 & 29.40 & \pm & 6.34 \\
\hline $\mathrm{HbAlc}(\%)$ & 5.83 & \pm & 0.2 & 5.78 & \pm & 0.1 \\
\hline $\mathrm{VO} 2 \max \left(\mathrm{L} \cdot \mathrm{min}^{-1}\right)$ & 3.2 & \pm & 0.2 & 3.8 & \pm & $0.1^{*}$ \\
\hline VO2max per kg & 36.8 & \pm & 2.0 & 48.8 & \pm & $1.8^{*}$ \\
\hline \multicolumn{7}{|l|}{$\left(\mathrm{mL} \cdot \mathrm{min}^{-1} \cdot \mathrm{kg}^{-1}\right)$} \\
\hline$W \max (W)$ & 203 & \pm & 16 & 300 & \pm & $9^{*}$ \\
\hline Wmax per $\mathrm{kg} F F M\left(\mathrm{~W} \cdot \mathrm{kg}^{-1}\right)$ & 3.27 & \pm & 0.20 & 4.67 & \pm & $0.13^{*}$ \\
\hline Maximal heartrate (bpm) & 164 & \pm & 7 & 172 & \pm & 3 \\
\hline Training history (years) & $\mathrm{n} / \mathrm{a}$ & & & 43 & \pm & 2 \\
\hline
\end{tabular}

Body mass index (BMI) is calculated dividing body mass by height ${ }^{2}$; Plasma glucose/insulini2omin represents plasma glucose/insulin concentrations at $t=120 \mathrm{~min}$. Data are means $\pm S E M .{ }^{*}$ significantly different from control group $(P<0.05)$ 
Table 2 Tracer kinetics

\begin{tabular}{|c|c|c|c|c|c|c|c|c|c|c|c|c|c|}
\hline & & \multicolumn{3}{|c|}{$\begin{array}{l}\text { Control } \\
(n=10)\end{array}$} & \multicolumn{3}{|c|}{$\begin{array}{l}\text { Trained } \\
(n=10)\end{array}$} & \multicolumn{3}{|c|}{$\begin{array}{l}\text { Control } \\
(n=10)\end{array}$} & \multicolumn{3}{|c|}{$\begin{array}{l}\text { Trained } \\
(n=10)\end{array}$} \\
\hline & & \multicolumn{6}{|c|}{$\mathrm{mmol} \cdot \mathrm{min}^{-1}$} & \multicolumn{6}{|c|}{$\mu \mathrm{mol} \cdot \mathrm{kg}$ FFM $^{-1} \cdot \mathrm{min}^{-1}$} \\
\hline \multicolumn{14}{|l|}{ Rest } \\
\hline $\mathrm{Ra}$ & palmitate & 0.16 & \pm & 0.02 & 0.17 & \pm & 0.02 & 2.59 & \pm & 0.26 & 2.65 & \pm & 0.24 \\
\hline $\mathrm{Rd}$ & palmitate & 0.16 & \pm & 0.02 & 0.17 & \pm & 0.02 & 2.56 & \pm & 0.26 & 2.64 & \pm & 0.25 \\
\hline Rox & palmitate & 0.06 & \pm & 0.001 & 0.06 & \pm & 0.001 & 1.03 & \pm & 0.13 & 1.00 & \pm 1 & 0.12 \\
\hline$\% \operatorname{Rd}$ ox & palmitate & 39.8 & \pm & 2.1 & 37.7 & \pm & 2.1 & 39.8 & \pm & 2.1 & 37.7 & \pm & $2.1^{*}$ \\
\hline $\mathrm{Ra}$ & glucose & 0.93 & \pm & 0.03 & 1.03 & \pm & $0.03^{*}$ & 15.29 & \pm & 0.74 & 16.16 & \pm 1 & 0.57 \\
\hline $\mathrm{Rd}$ & glucose & 0.94 & \pm & 0.03 & 1.07 & \pm & $0.03^{*}$ & 15.48 & \pm & 0.62 & 16.71 & \pm 1 & 0.56 \\
\hline$\% \operatorname{Ra} \mathrm{Rd}$ & glucose & 102 & \pm & 1 & 104 & \pm & 1 & 102 & \pm & 1 & 104 & \pm & $I^{*}$ \\
\hline \multicolumn{14}{|l|}{ Exercise } \\
\hline $\mathrm{Ra}$ & palmitate & 0.25 & \pm & $0.02 t$ & 0.36 & \pm & $0.02^{*}+$ & 4.01 & \pm & $0.28 t$ & 5.65 & \pm 1 & $0.44^{*}+$ \\
\hline $\mathrm{Rd}$ & palmitate & 0.24 & \pm & $0.02 t$ & 0.36 & \pm & $0.03^{*}+$ & 3.94 & \pm & $0.27 \dagger$ & 5.62 & \pm 1 & $0.44^{*}+$ \\
\hline Rox & palmitate & 0.20 & \pm & $0.02 t$ & 0.31 & \pm & $0.02^{*}+$ & 3.18 & \pm & $0.27 t$ & 4.83 & \pm 1 & $0.39^{*}+$ \\
\hline$\%$ Rd ox & palmitate & 80.8 & \pm & $3.64 t$ & 86.8 & \pm & $4.54 \dagger$ & 80.8 & \pm & $3.64 t$ & 86.8 & \pm & $4.54 \dagger$ \\
\hline $\mathrm{Ra}$ & glucose & 1.77 & \pm & $0.08 t$ & 1.51 & \pm & $0.06^{* t}$ & 29.07 & \pm & $1.45 \dagger$ & 23.59 & \pm & $1.18^{*}+$ \\
\hline Rd & glucose & 1.74 & \pm & $0.09 t$ & 1293.4 & \pm & $0.06^{*}+$ & 28.58 & \pm & $1.72 \dagger$ & 20.21 & \pm & $1.01^{*}+$ \\
\hline \%Ra Rd & glucose & 98 & \pm & 4 & 86 & \pm & $2^{*}+$ & 98 & \pm & 4 & 86 & \pm & $2^{*+}$ \\
\hline
\end{tabular}

\section{Recovery}

\begin{tabular}{|c|c|c|c|c|c|c|c|c|c|c|c|c|}
\hline $\mathrm{Ra}$ & palmitate & 0.17 & \pm & $0.01 \ddagger$ & 0.15 & $\pm 0.01 \ddagger$ & 2.83 & \pm & $0.18 \ddagger$ & 2.39 & \pm & $0.19 \ddagger$ \\
\hline $\mathrm{Rd}$ & palmitate & 0.17 & \pm & $11.6 \neq$ & 0.15 & $\pm 0.01 \neq$ & 2.82 & \pm & $0.18 \ddagger$ & 2.38 & \pm & $0.19 \ddagger$ \\
\hline Rox & palmitate & 0.07 & \pm & $0.01 \ddagger$ & 0.07 & $\pm 0.01 f$ & 1.22 & \pm & $0.11 \ddagger$ & 1.04 & \pm & $0.09 \ddagger$ \\
\hline$\%$ Rd ox & palmitate & 43.2 & \pm & $2.5 \ddagger$ & 43.9 & $\pm 1.9+\neq$ & 43.2 & \pm & $2.5 \ddagger$ & 43.9 & \pm & $1.9+\ddagger$ \\
\hline $\mathrm{Ra}$ & glucose & 0.75 & \pm & $0.04 t t$ & 0.79 & $\pm 0.02 t \ddagger$ & 12.29 & \pm & $0.81 t \ddagger$ & 12.39 & \pm & $0.38 t \ddagger$ \\
\hline $\mathrm{Rd}$ & glucose & 0.83 & \pm & $0.04 \uparrow \neq$ & 0.92 & $\pm 0.01 t \ddagger$ & 13.62 & \pm & $0.79+\ddagger$ & 14.38 & \pm & $0.37 t \neq$ \\
\hline \%Ra Rd & glucose & 113 & \pm & 6 & 117 & $\pm 3+t$ & 113 & \pm & 6 & 117 & \pm & $3+t$ \\
\hline
\end{tabular}

Tracer kinetics as determined at rest, during exercise ( $50 \% \mathrm{Wmax}$ ) and subsequent recovery. Ra, rate of appearance; Rd, rate of disappearance; Rox, rate of oxidation (mmol-min-1 and $\mu \mathrm{mol} \cdot \mathrm{kg}$ FFM-1.min1); \%Rd ox, percentage of Rd oxidised (\%); \% Ra Rd percentage of Ra that disappeared (\%). Values are means \pm SEM $(2 n=20)$. *significantly different from control group $(P<0.05)$ tsignificantly different from resting values $(\mathrm{P}<0.01)$; $\ddagger$ significantly different from exercise values $(\mathrm{P}<0.01)$. 

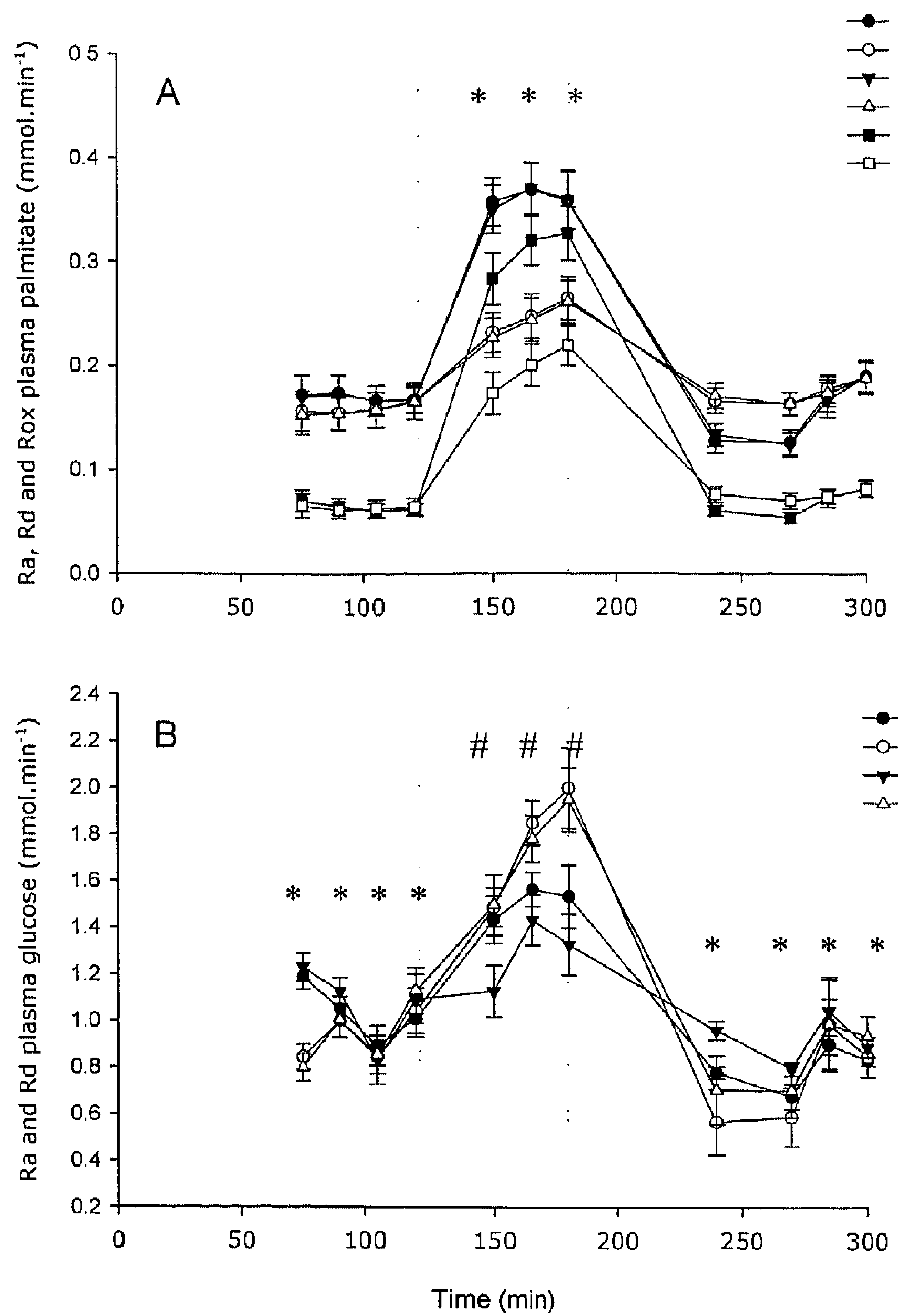

Figure 1. Tracer kinetics as determined at rest, during exercise ( $\mathrm{T}=120-180 \mathrm{~min}, 50 \% \mathrm{Wmax}$ ) and subsequent recovery. $\mathrm{Ra}$, rate of appearance; $\mathrm{Rd}$, rate of disappearance; Rox, rate of oxidation $(\mathrm{mmol} \cdot \mathrm{min}-1)$. Values are means $\pm \operatorname{SEM}(2 \mathrm{n}=20)$. Dotted lines mark beginning and end of exercise period. Fig. A: *Plasma palmitate $\mathrm{Ra}, \mathrm{Rd}$ and Rox significantly greater in trained subjects compared to controls ( $\mathrm{P}<0.001)$. Fig.B: *Plasma glucose $\mathrm{Ra}$ and $\mathrm{Rd}$ significantly greater in $\mathrm{T}$ as compared to controls at rest and during recovery. \#Plasma glucose Rd significantly lower in trained subjects (all $\mathrm{P}<0.05)$. 


\section{Tracer kinetics}

Acetate recovery factors averaged $0.15 \pm 0.02$ and $0.14 \pm 0.02$ (rest: NS), $1.00 \pm 0.03$ and $0.88 \pm 0.01$ (exercise: $P<0.05$ ) and $0.25 \pm 0.02$ and $0.28 \pm 0.02$ (recovery: NS), in the trained and sedentary group, respectively. At rest and during post-exercise recovery, plasma palmitate $\mathrm{Ra}, \mathrm{Rd}$ and Rox did not significantly differ between groups (Table 2, Figure 1). During exercise, plasma palmitate $\mathrm{Ra}$, Rd and Rox were significantly greater in trained subjects compared to controls $(\mathrm{P}<0.001)$. Plasma palmitate Ra reached plateau values within $15 \mathrm{~min}$ after the onset of exercise in the trained group, whereas in the control group, plasma palmitate $\mathrm{Ra}$ steadily increased during exercise. Plasma palmitate $\mathrm{Rd}$ and Rox increased significantly over time during exercise in both groups. Plasma glucose $\mathrm{Ra}$ and $\mathrm{Rd}$ were significantly greater in the trained subjects as compared to the sedentary controls at rest $(\mathrm{P}<0.001)$. In contrast, during exercise, plasma glucose $\mathrm{Rd}$ was greater in the sedentary controls. Plasma glucose $\mathrm{Ra}$ and $\mathrm{Rd}$ increased over time during exercise in the sedentary, but not in the trained subjects.

\section{Plasma metabolite concentrations}

Plasma glucose concentrations at rest did not differ between groups (Figure 2). During exercise, plasma glucose concentrations were higher in the trained group versus control $(\mathrm{P}<0.01)$. Plasma glucose values returned to pre-exercise levels during recovery in both groups. At rest, plasma FFA concentrations did not differ between groups. Plasma FFA concentrations during exercise tended to be higher in the trained group as compared to the sedentary controls $(\mathrm{P}=0.055)$. At the onset of exercise, plasma FFA decreased in the control but not in the trained group. In both groups, plasma FFA concentrations increased until 15 min after cessation of exercise. Plasma free glycerol concentrations increased significantly during exercise and returned to basal levels during recovery. Plasma free glycerol concentrations were significantly greater during exercise in the trained vs sedentary group $(\mathrm{P}<0.01)$. Plasma $\mathrm{TG}$ concentrations did not differ between groups. Plasma lactate concentrations increased during exercise, and were higher in the sedentary versus trained group $(\mathrm{P}<0.05)$. Plasma insulin levels declined during exercise in the sedentary group only $(\mathrm{P}<0.05)$. Plasma insulin concentrations did not differ between groups.

\section{Whole-body substrate source utilization}

At rest, energy expenditure averaged $5.30 \pm 0.12$ and $5.28 \pm 0.16 \mathrm{~kJ} \cdot \mathrm{min}^{-1}$ at rest, in the trained and sedentary group, respectively (Figure 3). Total fat oxidation rate $\left(\mathrm{g} \cdot \mathrm{min}^{-1}\right)$ at rest did not differ between groups $\left(0.09 \pm 0.00\right.$ and $\left.0.09 \pm 0.01 \mathrm{~g} \cdot \mathrm{min}^{-1}\right)$, 
contributing $70 \pm 3$ and $67 \pm 3 \%$ to total energy expenditure, respectively (Figure 3). Exercise was performed at a $50 \%$ Wmax workload, which resulted in an absolute workload set at $150 \pm 5(\mathrm{~T})$ and $101 \pm 8 \mathrm{~W}(\mathrm{UT}, \mathrm{P}<0.001)$ in the trained and sedentary group, respectively. Mean heartrate during exercise averaged $124 \pm 4(72 \pm 2 \%$ HRmax) and $122 \pm 5$ (75 $\pm 2 \%$ HRmax) in the trained and sedentary group (NS). Energy expenditure and oxygen uptake (expressed as \% of $\mathrm{VO}_{2 m a x}$ ) during exercise were higher in the trained versus sedentary controls $(49 \pm 2$ and $36 \pm 2$ $\mathrm{kJ} \cdot \mathrm{min}^{-1}$, and $61 \pm 1$ and $54 \pm 2 \% \mathrm{VO}_{2}$-max, respectively $\mathrm{P}<0.05$ ).
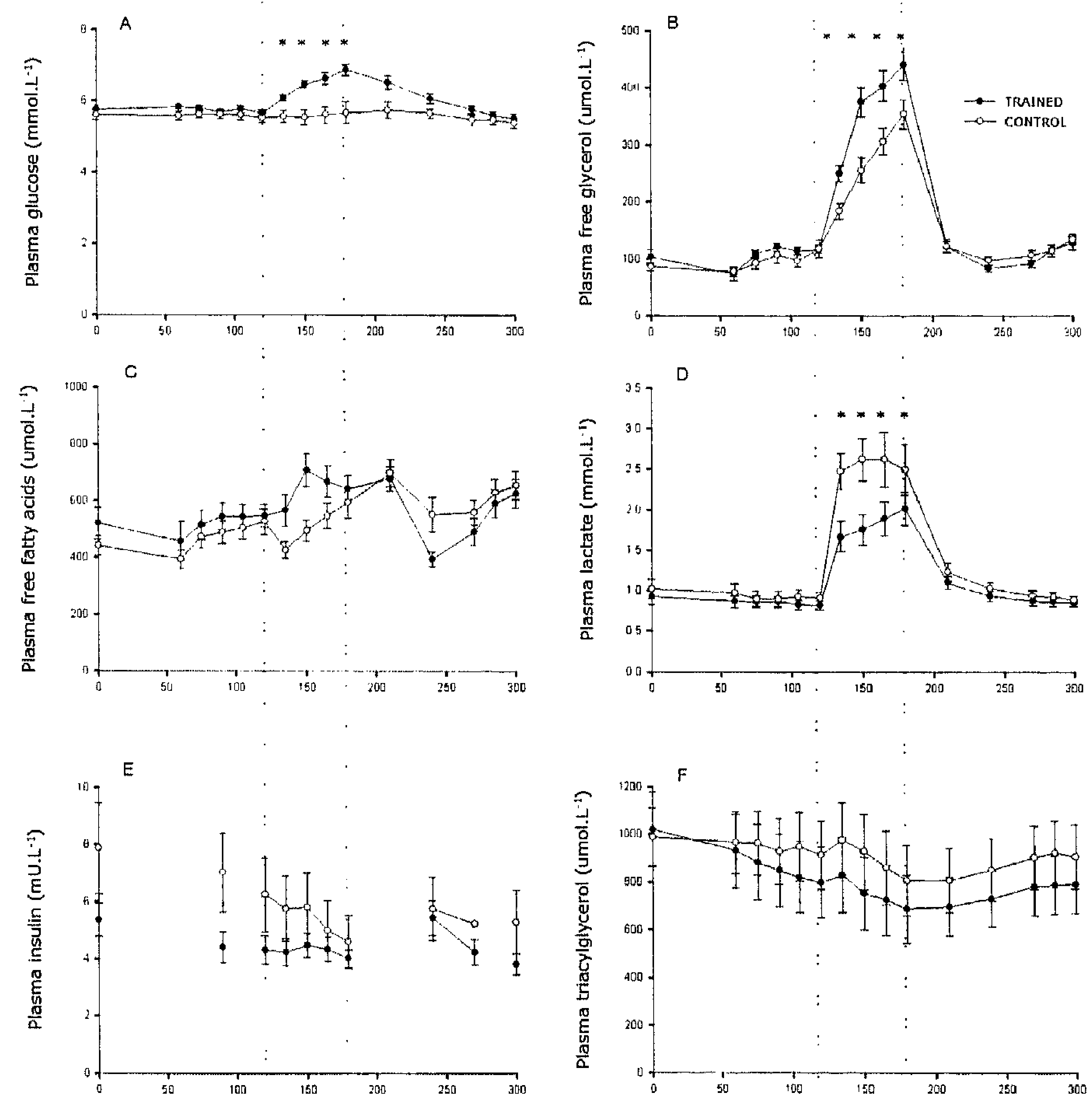

Figure 2. Plasma glucose (A), free glycerol (B), free fatty acids (C), lactate (D), insulin (E) and triacylglycerol $(\mathbf{F})$ concentrations. Values are means \pm SEM. Dotted lines mark beginning and end of exercise period. *Significantly different from control group $(\mathrm{P}<0.05)$. 
Total fat oxidation rates during exercise were significantly greater in the trained subjects versus sedentary controls $\left(0.52 \pm 0.03\right.$ and $0.35 \pm 0.03 \mathrm{~g} \cdot \mathrm{min}^{-1}$, respectively, $P<0.001)$, contributing $43 \pm 2$ and $39 \pm 3 \%$ to total energy expenditure $(P=0.19, N S)$. The greater total fat oxidation was attributed to higher plasma FFA oxidation rates, which were higher from an absolute $(\mathrm{P}<0.002)$ as well as relative point of view $(\mathrm{P}=0.06)$. Muscle and/or lipoprotein derived TG use significantly increased from rest to exercise to $0.12 \pm 0.02$ and $0.10 \pm 0.02 \mathrm{~g} \cdot \mathrm{min}^{-1}$, contributing $10 \pm 2$ and $11 \pm 3 \%$ in the trained and control group, respectively (NS; Figure 3). Total carbohydrate oxidation rates during exercise averaged $1.70 \pm 0.07$ and $1.37 \pm 0.08$ $\mathrm{g} \cdot \mathrm{min}^{-1}$ in the trained and sedentary control group, respectively $(\mathrm{P}<0.01)$, contributing $57 \pm 2$ and $61 \pm 3 \%$ to total energy expenditure (NS). Plasma glucose oxidation rates contributed $8 \pm 0$ and $14 \pm 1 \%$ of total energy expenditure in the trained versus sedentary groups, respectively $(\mathrm{P}<0.05)$. Muscle glycogen use contributed $49 \pm 2$ and $46 \pm 3 \%$ to total energy expenditure in the trained and sedentary group, respectively (NS; Figure 3 ).
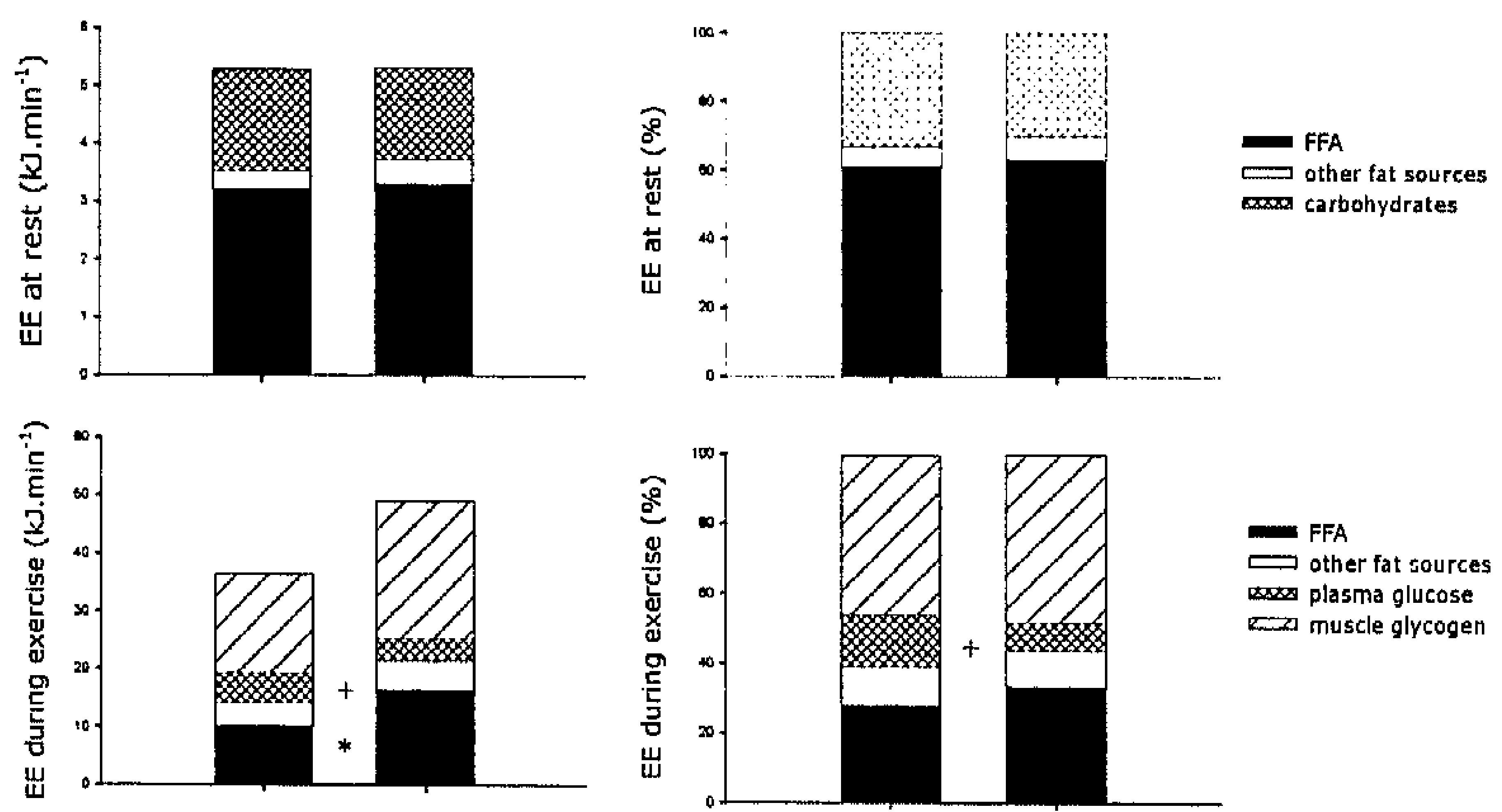

plasma glucose lycogen
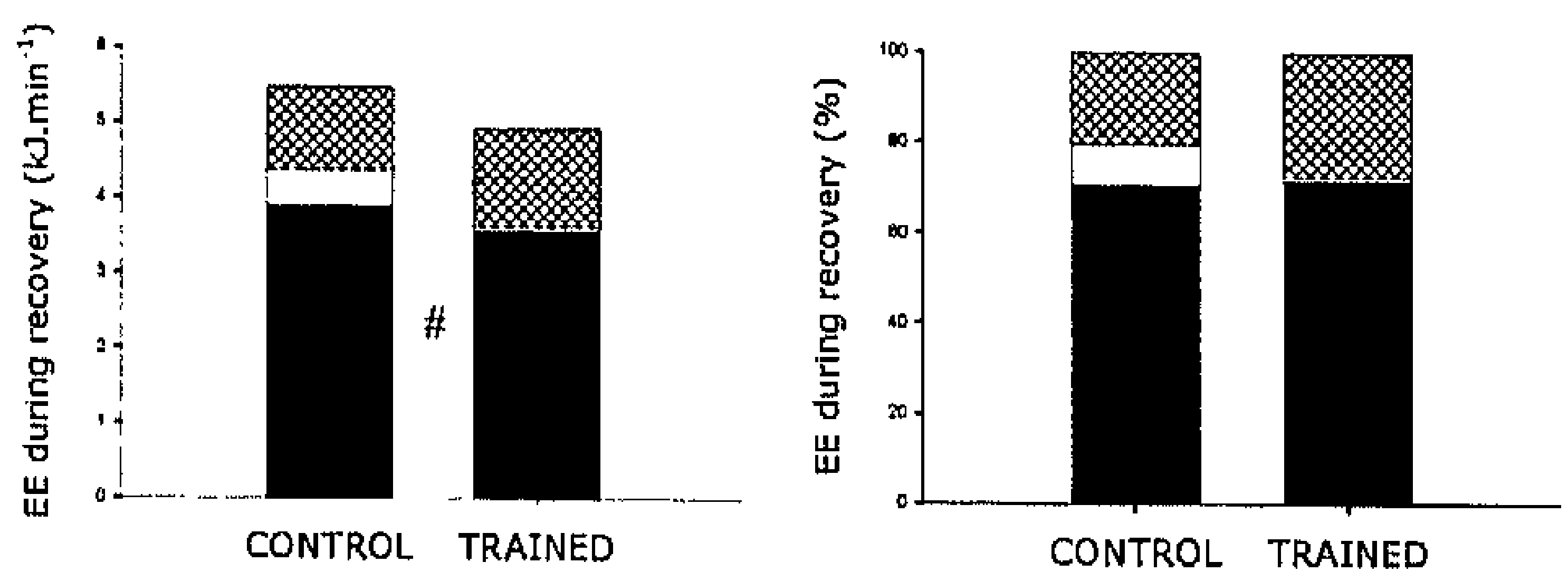
m. FFA
ther fat sources carbohydrates

Figure 3. Energy expenditure at rest, during exercise and subsequent recovery ( $\mathrm{kJ} \cdot \mathrm{min}^{-1}$ and EE\%). Values are means \pm SEM. * Significantly greater total fat and FFA oxidation $(\mathrm{P}<0.05)+$ Significantly lower total carbohydrate and plasma glucose oxidation $(\mathrm{P}<0.05)$ \# Significantly greater total fat oxidation $(\mathrm{P}<0.05)$. 
During post-exercise recovery, energy expenditure tended to be greater in the sedentary groups compared to the trained group $\left(5.5 \pm 0.2\right.$ and $4.9 \pm 0.2 \mathrm{~kJ} \cdot \mathrm{min}^{-1}$, respectively $(\mathrm{P}=0.06)$. This was attributed to a higher total fat oxidation rate $(\mathrm{P}<0.01)$. Neither plasma FFA or muscle and/or lipoprotein derived TG use differed between groups during post-exercise recovery (Figure 3 ).
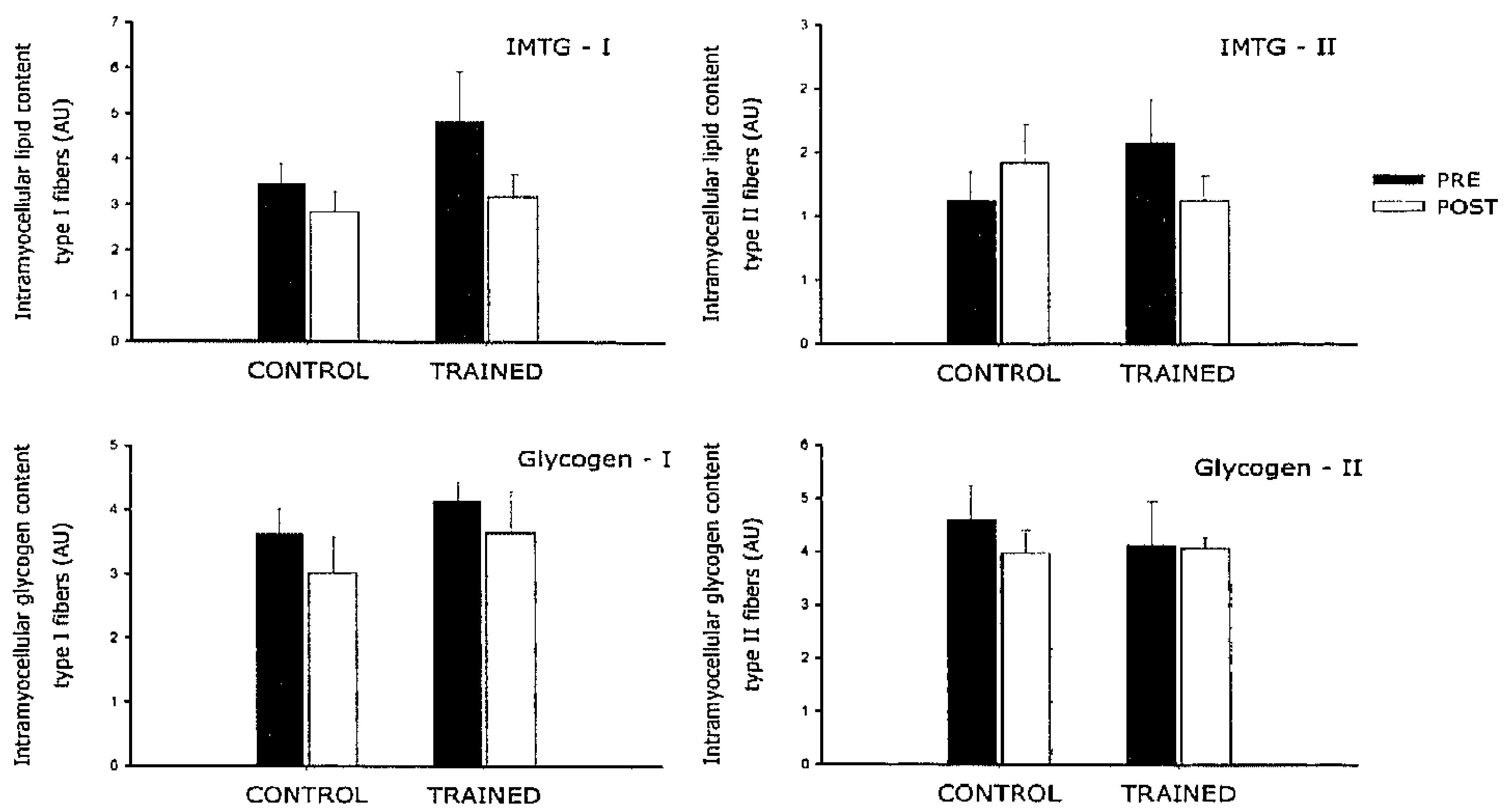

Figure 4. Fiber-type specific intramyocellular lipid (top) and glycogen (bottom) content in type I (left panel) and type II (right panel) fibers, pre (black bars) and post (white bars) exercise.

\section{Muscle tissue analysis}

Muscle fiber type specific lipid and glycogen content before and immediately after exercise are illustrated in Figure 4. Muscle fibre type analyses showed a significantly greater type I fiber content in the trained versus sedentary group (71 \pm 4 and $49 \pm 4 \%$ type I; $29 \pm 4$ and $51 \pm 4 \%$ type II fibers, respectively; $P<0.001$ ). In both groups, type I muscle fibers contained 2-3 fold more lipid than type II fibers $(\mathrm{P}<0.005)$. No significant net changes in type I or II muscle fiber lipid content were observed following exercise in either group (Figure 4). No significant net changes in muscle fiber glycogen content were observed in either group $(-14.7 \pm 13.0 \%$ and $18.0 \pm 10.8 \%$ in trained and control subjects, respectively, Figure 4). Muscle fiber type specific succinate dehydrogenase (SDH) activity is shown in Figure 5. Significantly greater SDH activity was observed in the type I and II muscle fibers in the trained subjects compared to the sedentary controls $(P<0.05)$. 


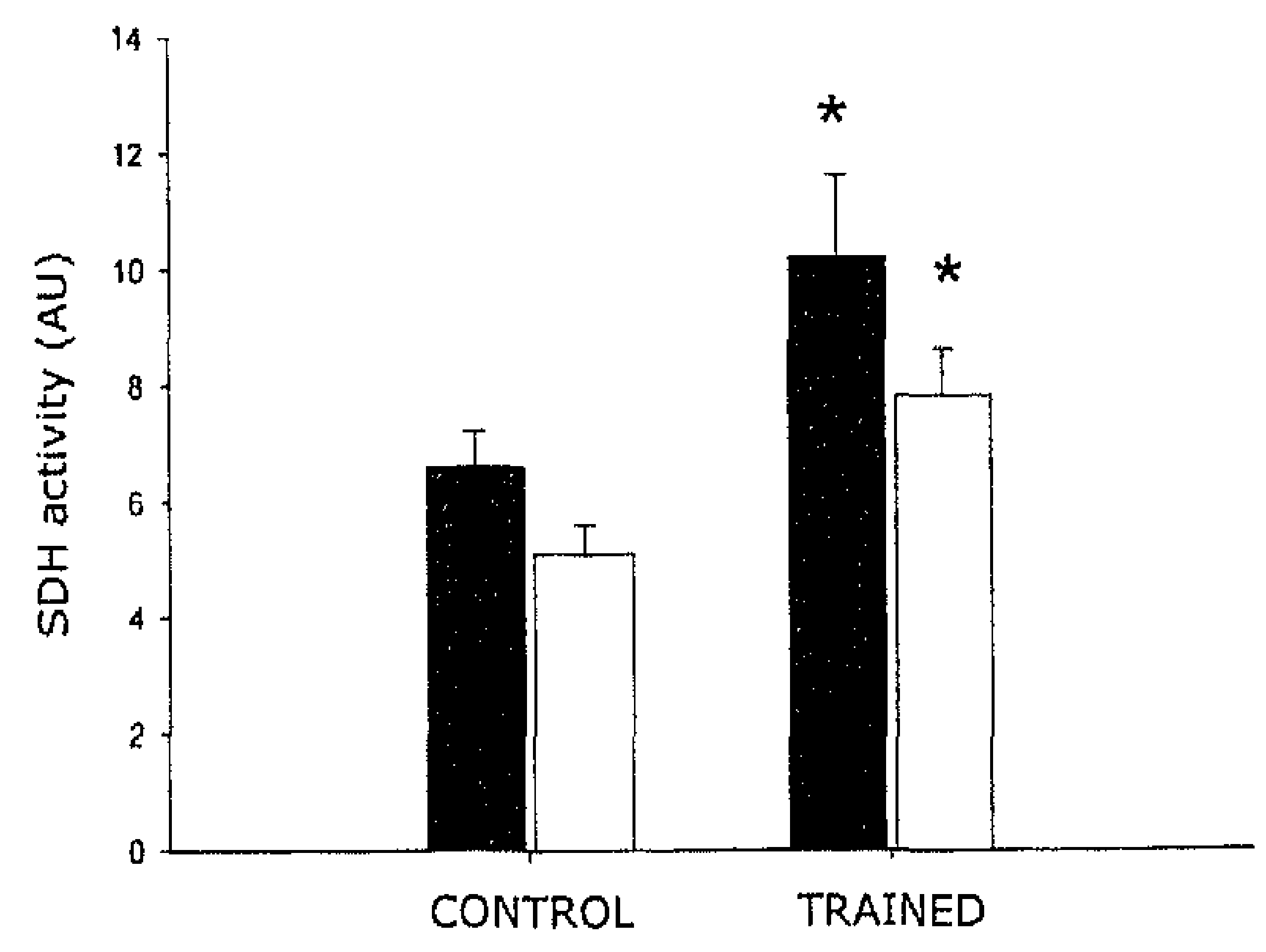

Figure 5. Fiber-type specific succinate dehydrogenase activity in type I (black bars) and type $\Pi$ (white bars) muscle fibers. *Significantly different from control group $(\mathrm{P}<0.05)$.

\section{DISCUSSION}

In the present study, we report a greater total fat oxidation rate during exercise of the same relative intensity in older, long-term exercising, endurance-trained males, as compared to age-matched sedentary controls. The greater fat use in the endurance-trained state is entirely attributed to a greater plasma FFA appearance, uptake and oxidation rate. In contrast, muscle and/or lipoprotein derived TG is of minor quantitative importance during $1 \mathrm{~h}$ of moderate intensity exercise in either endurance-trained or sedentary older males.

Older, endurance-trained males were shown to oxidise more fat during exercise of the same relative workload $(50 \% \mathrm{Wmax})$ when compared to sedentary, agematched controls (Figure 3). Despite an identical relative workload (W) and heartrate $(124 \pm 4 \mathrm{~b} / \mathrm{min}(72 \pm 2 \%$ of HRmax) versus $122 \pm 5(75 \pm 2 \%$ of HRmax)), exercise intensity expressed as a percentage of maximal oxygen uptake capacity was higher in the trained versus sedentary group $\left(61 \pm 1 \%\right.$ versus $54 \pm 2 \% \mathrm{VO}_{2}$ max, respectively). The greater whole-body and skeletal muscle oxidative capacity, and concomitant higher fat oxidation rate during exercise in the endurance-trained state are in accordance with previous findings in young endurance-trained subjects $(4,22,26,38)$, master athletes $(8,26)$, and middle- to older aged subjects after endurance training $(6,16,30,33,34,36)$. However, less consensus exists with regard to the specific endogenous fat sources that are being utilized to a greater extent in the endurance-trained versus untrained state. Studies applying shortterm training interventions generally report that greater fat oxidation rates during exercise are accounted for by an increased muscle (and/or lipoprotein) derived TG use $(14,27,29,33)$. In contrast, others report higher plasma FFA appearance, uptake and oxidation rates in the endurance-trained state $(4,10,11,20,38)$. This latter perspective is supported by the present study, as the greater whole-body fat 
oxidation rates in the endurance-trained subjects were entirely attributed to a higher plasma FFA appearance, uptake and oxidation rate (Table 2 and Figure 1,3). Furthermore, the use of muscle (and/or lipoprotein) derived TG was shown to be of relative minor importance in both groups, contributing only $10 \%$ of total energy expenditure. In accordance, no net decline in type I or II muscle fiber lipid content was observed following exercise in either group (Figure 4). As such, we conclude that, from a quantitative point of view, intramuscular triacylglycerol does not represent a major substrate source during $1 \mathrm{~h}$ of moderate intensity exercise in older endurance-trained or sedentary males.

Differences in training history between subjects' populations are likely to explain the apparent discrepancy on the effects of endurance training on fat source utilization during exercise. Schrauwen et al. (33) have applied the same stable isotope methodology to assess endogenous fat source utilization during exercise before and after 3 months of endurance training in middle-aged sedentary men. They reported that the greater fat oxidation following short-term endurance training was entirely accounted for by an increase in muscle (and/or lipoprotein) derived TG use (33). In the present study, we made a cross-sectional comparison between older, long-term exercising, endurance-trained cyclists and age-matched, sedentary men. Though genetic differences and self-selection bias could have contributed to our findings, we observed much greater plasma FFA oxidation rates during exercise in the endurance-trained subjects (Figure 3 ). This is in line with previous findings, showing that long-term endurance exercise training increases plasma FFA use $(4,18,38)$. The greater capacity to utilise plasma derived FFA is associated with a greater lipolytic response of adipose tissue (10, 11), a higher plasma FFA uptake rate during exercise $(4,18,38)$, and a greater skeletal muscle FA transport capacity in the endurance-trained state (18-20). These adaptive responses suggest that plasma derived FFA are the preferred substrate source to allow greater fat oxidation rates in the endurance-trained state. In this respect, the greater muscle (and/or lipoprotein) derived TG use following a short-term training intervention as observed by Schrauwen et al. (33) likely reflects an early adaptive response to exercise. We speculate that an increase in skeletal muscle fat oxidative capacity is an early response to exercise training, and that the adipose tissue lipolytic response and muscle FFA transport capacity are not yet upregulated at this stage to allow greater plasma FFA use. The latter is likely to occur after more prolonged (i.e. years of) endurance training. In further support of this view, plasma FFA Ra levels reached plateau values immediately after the onset of exercise in the trained athletes only, which indicates that the increased demand for plasma FFA is rapidly met by an increased adipose tissue lipolytic rate (Figure 1). These data imply that long-term 
endurance training augments the capacity of adipose tissue to respond rapidly to increased skeletal muscle FFA demands.

The balance between plasma FFA availability and demand in the older athletes was facilitated by their relative low absolute workload capacity when compared to young, endurance-trained athletes who generally exercise at much higher absolute workloads. It has been previously shown that plasma FFA availability determines IMTG mobilization and oxidation (41). Thus, under high workload conditions where plasma FFA availability cannot match FA turnover, muscle TG stores will be mobilized and oxidized to a greater extent. This also explains why the contribution of muscle TG oxidation to energy expenditure seems to be considerably greater in younger, trained athletes (40).

The greater fat oxidation rate during exercise in the trained subjects was accompanied by a significantly lower endogenous carbohydrate oxidation rate (Figure 3). The latter was mainly attributed to lower plasma glucose appearance and disappearance rates (Figure 1) and is in accordance with previous findings during exercise at the same relative intensity in an endurance-trained versus untrained state $(2,5)$. Even though whole-body glycogen use represented $\sim 50 \%$ of total energy expenditure during exercise (Figure 4), no significant net decline in type I or II muscle fiber glycogen content was observed in either group. It might be speculated that greater variance in fiber type specific muscle glycogen content as assessed by the PAS staining methodology prevented the net decline in muscle fiber type specific glycogen content from reaching statistical significance. We observed a non-significant $16 \pm 9 \%$ net decline in type I muscle fiber glycogen content in vastus lateralis tissue (Figure 4), which seems to be relatively small when compared to studies that measured mixed muscle glycogen content before and after similar exercise protocols in younger subjects $(24,42)$. Future studies are warranted to address the apparent discrepancy between findings.

In the post-exercise recovery phase, fat oxidation in the control subjects was stimulated when compared to resting conditions (Figure 3 ). This could largely be attributed to a greater plasma FFA oxidation rate in the control subjects, with no differences being observed in muscle (and/or lipoprotein) derived TG use. As such, the effects of exercise to stimulate adipose tissue lipolysis and subsequent plasma FFA release, uptake and oxidation extend to the post-exercise recovery phase.

Aging has been associated with a decline in skeletal muscle $(17,21,28,34)$ and/or whole-body $(26,35)$ oxidative capacity, a progressive decline in muscle mass, strength and a concomitant increase in body fat content $(13,21)$. These age-related changes in oxidative capacity and body composition contribute to an increased likelihood of developing chronic metabolic diseases $(28,31)$. Though we did not 
aim to assess the impact of age on substrate source utilization, our data suggest that decades of intense endurance type exercise training attenuate much of the decline in whole-body and skeletal muscle oxidative capacity observed with aging (Figure 5). Furthermore, the progressive loss of muscle mass and concomitant increase in body fat mass with aging seems to be largely prevented by maintaining high levels of physical activity throughout adulthood. These apparent clinical benefits of regular exercise are likely to reduce the risk of developing chronic metabolic disease at an advanced age.

In conclusion, endurance-trained master athletes oxidize more fat during moderate intensity exercise as compared to sedentary controls. The greater total fat oxidation rate during exercise in the endurance-trained state is attributed to a higher plasma FFA release, uptake and subsequent oxidation rate. In contrast, intramyocellular triacylglycerol does not represent a major substrate source during moderate intensity exercise in endurance-trained master athletes or sedentary men. Decades of endurance training seem to attenuate the decline in whole-body and skeletal muscle oxidative capacity and the concomitant changes in body composition, and likely reduces the risk of developing chronic metabolic disease at an advanced age.

\section{ACKNOWLEDGEMENTS}

All authors greatly acknowledge Annemie Gijsen, Mia Meers, Hanne Vandereyt, Joan Senden, Antoine Zorenc and Jos Stegen for their dedicated and expert analytical assistance, as well as all subjects for their enthusiastic participation. 


\section{REFERENCES}

1. Booth, F. W. and S. J. Lees. Physically active subjects should be the control group. Med Sci Sports Exerc. 38:405-406, 2006.

2. Carter, S. L, C. Rennie, and M. A. Tamopolsky. Substrate utilization during endurance exercise in men and women after endurance training. Am J Physiol Endocrinol Metab. 280:E898-907, 2001.

3. Coggan, A. R., W. M. Kohrt, R. J. Spina, D. M. Bier, and J. O. Holloszy. Endurance training decreases plasma glucose turnover and oxidation during moderate-intensity exercise in men. / Appl Pliysiol. 68:990-996, 1990.

4. Coggan, A. R., C. A. Raguso, A. Gastaldelli, L. S. Sidossis, and C. W. Yeckel. Fat metabolism during high-intensity exercise in endurance-trained and untrained men. Metabolism. 49:122-128, 2000.

5. Coggan, A. R., C. A. Raguso, B. D. Williams, L. S. Sidossis, and A. Gastaldelli. Glucose kinetics during high-intensity exercise in endurance-trained and untrained humans. ) Appl Physiol. 78:1203-1207, 1995.

6. Coggan, A. R., R. J. Spina, D. S. King, et al. Skeletal muscle adaptations to endurance training in 60- to 70-yr-old men and women. J Appl Physiol. 72:1780-1786, 1992.

7. Coggan, A. R., R. J. Spina, W. M. Kohrt, and J. O. Holloszy. Effect of prolonged exercise on muscle citrate concentration before and after endurance training in men. Am J Physiol. 264:E215-220, 1993.

8. Coggan, A. R., R. J. Spina, M. A. Rogers, et al. Histochemical and enzymatic characteristics of skeletal muscle in master athletes. J Appl Physiol. 68:1896-1901, 1990.

9. Coggan, A. R., S. C. Swanson, L. A. Mendenhall, D. L. Habash, and C. L. Kien. Effect of endurance training on hepatic glycogenolysis and gluconeogenesis during prolonged exercise in men. Am J Physiol. 268:E375-383, 1995.

10. Crampes, F., D. Riviere, M. Beauville, M. Marceron, and M. Garrigues. Lipolytic response of adipocytes to epinephrine in sedentary and exercise-trained subjects: sex-related differences. Eur J Appl Physiol Occup Physiol. 59:249-255, 1989.

11. Despres, J. P., C. Bouchard, R. Savard, A. Tremblay, M. Marcotte, and G. Theriault. Effects of exercise-training and detraining on fat cell lipolysis in men and women. Eur J Appl Physiol Occup Physiol. 53:25-30, 1984.

12. Friedlander, A. L., G. A. Casazza, M. A. Horning, M. J. Huie, and G. A. Brooks. Traininginduced alterations of glucose flux in men. J Appl Physiol. 82:1360-1369, 1997.

13. Goodpaster, B. H., S. W. Park, T. B. Harris, et al. The loss of skeletal muscle strength, mass, and quality in older adults: the health, aging and body composition study. I Gerontol A Biol Sci Med Sci. 61:1059-1064, 2006.

14. Hurley, B. F., P. M. Nemeth, W. H. Martin, 3rd, J. M. Hagberg, G. P. Dalsky, and J. O. Holloszy. Muscle triglyceride utilization during exercise: effect of training. I Appl Physiol. 60:562-567, 1986.

15. Jeukendrup, A. E., A. Raben, A. Gijsen, et al. Glucose kinetics during prolonged exercise in highly trained human subjects: effect of glucose ingestion. J Physiol. 515:579-589, 1999.

16. Jubrias, S. A., P. C. Esselman, L. B. Price, M. E. Cress, and K. E. Conley. Large energetic adaptations of elderly muscle to resistance and endurance training. J Appl Physiol. 90:1663-1670, 2001.

17. Kaczor, J. J., W. Ziolkowski, J. Antosiewicz, S. Hac, M. A. Tarnopolsky, and J. Popinigis. The effect of aging on anaerobic and aerobic enzyme activities in human skeletal muscle. J Gerontol A Biol Sci Med Sci. 61:339-344, 2006. 
Kiens, B., B. Essen-Gustavsson, N. J. Christensen, and B. Saltin. Skeletal muscle substrate utilization during submaximal exercise in man: effect of endurance training. J Physiol. 469:459-478, 1993.

19. Kiens, B., S. Kristiansen, P. Jensen, E. A. Richter, and L. P. Turcotte. Membrane associated fatty acid binding protein (FABPpm) in human skeletal muscle is increased by endurance training. Biochem Biophys Res Commun. 231:463-465, 1997.

20. Kiens, B., C. Roepstorff, J. F. Glatz, et al. Lipid-binding proteins and lipoprotein lipase activity in human skeletal muscle: influence of physical activity and gender. $J A p p l$ Physiol. 97:1209-1218, 2004.

21. Kirkendall, D. T. and W. E. Garrett, Jr. The effects of aging and training on skeletal muscle. Am J Sports Med. 26:598-602, 1998.

22. Klein, S., E. F. Coyle, and R. R. Wolfe. Fat metabolism during low-intensity exercise in endurance-trained and untrained men. Aml J Physiol. 267:E934-940, 1994.

23. Koopman, R., R. J. Manders, R. A. Jonkers, G. B. Hul, H. Kuipers, and L. J. van Loon. Intramyocellular lipid and glycogen content are reduced following resistance exercise in untrained healthy males. Eur I Appl Plysiol. 96:525-534, 2006.

24. Kraniou, G. N., D. Cameron-Smith, and M. Hargreaves. Acute exercise and GLUT4 expression in human skeletal muscle: influence of exercise intensity. I Appl Physiol. 101:934-937, 2006.

25. Leblanc, P. J., K. R. Howarth, M. J. Gibala, and G. J. Heigenhauser. Effects of 7 wk of endurance training on human skeletal muscle metabolism during submaximal exercise. $J$ Appl Physiol. 97:2148-2153, 2004.

26. Manetta, J., J. F. Brun, C. Prefaut, and J. Mercier. Substrate oxidation during exercise at moderate and hard intensity in middle-aged and young athletes vs sedentary men. Metabolism. 54:1411-1419, 2005.

27. Martin, W. H., 3rd, G. P. Dalsky, B. F. Hurley, et al. Effect of endurance training on plasma free fatty acid turnover and oxidation during exercise. Am I Physiol. 265:E708-714, 1993.

28. Petersen, K. F., D. Befroy, S. Dufour, et al. Mitochondrial dysfunction in the elderly: possible role in insulin resistance. Science. 300:1140-1142, 2003.

Phillips, S. M., H. J. Green, M. A. Tarnopolsky, G. F. Heigenhauser, R. E. Hill, and S. M. Grant. Effects of training duration on substrate turnover and oxidation during exercise. J Appl Physiol. 81:2182-2191, 1996.

Pruchnic, R., A. Katsiaras, J. He, D. E. Kelley, C. Winters, and B. H. Goodpaster. Exercise training increases intramyocellular lipid and oxidative capacity in older adults. An I Physiol Endocrinol Metab. 287:E857-862, 2004.

31. Rimbert, V., Y. Boirie, M. Bedu, J. F. Hocquette, P. Ritz, and B. Morio. Muscle fat oxidative capacity is not impaired by age but by physical inactivity: association with insulin sensitivity. Faseb ]. 18:737-739, 2004.

32. Schaart, G., R. P. Hesselink, H. A. Keizer, G. van Kranenburg, M. R. Drost, and M. K. Hesselink. A modified PAS stain combined with immunofluorescence for quantitative analyses of glycogen in muscle sections. Histochem Cell Biol. 122:161-169, 2004.

33. Schrauwen, P., D. P. van Aggel-Leijssen, G. Hul, et al. The effect of a 3-month lowintensity endurance training program on fat oxidation and acetyl-CoA carboxylase-2 expression. Diabetes. 51:2220-2226, 2002.

34. Short, K. R., J. L. Vittone, M. L. Bigelow, et al. Impact of aerobic exercise training on agerelated changes in insulin sensitivity and muscle oxidative capacity. Diabetes, 52:1888 1896, 2003. 

metabolism during exercise in elderly and young subjects. Am / Physiol. 271:E983-989, 1996.

Sial, S, A. R. Coggan, R. C. Hickner, and S. Klein. Training-induced alterations in fat and carbohydrate metabolism during exercise in elderly subjects. Am J Physiol. 274:E785-790, 1998.

37. Tarnopolsky, M. A., C. D. Rennie, H. A. Robertshaw, S. N. Fedak-Tarnopolsky, M. C. Devries, and M. J. Hamadeh. Influence of endurance exercise training and sex on intramyocellular lipid and mitochondrial ultrastructure, substrate use, and mitochondrial enzyme activity. Am J Physiol Regul Integr Comp Physiol. 292:R1271-1278, 2007.

38. Turcotte, L. P., E. A. Richter, and B. Kiens. Increased plasma FFA uptake and oxidation during prolonged exercise in trained vs. untrained humans. An J Physiol. 262:E791-799, 1992.

39. van Loon, L. J., A. E. Jeukendrup, W. H. Saris, and A. J. Wagenmakers. Effect of training status on fuel selection during submaximal exercise with glucose ingestion. J Appl Physiol. 87:1413-1420, 1999.

40. van Loon, L. J., R. Koopman, J. H. Stegen, A. J. Wagenmakers, H. A. Keizer, and W. H. Saris. Intramyocellular lipids form an important substrate source during moderate intensity exercise in endurance-trained males in a fasted state. J Physiol. 553:611-625, 2003.

41. van Loon, L. J., M. Thomason-Hughes, D. Constantin-Teodosiu, et al. Inhibition of adipose tissue lipolysis increases intramuscular lipid and glycogen use in vivo in humans. Am J Physiol Endocrinol Metab. 289:E482-493, 2005.

van Loon, L. J. C., P. L. Greenhaff, D. Constantin-Teodosiu, W. H. M. Saris, and A. J. M. Wagenmakers. The effects of increasing exercise intensity on muscle fuel utilisation in humans. J Physiol. 536:295-304, 2001.

van Loon, L. J. C., R. Koopman, R. Manders, W. van der Weegen, G. P. van Kranenburg, and $H$. A. Keizer. Intramyocellular lipid content in type 2 diabetes patients compared to overweight sedentary men and highly trained endurance athletes. Am J Physiol Endocrinol Metab. 287:E558-E565, 2004. 


\section{Intra-arterial AICA-riboside administration induces NO-dependent vasodilation in vivo in human skeletal muscle}

American Journal of Physiology - Endocrinology and Metabolism 2009; 297:E759-66.
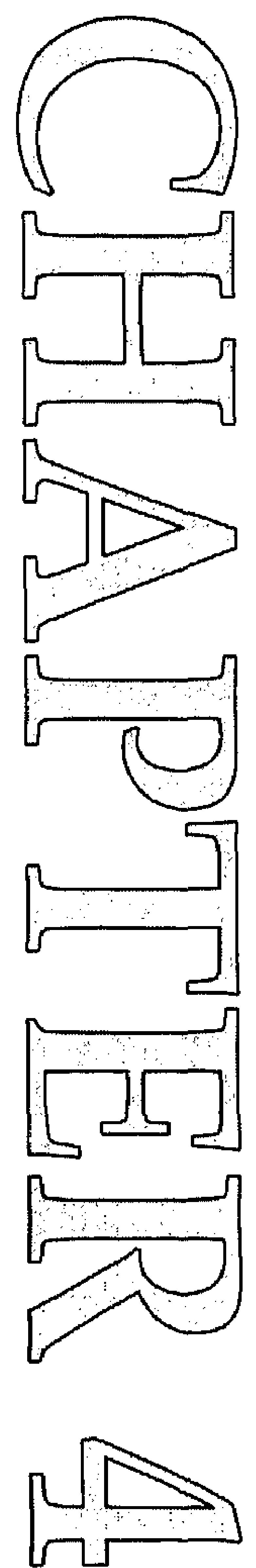


\section{ABSTRACT}

Aim

In animal models, administration of the adenosine analogue AICA-riboside has shown beneficial effects on ischemia-reperfusion injury and glucose homeostasis. The vascular and/or metabolic effects of AICA-riboside administration in humans remain to be established.

\section{Methods}

AICA-riboside was infused intra-arterially in 4 different dosages up to 8 $\mathrm{mg} / \mathrm{min} / \mathrm{dl}$ in 24 healthy subjects. Forearm blood flow (FBF) and glucose uptake, and plasma glucose, free fatty acid and AICA-riboside concentrations were assessed. We also combined AICA-riboside infusion $(2 \mathrm{mg} / \mathrm{min} / \mathrm{dl})$ with the intraarterial administration of the adenosine receptor antagonist caffeine (90 $\mu \mathrm{g} / \mathrm{min} / \mathrm{dl}, \mathrm{n}=6)$ and with the endothelial NO-synthase inhibitor L-NMMA $(0.4$ $\mathrm{mg} / \mathrm{min} / \mathrm{dl}, \mathrm{n}=6$ ). Additional in vitro experiments were performed to explain our in vivo effects of AICA-riboside in humans.

\section{Results}

AICA-riboside increased FBF dose-dependently from $2.0 \pm 0.2$ to $13.2 \pm 1.9$ $\mathrm{ml} / \mathrm{min} / \mathrm{dl}$ maximally ( $P<0.05$ for all dosages). The latter was not reduced by caffeine administration, but significantly attenuated by L-NMMA infusion. Despite high plasma AICA-riboside concentrations, forearm glucose uptake did not change. In vitro experiments showed rapid uptake of AICA-riboside by the equilibrative nucleoside transporter in erythrocytes and subsequent phosphorylation to AICA-ribotide (ZMP).

\section{Conclusion}

AICA-riboside induces a potent vasodilator response in humans, which is mediated by NO. Despite high local plasma concentrations, AICA-riboside does not increase skeletal muscle glucose uptake. 


\section{INTRODUCTION}

The adenosine analogue 5-aminoimidazole-4-carboxamide-riboside (AICAriboside, also known as acadesine) has been shown to improve ischemiareperfusion-injury $(7 ; 17 ; 21)$ and glucose homeostasis in various animal models (19). Although the exact molecular mechanisms remain to be elucidated, it seems evident that AICA-riboside induced activation of AMP-activated protein kinase (AMPK) plays a key role (14). AICA-riboside is taken up by skeletal muscle cells and subsequently phosphorylated by adenosine kinase to AICA-ribotide, or ZMP (8). ZMP is an intermediate of the de novo purine synthesis and is present in very low concentrations in normal cells. ZMP activates AMPK by mimicking the effects of AMP, without disturbing cellular levels of AMP, ADP or ATP (8). AMPK activation has been shown to stimulate endothelial NO-release (15), increase skeletal muscle glucose uptake (14) and inhibit hepatic glucose production (37). Consequently, AMPK represents a promising pharmacological target for the prevention and/or treatment of ischemic heart disease and/or insulin resistance (25).

Both in vitro (14) and in vivo animal studies (19) as well as in vitro human studies (22) have demonstrated that AICA-riboside stimulates GLUT4 translocation to the plasma membrane resulting in greater insulin sensitivity and increased glucose uptake. Until now, only 3 recent studies have described the in vivo metabolic effects of AICA-riboside administration in humans $(1 ; 6 ; 9)$. In our study, we observed a significant decline in plasma glucose concentrations following intravenous AICA-riboside infusion (6). This might, at least partly, be attributed to increased muscle perfusion leading to increased glucose uptake in skeletal muscle $(26 ; 27)$, as AICA-riboside has been suggested to have strong vasodilator properties being an analogue to adenosine (17). Adenosine plays an important role in the regulation of vascular tone and is a potent vasodilator (30). So far, the impact of AICA-riboside administration on blood flow in vivo in humans has not been established. In the present study, we investigated the impact of AICA-riboside administration on skeletal muscle forearm blood flow (FBF) and glucose uptake (FGU) in vivo in healthy humans. Additional in vitro experiments were performed to elucidate the mechanisms responsible for the vasodilator properties of AICA-riboside in vivo in humans. 


\section{METHODS}

\section{Study population}

A total of 32 healthy subjects ( 14 males, 18 females, 4 subjects participated twice) were selected to participate (age: $21.9 \pm 2.2 \mathrm{y}$, BMI: $21.5 \pm 1.7 \mathrm{~kg} / \mathrm{m}^{2}$, means $\pm \mathrm{SD}$ ). The investigation conforms to the principles outlined in the Declaration of Helsinki. The local ethics committee approved the study and all subjects gave their written informed consent.

\section{Protocol and experimental procedure}

AICA-riboside was infused into the brachial artery (perfused forearm model (38), see also below) for $110 \mathrm{~min}$ in 4 doses $(1,2,4$ or $8 \mathrm{mg} / \mathrm{min}$ per dl forearm tissue), each dose in a separate group of 6 volunteers. Hereafter, normal saline was infused intra-arterially for an additional $70 \mathrm{~min}$. The exact dose calculations of AICA-riboside are provided below.

The experiments started at $8.15 \mathrm{AM}$ after an overnight fast in a quiet, temperature controlled room $\left(23-24^{\circ} \mathrm{C}\right)$. The subjects abstained from caffeine and alcohol for at least $24 \mathrm{~h}$ prior to the experiments (29). A catheter (Angiocath: 20-gauge, $48 \mathrm{~mm}$, Becton Dickinson and Co., Sandy, Utah, USA) was inserted into the brachial artery of the non-dominant arm (experimental arm) for intra-arterial infusion of AICA-riboside and for obtaining arterial blood samples. The brachial artery catheter was connected with an arterial pressure monitoring line to a Hewlett Packard 78353 B monitor (Hewlett Packard GmbH, Böblingen Germany) for continuous blood pressure monitoring. In both arms a 20-Gauge catheter was inserted retrograde into a deep forearm vein for blood sampling, enabling measurement of forearm arterio-venous glucose differences ( $\triangle$ GlucA-v) in both arms. Thirty min after complete instrumentation; baseline data (FBF, $\triangle \mathrm{GlucA}-\mathrm{v}$, plasma insulin level, uric acid level and hematocrit) were collected. During administration of the highest dose of AICA-riboside $(8 \mathrm{mg} / \mathrm{min} / \mathrm{dl})$, plasma free fatty acid (FFA), free glycerol, lactate and triglyceride concentrations were also measured $(n=5)$. We used the venous occlusion plethysmography (34) in our experiments to measure baseline forearm blood flow (by a Hokanson EC-4 Plethysmograph) in both arms simultaneously and to measure the local vasodilator response to the administration of AICA-riboside into the brachial artery in one of the two arms. This technique is a well-validated method for these measurements $(3 ; 33)$. Intrabrachial administration of vaso-active drugs results in a high local concentration in the forearm vascular bed, but prevents significant systemic spillover of the drugs and subsequent systemic confounding effects or 
effects on the contra lateral arm. Venous outflow from the forearm is prevented by the placement of a cuff with repetitive inflation around the upper arm using an inclusion pressure of plus minus $40 \mathrm{mmHg}$ (E-20 Rapid Cuff Inflator, Hokanson). The arms are slightly elevated $(10 \mathrm{~cm})$ above heart level. One min before the start of the measurements, wrist cuffs are inflated to $100 \mathrm{mmHg}$ above systolic blood pressure to exclude hand and skin flow to enter the deep venous system at the wrist, because the blood flow in hands is predominantly through skin. The rate of swelling of the forearm, measured with mercury-in-silastic strain gauges, is used to assess FBF. We measured FBF in both arms, but we infused AICA-riboside only in the experimental arm. In the contra lateral arm no AICAriboside was infused and therefore we can use this as the "placebo arm". By using this study model, no other placebo experiments are needed, because the healthy subjects are their own controls.

To further characterize the vasodilator effects of AICA-riboside, we combined intra-arterial AICA-riboside administration $(2 \mathrm{mg} / \mathrm{min} / \mathrm{dl}$ ) with intra-arterial infusion of the adenosine receptor antagonist caffeine $(90 \mu \mathrm{g} / \mathrm{min} / \mathrm{dl}, \mathrm{n}=6)$ or the endothelial NO-synthase inhibitor, $\mathrm{NG}^{\mathrm{G}}$-monomethyl-L-arginine (L-NMMA, 4 $\mathrm{mg} / \mathrm{min} / \mathrm{dl}, \mathrm{n}=6$ ). In the caffeine experiment, we used the same experimental procedure as described above, with the exception that after $90 \mathrm{~min}$ of AICAriboside infusion, caffeine was concomitantly infused for $15 \mathrm{~min}$ to inhibit adenosine-induced vasodilation. We have recently demonstrated that this intraarterial dose of caffeine is effective in reducing adenosine-induced vasodilation $(28 ; 29)$. AICA-riboside in a dose of $2 \mathrm{mg} / \mathrm{min} / \mathrm{dl}$ showed approximately the same increase in FBF as adenosine in this study (28). In the experiments with L-NMMA (Clinalpha, Laufelfingen, Switzerland), we started first with $15 \mathrm{~min}$ of L-NMMA to completely inhibit NO-synthase. Hereafter, we infused AICA-riboside for 110 min. Every $15 \mathrm{~min}$ we combined AICA-riboside administration with L-NMMA ( $\mathrm{T}=15-30, \mathrm{~T}=45-60$ and $\mathrm{T}=75-90 \mathrm{~min}$ ). We recently described that this dose of $\mathrm{L}$ NMMA (4 mg/min/dl) maximally inhibits endothelial NO-synthase in the human forearm (35).

\section{AICA-riboside dose calculation}

AICA-riboside has been administered intravenously to healthy subjects $(12 ; 13)$ and to patients with cardiac disease $(10 ; 24)$ in studies regarding ischemic protection during major surgery. All dosages were well tolerated. Studies suggested that dosages up to 8 gram over $30 \mathrm{~min}$ do not impose any health risk (13). Assuming a baseline FBF of $2 \mathrm{ml} / \mathrm{min} / \mathrm{dl}$ (and plasma flow $\sim 1 \mathrm{ml} / \mathrm{min} / \mathrm{dl}$ ), an infusion rate of $1 \mathrm{mg} / \mathrm{min} / \mathrm{dl}$ would result in a local plasma AICA-riboside concentration of $1 \mathrm{mg} / \mathrm{ml}$, equalling $3.87 \mathrm{mmol} / \mathrm{l}$ (molecular weight 258.24). In 
vitro, AICA-riboside appeared to be pharmacologically active in this range (22). AICA-riboside (Toronto Research Chemicals, Toronto, Canada) was prepared for human use by our department of Clinical Pharmacy and was dissolved in normal saline.

\section{Measurement of AICA-riboside and ZMP concentrations}

In the AICA-riboside experiments $(8 \mathrm{mg} / \mathrm{min} / \mathrm{dl})$, we measured plasma AICAriboside concentrations and AICA-riboside and ZMP concentrations in erythrocytes, in venous blood samples taken from the experimental as well as from the control arm (at $\mathrm{T}=0,5,30,60,90$ and $180 \mathrm{~min}$ ). The erythrocyte data were used as a model for the intracellular handling of AICA-riboside in the vascular wall. One $\mathrm{ml}$ of blood was drawn in lithium-heparin tubes and directly stored on ice. To avoid further uptake or metabolism of AICA-riboside after sampling, the tubes were first filled with dipyridamole (Boehringer Ingelheim, Alkmaar, The Netherlands. Used concentrations were based on our own measurements, see Results section and figure 6) and A-13497, final blood concentration $25 \mu \mathrm{M}$ and $225 \mathrm{nM}$ respectively. Dipyridamole inhibits the endogenous equilibrative nucleoside transporter (ENT) and was found to block AICA-riboside uptake in erythrocytes (vide infra). A-13497 blocks adenosine kinase, an enzyme that converts AICA-riboside into ZMP. Erythrocytes were washed twice in normal saline and lysed with 10 volumes aqua pure (cold). Lysed erythrocytes and plasma were stored at $-80^{\circ} \mathrm{C}$ until final analysis.

\section{In vitro characterisation of AICA-riboside uptake in cells}

In additional in vitro experiments we further characterized the AICA-riboside uptake by erythrocytes. Assuming that AICA-riboside is taken up by the ENT, we measured intracellular AICA-riboside and ZMP concentrations under varying concentrations of the ENT inhibitor dipyridamole. We incubated at $37^{\circ} \mathrm{C}$ washed erythrocytes (50 $\mu$ l of $20 \%$ erythrocytes added to MOPS buffer (3-[Nmorpholino] propanesulfonic acid)) with dipyridamole (concentration range 0-50 $\mu \mathrm{M}) 5 \mathrm{~min}$ before adding $3 \mathrm{mM}$ AICA-riboside. After $5 \mathrm{~min}, 250 \mu \mathrm{M}$ dipyridamole was added to block the uptake of AICA-riboside completely and immediately stored on ice.

\section{Laboratory measurements and analysis}

Plasma glucose concentrations were measured by the glucose oxidation method (Beckman Glucose Analyzer II; Beckman, Fullerton, CA). Plasma Insulin was assessed in duplicate against IS $83 / 500$ by an in-house radioimmunoassay (RIA) 
using an anti-human insulin antiserum raised in guinea-pig and radio-iodinated human insulin as a tracer. Bound/free separation was carried out by addition of sheep anti-guinea-pig antiserum and precipitation by means of polyethylene glycol (PEG). Between- and within-run CV's were $4.6 \%$ and $5.8 \%$ respectively, at a level of $33 \mathrm{mU} / \mathrm{L}$.

At the highest AICA-riboside dose, blood was collected for determination of plasma FFA, glycerol, triglyceride and lactate concentrations by regular assays. Plasma AICA-riboside concentrations and AICA-riboside and ZMP levels in the erythrocytes were determined by high-performance liquid chromatography (HPLC) with ultraviolet detection set at $260 \mathrm{~nm}$. The used column was Hypersil BDS C18 $5 \mu 200 \times 4.6 \mathrm{~mm}$ (Thermo Quest). The mobile phase consisted of methanol, $10 \mathrm{mmol} / \mathrm{l}$ tetrabuthylammonium hydrogen sulphate and $5 \mathrm{mmol} / \mathrm{l}$ $\mathrm{K}_{2} \mathrm{HPO}_{4}$, pH $8.2(20: 80$, v/v). For the in vitro experiments, the AICA-riboside concentration in the supernatant was determined with HPLC, by use of a Polaris column. The mobile phase consisted of methanol, $50 \mathrm{mmol} / \mathrm{l} \mathrm{NH}_{4} \mathrm{H}_{2} \mathrm{PO}_{4}$ and 5 $\mathrm{mmol} / \mathrm{l}$ hexanesulfonic acids, $\mathrm{pH} 3.0(2: 98, \mathrm{v} / \mathrm{v})$. Plasma caffeine concentrations were determined by use of reversed-phase HPLC with ultraviolet detection set at $273 \mathrm{~nm}$.

\section{Calculations and statistical analysis}

FBF registrations of the last $2 \mathrm{~min}$ were averaged to a single value. FGU was calculated from $\triangle$ Gluc A-v and FBF, assuming that:

Whole blood glucose $=\quad(1-[0.3 \times$ Hematocrit $]) \times$ plasma blood glucose $(11)$ FGU =

$\triangle$ Gluc A-v $\times(1-[0.3 \times$ Hematocrit $]) \times \mathrm{FBF}$

All data are expressed as means $\pm S E M$, unless otherwise indicated. To detect changes in plasma metabolite concentrations and hemodynamic values over time, a repeated-measures ANOVA was applied. A Scheffé post hoc test was applied in cases of a significant $F$ ratio, to detect specific differences. A $P$ value of less than 0.05 was considered significant.

\section{RESULTS}

\section{Hemodynamic effects of AICA-riboside}

AICA-riboside induced a time- and dose-dependent vasodilation in the experimental arm only. From baseline to the end of the infusion (110 min), AICAriboside increased FBF for each of the 4 doses (all $P<0.05$, Figure 1, top). After discontinuation of AICA-riboside, FBF declined and returned towards baseline 
values. FBF in the contra lateral arm did not increase during AICA-riboside infusion at any of the 4 dosages (Figure 1, middle panel). Fifteen min of LNMMA infusion induced vasoconstriction $(1.6 \pm 0.2$ to $1.2 \pm 0.2 \mathrm{ml} / \mathrm{min} / \mathrm{dl}, P<0.05)$. During concomitant AICA-riboside infusion $(2 \mathrm{mg} / \mathrm{min} / \mathrm{dl})$, L-NMMA attenuated the vasodilator response to AICA-riboside significantly compared with the experiments with AICA-riboside (2 $\mathrm{mg} / \mathrm{min} / \mathrm{dl}$ ) only (Figure 2). Concomitant infusion of caffeine did not alter the vasodilator response to AICA-riboside. In this series, AICA-riboside $(2 \mathrm{mg} / \mathrm{min} / \mathrm{dl})$ infusion alone ( $\mathrm{T}=0$ $\min$ to $T=90$ ) induced a significant vasodilator response from $2.4 \pm 0.3$ to $5.7 \pm 0.7$ $\mathrm{ml} / \mathrm{min} / \mathrm{dl}$. After $15 \mathrm{~min}$ of concomitant caffeine infusion ( $\mathrm{T}=90$ to $\mathrm{T}=105 \mathrm{~min}$ ), FBF amounted to $5.0 \pm 0.8 \mathrm{ml} / \mathrm{min} / \mathrm{dl}$ (NS). Basal plasma caffeine concentrations were $0.1 \pm 0.1 \mathrm{mg} / \mathrm{l}$ and increased significantly to $10.0 \pm 1.9 \mathrm{mg} / \mathrm{l}$ in the experimental and to $0.3 \pm 0.1 \mathrm{mg} / \mathrm{l}$ in the control arm.
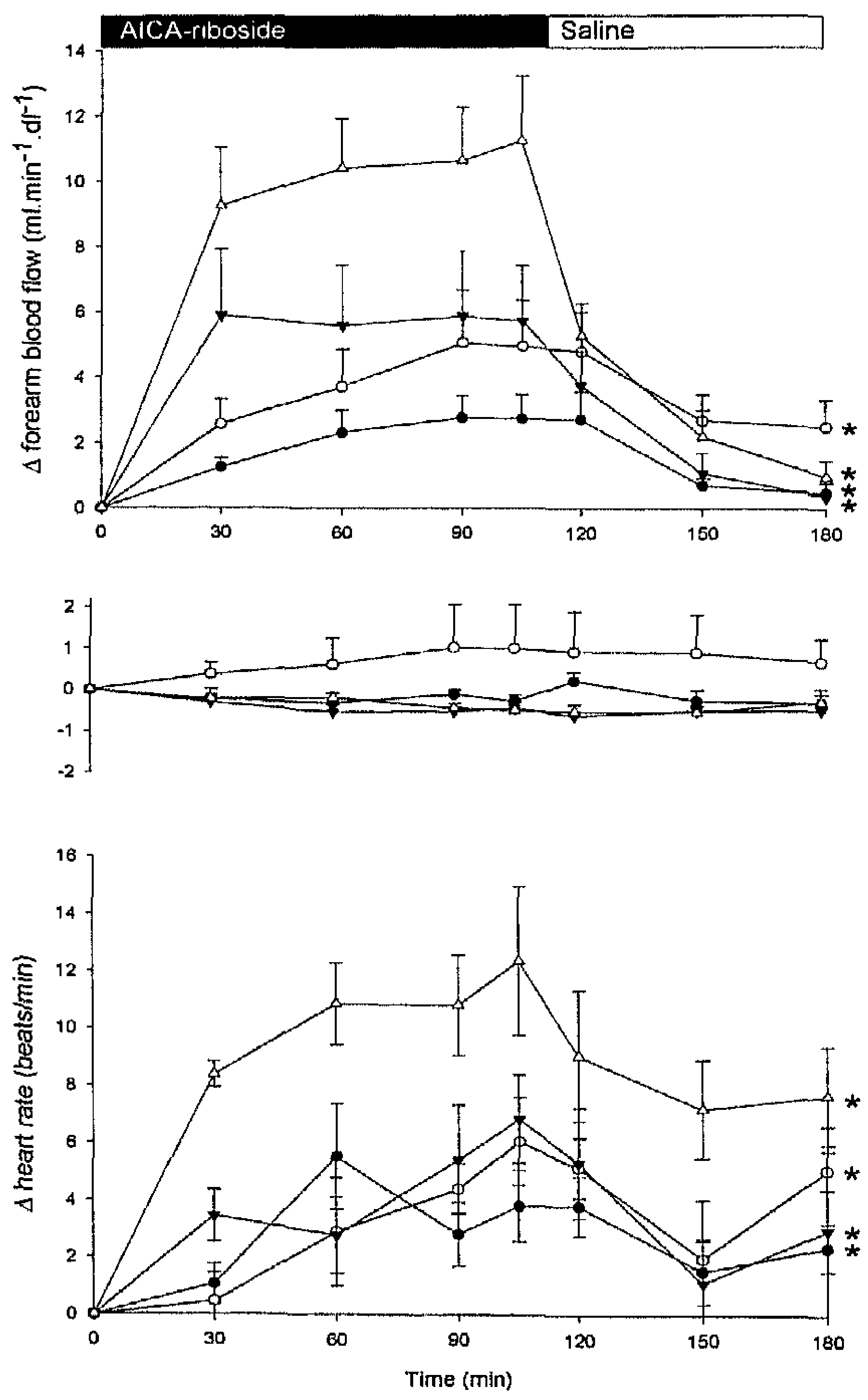

Figure 1: Mean ( $\triangle \mathrm{SEM}$ ) absolute change in forearm blood flow of the experimental arm (upper panel), control arm (middle panel) and heart rate (lower panel) during the 4 dosages of AICA-riboside. *Indicates significant changes during AICA-riboside infusion ( $t=0$ to $t=$ $110 \mathrm{~min}, P<0.05$ ). 
Figure 2 Mean $( \pm$ SEM) absolute change in forearm blood flow of the experimental arm during AICA-riboside $(2 \mathrm{mg} / \mathrm{min} / \mathrm{dl})$ only and during concomitant infusion with L-NMMA (4 $\mathrm{mg} / \mathrm{min} / \mathrm{dl}$ ).

L-NMMA infusion periods are marked with black bars. ${ }^{*} \mathrm{~L}-$ NMMA significantly

attenuated the increase in FBF compared with AICA-riboside only $(P<0.05)$.

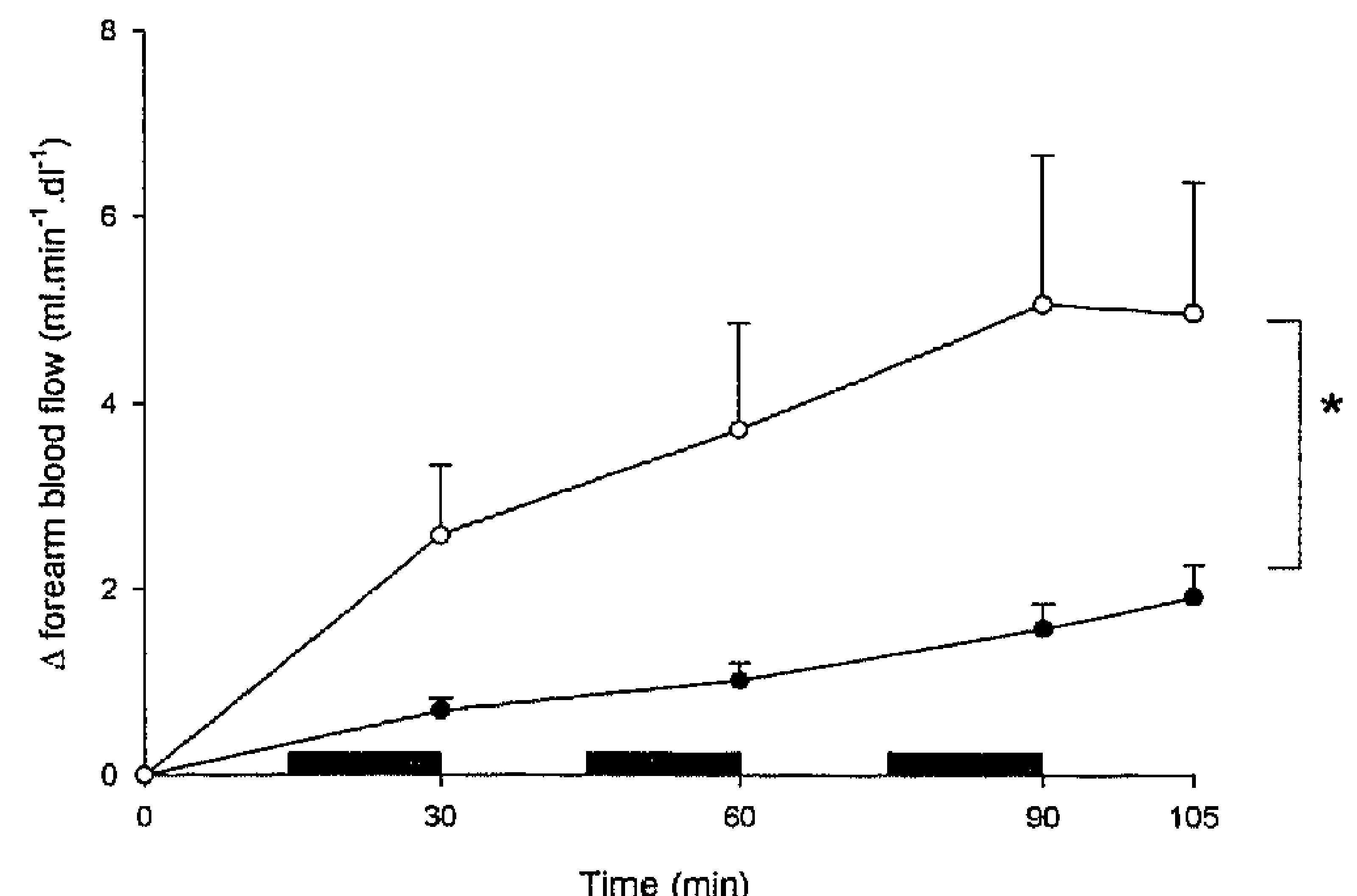

AICA-riboside infusion had no effect on blood pressure (MAP was $78 \pm 1 \mathrm{mmHg}$ at baseline versus $78 \pm 2 \mathrm{mmHg}$ at the end of the highest dose of AICA-riboside, $P=\mathrm{NS}$ ), but heart rate increased significantly following AICA-riboside administration in all 4 dosages (Figure 1, bottom).

\section{Metabolic effects of AICA-riboside}

Arterial ( $=$ systemic) plasma glucose levels decreased from $4.9 \pm 0.1$ to $4.4 \pm 0.1$ $\mathrm{mmol} / \mathrm{l}$ (pooled data, $n=24, P<0.001$ ) after $110 \mathrm{~min}$ of AICA-riboside infusion. This decrease was not strictly dose-dependent, although the most pronounced results were obtained at the highest dose $(P<0.05$ for 2 and $8 \mathrm{mg} / \mathrm{min} / \mathrm{dl}$, and $P=0.06$ for 4 $\mathrm{mg} / \mathrm{min} / \mathrm{dl}$, Figure 3, top). The decrease in systemic plasma glucose concentrations at the highest dose of AICA-riboside was most pronounced after $60 \mathrm{~min}$. After discontinuation of AICA-riboside administration, arterial plasma glucose levels returned towards baseline values in all dosages (pooled data, $n=24$, $P=0.4$ versus baseline values). Venous blood glucose levels decreased in parallel to those of the arterial blood, both in the experimental and control arm (Figure 3, middle and bottom, $P<0.05$ for AICA-riboside in the dose of 4 and $8 \mathrm{mg} / \mathrm{min} / \mathrm{dl}$ ). As a result, $\triangle$ Gluc $A-V$ decreased and as such, intrabrachial AICA-riboside infusion had no effect on the calculated FGU in all dosages. Figure 4 shows $\Delta$ Gluc A-v and FGU-data for the highest dose of AICA-riboside. During this experiment, FGU did not increase compared with the control arm. Comparable observations were obtained for all lower AICA-riboside dosages.

Plasma insulin concentrations increased significantly after $\mathrm{T}=90$ and $\mathrm{T}=120 \mathrm{~min}$ in the experiments with AICA-riboside in a dosage of $4 \mathrm{mg} / \mathrm{min} / \mathrm{dl}$. During the highest dose of AICA-riboside, insulin levels decreased significantly from $37 \pm 7$ at 
baseline to a nadir of $26 \pm 5 \mathrm{pmol} / \mathrm{l}$ at $\mathrm{T}=180 \mathrm{~min}(\mathrm{P}=0.002)$. In the other experiments, insulin levels did not change significantly.

During administration of the highest AICA-riboside dose, arterial plasma FFA concentrations decreased significantly. The latter was most pronounced after 60
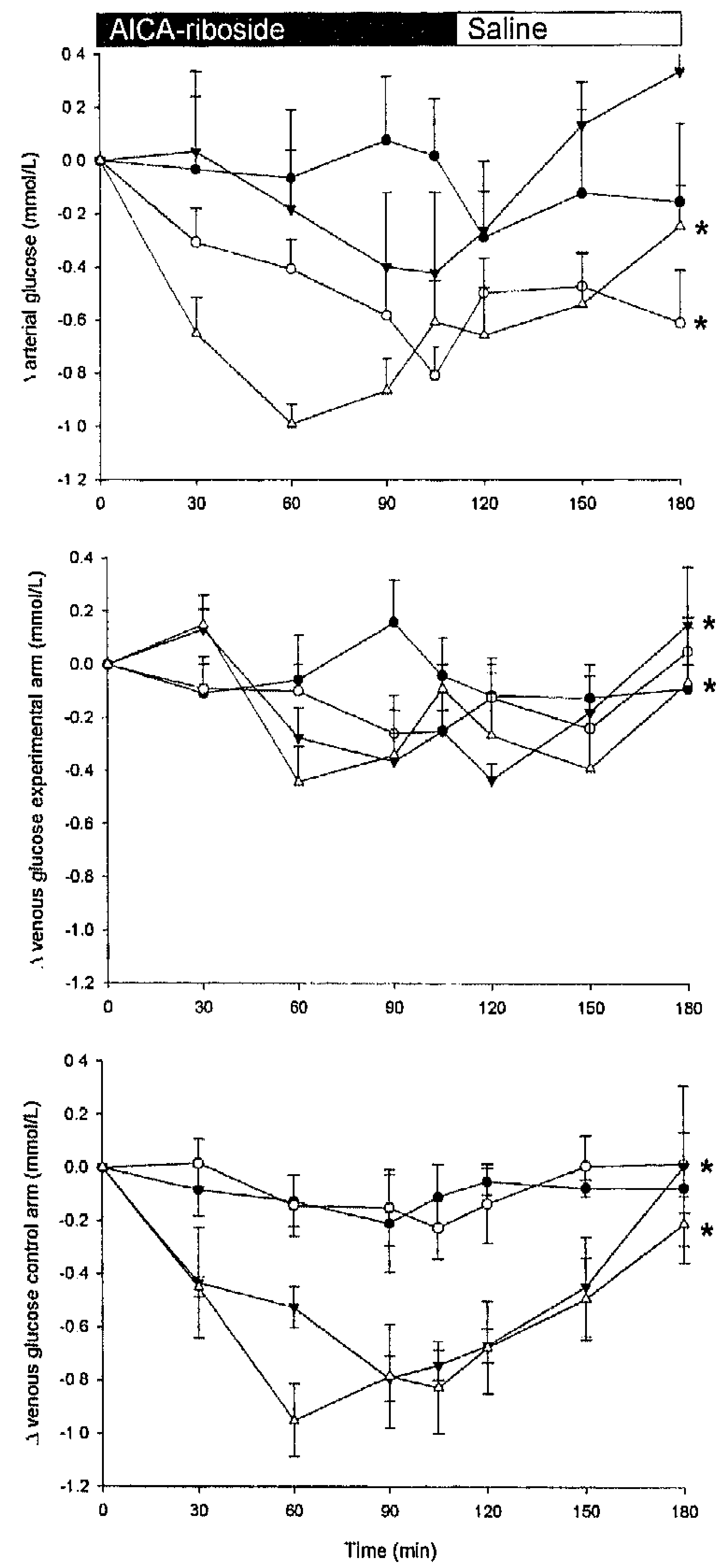

Figure 3: Upper panel : mean ( \pm SEM) absolute change in arterial glucose levels (in mmol/l) at the experimental arm. Middle and lower panel: absolute change in venous glucose levels at the experimental and control arm (resp.) at the 4 doses of AICA-riboside. *Indicates significant changes over time during AICA-riboside infusion $(P<0.05)$. 
min of infusion (Figure 5). Both venous plasma FFA levels decreased in parallel to those of the arterial blood. There was a significant increase in plasma lactate concentrations both at the venous and arterial sites (for all $P<0.05$ compared to baseline values). Peak concentrations were reached at $\mathrm{T}=150 \mathrm{~min}$ (Figure 5). Plasma glycerol and total triglyceride concentrations decreased during AICAriboside infusion ( $P<0.05$ to baseline for the arterial values).

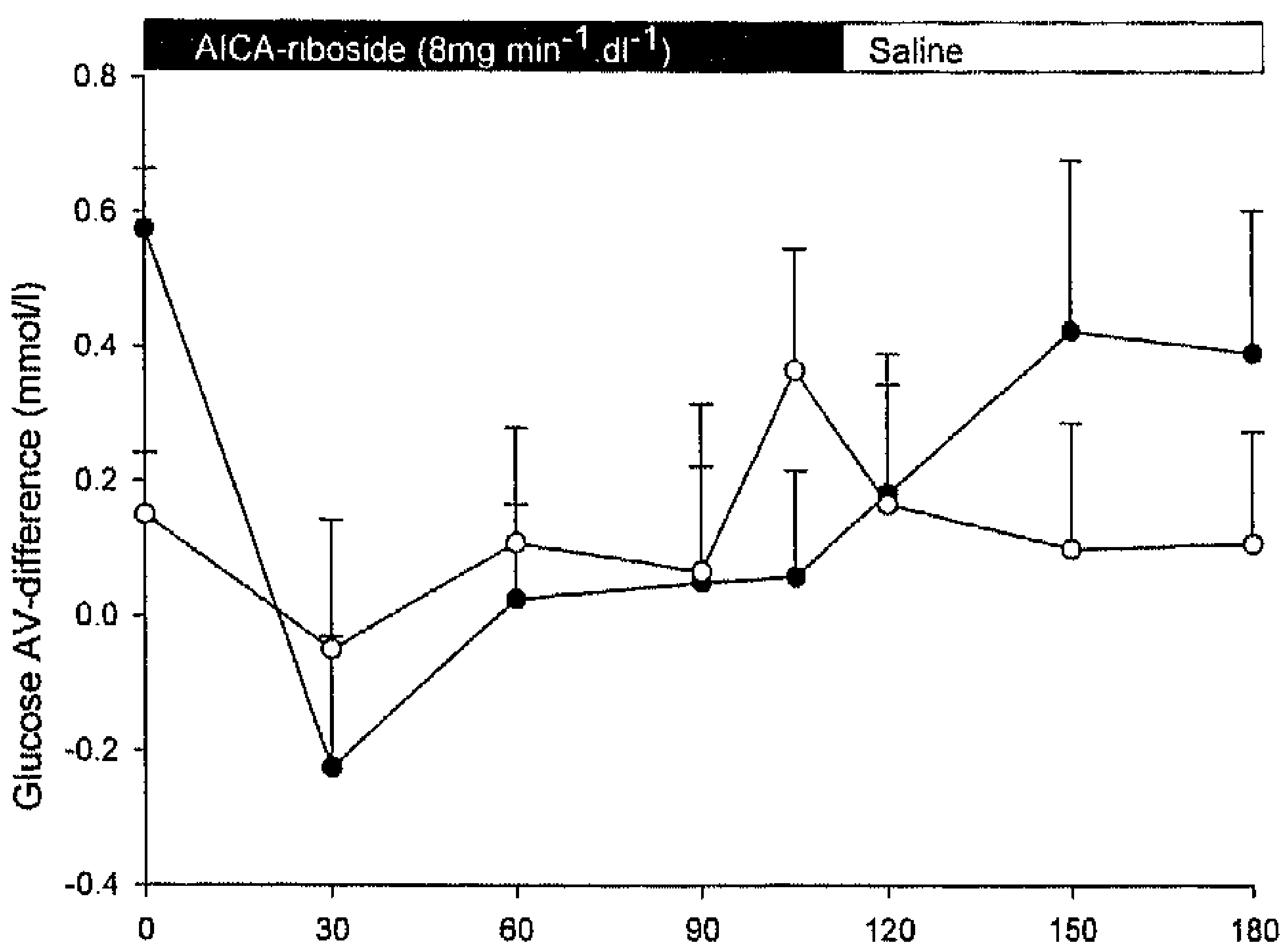

Figure 4: Mean values $( \pm$ SEM) of arterio-venous glucose difference (upper panel) and of forearm glucose uptake (FGU, lower panel) before, during and after infusion of AICA-riboside $(8 \mathrm{mg} / \mathrm{min} / \mathrm{dl})$.

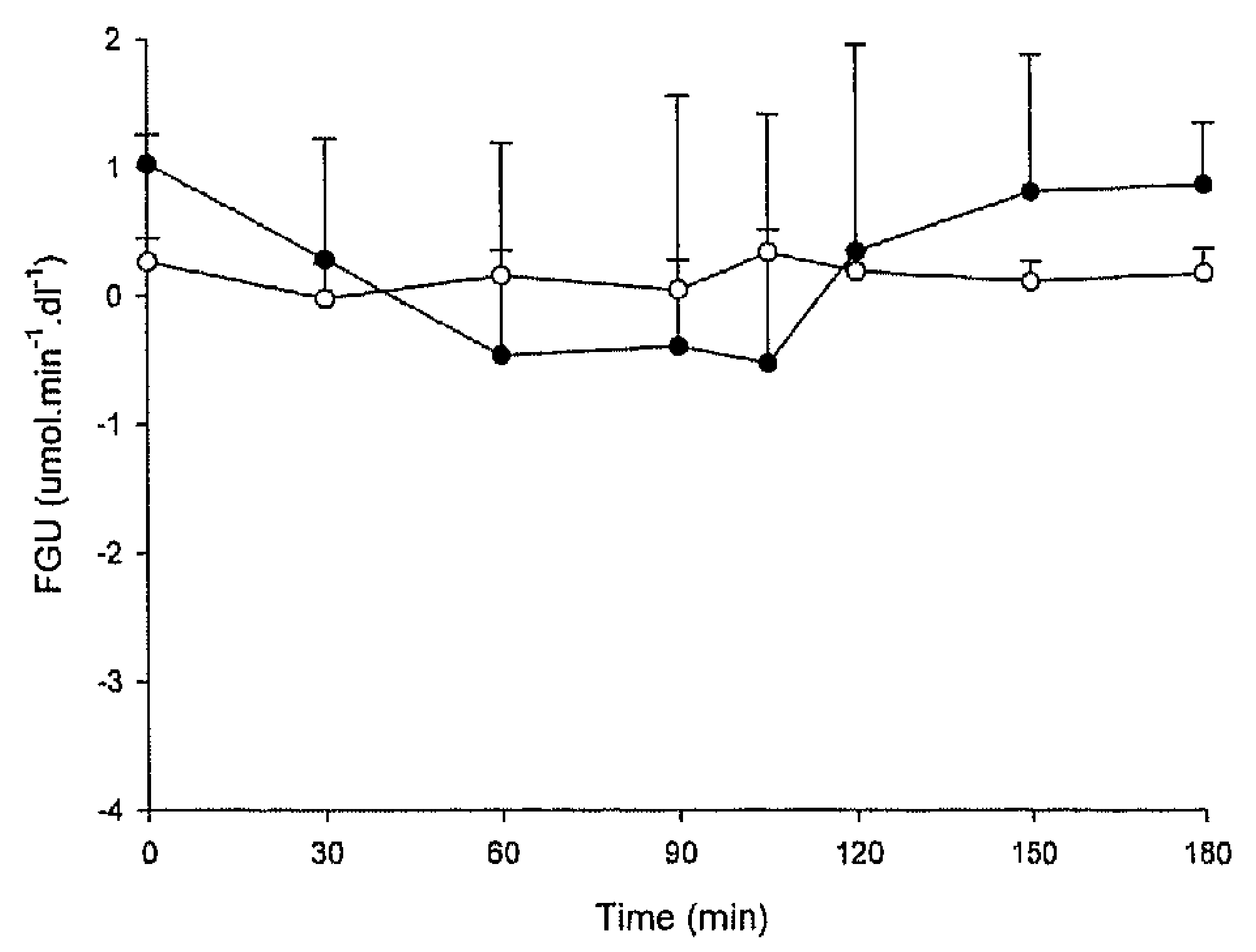

\section{AICA-riboside and ZMP concentrations}

During AICA-riboside infusion at the highest dosage of $8 \mathrm{mg} / \mathrm{min} / \mathrm{dl}$, we observed a strong significant increase in venous plasma and erythrocytes AICAriboside concentrations at the experimental arm (Table 1, $n=5$ ). At the control side, 
venous plasma and erythrocytes AICA-riboside concentration increased significantly, but not as pronounced when compared to the experimental arm. After discontinuation of AICA-riboside, plasma and erythrocytes AICA-riboside concentrations of both arms decreased. The phosphorylated form of AICAriboside (ZMP) increased gradually over time, similarly at both sides. Intracellular ZMP levels remained unchanged up to 70 min after discontinuation of AICA-riboside infusion. At lower dosages of AICA-riboside (1, 2 and 4 $\mathrm{mg} / \mathrm{min} / \mathrm{dl}$ ), we observed a comparable and dose-dependent pattern of AICAriboside and ZMP accumulation in erythrocytes (data not shown).

Table 1: AICA-riboside and ZMP concentrations

\begin{tabular}{lllllll}
\multicolumn{7}{c}{ Intra-arterial infusion of AICAR $(8 \mathrm{mg} / \mathrm{min} / \mathrm{dl})$} \\
\hline Ipsilateral sample: & \multicolumn{7}{c}{} & & & \\
& Baseline $5 \mathrm{~min}$ & $30 \mathrm{~min}$ & $60 \mathrm{~min}$ & $90 \mathrm{~min}$ & $180 \mathrm{~min}$ \\
\hline AICAR (plasma) & zero & $2903 \pm 616$ & $1753 \pm 631$ & $1827 \pm 437$ & $2372 \pm 725$ & $85 \pm 16$ \\
AICAR (cells) & zero & $1315 \pm 260$ & $991 \pm 299$ & $1114 \pm 231$ & $1320 \pm 264$ & $45 \pm 10$ \\
ZMP (cells) & zero & $95 \pm 16$ & $221 \pm 35$ & $396 \pm 37$ & $537 \pm 59$ & $511 \pm 61$ \\
\hline \multicolumn{7}{c}{ Contralateral sample: } \\
AICAR (plasma) & zero & $41 \pm 6$ & $57 \pm 7$ & $72 \pm 8$ & $91 \pm 10$ & $17 \pm 4$ \\
AICAR (cells) & zero & $10 \pm 2$ & $21 \pm 4$ & $28 \pm 2$ & $45 \pm 7$ & $7 \pm 1$ \\
ZMP (cells) & zero & $22 \pm 2$ & $153 \pm 12$ & $300 \pm 34$ & $487 \pm 10$ & $528 \pm 37$ \\
\hline
\end{tabular}

AICA-riboside concentrations (in $\mu \mathrm{M}$ ) in plasma and AICA-riboside and ZMP concentrations (in $\mu \mathrm{M}$ ) in erythrocytes at the highest dose of AICA-riboside ( $\left.8 \mathrm{mg} \cdot \mathrm{min}^{-1} \cdot \mathrm{dl}^{-1}\right)$. Venous blood samples were taken from the experimental arm (= ipsilateral sample) and the control arm (= contralateral sample). AICA-riboside was infused intra-arterially from $T=0$ to $T=110 \mathrm{~min}$. All values are significantly different from baseline concentrations $(P<0,05)$. AICAR $=$ AICA-riboside, $\mathrm{ZMP}=$ AICA-ribotide 

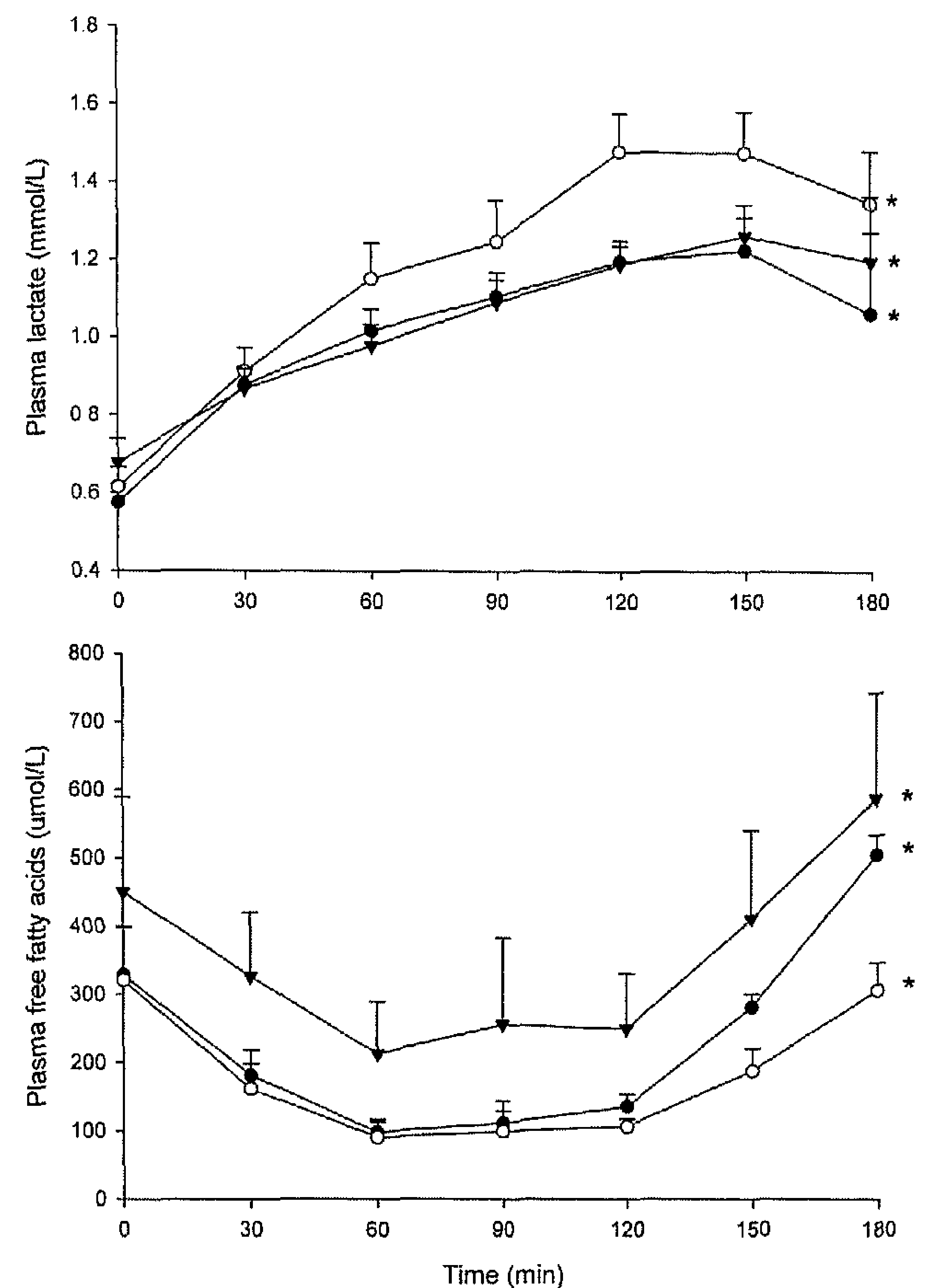

Figure 5: Top: plasma lactate concentrations in mmol/l. Bottom: plasma free fatty acid concentrations in $\mu \mathrm{mol} / \mathrm{l}$ in response to AICA-riboside infusion $(8 \mathrm{mg} / \mathrm{min} / \mathrm{dl})$. ${ }^{*}$ Indicates significant changes over time during AICA-riboside infusion $(P<0.05)$.

\section{AICA-riboside uptake experiments (in vitro)}

Accumulation of AICA-riboside and ZMP in erythrocytes was completely inhibited by increasing concentrations of dipyridamole, a well-documented inhibitor of the ENT (Figure 6), confirming that AICA-riboside is taken up by the dipyridamole-sensitive ENT. At a concentration of $-4.6 \log (=25 \mu \mathrm{M})$ of dipyridamole, the uptake of AICA-riboside is completely inhibited. 


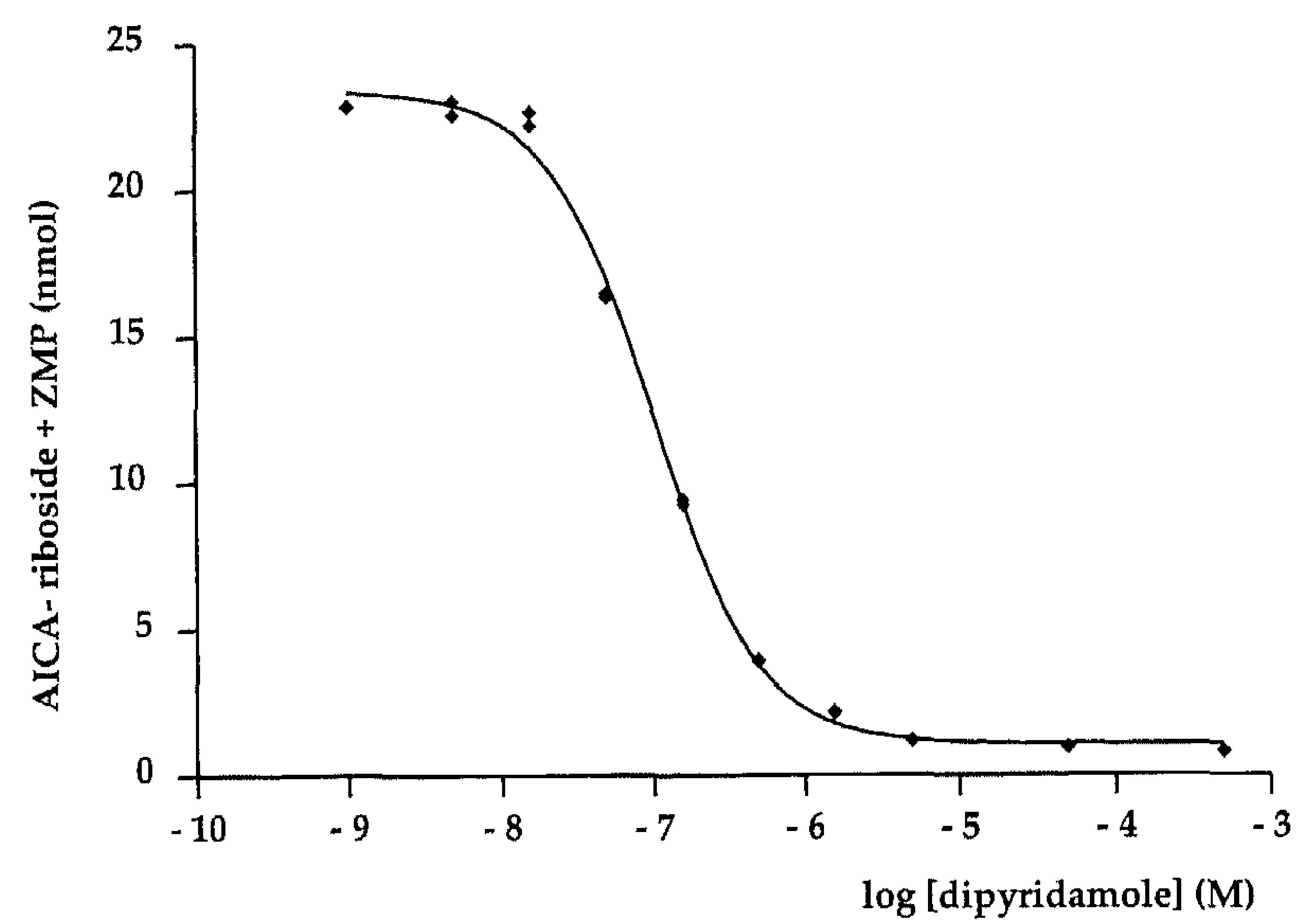

Figure 6: Effect of the adenosine uptake inhibitor dipyridamole on the uptake of AICA- riboside into erythrocytes.

\section{Side effects}

No side effects of AICA-riboside were reported, except for one subject following infusion with the highest AICA-riboside dose. The latter reported minor headache and some nausea after the experiment. These complaints disappeared spontaneously after leaving the clinical research centre. Uric acid, an end product of purine metabolism, increased in plasma $(P<0.05$ when compared with baseline values in all 4 dosages, table 2).

Table 2: Uric acid levels (in mmol/l) in the 4 different doses of AICA-riboside

\begin{tabular}{llll}
\hline & Baseline & $\mathrm{T}=120 \mathrm{~min}$ & $\mathrm{~T}=180 \mathrm{~min}$ \\
\hline AICA-riboside $1 \mathrm{mg} / \mathrm{min} / \mathrm{dl}$ & $0.22 \pm 0.03$ & $0.26 \pm 0.03^{*}$ & $0.26 \pm 0.03^{*}$ \\
AICA-riboside $2 \mathrm{mg} / \mathrm{min} / \mathrm{dl}$ & $0.19 \pm 0.01$ & $0.31 \pm 0.02^{*}$ & $0.31 \pm 0.02 *$ \\
AICA-riboside $4 \mathrm{mg} / \mathrm{min} / \mathrm{dl}$ & $0.21 \pm 0.03$ & $0.43 \pm 0.03^{*}$ & $0.44 \pm 0.03 *$ \\
AICA-riboside $8 \mathrm{mg} / \mathrm{min} / \mathrm{dl}$ & $0.21 \pm 0.02$ & $0.59 \pm 0.02 *$ & $0.67 \pm 0.02 *$ \\
\hline
\end{tabular}

Reference value for uric acid is $0.15-0.4 \mathrm{mmol} / \mathrm{l}$. *Indicates $P<0.05$ compared to baseline values. 


\section{DISCUSSION}

The main findings of our human in vivo study are: 1) intra-arterial AICA-riboside infusion induces a potent, time and dose-dependent vasodilation in the skeletal muscle vascular bed, 2) this vasodilator effect is mediated by endothelial NOrelease, but not by adenosine receptor stimulation, 3) AICA-riboside does not increase forearm glucose uptake, and 4) AICA-riboside is rapidly taken up by the dipyridamole-sensitive equilibrative nucleoside transporter in erythrocytes (and probably likewise in endothelial and vascular smooth muscle cells).

In the present study, we demonstrate that AICA-riboside induces a strong, time and dose-dependent vasodilation in skeletal muscle tissue. At the highest administration dose, AICA-riboside administration increases blood flow more than 6 fold when compared with baseline values. And even at the lowest dosage, this increase is still substantial with a more than 2 fold increase in blood flow. At low dosages, this vasodilator effect is gradual and plateaus after $\sim 90 \mathrm{~min}$, but at higher dosages the maximum effect is reached earlier ( $30 \mathrm{~min})$. This time course argues against increased adenosine levels in blood (17) by AICA-riboside or a direct binding of AICA-riboside to the adenosine receptor, as intra-arterial adenosine infusion triggers a prompt vasodilation (30). This finding is in accordance with our observation that the adenosine receptor antagonist caffeine, in the same dose that blunted adenosine-induced vasodilation $(28 ; 29)$, failed to reduce the vasodilator response to AICA-riboside.

Theoretically, AICA-riboside may be taken up by endothelial or smooth muscle cells by the Endogenous Nucleoside Transporter (ENT). Once intracellular, it it phosphorylated to ZMP and may bind to AMPK and subsequently decrease vascular tone. Whether AICA-riboside is taken up by endothelial cells was not determined in the present study. However, in a subset of experiments we were able to measure a dose-dependent accumulation of AICA-ribotide (ZMP) in red blood cells consistent with cellular AICA-riboside uptake and subsequent phosphorylation (see table 1, data not shown for the lower dosages). We observed that the uptake of AICA-riboside was inhibited by dipyridamole, a welldocumented inhibitor of the ENT, confirming that AICA-riboside, just as adenosine (16), is taken up by the ENT. The uptake of AICA-riboside and the subsequent phosphorylation to ZMP in endothelial cells may also be important with respect to the slowly progressive vasodilator response after AICA-riboside. During the course of the AICA-riboside infusion, the vasodilator pattern correlates more with the rising intracellular AICA-riboside concentration (and subsequent activation of AMPK) in erythrocytes (and probably vis-à-vis also in locally exposed endothelial cells), than with the intracellular ZMP levels, as 70 
min after the end of the infusion, the FBF was back to baseline levels while the intracellular ZMP-levels remained high, see table 1. In this respect, it is interesting, that animal in vitro data have shown that AMPK activation by AICAriboside induces endothelial release of the endogenous vasodilator substance nitric oxide (15). By additional experiments, we demonstrate that the endothelial NO-synthase inhibitor L-NMMA, attenuated the vasodilator response of AICAriboside, which confirms that the vasodilation induced by AICA-riboside is mediated by release of NO (Figure 2).

Besides the strong increase in blood flow, we also show an obvious increase in heart rate, probably reflecting a baroreceptor-mediated compensation to (generalized and skeletal muscle) vasodilation. Another possibility is that AICAriboside may have a direct effect on the heart (just as adenosine), however we can not measure this in the used study set-up. In previous clinical studies $(10 ; 24)$, AICA-riboside was given as an ischemia-protecting agent in patients undergoing cardiac surgery. AICA-riboside was thought to be effective only in ischemic as opposed to non-ischemic tissue, which was confirmed by one animal in vivo study (20). In these studies, no vasodilator effect or relevant changes in heart rate or blood pressure were reported. Neither were any hemodynamic efforts reported in a previous study that focused on effects of AICA-riboside on skeletal muscle tissue in healthy subjects (9). In short, the present study shows that AICAriboside administration in vivo in humans induces a strong, time and dosedependent vasodilation in non-ischemic skeletal muscle tissue, and also increases heart rate significantly.

Several studies $(2 ; 32)$ have indicated that NO-dependent vasodilation augments nutritive blood flow and subsequently stimulates glucose uptake. The strong NOdependent vasodilator effect of AICA-riboside may thus translate in augmented muscle perfusion and thus in an increase in skeletal muscle glucose uptake. In vitro studies (14) and animal in vivo studies (18) show an increase in glucose uptake by AICA-riboside. However, even though forearm perfusion was increased in our healthy, young subjects, no effects were observed on local skeletal muscle forearm glucose uptake following AICA-riboside infusion. Until now, only 3 recent in vivo studies have investigated the metabolic effects of AICAriboside infusion in humans $(1 ; 6 ; 9)$. We (6) investigated the effects of AICAriboside in patients with type 2 diabetes during continuous i.v. infusion of AICAriboside $(0.75 \mathrm{mg} / \mathrm{kg} / \mathrm{min}$ ) and $\mathrm{NaCl} 0.9 \%$ (placebo controlled) during 2 hours. Stable isotope methodology and blood and muscle biopsy sampling were applied to asses blood glucose and fatty acid kinetics following AICA-riboside infusion. 
We observed that AICA-riboside infusion inhibits hepatic glucose output, while maintaining whole body glucose output, which results in a decrease in systemic glucose levels. Plasma AICA-riboside concentrations increased to $161 \pm 11 \mu \mathrm{mol} / 1$ during AICA-riboside infusion. Cuthbertson et al. investigated the effects of AICA-riboside in healthy subjects (9) and in healthy older subjects with or without type 2 diabetes (1). They $(1 ; 9)$ measured 2-deoxyglucose (2-DG) accumulation in skeletal muscle biopsies during systemic 2-DG infusion. Following AICA-riboside treatment $(10 \mathrm{mg} / \mathrm{kg} / \mathrm{h}$, during $3 \mathrm{~h}$ ), the authors observed a more pronounced increase in 2-DG in healthy humans (9). Furthermore, euglycemic hyperinsulinemic clamping $(n=4$, no control experiments) in combination with AICA-riboside infusion revealed an increase of $7 \%(9.3 \pm 0.6$ to $10 \pm 0.6 \mathrm{mg} / \mathrm{kg} / \mathrm{min}, P<0.05)$ in glucose infusion rate during AICAriboside administration (3-6 h) when compared to insulin administration $(0-3 \mathrm{~h})$. However, such an increase over time is in complete agreement with the slowly increasing glucose infusion observed during prolonged clamping $(5 ; 31)$ and does not indicate a major effect on skeletal muscle. In the second study, the 2-DG uptake was attenuated in older men and in male patients with type 2 diabetes during AICA-riboside infusion $(10 \mathrm{mg} / \mathrm{kg} / \mathrm{h}$ and $20 \mathrm{mg} / \mathrm{kg} / \mathrm{h}$, during $3 \mathrm{~h}$ ). No systemic decrease in glucose levels was observed in both studies $(1 ; 9)$. In the first study (9), AICA-riboside plasma levels reached to $180 \pm 40 \mu \mathrm{mol} / 1$. No changes in skeletal muscle AMPK phosphorylation status and/or AMPK activity were observed following AICA-riboside administration in vivo in humans $(1 ; 6 ; 9)$. However, Cuthbertson et al found increased ERK1/2 phosphorylation and we observed a significant increase in ACC after AICA-riboside infusion. More studies have to be done to evaluate this difference. It is difficult to compare those 3 human in vivo studies with this one, because we infused AICA-riboside intraarterially instead of i.v. Although we used another study set-up, we obtained systemic AICA-riboside levels of maximally $90 \mu \mathrm{mol} / \mathrm{l}$ in the highest dose of AICA-riboside $(8 \mathrm{mg} / \mathrm{min} / \mathrm{dl})$. The locally reached concentrations were much higher. It is notably that we gave AICA-riboside in 4 increasing dosages and that we did not observe any effect of AICA-riboside on skeletal muscle in all 4 dosages.

To understand the discrepancy between the effects of AICA-riboside on blood flow versus glucose uptake, we have extensively explored the local pharmacokinetics after intra-arterial AICA-riboside infusion. We demonstrate that AICA-riboside is rapidly taken up by the dipyridamole-sensitive ENT in erythrocytes. As such, erythrocytes can be considered a representative model for the cellular uptake of AICA-riboside in endothelial and vascular smooth muscle cells, which also contain the same ENT (16). The ENT is also responsible for 
transport of adenosine across membranes (16). Recent human in vivo reports suggest that intra-arterially infused adenosine might not reach skeletal muscle, because erythrocytes, endothelial and vascular smooth muscle layers (in which the ENT is abundantly expressed) function as a sink for adenosine (16). They might act as an effective barrier to adenosine, impeding its diffusion from the intravascular compartment to the interstitial space. As such, AICA-riboside, being transported by the same dipyridamole-sensitive ENT as adenosine (16), may not reach the skeletal muscle tissue either, despite direct intra-arterial infusion. This is also consistent with the findings of a pharmacological study about AICA-riboside in humans (13). They observed that ZMP was trapped in the erythrocytes for several days and could not be metabolized nor diffuse to the extracellular space (13). This might explain the vasodilator effects and the failure of AICA-riboside administration to increase glucose uptake, because no adequate muscle tissue concentrations of AICA-riboside can be obtained, despite local plasma AICAriboside concentrations being 4-5 times higher as compared to animal in vivo studies (4).

Despite the absence of a measurable impact of AICA-riboside administration on skeletal muscle glucose uptake in vivo in humans, we observed a substantial decline in systemic plasma glucose concentrations (Figure 3). The latter seems consistent with previous findings, showing a substantial reduction in plasma glucose concentration following AICA-riboside administration in vivo in animal $(4 ; 18 ; 36)$ and in patients with coronary artery disease $(10)$ and with type 2 diabetes (6). This has been shown to be attributed to the inhibitory effects of AICA-riboside administration on hepatic glucose output $(6 ; 36)$. A possible explanation for the potent effect of AICA-riboside administration on hepatic tissue as opposed to muscle tissue, might be related to the fact that hepatic endothelium is unique, because it has fenestrae, lacks a basal lamina and can transfer molecules and particles by endocytosis (23). The latter might allow a substantial uptake of AICA-riboside in hepatic as opposed to muscle tissue, resulting in greater $A M P K$ stimulation in hepatic tissue.

Our study has some limitations. Although we could not correlate an increase in forearm blood flow in an subsequent rise in glucose uptake, we can not exclude that the increase in forearm blood flow in itself can stimulate glucose uptake in skeletal muscle, as previously described $(2 ; 32)$. Another (possible) limitation of our study is that over activity of the sympathetic nervous system can influence glucose uptake negatively. The observed significant increase in heart rate may also be an expression of this. Unfortunately, no catecholamines have been measured in our study. Thirdly, for safety and ethical reasons, we did not take 
local muscle biopsies of the forearm, thus we were unable to measure AICAriboside uptake and subsequent AMPK phosphorylation in skeletal muscle. Although muscle biopsies might have been very informative about phosphorylation of AMPK and any signaling in skeletal muscle tissue, it should also be realized that the changes might be too limited or too temporary to be detectable.

In conclusion, intra-arterial AICA-riboside in humans induces a potent, time and dose-dependent vasodilation in the skeletal muscle vascular bed. This vasodilation is mediated by release of $\mathrm{NO}$ and not by adenosine receptor stimulation. Despite stimulating skeletal muscle blood flow, AICA-riboside administration does not substantially augment skeletal muscle glucose uptake in vivo in humans.

\section{ACKNOWLEDGEMENTS}

We thank Aarnout Jansen van Roosendaal for his contribution to this work (assistance during experiments). 


\section{REFERENCES}

1. Babraj JA, Mustard K, Sutherland C, Towler MC, Chen S, Smith K, Green K, Leese G, Hardie DG, Rennie MJ and Cuthbertson DJ. Blunting of AICAR-induced human skeletal muscle glucose uptake in type 2 diabetes is dependent on age rather than diabetic status. Am J Physiol Endocrinol Metab 296: E1042-E1048, 2009.

2. Baron $\mathrm{AD}$ and Clark MG. Role of blood flow in the regulation of muscle glucose uptake. Annu Rev Nutr 17: 487-499, 1997.

3. Benjamin N, Calver A, Collier J, Robinson B, Vallance P and Webb D. Measuring forearm blood flow and interpreting the responses to drugs and mediators. Hypertension 25: 918-923, 1995.

4. Bergeron R, Russell RR III, Young LH, Ren JM, Marcucci M, Lee A and Shulman Gr. Effect of AMPK activation on muscle glucose metabolism in conscious rats. Am J Physiol 276: E938-E944, 1999.

5. Boden $G$, Chen X, Kolaczynski JW and Polansky $M$. Effects of prolonged hyperinsulinemia on serum leptin in normal human subjects. J Clin Invest 100: 1107$1113,1997$.

6. Boon H, Bosselaar M, Praet SF, Blaak EE, Saris WH, Wagenmakers AJ, McGee SL, Tack $\mathrm{CJ}$, Smits $\mathrm{P}$, Hargreaves $\mathrm{M}$ and van Loon LJ. Intravenous AICAR administration reduces hepatic glucose output and inhibits whole body lipolysis in type 2 diabetic patients. Diabetologin 51: 1893-1900, 2008.

7. Burckhartt B, Yang XM, Tsuchida A, Mullane KM, Downey JM and Cohen MV. Acadesine extends the window of protection afforded by ischaemic preconditioning in conscious rabbits. Cardiovasc Res 29: 653-657, 1995.

8. Corton JM, Gillespie JG, Hawley SA and Hardie DG. 5-aminoimidazole-4-carboxamide ribonucleoside. A specific method for activating AMP-activated protein kinase in intact cells? Eur J Biochem 229: 558-565, 1995.

9. Cuthbertson DJ, Babraj JA, Mustard KJ, Towler MC, Green KA, Wackerhage H, Leese GP, Baar K, Thomason-Hughes M, Sutherland C, Hardie DG and Rennie MJ. AICAR acutely stimulates skeletal muscle 2-deoxyglucose uptake in healthy men. Diabetes 56 : 2078-84, 2007.

10. de Jonge $R$, Macleod DC, Suryapranata $H$, van Es GA, Friedman J, Serruys PW and de Jong JW. Effect of acadesine on myocardial ischaemia in patients with coronary artery disease. Eur J Pharmacol 337: 41-44, 1997.

11. Dillon RS. Importance of the hematocrit in interpretation of blood sugar. Diabetes 14: 672-674, 1965.

12. Dixon R, Fujitaki J, Sandoval T and Kisicki J. Acadesine (AICA-riboside): disposition and metabolism of an adenosine-regulating agent. J Clin Pharmacol 33: 955-958, 1993.

13. Dixon R, Gourzis J, McDermott D, Fujitaki J, Dewland P and Gruber H. AICA-riboside: safety, tolerance, and pharmacokinetics of a novel adenosine-regulating agent. J Clin Pharmacol 31: 342-347, 1991.

14. Fisher JS, Gao J, Han DH, Holloszy JO and Nolte LA. Activation of AMP kinase enhances sensitivity of muscle glucose transport to insulin. Am I Physiol Endocrinol Metab 282: E18-E23, 2002.

15. Fryer LG, Hajduch E, Rencurel F, Salt IP, Hundal HS, Hardie DG and Carling D. Activation of glucose transport by AMP-activated protein kinase via stimulation of nitric oxide synthase. Diabetes 49: 1978-1985, 2000. 

Biaggioni I. Blockade of nucleoside transport is required for delivery of intra-arterial adenosine into the interstitium: relevance to therapeutic preconditioning in humans. Circulation 108: 2631-2635, 2003.

17. Gruber HE, Hoffer ME, McAllister DR, Laikind PK, Lane TA, Schmid-Schoenbein GW and Engler RL. Increased adenosine concentration in blood from ischemic myocardium by AICA riboside. Effects on flow, granulocytes, and injury. Circulation 80: 1400-1411, 1989.

18. Iglesias MA, Furler SM, Cooney GJ, Kraegen EW and Ye JM. AMP-activated protein kinase activation by AICAR increases both muscle fatty acid and glucose uptake in white muscle of insulin-resistant rats in vivo. Diabetes 53: 1649-1654, 2004.

19. Iglesias MA, Ye JM, Frangioudakis G, Saha AK, Tomas E, Ruderman NB, Cooney GJ and Kraegen EW. AICAR administration causes an apparent enhancement of muscle and liver insulin action in insulin-resistant high-fat-fed rats. Diabetes 51: 2886-2894, 2002. Ishibashi Y, Quebbeman BB, Duncker DJ, Klassen C and Bache RJ. Acadesine increases blood flow in the collateralized heart during exercise. / Cardiounsc Pharmacol 32: 552-561, 1998.

21. Kingma JG Jr., Simard D and Rouleau JR. Timely administration of AICA riboside reduces reperfusion injury in rabbits. Cardiovasc Res 28: 1003-1007, 1994.

22. Koistinen HA, Galuska D, Chibalin AV, Yang J, Zierath JR, Holman GD and WallbergHenriksson H. 5-amino-imidazole carboxamide riboside increases glucose transport and cell-surface GLUT4 content in skeletal muscle from subjects with type 2 diabetes. Diabetes 52: 1066-1072, 2003.

Malarkey DE, Johnson $\mathrm{K}$, Ryan L, Boorman $G$ and Maronpot RR. New insights into functional aspects of liver morphology. Toxicol Pathol 33: 27-34, 2005.

24. Mangano DT, Miao Y, Tudor IC and Dietzel C. Post-reperfusion myocardial infarction: long-term survival improvement using adenosine regulation with acadesine. J Am Coll Cardiol 48: 206-214, 2006.

25. Moller DE. New drug targets for type 2 diabetes and the metabolic syndrome. Nature 414: 821-827, 2001.

26. Rattigan S, Clark MG and Barrett EJ. Hemodynamic actions of insulin in rat skeletal muscle: evidence for capillary recruitment. Diabetes 46: 1381-1388, 1997.

27. Rattigan S, Wallis MG, Youd JM and Clark MG. Exercise training improves insulinmediated capillary recruitment in association with glucose uptake in rat hindlimb. Diabetes 50: 2659-2665, 2001.

28. Riksen NP, Bosselaar M, Bakker SJ, Heine RJ, Rongen GA, Tack CJ and Smits P. Acute elevation of plasma non-esterified fatty acids increases pulse wave velocity and induces peripheral vasodilation in humans in vivo. Clin Sci (Lond) 113: 33-40, 2007.

29. Smits P, Lenders IW and Thien T. Caffeine and theophylline attenuate adenosineinduced vasodilation in humans. Clin Pharmacol Ther 48: 410-418, 1990.

30. Smits P, Williams SB, Lipson DE, Banitt P, Rongen GA and Creager MA. Endothelial release of nitric oxide contributes to the vasodilator effect of adenosine in humans. Circulation 92: 2135-2141, 1995.

31. Soop M, Nygren J, Brismar $K$, Thorell $A$ and Ljungqvist $O$. The hyperinsulinaemiceuglycaemic glucose clamp: reproducibility and metabolic effects of prolonged insulin infusion in healthy subjects. Clin Sci (Lond) 98: 367-374, 2000.

32. Steinberg $\mathrm{HO}$, Brechtel G, Johnson A, Fineberg $\mathrm{N}$ and Baron AD. Insulin-mediated skeletal muscle vasodilation is nitric oxide dependent. A novel action of insulin to increase nitric oxide release. J Clin Invest 94: 1172-1179, 1994. 
33. Thijssen DH, Bleeker MW, Smits P and Hopman MT. Reproducibility of blood flow and post-occlusive reactive hyperaemia as measured by venous occlusion plethysmography. Clin Sci (Lond) 108: 151-157, 2005.

34. van Ginneken EE, Rongen CA, Russel FG and Smits P. Diadenosine pentaphosphate vasodilates the forearm vascular bed: inhibition by theophylline and augmentation by dipyridamole. Clin Pharmacol Ther 71: 448-456, 2002.

35. Veldman BA, Waanders $M$ and Smits P. Pharmacodynamics of L-NMMA in type 1 diabetes patients and control subjects. J Cardiovasc Pharmacol 44: 231-234, 2004.

36. Vincent MF, Erion MD, Gruber HE and Van den Berghe G. Hypoglycaemic effect of AICAriboside in mice. Diabetologin 39: 11.48-1155, 1996.

37. Vincent MF, Marangos PJ, Gruber HE and Van den Berghe G. Inhibition by AICA riboside of gluconeogenesis in isolated rat hepatocytes. Diabetes 40: 1259-1266, 1991.

38. Whitney RJ. The measurement of volume changes in human limbs. J Physiol 121: 1-27, 1953. 


\section{Intravenous AICAR administration reduces hepatic glucose output and inhibits whole body lipolysis in type 2 diabetic patients}

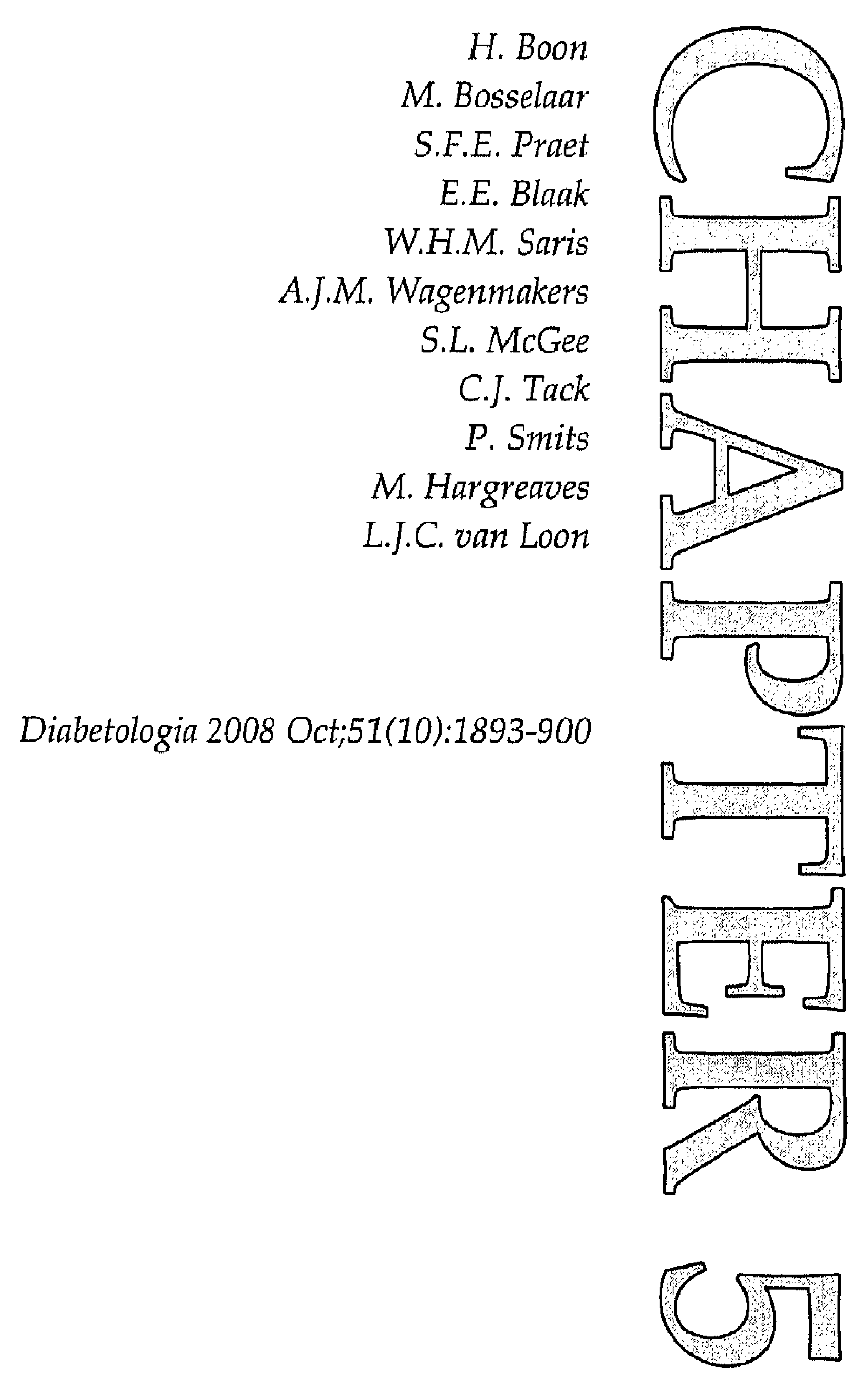




\section{ABSTRACT}

\section{Aims/hypothesis}

The 5'-AMP-activated protein kinase (AMPK) pathway is intact in type 2 diabetic patients and is seen as a target for diabetes treatment. In this study, we aimed to assess the impact of the AMPK activator 5-aminoimidazole-4-carboxamide riboside 5-aminoimidazole-4-carboxamide riboside (AICAR) on both glucose and fatty acid metabolism in vivo in type 2 diabetic patients.

\section{Methods}

Stable isotope methodology and blood and muscle biopsy sampling were applied to assess blood glucose and fatty acid kinetics following continuous i.v. infusion of AICAR $\left(0.75 \mathrm{mg} \mathrm{kg}^{-1} \mathrm{~min}^{-1}\right)$ and/or $\mathrm{NaCl}(0.9 \%)$ in ten male type 2 diabetic patients (age $64 \pm 2$ years; BMI $28 \pm 1 \mathrm{~kg} / \mathrm{m}^{2}$ ).

\section{Results}

Plasma glucose rate of appearance $\left(R_{a}\right)$ was reduced following AICAR administration, while plasma glucose rate of disappearance $\left(R_{\mathrm{d}}\right)$ was similar in the AICAR and control test. Consequently, blood glucose disposal $\left(R_{\mathrm{d}}\right.$ expressed as a percentage of $R_{\mathrm{a}}$ ) was increased following AICAR infusion $(p<0.001)$. Accordingly, a greater decline in plasma glucose concentration was observed following AICAR infusion $(\mathrm{p}<0.001)$. Plasma NEFA $R_{\mathrm{a}}$ and $R_{\mathrm{d}}$ were both significantly reduced in response to AICAR infusion, and were accompanied by a significant decline in plasma NEFA concentration. Although AMPK phosphorylation in skeletal muscle was not increased, we observed a significant increase in acetyl-CoA carboxylase phosphorylation ( $\mathrm{p}<0.001)$.

\section{Conclusions/interpretation}

The i.v. administration of AICAR reduces hepatic glucose output, thereby lowering blood glucose concentrations in vivo in type 2 diabetic patients. Furthermore, AICAR administration stimulates hepatic fatty acid oxidation and/or inhibits whole body lipolysis, thereby reducing plasma NEFA concentration. 


\section{INTRODUCTION}

5'-AMP-activated protein kinase (AMPK) is a key enzyme in the regulation of energy metabolism. It acts as a cellular energy sensor, and is activated by metabolic stress, such as hypoxia, and muscle contraction [1]. AMPK controls both fatty acid and carbohydrate metabolism [2-6] by increasing skeletal muscle glucose $[2,4,6,7]$ and fatty acid $[2,3]$ uptake and/or oxidation, suppression of hepatic glucose output [4] and inhibition of adipose tissue lipolysis [5, 8]. Importantly, AMPK regulates these processes in an insulin-independent manner. The AMPK pathway appears largely intact in obese and/or type 2 diabetic rodents [3, 9-12] and humans [5, 13-16]. Consequently, AMPK is regarded as a potential target for the treatment of type 2 diabetes.

AMPK is activated by 5 -aminoimidazole-4-carboxamide riboside (AICAR) in skeletal muscle [2-4], adipocytes [8] and hepatocytes [17]. Although this agent has been widely used to study the metabolic effects of AMPK activation in rodents [2$4,8,17]$, studies investigating the effect of AICAR on AMPK-regulated substrate metabolism in human tissue are scarce $[13,14,18]$. A recent study investigated the effect of AICAR infusion (10 mg kg-1 $\mathrm{h}^{-1}$ ) on skeletal muscle 2-deoxyglucose uptake in young, healthy males [19]. However, no studies have examined the impact of AICAR on whole body glucose or fatty acid metabolism in humans. Furthermore, the effects of AICAR administration in type 2 diabetic patients remain to be established.

We hypothesize that i.v. AICAR administration in type 2 diabetic patients reduces both plasma glucose and NEFA concentrations by stimulating blood glucose disposal, lowering hepatic glucose output, and inhibiting adipose tissue lipolysis. In the present study, we combine stable isotope methodology with blood and muscle biopsy sampling to determine the effect of i.v. AICAR administration on blood glucose and fatty acid kinetics in vivo in type 2 diabetic patients.

\section{METHODS}

\section{Participants}

Ten male type 2 diabetic patients (age $64+2$ years, BMI $28 \pm 1 \mathrm{~kg} / \mathrm{m}^{2}$, body fat $29 \pm 1 \%$, $\mathrm{HbA}_{1 \mathrm{c}} 6.6 \pm 0.2 \%$, duration of diabetes $7 \pm 1$ years) were selected to participate in this study. Exclusion criteria were severe diabetes complications, impaired renal or liver function, cardiovascular complications, severe obesity $\left(\mathrm{BMI}>35 \mathrm{~kg} / \mathrm{m}^{2}\right)$, gout, participation in any regular exercise programme and/or 
exogenous insulin therapy. All participants were sedentary and taking metformin, sulfonylurea derivatives and/or thiazolidinediones. Skinfold thickness was measured twice using skinfold calipers at the triceps, biceps, subscapular and suprailiacal region. The sum of the skinfold thicknesses was used to calculate body fat percentage [20]. Volunteers were informed about the nature and risks of the experimental procedures before their informed consent was obtained. The study was carried out in accordance with the principles of the Declaration of Helsinki and was approved by the Medical Ethics Committee of the Radboud University Nijmegen Medical Centre (Nijmegen, the Netherlands).

\section{Experimental trials}

Each volunteer participated in two experimental tests; one in which AICAR $(0.75$ mg kg-1 $\left.\mathrm{min}^{-1}\right)$ was infused and one in which only $\mathrm{NaCl}(0.9 \%)$ was infused to ensure equal volume administration. The order of the tests was randomised, and tests were separated by at least 2 weeks. Each test consisted of $90 \mathrm{~min}$ of resting measurements, during which $\mathrm{NaCl}(0.9 \%)$ was infused, followed by either 120 min of AICAR or $\mathrm{NaCl}(0.9 \%)$ infusion. [2,2-2 $\left.\mathrm{H}_{2}\right]$ Palmitate and [6,6-2 $\left.\mathrm{H}_{2}\right]$ glucose were infused intravenously, with arterialised blood samples collected at $15 \mathrm{~min}$ intervals. Muscle biopsy samples from the vastus lateralis muscle were collected before the start of the AICAR test and immediately after the last blood sample was obtained, at which time AICAR was still being continuously infused.

\section{Medication, diet and physical activity prior to testing}

All participants discontinued their use of blood glucose lowering medication for 4 days prior to the tests and abstained from strenuous physical activity for 2 days prior to testing. In addition, they were asked to record their dietary intake during the 2 days prior to the first test and to repeat this diet prior to the second test. Consumption of caffeine-containing food and beverages was not allowed for $24 \mathrm{~h}$ prior to the tests, as caffeine is a potent adenosine receptor antagonist [21]. The evening prior to each test, all participants consumed the same standardised meal $(42 \mathrm{~kJ} / \mathrm{kg}$; containing $61 \%$ of energy as carbohydrate, $24 \%$ as fat and $15 \%$ as protein).

\section{Protocol}

After an overnight fast, participants arrived at the research centre at $08.00 \mathrm{~h}$ by car or public transport. Two Teflon catheters (Baxter, Utrecht, the Netherlands) were inserted into separate veins of one forearm for isotope and AICAR and/or $\mathrm{NaCl}$ $(0.9 \%)$ infusion. To obtain arterialised venous blood, a third catheter was inserted 
into a superficial dorsal hand vein of the contralateral arm, after which the hand was warmed in a hot box that circulated air at $55^{\circ} \mathrm{C}$, to achieve adequate arterialisation [22]. In the AICAR test, a percutaneous muscle biopsy sample was taken from the vastus lateralis muscle after the participant had rested for $30 \mathrm{~min}$ in the supine position. After an additional $15 \mathrm{~min}$ of rest, participants were administered a single i.v. primed infusion of $\left[6,6-{ }^{2} \mathrm{H}_{2}\right]$ glucose $(13.5 \mu \mathrm{mol} / \mathrm{kg})$. Thereafter, continuous infusions of $\left[6,6-{ }^{2} \mathrm{H}_{2}\right]$ glucose $\left(0.3 \mu \mathrm{mol} \mathrm{kg}^{-1} \mathrm{~min}^{-1}\right)$ and $[2,2-$ ${ }_{2}^{2} \mathrm{H}_{2}$ ]palmitate $\left(0.035 \mu \mathrm{mol} \mathrm{kg}{ }^{-1} \mathrm{~min}^{-1}\right.$; Cambridge Isotope Laboratories, Andover, MA, USA) were started ( $t=0 \mathrm{~min}$ ) via a calibrated IVAC pump (CAN Medical, Royse City, TX, USA); $\mathrm{NaCl}(0.9 \%)$ was infused for 90 min via an IVAC pump. In the AICAR test, an AICAR infusion $\left(0.75 \mathrm{mg} \mathrm{kg}^{-1} \mathrm{~min}^{-1}\right.$; Toronto Research Chemicals, Toronto, ON Canada) was started at $t=90 \mathrm{~min}$ and continued for 120 min, whereas in the control trial an $\mathrm{NaCl}$ infusion was continued at an infusion rate equal to that in the AICAR trial. A second muscle biopsy sample was taken immediately after the last blood sample was obtained but under continued AICAR infusion.

\section{Blood sample analysis}

Blood samples $(8 \mathrm{ml})$ were collected in EDTA-containing tubes and immediately centrifuged at $1000 . \mathrm{g}$ for $10 \mathrm{~min}$ at $4{ }^{\circ} \mathrm{C}$. Aliquots of plasma were immediately frozen in liquid nitrogen and stored at $-80^{\circ} \mathrm{C}$. plasma glucose (Roche, Basel, Switzerland), lactate (Wako Chemicals, Neuss, Germany), NEFA (Wako Chemicals), glycerol (Roche Diagnostics, Indianapolis, IN, USA) and triacylglycerol (Sigma Diagnostics, St Louis, MO, USA) concentrations were analyzed with a COBAS semi-automatic analyser (Roche). Plasma insulin was measured by radioimmunoassay (Linco, St Charles, MO, USA). Blood HbAic was analysed by HPLC (Variant II; Bio-Rad, Munich, Germany). For determination of plasma palmitate and NEFA kinetics, NEFA were extracted, isolated by thin-layer chromatography and derivatised to their methyl esters. Isotope enrichment of palmitate was analysed by GC-MS (Agilent, Little Falls, DE, USA). Plasma palmitate concentration was determined on an analytical GC with flame ionisation detection using nonadecaenoic acid as the internal standard, and was found to constitute $23.9 \pm 0.18 \%$ of total NEFA. Following derivatisation, plasma [6,6-2 $\left.\mathrm{H}_{2}\right]$ glucose enrichment was determined by electron ionisation GC-MS (Agilent). Palmitate and glucose tracer concentrations in the infusates averaged $2.34 \pm 0.03$ and $37.3 \pm 0.10 \mathrm{mmol} / \mathrm{l}$, respectively, in the AICAR test vs $2.27 \pm 0.06$ and $37.3 \pm 0.06 \mathrm{mmol} / \mathrm{l}$ in the control test. Therefore, the exact palmitate and glucose tracer infusion rates averaged $27 \pm 1$ and $272 \pm 7 \mathrm{nmol} \mathrm{kg-1} \mathrm{min}^{-1}$, respectively, in the AICAR test vs $28 \pm 1$ and $272 \pm 8 \mathrm{nmol} \mathrm{kg}^{-1} \mathrm{~min}^{-1}$ in the control test. Plasma AICAR 
concentrations were determined by HPLC, with UV detection set at $260 \mathrm{~nm}$, using a $200 \times 4.6 \mathrm{~mm} 5 \mu \mathrm{m}$ Hypersil BDS C18 column (ThermoFisher, Waltham, MA, USA). The mobile phase consisted of methanol, $10 \mathrm{mmol} / \mathrm{l}$ tetrabutylammonium hydrogen sulphate and $5 \mathrm{mmol} / \mathrm{l} \mathrm{K}_{2} \mathrm{HPO}_{4}, \mathrm{pH} 8.2$ (20:80, vol./vol.)

\section{Tracer calculations}

Rate of appearance $\left(R_{\mathrm{a}}\right)$ and rate of disappearance $\left(R_{\mathrm{d}}\right)$ of palmitate and glucose were calculated using the single-pool non-steady-state Steele equations adapted for stable isotope methodology.

$$
\begin{aligned}
& \mathrm{Ra}=\frac{\mathrm{F}-\mathrm{V}\left[\left(\mathrm{C}_{2}+\mathrm{C}_{1}\right) / 2\right]\left[\left(\mathrm{E}_{2}-\mathrm{E}_{1}\right) /\left(\mathrm{t}_{2}-\mathrm{t}_{1}\right)\right]}{\left[\left(\mathrm{E}_{2}+\mathrm{E}_{1}\right) / 2\right]} \\
& \mathrm{Rd}=\mathrm{Ra}-\mathrm{V}\left(\frac{\mathrm{C}_{2}-\mathrm{C}_{1}}{\mathrm{t}_{2}-\mathrm{t}_{1}}\right)
\end{aligned}
$$

Where $F$ is the infusion rate (in $\mu \mathrm{mol} \mathrm{kg}^{-1} \mathrm{~min}^{-1}$ ); $V$ is distribution volume for palmitate or glucose (40 and $160 \mathrm{ml} / \mathrm{kg}$, respectively); $C_{1}$ and $C_{2}$ are palmitate or glucose concentrations $(\mathrm{mmol} / \mathrm{l})$ at time $1\left(t_{1}\right)$ and $2\left(t_{2}\right)$, respectively, and $E_{2}$ and $E_{1}$ are the plasma palmitate or glucose enrichments (tracer/tracee ratios, TTR) at $t_{1}$ and $t_{2}$, respectively.

\section{Muscle sample analysis}

Muscle samples were dissected, freed from any visible non-muscle material and immediately frozen in liquid nitrogen. Approximately $30 \mathrm{mg}$ of muscle was homogenised in ten volumes of homogenisation buffer $(50 \mathrm{mmol} / \mathrm{l}$ Tris $\mathrm{pH} 7.5,1$ $\mathrm{mmol} / \mathrm{l} \mathrm{EDTA}, 1 \mathrm{mmol} / \mathrm{l} \mathrm{EGTA}, 50 \mathrm{mmol} / \mathrm{l} \mathrm{NaF}, 5 \mathrm{mmol} / \mathrm{l} \mathrm{Na} 4 \mathrm{P}_{2} \mathrm{O}_{7}$ 10\% glycerol (wt/vol), 1\% Triton $\mathrm{X}-100(\mathrm{wt} / \mathrm{vol}), 1 \mathrm{mmol} / \mathrm{l} \mathrm{DTT}$, protease inhibitor cocktail). Samples were centrifuged at $1000 \cdot g$ for $5 \mathrm{~min}$, and then the supernatant fractions were assayed for total protein and $50 \mu \mathrm{g}$ of protein was resolved by SDS-PAGE and transferred to nitrocellulose membranes. Membranes were incubated with antibodies for pT172 AMPK $\alpha 1$, AMPK $\alpha 2$, pS79 acetyl-CoA carboxylase (ACC), phospho-Akt Substrate of $160 \mathrm{kDa}$ (AS160), pT202/Y204 extracellular signalregulated protein kinase (ERK), pS21/9 glycogen synthase kinase (GSK) $3 \alpha / \beta$, Akt and histone deacetylase 5 (HDAC5) (Cell Signaling, Danvers, MA, USA). Antibodies recognising HDAC5 phosphorylated at $\mathrm{S259}$ and $\mathrm{S} 498$ were produced as previously described [23]. Following incubation with appropriate HRP 
conjugated secondary antibodies, bands were visualised following enhanced chemiluminescence exposure using the ChemiDoc system (Bio-Rad, Hercules, CA, USA) and quantified using 1D software (Bio-Rad, Hercules, CA, USA). AMPK activity assays were performed as previously described [23]. Briefly, AMPK $\alpha 1$ and $-\alpha 2$ were immunoprecipitated from $100 \mu \mathrm{g}$ of protein using isoform-specific antibodies $(2 \mu \mathrm{g})$ coupled to $15 \mu \mathrm{l}$ of protein A beads (Pierce, Rockford, IL, USA). Immune complexes were washed twice with $1 \mathrm{ml}$ of lysis buffer containing $0.5 \mathrm{~mol} / \mathrm{l} \mathrm{NaCl}$, and once with $1 \mathrm{ml}$ of Buffer $\mathrm{A}(50 \mathrm{mmol} / \mathrm{l}$ Tris $\mathrm{pH} 7.5,0.1 \mathrm{mmol} / 1$ EGTA, 0.1\% 2-mercaptoethanol). Assays were performed in a total volume of $50 \mu \mathrm{l}(50 \mathrm{mmol} / \mathrm{l}$ Tris $\mathrm{pH} 7.5,0.1 \mathrm{mmol} / \mathrm{l} \mathrm{EGTA}, 0.1 \% 2$ mercaptoethanol, $10 \mathrm{mmol} / 1 \mathrm{MgCl} 2,0.1 \mathrm{mmol} / 1$ [32P]ATP $(\sim 200 \mathrm{cpm} / \mathrm{pmol})$ and 30 $\mu \mathrm{mol} / 1$ AMARA peptide (AMARAASAAALARRR). The assays were carried out for $30 \mathrm{~min}$ at $30^{\circ} \mathrm{C}$ and terminated by applying $40 \mu \mathrm{l}$ of the reaction mixture onto P81 papers. Phosphotransferase activity was measured by scintillation counting.

\section{Statistics}

All data are expressed as mean $\$$ SEM. To compare tracer kinetics and plasma metabolite concentrations over time, a repeated-measures ANOVA was applied. A Scheffé post hoc test was applied in cases of a significant $F$ ratio, to detect specific differences. For non-time-dependent variables, a Student's $t$ test for paired or unpaired (as applicable) observations was used. A $p$ value of less than 0.05 was considered significant.

\section{RESULTS}

\section{Plasma glucose kinetics}

There were no significant differences in the basal $R_{a}$ or disappearance $R_{d}$ between the AICAR and control tests (Figs 1,2 and Table 1). In both the AICAR and control tests, plasma glucose $R_{\mathrm{a}}$ and $R_{\mathrm{d}}$ were significantly lower during the intervention period (from $t=105$ to $t=210 \mathrm{~min}$ ) than at baseline (Table 1). However, during AICAR infusion, glucose $R_{\mathrm{a}}$ was significantly lower than $R_{\mathrm{d}}(7.18 \pm 0.32 \mathrm{vs}$ $9.94 \pm 0.47 \mu \mathrm{mol} \mathrm{kg-1} \mathrm{min}^{-1}, \mathrm{p}<0.001$ ), while glucose $R_{d}$ rates were similar in the AICAR and control test $\left(9.94 \pm 0.47\right.$ vs $\left.10.49 \pm 0.55 \mu \mathrm{mol} \mathrm{kg}^{-1} \mathrm{~min}^{-1}, \mathrm{p}=0.29\right)$. Consequently, plasma glucose disposal ( $R_{d}$ expressed as a percentage of $R_{a}$ ) during AICAR infusion was significantly greater when compared with the control test (141.8 \pm 2.6 vs $110.6 \pm \%$, respectively, $\mathrm{p}<0.0001)$. 

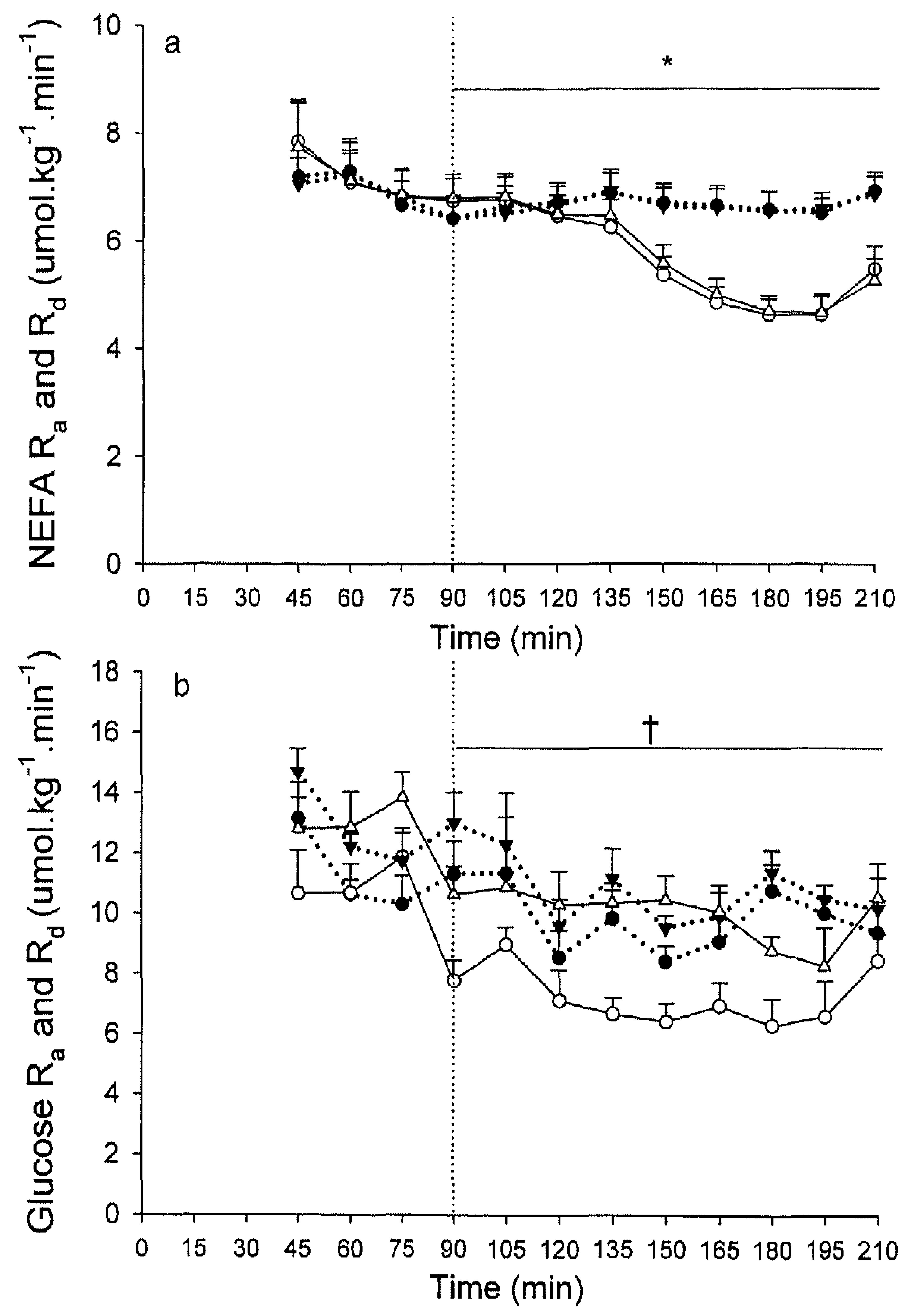

Fig. 1. Plasma NEFA (a) and plasma glucose (b) tracer kinetics as determined during the administration of i.v. AICAR $\left(0.75 \mathrm{mg} \mathrm{kg}^{-1} \mathrm{~min}^{-1}\right)$ and/or $\mathrm{NaCl}(0.9 \%)$. In the AICAR test, the AICAR infusion was started at $t=90 \mathrm{~min}$. White symbols represent data from the AICAR test, black symbols represent data from the control test. Circles represent $R_{\mathrm{a}}$, triangles represent $R_{\mathrm{d}}$. The dotted line indicates the beginning of AICAR infusion in the AICAR trial. Values are means \pm SEM. *Plasma NEFA $R_{a}$ and $R_{d}$ significantly lower during infusion of AICAR vs the control test. ${ }^{\text {Significantly lower glucose }}$ $R_{\mathrm{a}}$ during AICAR infusion $(p<0.05)$ 
Table 1. Tracer kinetics

\begin{tabular}{|c|c|c|}
\hline & $\begin{array}{l}\text { AICAR } \\
(n=10)\end{array}$ & $\begin{array}{l}\text { CONTROL } \\
(n=10)\end{array}$ \\
\hline & \multicolumn{2}{|c|}{$\mu \mathrm{mol} \cdot \mathrm{kg}^{-1} \cdot \mathrm{min}^{-1}$} \\
\hline \multicolumn{3}{|l|}{ BASELINE } \\
\hline Ra glucose & $10.24 \pm 0.51$ & $11.54 \pm 0.69$ \\
\hline Rd glucose & $12.53 \pm 0.70$ & $13.07 \pm 0.64$ \\
\hline$\%$ Ra Rd glucose & $126.5 \pm 3.8^{\mathrm{a}}$ & $114.7 \pm 1.8$ \\
\hline Ra NEFA & $7.56 \pm 0.73$ & $6.89 \pm 0.46$ \\
\hline Rd NEFA & $7.55 \pm 0.74$ & $6.87 \pm 0.47$ \\
\hline \%Ra Rd NEFA & $99.8 \pm 0.4$ & $99.8 \pm 0.4$ \\
\hline \multicolumn{3}{|l|}{ AICAR/ } \\
\hline \multirow{2}{*}{\multicolumn{3}{|c|}{$\begin{array}{l}\mathrm{NaCl} \text { infusion } \\
(\mathrm{t}=90 \text { to } \mathrm{t}=120)\end{array}$}} \\
\hline & & \\
\hline Ra glucose & $7.18 \pm 0.32^{\mathrm{a}, \mathrm{b}}$ & $9.61 \pm 0.58^{\mathrm{b}}$ \\
\hline Rd glucose & $9.94 \pm 0.47^{b}$ & $10.49 \pm 0.55^{b}$ \\
\hline$\%$ Ra Rd glucose & $141.8 \pm 2.6^{a, b}$ & $110.6 \pm 1.1^{b}$ \\
\hline Ra NEFA & $5.52 \pm 0.27^{\mathrm{a}, \mathrm{b}}$ & $6.69 \pm 0.32$ \\
\hline Rd NEFA & $5.59 \pm 0.28^{a, b}$ & $6.65 \pm 0.32$ \\
\hline$\%$ Ra Rd NEFA & $101.4 \pm 0.4^{\mathrm{a}, \mathrm{b}}$ & $99.5 \pm 0.2$ \\
\hline
\end{tabular}

Table 1. Tracer kinetics as determined at baseline ( $\mathrm{NaCl}$ infusion), and during AICAR or continued $\mathrm{NaCl}(0.9 \%)$ infusion. Ra, rate of appearance; Rd, rate of disappearance; \% $\mathrm{Ra} R d$ percentage of Ra that is taken up (\%). Values are means $\pm \operatorname{SEM}(n=10)$. asignificantly different from control group $(p<0.05)$ bsignificantly different from basal values $(\mathrm{p}<0.05)$.

\section{Plasma NEFA kinetics}

No significant differences were observed in baseline NEFA $R_{\mathrm{a}}, R_{\mathrm{d}}$ and/or NEFA disposal between tests (Figs 1, 2 and Table 1). Plasma NEFA $R_{a}$ and $R_{d}$ were significantly lower during AICAR infusion than at baseline or during the control test (Figs 1, 2 and Table 1). Plasma NEFA $R_{\mathrm{d}}$ remained significantly higher than $R_{\mathrm{a}}$ 
during AICAR infusion $\left(5.59 \pm 0.28\right.$ vs $\left.5.52 \pm 0.27 \mu \mathrm{mol} \mathrm{kg} \mathrm{kg}^{-1} \mathrm{~min}^{-1}, \mathrm{p}<0.02\right)$. On average, plasma NEFA disposal rates were significantly higher during AICAR infusion than during the control infusion $(101.4 \pm 0.4$ and $99.5 \pm 0.2 \%$, respectively, p<0.001, Fig. 2).
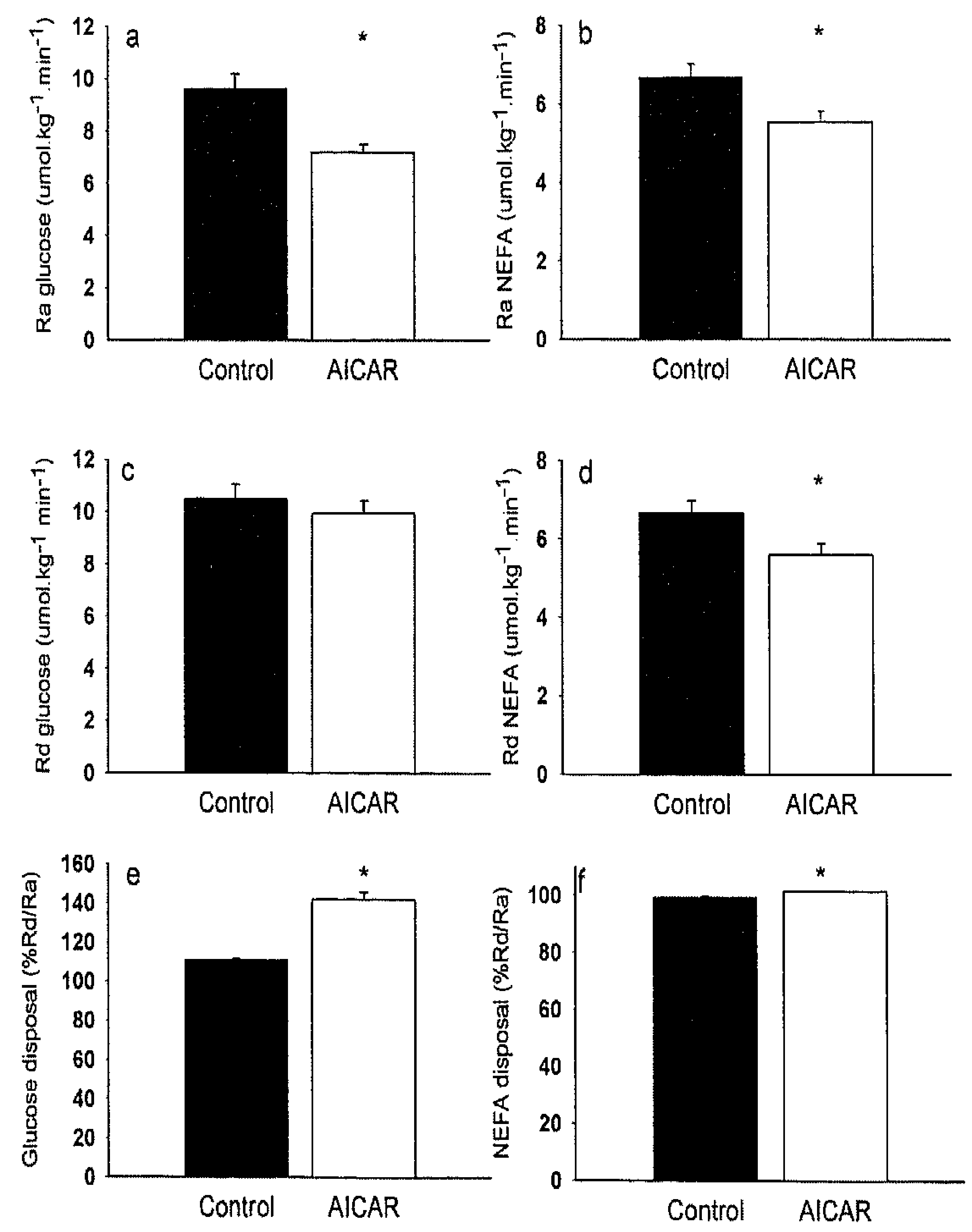

Figure. 2. Tracer kinetics during i.v. AICAR $\left(0.75 \mathrm{mg} \mathrm{kg}^{-1} \mathrm{~min}^{-1}\right)$ or $\mathrm{NaCl}(0.9 \%)$ infusion. Values represent means \pm SEM as calculated between $t=90$ and $t=210 \mathrm{~min}$ (period of AICAR infusion in AICAR test). Disposal is $R_{\mathrm{d}}$ expressed as a percentage of $R_{\mathrm{a} .}{ }^{*} p<0.05 \mathrm{vs}$ control test. 

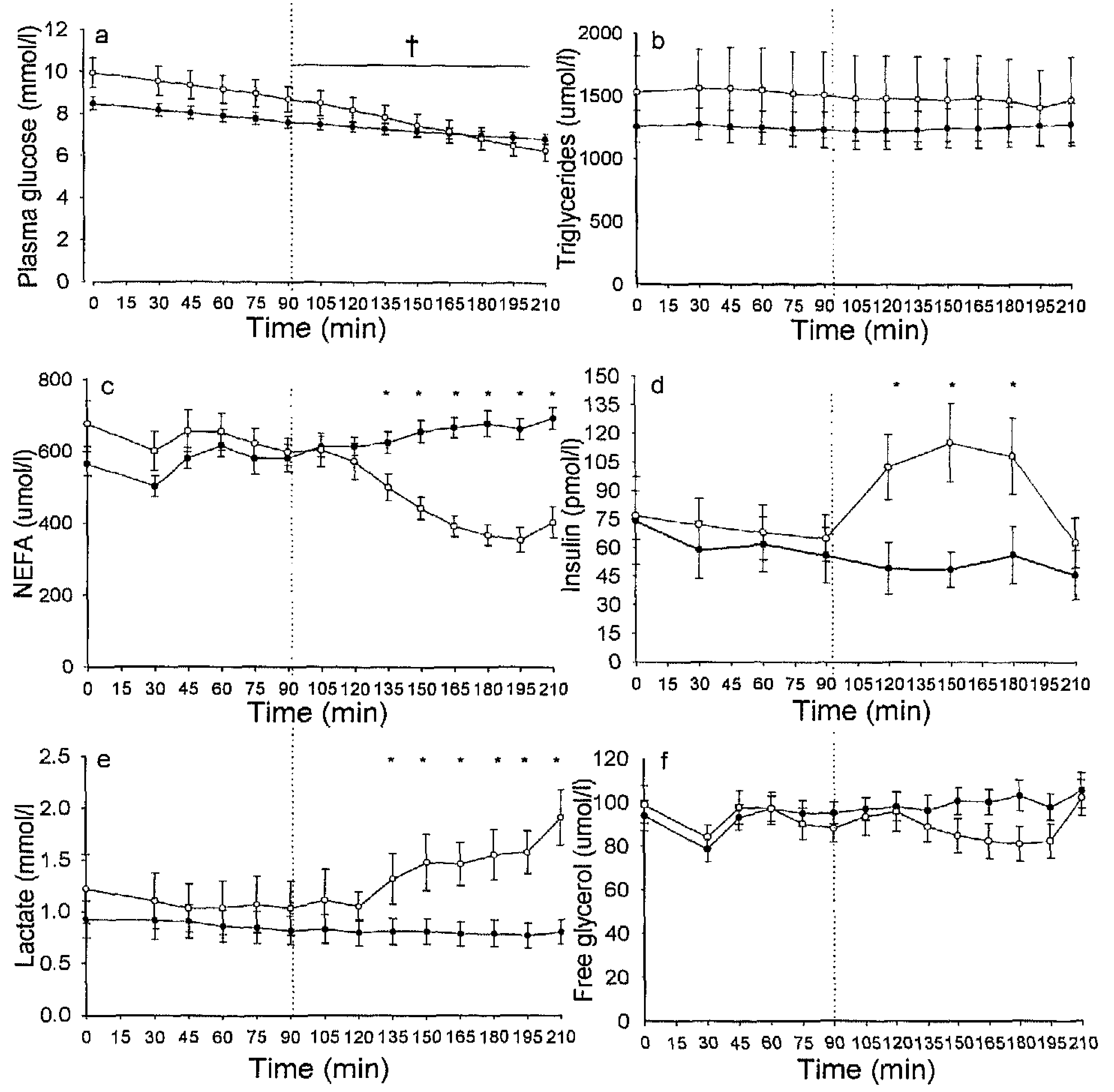

Figure 3. Plasma glucose (a), triglycerides (b), NEFA (c), insulin (d), lactate (e) and free glycerol (f) concentrations. Values are means \pm SEM. White symbols represent data from the AICAR test, black symbols represent data from the control test. Dotted lines mark the beginning of AICAR infusion in the AICAR trial. Infusion of $\mathrm{NaCl}$ was continued in the control trial. ${ }^{*} p<0.05$ vs control test; $+p<0.05$ for rate for vs control test $(p<0.05)$. 


\section{Plasma metabolite concentrations}

Plasma metabolite concentrations are displayed in Fig. 3. The decline in plasma glucose concentration during the intervention period, corrected for baseline plasma glucose concentration, was significantly greater during AICAR infusion than during the control test ( $\mathrm{p}<0.0001$ for group interaction). Plasma lactate concentrations increased significantly from $1.03 \pm 0.26$ to $1.92 \pm 0.27 \mathrm{mmol} / \mathrm{l}$ in response to AICAR infusion and were significantly higher when compared with the control test $(p<0.02)$. Plasma NEFA concentrations declined significantly during AICAR infusion and were significantly lower when compared with the control test $(p<0.002)$. Furthermore, a small but significant rise in circulating plasma insulin concentrations was observed following the onset of AICAR infusion $(p<0.001)$. No significant differences in plasma triacylglycerol or free glycerol concentrations were observed between tests. Plasma AICAR concentrations increased during AICAR infusion up to $161 \pm 11 \mu \mathrm{mol} / \mathrm{l}$ (Fig. 4).

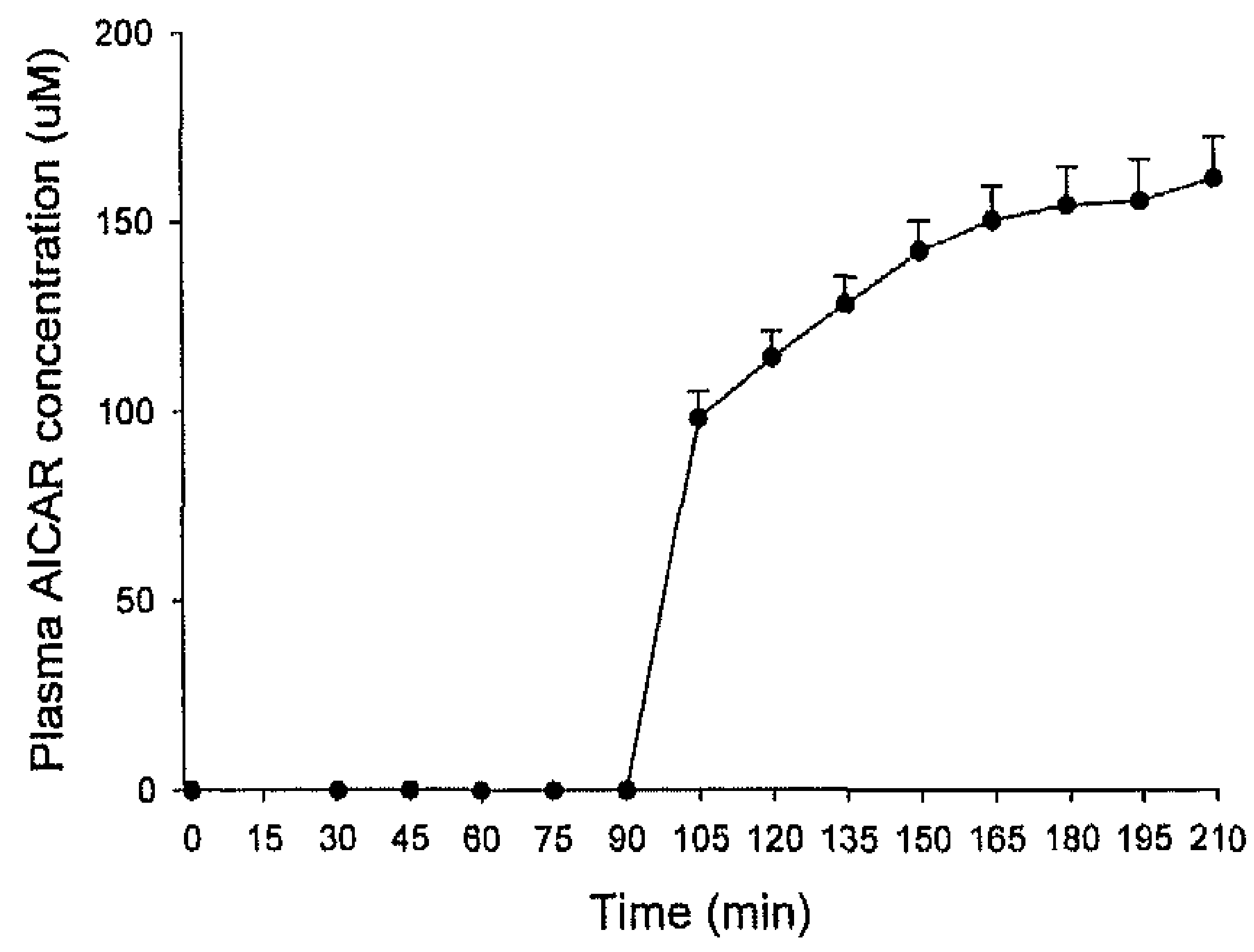

Figure 4. Plasma AICAR concentrations during i.v. AICAR administration. Values are means \pm SEM.

\section{Muscle analyses}

Western blotting performed on muscle biopsy samples collected prior to and after AICAR administration showed a significant $185 \pm 28 \%$ increase in the acetyl-CoA carboxylase (ACC) phosphorylation state following AICAR administration (Fig. 5). No significant changes were observed in the phosphorylation state of AMPK, AS160, GSK3 $\alpha$, GSK3 $\beta$, HDAC5 (S259 and S498), Akt and ERK. AMPK activity assays showed a 1.7 \pm 0.5 -fold change in AMPK $\alpha 1$ activity ( $\mathrm{p}=0.16$ ), and a $1.01 \pm 0.3$ fold change in AMPK $\alpha 2$ activity (NS) following AICAR infusion. 

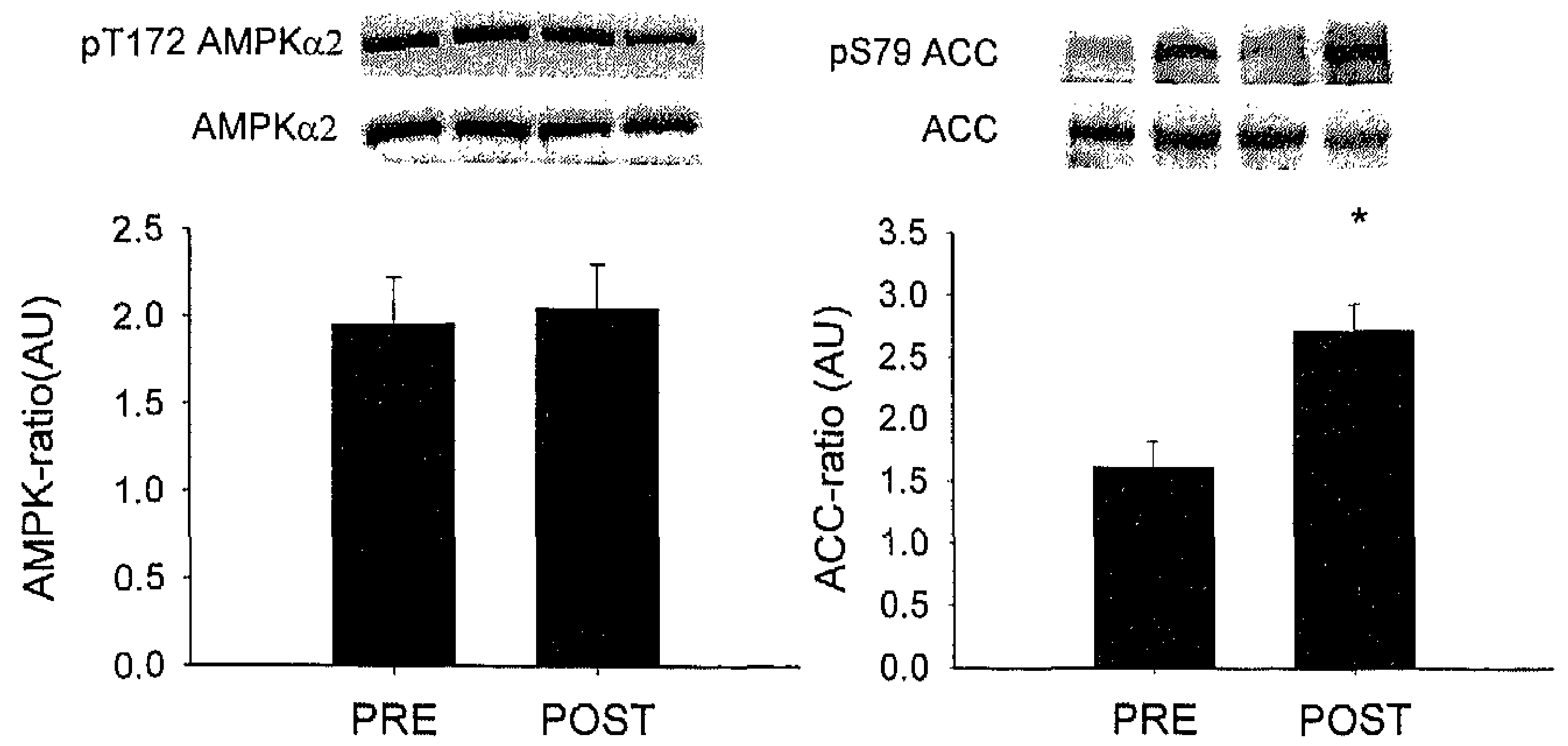

Figure 5. Skeletal muscle AMPK and ACC phosphorylation prior to (PRE) and after (POST) i.v. AICAR infusion $\left(0.75 \mathrm{mg} \mathrm{kg}^{-1} \mathrm{~min}^{-1}\right)$. Values are means \pm SEM. AU, arbitrary units. ${ }^{*} \mathrm{p}<0.05$ vs control lest

\section{DISCUSSION}

The present study shows that i.v. AICAR infusion in vivo in type 2 diabetic patients inhibits hepatic glucose output while maintaining whole body glucose uptake, thereby lowering plasma glucose concentrations. Furthermore, AICAR infusion is shown to suppress whole body lipolysis, resulting in a decline in plasma NEFA concentration.

The effects of AICAR on glucose metabolism have been studied extensively in rodent models, both in vitro and in vivo. These studies demonstrate that AMPK activation by AICAR stimulates glucose uptake $[2-4,6,7]$ and inhibits hepatic glucose output [5] in an insulin-independent manner. In obese and/or insulinresistant rodent models, glucose tolerance is improved after long-term AICAR administration [10-12]. Ex vivo studies in human skeletal muscle tissue samples have yielded similar results, demonstrating that AICAR increases glucose transport [13] and fatty acid oxidation [14], which is accompanied by an increase in AMPK phosphorylation and/or activity $[13,14]$ and ACC phosphorylation [13, 14]. It is evident that it would be of great interest to determine the effects of in vivo AICAR administration in humans. Cuthbertson et al. [19] recently described a twofold increase in 2-deoxyglucose uptake in skeletal muscle after $3 \mathrm{~h}$ of AICAR infusion $\left(10 \mathrm{mg}^{-1} \mathrm{~kg}^{-1} \mathrm{~h}^{-1}\right)$ in young men. However, this was not accompanied by changes in plasma glucose concentration [19]. During an euglycaemic-hyperinsulinaemic clamp in combination with AICAR infusion, whole body glucose uptake (i.e. $M$ value) was slightly increased (7\%) [19]. 
To date, no study has investigated the effects of AICAR administration on plasma glucose and fatty acid kinetics in vivo in type 2 diabetic patients. In the present study, we demonstrate a strong decline in the rate of appearance of plasma glucose following AICAR infusion $\left(0.75 \mathrm{mg} \mathrm{kg}^{-1} \mathrm{~min}^{-1}\right.$, or $45 \mathrm{mg} \mathrm{kg} \mathrm{h}^{-1}$ ), suggesting that AICAR infusion strongly suppresses hepatic glucose output in type 2 diabetic patients. This is in accordance with previous results in obese Zucker rats, in which AICAR infusion was shown to suppress hepatic glucose output [5]. Even though plasma glucose appearance rates declined during AICAR infusion, whole body glucose uptake remained unchanged (Figs 1, 2). Consequently, glucose disposal (when defined as the percentage of glucose $R_{a}$ that is taken up from the circulation) was significantly greater during AICAR infusion (Figs 1,2). These findings extend the previous observations by Cuthbertson et al. [19] and indicate that AICAR infusion in patients with type 2 diabetes has only a modest impact on plasma glucose uptake but strongly inhibits hepatic glucose output. In contrast to Cuthbertson et al. [19], we observed a significant decline in plasma glucose levels during AICAR infusion. This discrepancy between studies may be attributed to the 4.5-fold higher AICAR dose that was administered and the selection of insulin-resistant type 2 diabetic patients as opposed to healthy, young men.

In the present study we also assessed the effect of AICAR infusion on plasma NEFA kinetics. Activation of AMPK by AICAR has been shown to inhibit lipolysis and lipogenesis in vitro in adipocytes $[8,24,25]$ and in vivo in both lean and insulin-resistant obese rat models [5]. This study is the first to demonstrate that i.v. AICAR infusion ( $\left.0.75 \mathrm{mg} \mathrm{kg}^{-1} \mathrm{~min}^{-1}\right)$ inhibits the whole body lipolytic rate in type 2 diabetic patients, resulting in a significant decline in circulating plasma NEFA concentrations (Fig. 3). Furthermore, as AMPK activation in the liver also stimulates hepatic fatty acid oxidation [26], it might be assumed that the decline in the rate of appearance of plasma NEFA is also partly due to a greater hepatic extraction and oxidation rate of fatty acids released from the splanchnic area. Altogether, it appears that the effects of AICAR infusion on plasma glucose and NEFA levels in type 2 diabetic patients are mainly exerted through its effects on the liver and adipose tissue, by inhibition of endogenous glucose production, stimulation of hepatic fatty acid oxidation and/or a reduction in whole body lipolysis. Contrary to our expectations, the effect of AICAR infusion on whole body and/or skeletal muscle glucose and NEFA uptake seems to be of less quantitative importance in type 2 diabetic patients.

To investigate the effects of AICAR on AMPK activation in skeletal muscle tissue, we measured potential changes in the phosphorylation state of AMPK and its downstream target, $A C C$, as a more sensitive marker of AMPK activation [27]. 
Although we failed to detect a significant increase in AMPK phosphorylation (Fig. 4), we did observe a substantial increase in ACC phosphorylation in muscle biopsy samples collected after $2 \mathrm{~h}$ of AICAR infusion (185 $\pm 28 \%$ ). As the ACC phosphorylation state can be used as a more sensitive measure of in vivo AMPK activity, our findings suggest that modest allosteric activation of AMPK had occurred without substantial phosphorylation of AMPK by its kinase. However, this was not supported by the AMPK activity assays, which showed no changes in either AMPK $\alpha 1$ or $-\alpha 2$ activity. Alternatively, it is possible that an unknown kinase that is responsive to AICAR was responsible for the increase in ACC phosphorylation. We did not detect any effect of AICAR infusion on the phosphorylation of other known AMPK substrates, such as AS160, GSK3 $\alpha$, GSK3 $\beta$ and HDAC5 (S259 and S498). Cuthbertson et al. [19] showed an increase in ERK1/2 phosphorylation with AICAR infusion in humans. However, no change was detected in the present study. As such, our data indicate that AICAR infusion in vivo in type 2 diabetic patients only modestly activates AMPK in skeletal muscle tissue. The impact of AICAR infusion on AMPK activation seems to be much greater in adipose and/or liver tissue. It should be noted that a small but significant increase in circulating plasma insulin concentrations during the AICAR test might have contributed to the observed effects on hepatic glucose output and whole body lipolysis [28]. Future studies using AICAR administration in vivo in humans might consider the use of octreotide to suppress insulin secretion. Furthermore, it should be mentioned that some effects of AICAR may not be AMPK-mediated, especially the effects on hepatic glucose output [29]. As adipose and/or liver tissue samples were not collected, we can only speculate on the impact of AICAR infusion on AMPK activation in hepatic and/or adipose tissue.

In conclusion, i.v. AICAR infusion $\left(0.75 \mathrm{mg} \mathrm{kg}^{-1} \mathrm{~min}^{-1}\right)$ in type 2 diabetic patients inhibits hepatic glucose output, stimulates hepatic fatty acid oxidation and/or reduces whole body lipolysis in vivo, thereby lowering plasma glucose and NEFA concentrations.

\section{ACKNOWLEDGEMENTS}

The authors thank A.Jansen Van Roosendaal and M. van Helden of the Clinical Research Centre Nijmegen for their practical assistance, S. Kok and A.Blenke from the Department of Clinical Pharmacy (UMCN) for preparation of AICAR and tracers, and P. van den Broek (UMCN), A.Gijsen (UM) and J.Senden (UM) for analytical assistance. 


\section{REFERENCES}

1. Wojtaszewski JF, Nielsen P, Hansen BF, Richter EA, Kiens B (2000) Isoform-specific and exercise intensity-dependent activation of 5'-AMP-activated protein kinase in human skeletal muscle. J Physiol 528:221-226

2. Merrill GF, Kurth EJ, Hardie DG, Winder WW (1997) AICA riboside increases AMPactivated protein kinase, fatty acid oxidation, and glucose uptake in rat muscle. Am J Physiol 273:E1107-E1112

3. Iglesias MA, Furler SM, Cooney GJ, Kraegen EW, Ye JM (2004) AMP-activated protein kinase activation by AICAR increases both muscle fatty acid and glucose uptake in white muscle of insulin-resistant rats in vivo. Diabetes 53:1649-1654

4. Bergeron R, Russell RR 3rd, Young LH et al. (1999) Effect of AMPK activation on muscle glucose metabolism in conscious rats. Am J Physiol 276:E938-E944

5. Bergeron R, Previs SF, Cline GW et al. (2001) Effect of 5-aminoimidazole-4-carboxamide-1beta-D-ribofuranoside infusion on in vivo glucose and lipid metabolism in lean and obese Zucker rats. Diabetes 50:1076-1082

6. Hayashi T, Hirshman MF, Kurth EJ, Winder WW, Goodyear LJ (1998) Evidence for 5' AMPactivated protein kinase mediation of the effect of muscle contraction on glucose transport. Diabetes 47:1369-1373

7. Kurth-Kraczek EJ, Hirshman MF, Goodyear LJ, Winder WW (1999) 5' AMP-activated protein kinase activation causes GLUT4 translocation in skeletal muscle. Diabetes 48:16671671

8. Sullivan JE, Brocklehurst KJ, Marley AE, Carey F, Carling D, Beri RK (1994) Inhibition of lipolysis and lipogenesis in isolated rat adipocytes with AICAR, a cell-permeable activator of AMP-activated protein kinase. FEBS Lett 353:33-36

9. Iglesias MA, Ye JM, Frangioudakis G et al. (2002) AICAR administration causes an apparent enhancement of muscle and liver insulin action in insulin-resistant high-fat-fed rats. Diabetes 51:2886-2894

10. Song XM, Fiedler M, Galuska $D$ et al. (2002) 5-Aminoimidazole-4-carboxamide ribonucleoside treatment improves glucose homeostasis in insulin-resistant diabetic $(o b / o b)$ mice. Diabetologia 45:56-65

11. Pold R, Jensen LS, Jessen $\mathrm{N}$ et al. (2005) Long-term AICAR administration and exercise prevents diabetes in ZDF rats. Diabetes 54:928-934

12. Buhl ES, Jessen N, Pold R et al. (2002) Long-term AICAR administration reduces metabolic disturbances and lowers blood pressure in rats displaying features of the insulin resistance syndrome. Diabetes 51:2199-2206

13. Koistinen HA, Galuska D, Chibalin AV et al. (2003) 5-Amino-imidazole carboxamide riboside increases glucose transport and cell-surface GLUT4 content in skeletal muscle from subjects with type 2 diabetes. Diabetes 52:1066-1072

14. Steinberg GR, Smith AC, Van Denderen BJ et al. (2004) AMP-activated protein kinase is not down-regulated in human skeletal muscle of obese females. J Clin Endocrinol Metab 89:4575-4580

15. Sriwijitkamol A, Coletta DK, Wajcberg E et al. (2007) Effect of acute exercise on AMPK signaling in skeletal muscle of subjects with type 2 diabetes: a time-course and doseresponse study. Diabetes 56:836-848

16. Musi N, Fujii N, Hirshman MF et al. (2001) AMP-activated protein kinase (AMPK) is activated in muscle of subjects with type 2 diabetes during exercise. Diabetes 50:921-927

17. Henin N, Vincent MF, Gruber HE, Van den Berghe G (1995) Inhibition of fatty acid and cholesterol synthesis by stimulation of AMP-activated protein kinase. FASEB j 9:541-546 
Al-Khalili L, Krook A, Zierath JR, Cartee GD (2004) Prior serum- and AICAR-induced AMPK activation in primary human myocytes does not lead to subsequent increase in insulin-stimulated glucose uptake. Am J Physiol Endocrinol Metab 287:E553-E557 Cuthbertson DJ, Babraj JA, Mustard KJ et al. (2007) 5-Aminoimidazole-4-carboxamide 1beta-D-ribofuranoside acutely stimulates skeletal muscle 2-deoxyglucose uptake in healthy men. Diabetes 56:2078-2084

Durnin JV, Womersley J (1974) Body fat assessed from total body density and its estimation from skinfold thickness: measurements on 481 men and women aged from 16 to 72 years. $\mathrm{Br}$ J Nutr 32:77-97

21. Smits $\mathrm{P}$, Lenders JW, Thien $\mathrm{T}$ (1990) Caffeine and theophylline attenuate adenosine-induced vasodilation in humans. Clin Pharmacol Ther 48:410-418

22. Abumrad NN, Rabin D, Diamond MP, Lacy WW (1981) Use of a heated superficial hand vein as an alternative site for the measurement of amino acid concentrations and for the study of glucose and alanine kinetics in man. Metabolism 30:936-940 McGee SL, van Denderen BJ, Howlett KF et al. (2008) AMP-activated protein kinase regulates GLUT4 transcription by phosphorylating histone deacetylase 5. Diabetes 57:860867

Dagon Y, Avraham Y, Berry EM (2006) AMPK activation regulates apoptosis, adipogenesis, and lipolysis by eIF2alpha in adipocytes. Biochem Biophys Res Commun 340:43-47

25. Gaidhu MP, Fediuc S, Ceddia RB (2006) 5-Aminoimidazole-4-carboxamide-1-beta-Dribofuranoside-induced AMP-activated protein kinase phosphorylation inhibits basal and insulin-stimulated glucose uptake, lipid synthesis, and fatty acid oxidation in isolated rat adipocytes. J Biol Chem 281:25956-25964

Viollet B, Foretz M, Guigas B et al. (2006) Activation of AMP-activated protein kinase in the liver: a new strategy for the management of metabolic hepatic disorders. J Physiol 574:41-53 Winder WW, Wilson HA, Hardie DG et al. (1997) Phosphorylation of rat muscle acetyl-CoA carboxylase by AMP-activated protein kinase and protein kinase A. J Appl Physiol 82:219225

Wang CZ, Wang Y, Di A et al. (2005) 5-Amino-imidazole carboxamide riboside acutely potentiates glucose-stimulated insulin secretion from mouse pancreatic islets by KATP channel-dependent and -independent pathways. Biochem Biophys Res Commun 330:10731079

29. Vincent MF, Erion MD, Gruber HE, Van den Berghe G (1996) Hypoglycaemic effect of AICAriboside in mice. Diabetologia 39:1148-1155 


\section{General Discussion}

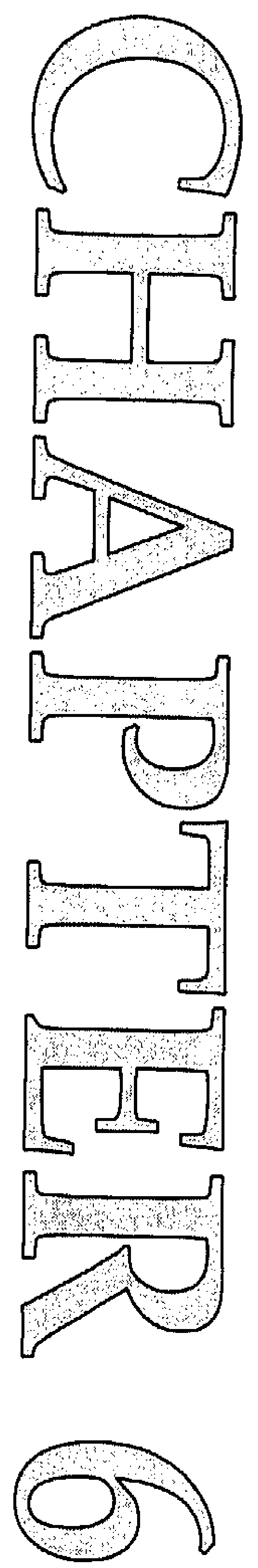


Disturbances in substrate metabolism in type 2 diabetes

An exercise approach to disturbances in substrate metabolism

Acute exercise and substrate metabolism in type 2 diabetes

Life-long exercise training and substrate metabolism

AMPK - a metabolic master switch in substrate metabolism

Concluding remarks

Future research 
The epidemic nature of type 2 diabetes and its burden on patients [1, 2], society [3] and economy [2,3] urges scientific research to unravel the underlying physiological mechanisms and to provide a rationale for effective intervention strategies. Obesity and physical inactivity are major risk factors of modern chronic metabolic diseases and cause disturbances in glucose and fatty acid metabolism that are fundamental characteristics of the type 2 diabetic state $[4,5]$. This thesis focuses on disturbances in glucose and fatty acid metabolism in type 2 diabetes mellitus (T2DM) and studies two approaches to prevent and/or correct these disturbances: exercise and pharmacological targeting of the insulinindependent AMPK pathway. The AMPK pathway underlies at least part of the effects of exercise on substrate metabolism. This final chapter lists the major findings of the results described in this thesis and provides a broader perspective on the nature of these disturbances, their underlying mechanisms, and consequences for the prevention and/or treatment of T2DM. Finally, from this perspective a number of important issues that need to be addressed in future research are proposed.

\section{Disturbances in substrate metabolism in type 2 diabetes}

Type 2 diabetes mellitus is a disease characterised by disturbances in both glucose and fatty acid (FA) metabolism. Obesity and physical inactivity are fundamental causes of these disturbances. In genetically predisposed subjects, obesity and physical inactivity can lead to the diabetic phenotype and to concomitant metabolic disturbances, which include decreased insulin-stimulated glucose uptake, increased hepatic glucose output, impaired insulin secretion, a reduced lipid buffering capacity of adipose tissue and impaired fat oxidation [6-10].

In chapter 2, we describe a higher whole-body plasma FFA rate of appearance (Ra) and rate of disappearance ( $\mathrm{Rd}$ ) in overweight type 2 diabetes patients compared with weight-matched control subjects. This difference was accompanied by a higher total fat oxidation that could be attributed to a higher plasma FFA-derived oxidation rate, and a lower carbohydrate oxidation rate. The lower carbohydrate oxidation rate occurred despite substantially greater hepatic glucose output and marked hyperglycemia, thus indicating that carbohydrate metabolism is severely impaired in long-term diagnosed T2DM patients. The higher plasma FFA oxidation may be largely explained by the greater plasma FFA Ra, which in turn is most likely due to an increased fasting adipose tissue lipolysis in T2DM. This increased lipolysis may be the result of both insulin resistance of lipolysis in T2DM, as reported before [11, 12] and an absence of compensatory hyperinsulinemia, as fasting insulin concentrations in type 2 diabetic and control subjects were not significantly different and within normal 
range (chapter 2). Thus, adipose tissue insulin resistance, which is expected to be more pronounced in T2DM $[11,12]$, is no longer compensated by hyperinsulinemia due to pancreatic B-cell failure, and basal FFA release from adipose tissue will be significantly higher in T2DM than in healthy control subjects. Absence of compensatory hyperinsulinemia can possibly explain the difference with previous studies that did not find an increased fasting plasma FFA $\mathrm{Ra}$ and increased plasma FFA oxidation in T2DM and in which compensatory hyperinsulinemia was still present [7, 13]. The absence of compensatory hyperinsulinemia can likely be explained by a long duration of disease in the patients of the present study. Other important factors that can affect FFA supply and consequent, FFA oxidation [14], are a dysfunction of adipose tissue to buffer lipids [15-18], low skeletal muscle FA oxidative capacity and diet composition [19]. Differences in subjects' characteristics can cause differences in FFA Ra and Rd between studies and may complicate the interpretation of the study results and comparison with previous data. Therefore, we suggest that a detailed phenotypic characterisation of subjects with respect to basal concentrations of metabolites and hormones, body composition, $\mathrm{VO}_{2} \max$, habitual diet and duration of disease should be performed in all studies on substrate metabolism in type 2 diabetes.

\section{An exercise approach to disturbances in substrate metabolism}

Increased industrialisation and modernisation have had a significant impact on the current level of physical activity including work-related activity, leisure time activity and sports. Along with excessive energy intake and obesity, physical inactivity is an important environmental cause of modern chronic metabolic diseases, including type 2 diabetes [20-22]. In 20 ${ }^{\text {th }}$-century hunting-gathering societies such as the San (Bushmen) or Inuit, where gathering of food requires a significant amount of energy, prevalence of T2DM is $0-2 \%$, whereas this is $6-10 \%$ in industrialised countries [23]. Furthermore, in the Harvard Nurses' Study, 91\% of the cases of T2DM could be attributed to a high-risk lifestyle, which includes physical inactivity [20]. Physical inactivity is also a risk factor for T2DM independent of BMI $[21,22]$. Type 2 diabetes mellitus can thus be viewed as a consequence of physical inactivity. An extensive review of the mechanisms by which exercise affects metabolic dysfunction in general and substrate metabolism in particular is beyond the limits of this Discussion and can be found elsewhere $[19,24-30]$. In short, these metabolic effects of exercise include a lower body fat mass, a greater total muscle mass, an improved adipose tissue function to buffer lipid fluxes, increased skeletal muscle fat oxidative capacity, increased insulin sensitivity of both muscle and adipose tissue as well as increased activation of the 
insulin-independent glucose uptake pathway in skeletal muscle [19, 24-30]. Exercise and exercise training thus have the potential to reverse metabolic disturbances and/or bypass the defective insulin-dependent signalling pathway of glucose uptake into skeletal muscle.

\section{Acute exercise and substrate metabolism in type 2 diabetes}

Thus, there is a general acceptance that lack of exercise is an important factor in the development and/or progression of type 2 diabetes. Not only exercise training, but even a single bout of moderate-intensity exercise increases glucose uptake, fat oxidation and energy expenditure. Nevertheless, some issues have not yet been resolved. In particular, conflicting data exist on the exact effects of acute exercise on the utilisation of different FA and glucose sources, as well as possible disturbances therein during exercise in type 2 diabetes [6, 7, 31-33]. Previous studies have suggested that the use of total fat [32], muscle glycogen $[7,31]$, plasma FFA [6] and/or IMTG [33] as a substrate source during exercise is substantially impaired in T2DM patients versus control subjects. Therefore, in chapter 2, we investigated the effects of acute moderate-intensity exercise on substrate source metabolism in T2DM patients. As repeatedly demonstrated before $[6,7,31,32]$, plasma glucose concentrations dropped significantly in the T2DM patients during exercise, as a result of increased glucose disposal. Interestingly, despite previous data showing otherwise [6, 7, 31-33], no significant differences in substrate source metabolism were found between diabetes patients and the control group during 60 minutes of exercise at $50 \% \mathrm{Wmax}$. However, it should be noted that the apparently normal FFA and TG-derived oxidation rates in T2DM were observed in the presence of a significantly greater FFA turnover. Furthermore, plasma FFA oxidation tended to be greater in T2DM. The findings of greater rates of plasma FFA Ra and consequently, of higher Rd and a tendency to higher FFA Rox in T2DM are in line with the finding in the fasted state that plasma FFA Ra (reflecting adipose tissue lipolysis) and thus, FFA availability determines at least part of plasma FFA disposal (Rd) and Rox. Although significantly greater FFA turnover was observed, our data do not support the hypothesis that the capacity to oxidize plasma FFA and/or IMTG during exercise is substantially different in type 2 diabetes patients when compared to normoglycemic controls $[6,33]$. This may be explained by differences between subjects' populations in plasma FFA release from adipose tissue and consequently, in plasma FFA Rd. IMTG oxidation has been suggested to be lower in T2DM when compared with a young lean endurance-trained control group [33], but was greater when compared with obese age-matched control subjects [6]. In the latter study, the T2DM patients displayed a lower adipose tissue lipolytic 
rate and lower whole-body plasma FA uptake and oxidation as compared with obese controls [6], whereas in the present study, plasma FFA Ra and Rd were significantly greater as compared with the control group. This is in line with the idea that plasma FFA Ra determines, at least part of, plasma FFA Rd, IMTG and FFA oxidation rate $[34,35]$ and that therefore, differences between studies and/or study populations can at least in part be explained by differences in FFA release from adipose tissue, which drives FFA uptake and oxidation. During exercise, the impairment in fasting plasma glucose uptake is improved to a level comparable to that in healthy overweight control subjects. Amongst others, one possible mechanism to explain the normalized glucose uptake is the AMPK-pathway. As discussed in further detail below, AMPK is an important regulator of substrate metabolism. It has also been called a 'metabolic master switch', sensing fuel availability and inducing physiological processes to restore the energy balance [36-40] such as an insulin-independent increase in glucose uptake. It is activated during exercise and appears largely intact in the T2DM state [41-45]. Activation of the AMPK pathway during exercise may therefore explain the increased glucose uptake during exercise in T2DM. Taken together, no significant disturbances in FA or glucose oxidation rates appear to be present during acute moderateintensity exercise in overweight long-term diagnosed T2DM patients when compared with overweight normoglycemic controls.

\section{Life-long exercise training and substrate metabolism}

As mentioned earlier, exercise training significantly reduces body fat percentage, improves the capacity of adipose tissue to buffer lipid flux, increases skeletal muscle FA oxidative capacity and thus, potentially lowers ectopic lipid accumulation and insulin resistance. However, data on the effects of short-term training programs on substrate metabolism are in contrast to data derived from cross-sectional comparisons between sedentary subjects and endurance-trained athletes that have been training for several years. The latter ascribe the traininginduced increase in whole-body fat oxidation during exercise to a greater adipose tissue lipolysis, FFA skeletal muscle uptake and oxidation of plasma FFA [46-50]. In contrast, short-term $(<1 \mathrm{y})$ training studies suggest that a greater IMTG oxidation explains the increase in whole-body fat oxidation [51-54]. Secondly, data on the effects of long-term training deducted from young athletes might not be representative for the effects that can be attained at a higher age, at which T2DM usually develops. Therefore, as described in chapter 3, we studied resting and exercise $(50 \%$ Wmax) substrate metabolism in older athletes who had been involved in regular training for at least 25 years. As compared with age-matched sedentary controls, the athletes indeed had a significantly greater total fat 
oxidation during exercise, which was attributed entirely to higher plasma FFA oxidation rates. Furthermore, athletes had a significantly higher resting muscle succinate dehydrogenase (SDH) activity (a measure of skeletal muscle oxidative capacity) and a significantly lower body mass, BMI and body fat percentage. This suggests that, despite higher age, a high fat oxidative capacity and low percentage body fat can be maintained. Though it is tempting to explain the difference in fat oxidative capacity between athletes and sedentary subjects by the difference in physical fitness, activity level and/or body composition, a primary genetic difference between athletes and sedentary subjects cannot be excluded [55]. Taken together, the results described in chapter 2 and 3 of this thesis add to existing data that exercise can contribute to a healthy metabolic state. Acute exercise in type 2 diabetes patients decreases plasma glucose levels (chapter 2), while being active throughout life is associated with an increased workload capacity, an increased capacity for fatty acid oxidation and low percentage body fat (chapter 3). On the contrary, a sedentary lifestyle is associated with increased adipose tissue FA release, elevated plasma FFA concentrations and a lower fat oxidative capacity (chapter 2 and 3). It is therefore not surprising that some authors have provocatively defined physical inactivity as the major cause of T2DM and state that a population wide increase in physical activity may reverse the diabetes epidemic $[5,26,56]$.

\section{AMPK - a metabolic master switch in substrate metabolism}

The regulation of substrate metabolism is extremely complex and the exact mechanisms of its regulation are a major focus in diabetes research. As exercise can reverse at least some of the previously mentioned metabolic disturbances in type 2 diabetes, the biochemical regulation of metabolism during exercise is particularly interesting. The discovery of the AMP-activated protein kinase (AMPK) and its functions is therefore an important advance of this field. AMPK is activated under conditions of cell stress such as exercise and hypoxia $[38,39]$ by both allosteric mechanisms (through an increase in the AMP:ATP ratio, [36]) and covalent mechanisms, through activation by AMPK kinases such as LKB1 and CaMKK [40, 57]. Activation processes are generally thought to be localized intracellularly, but adipokines such as IL-6, adiponectin and leptin and other hormones have also been found to activate AMPK (reviewed in [58]). AMPK is geared towards re-establishing the AMP:ATP ratio by turning on energyproducing pathways and turning off energy-consuming pathways [36]. Amongst others, AMPK activation increases glucose uptake into skeletal muscle [59], decreases glucose production by the liver [60] and decreases lipolysis in adipose tissue $[61,62]$. It is also involved in the hypothalamic regulation of feeding $[63$, 
64], mitochondrial biogenesis and the regulation of gene expression [37]. The AMPK pathway appears largely intact in obese and/or type 2 diabetes patients [41-45]. Therefore, its effect on substrate metabolism suggests that AMPK and its activators could be a target to prevent and/or treat the disturbances in glucose and FA metabolism in T2DM. AMPK has been studied extensively in vitro and in vivo in several organs and cell types using the AMPK activator AICAR [59, 65-70]. Despite this, in vivo studies in humans are scarce $[71,72]$ and in vivo research in type 2 diabetes patients was non-existent at the time of our studies. In chapter 4 and 5 we describe the effects of AICAR infusion in healthy young and type 2 diabetes patients, respectively. In chapter 4, we showed that intra-arterial AICAR administration in young, healthy subjects significantly lowers plasma glucose levels. The decline in plasma glucose concentrations was dose-dependent and without side effects. Unexpectedly, AICAR also induced a significant decline in plasma FFA levels, but the underlying mechanisms could not be clarified with the methods used in this protocol. For this aim, we designed and performed the study described in chapter 5 . In this study, stable isotope methodology and blood and muscle biopsy sampling were applied to assess blood glucose and fatty acid kinetics during continuous intravenous infusion of AICAR in type 2 diabetes patients. In contrast to our expectations, we found rather small effects on skeletal muscle glucose or FFA uptake, but a significant reduction in plasma glucose and FFA $\mathrm{Ra}$, representing hepatic glucose output and adipose tissue lipolysis, respectively. From the perspective of the lipid overflow theory, these are intruiging results. Lowering of adipose tissue lipolysis and consequently, of plasma FFA concentration, by the artificial AMPK-activator AICAR will lower the supply of FA to non-adipose tissue. A decreased supply of FA potentially lowers ectopic lipid accumulation and the risk for the development or progression of insulin resistance. Furthermore, AICAR decreased hepatic glucose output, thus decreasing hyperglycemia. The mechanism underlying the effects of AICAR on adipose tissue lipolysis and hepatic glucose output are incompletely understood. AICAR-induced suppression of adipose tissue lipolysis seems to be mediated by a suppression of the activity of the lipolytic enzyme hormone sensitive lipase (HSL) [73]. The role of the recently identified adipose triglyceride lipase (ATGL) on acute AICAR-induced effects on lipolysis is currently not clear and this question should be addressed in future research [74]. Inhibition of gluconeogenesis by AICAR has been proposed to occur via inhibition of transcription of the gluconeogenic enzymes phosphoenolpyruvate carboxykinase (PEPCK) and glucose-6-phosphatase (G6P) [60]. Taken together, the effects of AICAR on adipose tissue lipolysis and hepatic glucose output would make activation of AMPK, either by pharmacological or physiological means, an 
interesting treatment for the disturbances in substrate metabolism in T2DM. The idea of therapeutic activation of AMPK through AICAR or another artificial activator is an attractive thought for sedentary patients unwilling or unable to perform regular daily exercise. However, some concerns may be raised [75], though these are theoretical rather than evidence-based, as in vivo studies on long-term AICAR administration in humans are lacking. For one, AICAR itself has poor bioavailability via oral administration [76] and its effects disappear upon discontinuation of infusion (chapter 4 and 5). Secondly, the AMP-activated protein kinase is a complex protein with multiple isoforms distributed over different tissues [77] thus it can be hypothesized that any AMPK activator should target all isoforms but at the same time not activate other AMP-sensitive enzymes such as glycogen phosphorylase and fructose-1,6-bifosfonate [78, 79]. Furthermore, the metabolic (side-)effects of artificially activating AMPK on a whole-body level might be unwanted. Artificially activating AMPK in the hypothalamus stimulates food intake [64] and might thus induce weight gain. Indeed, two existing classes of drugs used in the treatment of type 2 diabetes, i.e. the thiazolidinediones (e.g. rosiglitazone) and biguanides (e.g. metformin) can both activate AMPK and are shown to induce weight gain [80]. Weight gain and continuous suppression of adipose tissue lipolysis can be hypothesized to exacerbate adipose tissue dysfunction as they will increase the demand for FA storage and might thus increase adipocyte size. As mentioned earlier, enlargement of adipocytes can result in impaired buffering capacity of adipose tissue and increased FA flow to the circulation, as well as increased secretion of inflammatory factors and/or adipokines and thus cause insulin resistance [81]. Finally, although AMPK activation may be a very promising novel cancer treatment [82], as it inhibits protein synthesis, cell growth and proliferation [83, $84]$, an inability of healthy cells to grow or proliferate due to high AMPK activation is certainly undesired. However, as mentioned, these arguments are all theory-based rather than evidence-based and pharmacological AMPK activation for the treatment of type 2 diabetes should not be ruled out based only on these theoretical arguments. From the data described in this thesis, which include the first data in type 2 diabetes patients, we can conclude that in vivo AICAR administration is a safe and effective means to acutely lower plasma glucose and FFA levels in both healthy subjects and type 2 diabetes patients. Based on animal studies, a general consensus exists that agents, like AICAR, that activate AMPK may be useful in the treatment of obesity and diabetes. This could be especially important for patients who are unable to exercise because of severe musculoskeletal or cardiovascular conditions. 


\section{Concluding remarks}

Type 2 diabetes mellitus (T2DM) is a disease characterised by a decreased lipid buffering capacity of adipose tissue, an impaired insulin-mediated glucose uptake and impaired skeletal muscle FA oxidative capacity. Acknowledging the complexity of the regulation of substrate metabolism, where organs communicate by closely connected neural, endocrine and/or paracrine pathways, it is easy to understand that a severe metabolic dysregulation as in T2DM is accompanied by dysfunctions in more than one organ and/or tissue. The latter include not only skeletal muscle, adipose tissue or pancreas, but also the liver and central nervous system. Some aspects of this perspective of 'multiple organ dysfunction' were confirmed in the studies described in this thesis. In particular, the results suggest that in T2DM, the regulation of FA metabolism by several organs as well as the crosstalk between these tissues is disturbed. Adipose tissue lipolysis appeared to be increased under fasting conditions in longer-term diagnosed T2DM patients (chapter 2), which was likely due to both insulin resistance of adipose tissue and an inability of the pancreas to secrete sufficient insulin (chapter 2) to inhibit adipose tissue lipolysis. In turn, this increased release of FFA from adipose tissue seems to drive the rate of plasma FFA disposal and oxidation in skeletal muscle (chapter 2 and 3). On the other hand, skeletal muscle fat oxidative capacity was lower in obese and T2DM subjects as compared to trained controls, which compromised the ability to oxidize the greater FA load (chapter 3) and predisposes to increased ectopic lipid accumulation. Research has led to increased awareness of the complexity of type 2 diabetes, which is expressed by an increased study of the inter-organ crosstalk. In the studies described in this thesis this interaction between organs in the (dys)regulation of substrate metabolism was confirmed. As a consequence, we strongly encourage further research that emanates from such an integrated perspective.

Physical inactivity and obesity are the prime deregulatory factors of substrate metabolism, and some even argue that a lack of physical activity is the main cause of the obesity and diabetes epidemic [5, 26, 28]. With physical inactivity being at the roots of chronic metabolic diseases, including type 2 diabetes, the most efficient approach to prevent and/or treat the diabetes epidemic would be to target physical inactivity. Chapter 2 of this thesis confirms previous data from the literature, demonstrating that acute physical activity increases glucose disposal in type 2 diabetes patients. Chapter 3 adds to existing data on short-term training studies and cross-sectional comparisons between young athletes and sedentary controls, by demonstrating that a lifelong high physical activity level is associated with an increased workload capacity, an increased capacity for fatty acid 
oxidation and low percentage body fat. Furthermore, AICAR, which has been regarded as an exercise-mimetic [75, 85], was shown to lower plasma glucose and FFA concentrations in in healthy control subjects (chapter 4) and in type 2 diabetes patients (chapter 5). Thus, physical activity or activation of its pathways has the potential to reverse at least some of the metabolic disturbances of type 2 diabetes. Further research is needed to understand the biomolecular pathways that underlie the metabolic effects of exercise and determine mode, volume, frequency and intensity of exercise that is both effective as well as socially and economically feasible.

\section{Future research}

Although the research described in this thesis contributes to the understanding of the physiological mechanisms underlying the disturbances in fatty acid and glucose metabolism in type 2 diabetes, several questions remain to be answered.

AMPK may inhibit FFA release from adipose tissue (chapter 4) and might thus reduce lipid overflow to non-adipose tissues in obesity and/or T2DM. However, data on the role of AMPK in adipose tissue in the obese and/or T2DM state, and the effects of exercise (training) on AMPK and/or adipose tissue function is scarce. Furthermore, the biochemical pathway underlying the inhibition of FFA release into the plasma by AICAR likely involves inhibition of adipose tissue lipolysis, but this is currently unclear.

Therefore, we propose the following research questions:

- Is basal AMPK expression (mRNA and protein) and/or basal and exerciseinduced in vivo AMPK activity different in the T2DM state when compared with the obese, lean and/or endurance-trained state?

- Does AMPK activation by AICAR in vitro and in vivo inhibit lipolysis in adipocytes from T2DM patients and is this response different from that in obese, lean and/or endurance-trained subjects?

- Can endurance exercise training correct regulation of basal and/or postprandial adipose tissue lipolysis in T2DM and is this accompanied by changes in AMPK activity and/or expression?

- Is the reduction in lipid overflow that is expected after exercise training accompanied by an improved adipose tissue function (i.e. altered secretion of adipokines and/or pro-and anti-inflammatory factors)? 


\section{REFERENCES}

1. Katon WJ (2008) The comorbidity of diabetes mellitus and depression. Am J Med 121: S815

2. Poos MJJC, Smit JM, Groen J, Kommer GJ, Slobbe LCJ (2008) Kosten van ziekten in Nederland 2005. In. Rijksinstituut voor Volksgezondheid en Milieu, Bilthoven

3. Association AD (2008) Economic costs of diabetes in the U.S. in 2007. In: Diabetes Care, pp 596-615

4. Reaven GM (1988) Banting lecture 1988. Role of insulin resistance in human disease. Diabetes 37: 1595-1607

5. Telford RD (2007) Low physical activity and obesity: causes of chronic disease or simply predictors? Med Sci Sports Exerc 39: 1233-1240

6. Blaak EE, van Aggel-Leijssen DP, Wagenmakers AJ, Saris WH, van Baak MA (2000) Impaired oxidation of plasma-derived fatty acids in type 2 diabetic subjects during moderate-intensity exercise. Diabetes 49: 2102-2107

7. Borghouts LB, Wagenmakers AJM, Goyens PLL, Keizer HA (2002) Substrate utilization in non-obese type II diabetic patients at rest and during exercise. Clinical Science 103: 559566

8. Colberg SR, Hagberg JM, McCole SD, Zmuda JM, Thompson PD, Kelley DE (1996) Utilization of glycogen but not plasma glucose is reduced in individuals with NIDDM during mild-intensity exercise. J Appl Physiol 81: 2027-2033

9. Kelley DE, Mandarino LJ (1990) Hyperglycemia normalizes insulin-stimulated skeletal muscle glucose oxidation and storage in noninsulin-dependent diabetes mellitus. J Clin Invest 86: 1999-2007

10. Kelley DE, Simoneau J-A (1994) Impaired free fatty acid utilization by skeletal muscle in non-insulin dependent diabetes mellitus. J Clin Invest 94: 2349-2356

11. Groop LC, Bonadonna RC, DelPrato S, et al. (1989) Glucose and free fatty acid metabolism in non-insulin-dependent diabetes mellitus. Evidence for multiple sites of insulin resistance. J Clin Invest 84: 205-213

12. Groop LC, Saloranta C, Shank M, Bonadonna RC, Ferrannini E, DeFronzo RA (1991) The role of free fatty acid metabolism in the pathogenesis of insulin resistance in obesity and noninsulin-dependent diabetes mellitus. J Clin Endocrinol Metab 72: 96-107

13. Blaak EE, Wagenmakers AJM, Glatz JFC, et al. (2000) Plasma FFA utilization and fatty acid-binding protein content are diminished in type 2 diabetic muscle. Am J Physiol Endocrinol Metab 279: E146-E154

14. Boden G, Chen X (1995) Effects of fat on glucose uptake and utilization in patients with non-insulin-dependent diabetes. J Clin Invest 96: 1261-1268

15. Coppack SW, Evans RD, Fisher RM, et al. (1992) Adipose tissue metabolism in obesity: lipase action in vivo before and after a mixed meal. Metabolism 41: 264-272

16. Frayn $\mathrm{KN}$ (2002) Adipose tissue as a buffer for daily lipid flux. Diabetologia 45: 1201-1210

17. Potts JL, Coppack SW, Fisher RM, Humphreys SM, Gibbons GF, Frayn KN (1995) Impaired postprandial clearance of triacylglycerol-rich lipoproteins in adipose tissue in obese subjects. Am J Physiol 268: E588-594

18. Riemens SC, Sluiter WJ, Dullaart RP (2000) Enhanced escape of non-esterified fatty acids from tissue uptake: its role in impaired insulin-induced lowering of total rate of appearance in obesity and Type II diabetes mellitus. Diabetologia 43: 416-426

19. Achten J, Jeukendrup AE (2004) Optimizing fat oxidation through exercise and diet. Nutrition 20: 716-727 
Hu FB, Manson JE, Stampfer MJ, et al. (2001) Diet, lifestyle, and the risk of type 2 diabetes mellitus in women. N Engl J Med 345: 790-797

Hu FB, Sigal RJ, Rich-Edwards JW, et al. (1999) Walking compared with vigorous physical activity and risk of type 2 diabetes in women: a prospective study. JAMA 282: 1433-1439 Sullivan PW, Morrato EH, Ghushchyan V, Wyatt HR, Hill JO (2005) Obesity, inactivity, and the prevalence of diabetes and diabetes-related cardiovascular comorbidities in the U.S., 2000-2002. Diabetes Care 28: 1599-1603

Eaton SB, Konner M, Shostak M (1988) Stone agers in the fast lane: chronic degenerative diseases in evolutionary perspective. Am J Med 84: 739-749

Albright A, Franz M, Hornsby G, et al. (2000) American College of Sports Medicine position stand. Exercise and type 2 diabetes. Med Sci Sports Exerc 32: 1345-1360

Blaak EE, Saris WH (2002) Substrate oxidation, obesity and exercise training. Best Pract Res Clin Endocrinol Metab 16: 667-678

Booth FW, Gordon SE, Carlson CJ, Hamilton MT (2000) Waging war on modern chronic diseases: primary prevention through exercise biology. J Appl Physiol 88: 774-787

Bruce CR, Hawley JA (2004) Improvements in insulin resistance with aerobic exercise training: a lipocentric approach. Med Sci Sports Exerc 36: 1196-1201

Hawley JA (2004) Exercise as a therapeutic intervention for the prevention and treatment of insulin resistance. Diabetes Metab Res Rev 20: 383-393

Hayashi T, Woitaszewski JF, Goodyear L] (1997) Exercise regulation of glucose transport in skeletal muscle. Am J Physiol 273: E1039-1051

Martin WH, 3rd (1996) Effects of acute and chronic exercise on fat metabolism. Exerc Sport Sci Rev 24: 203-231

Colberg SR, Simoneau JA, Thaete FL, Kelley DE (1995) Skeletal muscle utilization of free fatty acids in women with visceral obesity. J Clin Invest 95: 1846-1853

Martin IK, Katz A, Wahren J (1995) Splanchnic and muscle metabolism during exercise in NIDDM patients. Am J Physiol 269: E583-590

van Loon LJC (2004) Use of intramuscular triacylglycerol as a substrate source during exercise in humans. J Appl Physiol 97: 1170-1187

van Loon LJ, Manders RJ, Koopman R, et al. (2005) Inhibition of adipose tissue lipolysis increases intramuscular lipid use in type 2 diabetic patients. Diabetologia 48: 2097-2107

van Loon LJ, Thomason-Hughes M, Constantin-Teodosiu D, et al. (2005) Inhibition of adipose tissue lipolysis increases intramuscular lipid and glycogen use in vivo in humans. Am J Physiol Endocrinol Metab 289: E482-493

Carling D, Clarke PR, Zammit VA, Hardie DG (1989) Purification and characterization of the AMP-activated protein kinase. Copurification of acetyl-CoA carboxylase kinase and 3hydroxy-3-methylglutaryl-CoA reductase kinase activities. Eur J Biochem 186: 129-136 Hardie DG (2008) AMPK: a key regulator of energy balance in the single cell and the whole organism. Int J Obes (Lond) 32 Suppl 4: S7-12

Hardie DG, Carling D, Carlson M (1998) The AMP-activated/SNF1 protein kinase subfamily: metabolic sensors of the eukaryotic cell? Annu Rev Biochem 67: 821-855

9. Hardie DG, Salt IP, Davies SP (2000) Analysis of the role of the AMP-activated protein kinase in the response to cellular stress. Methods in molecular biology 99: 63-74

Sakamoto K, McCarthy A, Smith D, et al. (2005) Deficiency of LKB1 in skeletal muscle prevents AMPK activation and glucose uptake during contraction. EMBO J 24: 1810-1820 Koistinen HA, Galuska D, Chibalin AV, et al. (2003) 5-amino-imidazole carboxamide riboside increases glucose transport and cell-surface GLUT4 content in skeletal muscle from subjects with type 2 diabetes. Diabetes 52: 1066-1072 
42. Musi N, Fujii N, Hirshman MF, et al. (2001) AMP-activated protein kinase (AMPK) is activated in muscle of subjects with type 2 diabetes during exercise. Diabetes 50: 921-927

43. Musi N, Hirshman MF, Nygren J, et al. (2002) Metformin increases AMP-activated protein kinase activity in skeletal muscle of subjects with type 2 diabetes. Diabetes 51 : 2074-2081

44. Sriwijitkamol A, Coletta DK, Wajcberg E, et al. (2007) Effect of acute exercise on AMPK signaling in skeletal muscle of subjects with type 2 diabetes: a time-course and doseresponse study. Diabetes 56: 836-848

45. Steinberg GR, Smith AC, Van Denderen BJ, et al. (2004) AMP-activated protein kinase is not down-regulated in human skeletal muscle of obese females. J Clin Endocrinol Metab 89: 4575-4580

46. Coggan AR, Spina RJ, King DS, et al. (1992) Skeletal muscle adaptations to endurance training in 60- to 70-yr-old men and women. J Appl Physiol 72: 1780-1786

47. Crampes F, Riviere D, Beauville M, Marceron M, Garrigues M (1989) Lipolytic response of adipocytes to epinephrine in sedentary and exercise-trained subjects: sex-related differences. Eur J Appl Physiol Occup Physiol 59: 249-255

48. Despres JP, Bouchard C, Savard R, Tremblay A, Marcotte M, Theriault G (1984) Effects of exercise-training and detraining on fat cell lipolysis in men and women. Eur J Appl Physiol Occup Physiol 53: 25-30

49. Kiens B, Roepstorff C, Glatz JF, et al. (2004) Lipid-binding proteins and lipoprotein lipase activity in human skeletal muscle: influence of physical activity and gender. J Appl Physiol 97: 1209-1218

50. Turcotte LP, Richter EA, Kiens B (1992) Increased plasma FFA uptake and oxidation during prolonged exercise in trained vs. untrained humans. Am J Physiol 262: E791-799

51. Hurley BF, Nemeth PM, Martin WH, 3rd, Hagberg JM, Dalsky GP, Holloszy JO (1986) Muscle triglyceride utilization during exercise: effect of training. J Appl Physiol 60: 562567

52. Martin WH, 3rd, Dalsky GP, Hurley BF, et al. (1993) Effect of endurance training on plasma free fatty acid turnover and oxidation during exercise. Am J Physiol 265: E708-714

53. Phillips SM, Green HJ, Tarnopolsky MA, Heigenhauser GF, Hill RE, Grant SM (1996) Effects of training duration on substrate turnover and oxidation during exercise. J Appl Physiol 81: 2182-2191

54. Schrauwen P, van Aggel-Leijssen DP, Hul G, et al. (2002) The effect of a 3-month lowintensity endurance training program on fat oxidation and acetyl-CoA carboxylase-2 expression. Diabetes 51: 2220-2226

55. Joosen AM, Gielen M, Vlietinck R, Westerterp KR (2005) Genetic analysis of physical activity in twins. Am J Clin Nutr 82: 1253-1259

56. Booth FW, Chakravarthy MV, Spangenburg EE (2002) Exercise and gene expression: physiological regulation of the human genome through physical activity. J Physiol 543: 399-411

57. Wilson WA, Hawley SA, Hardie DG (1996) Glucose repression/derepression in budding yeast: SNF1 protein kinase is activated by phosphorylation under derepressing conditions, and this correlates with a high AMP:ATP ratio. Curr Biol 6: 1426-1434

58. Kahn BB, Alquier T, Carling D, Hardie DG (2005) AMP-activated protein kinase: ancient energy gauge provides clues to modern understanding of metabolism. Cell Metab 1: 15-25

59. Merrill GF, Kurth EJ, Hardie DG, Winder WW (1997) AICA riboside increases AMPactivated protein kinase, fatty acid oxidation, and glucose uptake in rat muscle. Am J Physiol 273: E1107-1112 
Lochhead PA, Salt IP, Walker KS, Hardie DG, Sutherland C (2000) 5-aminoimidazole-4carboxamide riboside mimics the effects of insulin on the expression of the 2 key gluconeogenic genes PEPCK and glucose-6-phosphatase. Diabetes 49: 896-903

61. Daval M, Diot-Dupuy F, Bazin R, et al. (2005) Anti-lipolytic action of AMP-activated protein kinase in rodent adipocytes. J Biol Chem 280: 25250-25257

62. Garton AJ, Campbell DG, Carling D, Hardie DG, Colbran RJ, Yeaman SJ (1989) Phosphorylation of bovine hormone-sensitive lipase by the AMP-activated protein kinase. A possible antilipolytic mechanism. Eur J Biochem 179: 249-254

63. Andersson U, Filipsson K, Abbott CR, et al. (2004) AMP-activated protein kinase plays a role in the control of food intake. J Biol Chem 279: 12005-12008

64. Minokoshi Y, Alquier T, Furukawa N, et al. (2004) AMP-kinase regulates food intake by responding to hormonal and nutrient signals in the hypothalamus. Nature 428: 569-574

65. Bergeron R, Previs SF, Cline GW, et al. (2001) Effect of 5-aminoimidazole-4-carboxamide1-beta-D-ribofuranoside infusion on in vivo glucose and lipid metabolism in lean and obese Zucker rats. Diabetes 50: 1076-1082

66. Bergeron R, Ren JM, Cadman KS, et al. (2001) Chronic activation of AMP kinase results in NRF-1 activation and mitochondrial biogenesis. Am J Physiol Endocrinol Metab 281: E1340-E1346

67. Bergeron R, Russell RR, 3rd, Young LH, et al. (1999) Effect of AMPK activation on muscle glucose metabolism in conscious rats. Am J Physiol 276: E938-944

68. Iglesias MA, Furler SM, Cooney GJ, Kraegen EW, Ye J-M (2004) AMP-activated protein kinase activation by AICAR increases both muscle fatty acid and glucose uptake in white muscle of insulin-resistant rats in vivo. Diabetes 53: 1649-1654

69. Iglesias MA, Ye JM, Frangioudakis G, et al. (2002) AICAR administration causes an apparent enhancement of muscle and liver insulin action in insulin-resistant high-fat-fed rats. Diabetes 51: 2886-2894

70. Kurth-Kraczek EJ, Hirshman MF, Goodyear LJ, Winder WW (1999) 5' AMP-activated protein kinase activation causes GLUT4 translocation in skeletal muscle. Diabetes 48: $1667-1671$

71. Cuthbertson DJ, Babraj JA, Mustard KJ, et al. (2007) 5-aminoimidazole-4-carboxamide 1beta-D-ribofuranoside acutely stimulates skeletal muscle 2-deoxyglucose uptake in healthy men. Diabetes 56: 2078-2084

72. Babraj JA, Mustard K, Sutherland C, et al. (2009) Blunting of AICAR-induced human skeletal muscle glucose uptake in type 2 diabetes is dependent on age rather than diabetic status. Am J Physiol Endocrinol Metab 296: E1042-1048

73. Anthony NM, Gaidhu MP, Ceddia RB (2009) Regulation of Visceral and Subcutaneous Adipocyte Lipolysis by Acute AICAR-induced AMPK Activation. Obesity (Silver Spring) Gaidhu MP, Fediuc S, Anthony NM, et al. (2008) Prolonged aicar-induced amp-kinase activation promotes energy dissipation in white adipocytes: Novel mechanisms integrating HSL and ATGL. J Lipid Res

75. Goodyear LJ (2008) The exercise pill-mtoo good to be true? N Engl J Med 359: 1842-1844

76. Dixon R, Gourzis J, McDermott D, Fujitaki J, Dewland P, Gruber H (1991) AICA-riboside: safety, tolerance, and pharmacokinetics of a novel adenosine-regulating agent. J Clin Pharmacol 31: 342-347

77. Towler MC, Hardie DG (2007) AMP-activated protein kinase in metabolic control and insulin signaling. Circ Res 100: 328-341

78. Longnus SL, Wambolt RB, Parsons HL, Brownsey RW, Allard MF (2003) 5Aminoimidazole-4-carboxamide 1-beta -D-ribofuranoside (AICAR) stimulates myocardial 
glycogenolysis by allosteric mechanisms. Am J Physiol Regul Integr Comp Physiol 284: R936-944

79. Vincent MF, Marangos PJ, Gruber HE, Van den Berghe G (1991) Inhibition by AICA riboside of gluconeogenesis in isolated rat hepatocytes. Diabetes 40: 1259-1266

Fryer LG, Parbu-Patel A, Carling D (2002) The Anti-diabetic drugs rosiglitazone and metformin stimulate AMP-activated protein kinase through distinct signaling pathways. J Biol Chem 277: 25226-25232

81. Goossens GH (2008) The role of adipose tissue dysfunction in the pathogenesis of obesityrelated insulin resistance. Physiol Behav 94: 206-218

82. Kuhajda FP (2008) AMP-activated protein kinase and human cancer: cancer metabolism revisited. Int J Obes (Lond) 32 Suppl 4: S36-41

83. Bolster DR, Crozier SJ, Kimball SR, Jefferson LS (2002) AMP-activated protein kinase suppresses protein synthesis in rat skeletal muscle through down-regulated mammalian target of rapamycin (mTOR) signaling. J Biol Chem 277: 23977-23980

84. Kimura N, Tokunaga C, Dalal S, et al. (2003) A possible linkage between AMP-activated protein kinase (AMPK) and mammalian target of rapamycin (mTOR) signalling pathway. Genes Cells 8: 65-79

85. Narkar VA, Downes M, Yu RT, et al. (2008) AMPK and PPARdelta agonists are exercise mimetics. Cell 134: 405-415 
Summary

Samenvatting 
Type 2 diabetes mellitus (T2DM) is a disease diagnosed by hyperglycemia but characterised by severe disturbances in the regulation of both glucose and fat metabolism. A high energy intake and low energy expenditure through low physical acivity are important risk factors for the development and progression of T2DM. Enlarged adipose tissue may have a decreased capacity to adequately take up and store dietary fatty acids (FA), leading to increased plasma FA flux to non-adipose tissues including skeletal muscle. This is particularly precarious when levels of physical activity and skeletal muscle FA oxidative capacity are decreased, as storage of these FA is then more likely to occur. This accumulation of lipids and subsequent formation of lipid metabolites may disturb cell function and induce or exacerbate insulin resistance in skeletal muscle. Exercise and exercise training may positively affect the disturbances in supply, uptake and oxidation of FA and carbohydrate, e.g. by increasing glucose uptake, FA oxidation and skeletal muscle FA oxidative capacity and by decreasing FA release. This occurs at least in part through pathways mediated by the AMP-activated protein kinase (AMPK). The AMPK pathway is not only an interesting target for the study of metabolic regulation in response to exercise, but also for pharmacological intervention. This thesis includes a series of studies on disturbances in glucose and fatty acid metabolism in type 2 diabetes mellitus and investigates two approaches to prevent and/or correct these disturbances: exercise and pharmacological targeting of the insulinindependent AMPK pathway. Chapter 2 of this thesis describes a detailed study of substrate metabolism at rest, during exercise and subsequent postexercise recovery in overweight type 2 diabetes patients using contemporary stable isotope tracer methodology. In long-term diagnosed, overweight T2DM patients adipose tissue lipolysis is increased when compared with healthy ageand weight-matched controls, resulting in higher FFA availability, uptake and oxidation, and lower carbohydrate oxidation rates at rest and during exercise. The greater adipose tissue lipolysis in T2DM is likely explained by adipose tissue insulin resistance to the suppression of lipolysis and an absence of hyperinsulinemia to compensate for this insulin resistance. Slight differences between our and previous data furthermore indicate that subjects' characteristics such as BMI, diet, level of physical fitness and basal plasma values can significantly influence the obtained results and are thus likely to complicate data interpretation if they remain unidentified. The results described in chapters 2 and 3 of this thesis indicate that exercise, as a single bout or as part of a lifelong training program, represents an effective approach to prevent and/or improve metabolic disturbances associated with insulin resistance and T2DM. The results in chapter 2 describe that acute exercise in type 2 diabetes 
patients decreases plasma glucose levels. In addition, chapter 3 demonstrates that being active throughout life is associated with an increased workload capacity, an increased capacity for FA oxidation and a lower body fat percentage when compared with healthy sedentary controls. This implies that a high fat oxidative capacity and healthy body composition can be maintained as long as sufficient physical activity is performed, even at a more advanced age. The lower skeletal muscle fat oxidative capacity found in obese and T2DM subjects when compared with trained controls may compromise the ability to oxidise the greater FA load and may predispose to greater ectopic lipid accumulation, insulin resistance and T2DM. At least part of the beneficial effects of exercise on substrate metabolism are proposed to be mediated by AMPK. Chapters 4 and 5 of this thesis describe the effects of in vivo administration of the pharmacological AMPK activator AICAR on substrate metabolism in healthy subjects and type 2 diabetes patients, respectively. AICAR infusion induced a significant decline in plasma FFA and glucose concentrations, which was attributed to an inhibition of adipose tissue lipolysis and hepatic glucose output. These data suggest that AICAR has a significant inhibitory effect on adipose tissue FA release and plasma FFA concentration, which might lower lipid accumulation in non-adipose tissues and associated development or progression of insulin resistance. Though acute AICAR administration is shown to be safe and without direct side-effects, its long-term side effects warrant further investigation. 
Type 2 diabetes (T2DM) is een aandoening die wordt gediagnosticeerd op basis van een verhoogde plasma glucoseconcentratie, maar die zich kenmerkt door ernstige verstoringen in niet alleen het glucose- maar ook het vetmetabolisme. Bij een grote massa vetweefsel kan de capaciteit van dit vetweefsel om vetten op te nemen of vast te houden in de vetcellen verminderd zijn. Dit leidt ertoe dat er een grotere flux van vetzuren zal zijn van het vetweefsel naar het bloed en vervolgens naar de overige organen, zoals de skeletspieren en pancreas. Vooral als er ook sprake is van weinig lichamelijke inspanning of een lage capaciteit van de spieren om vetten te verbranden, kan dit een probleem worden. In dit geval zal er eerder een opslag van vetzuren en vorming van lipidintermediairen zijn in de skeletspieren en andere organen ('ectopische vetopslag'), wat kan leiden tot insulineresistentie. Lichamelijke inspanning en training kunnen de verstoringen in aanvoer, opname en verbranding van vetten en koolhydraten verbeteren, onder andere door het verhogen van de glucoseopname, de verbranding van vetzuren en de oxidatieve capaciteit van de skeletspieren. Deze processen worden deels gemedieerd door AMPK ('AMPactivated protein kinase'), een enzym dat de energiestatus in cellen reguleert. Dit proefschrift beschrijft een reeks studies naar verstoringen in glucose- en vetstofwisseling in type 2 diabetes mellitus en onderzoekt twee benaderingen ter voorkoming en / of correctie van deze verstoringen: lichaamsbeweging en farmacologische stimulering van de insuline-onafhankelijke AMPK signaleringscascade. Hoofdstuk 2 van dit proefschrift geeft een gedetailleerde beschrijving van substraatstofwisseling in rust, tijdens lichamelijke inspanning en het daaropvolgende herstel in T2DM patiënten met overgewicht. Hierbij wordt gebruik gemaakt van stabiele isotoop tracer methodologie. Bij langetermijn gediagnosticeerde T2DM patiënten met overgewicht is de afgifte van vrije vetzuren vanuit het vetweefsel hoger, wat resulteert in een hogere plasma vrije vetzuur concentratie, en een hogere vetzuur opname en verbranding in weefsels. De koolhydraatverbranding in rust en tijdens inspanning is lager in vergelijking met gezonde controle personen met eenzelfde leeftijd en gewicht. De grotere afgifte van vetzuren door vetweefsel in T2DM is waarschijnlijk te verklaren door een verminderde gevoeligheid van het vetweefsel voor de onderdrukking van lipolyse door insuline en het ontbreken van hyperinsulinemie om voor deze insulineresistentie te compenseren. Deze resultaten bevestigen eerdere data die verstoringen in vetmetabolisme bij T2DM beschrijven. Bovendien blijkt uit deze data dat persoonskenmerken zoals BMI, dieet, het niveau van de fysieke fitheid en basale plasma waarden een grote invloed op de resultaten kunnen hebben en de interpretatie van de data kunnen bemoeilijken als zij niet gerapporteerd worden. De resultaten 
beschreven in de hoofdstukken 2 en 3 van dit proefschrift geven aan dat lichamelijke activiteit, of dat nu eenmalig of als onderdeel van een trainingsprogramma is, een effectieve manier is om verstoringen in de vet en koolhydraatstofwisseling karakteristiek voor insulineresistentie en T2DM te voorkomen en/of te verbeteren. De resultaten in hoofdstuk 2 beschrijven dat eenmalige inspanning bij T2DM patiënten de plasmaglucoseconcentratie verlaagt. Daarnaast blijkt uit hoofdstuk 3 dat een actieve leefstijl gedurende tientallen jaren geassocieerd is met een groter vermogen tot inspanning, een grotere capaciteit voor vetverbranding en een lager percentage lichaamsvet in vergelijking met een sedentaire leefstijl. Dit impliceert dat een hoge capaciteit tot vetverbranding en een gezonde lichaamssamenstelling kan worden gehandhaafd zolang er sprake is van voldoende lichamelijke inspanning, zelfs op een meer gevorderde leeftijd ( $\sim 60$ jaar). De lagere capaciteit om vetten te verbranden bij proefpersonen met obesitas en T2DM in vergelijking met getrainde controles kan hun capaciteit om een grote vetzuuraanvoer te verwerken, verminderen. Dit kan de kans op een grotere ectopische vetopslag, insulineresistentie en T2DM vergroten. Een deel van de gunstige effecten van lichaamsbeweging op substraatmetabolisme worden bewerkstelligd door AMPK, zoals een verbeterde opname van glucose in de spier, een hogere FA verbranding en verlaagde afgifte van FA. AMPK kan ook op farmacologische wijze worden geactiveerd door het middel 'AICAR'. In de hoofdstukken 4 en 5 van dit proefschrift hebben we onderzoek gedaan naar de effecten van in vivo toediening van AICAR op substraatmetabolisme bij respectievelijk gezonde proefpersonen en type 2 diabetes patiënten. AICAR infusie veroorzaakt een aanzienlijke daling in plasma vrije vetzuur en glucose concentraties, die wordt toegeschreven aan een remming van vetweefsel lipolyse en hepatische glucose afgifte. Dit verlagende effect op de vrije vetzuurconcentratie zou een lagere ectopische vetopslag tot gevolg kunnen hebben, en de daarmee samenhangende ontwikkeling of progressie van insulineresistentie kunnen voorkomen of vertragen. Hoewel acute AICAR infusie veilig en zonder bijwerkingen is gebleken, behoeven eventuele bijwerkingen die na langere termijn kunnen onstaan, nog nader onderzoek. 


\section{Dankwoord}

\section{Acknowledgements}


"Nobody said it was easy." (Coldplay, The Scientist)

en

"Always look on the bright side of life." (Monty Python, Life of Brian)

Twee regels die misschien standaard klinken, maar erg van toepassing zijn op de afgelopen jaren. Makkelijk was het niet, maar de vele leuke, grappige, gezellige en mooie tijden zal ik niet vergeten.

Dus hier is dan mijn proefschrift. Een slordige 150 pagina's serieus 'wetenschappelijk werk'. Het is algemeen bekend dat het dankwoord het meest gelezen onderdeel van een proefschrift is. Heel begrijpelijk, tijd is schaars en Jip en Janneke is toch wel beter leesbaar. Gelukkig geeft zelfs heel snel doorbladeren al een indruk van het werk dat aan dit proefschrift ten grondslag ligt. Uiteraard heb ik dat niet allemaal alleen kunnen doen, en in dit dankwoord neem ik dan ook graag de ruimte om diegenen te bedanken die in de afgelopen jaren, op welke wijze dan ook, hebben bijgedragen aan dit proefschrift.

Luc, mijn mail-aanhef is veranderd van 'Geachte heer van Loon' tot 'Hej Luc', en staat symbool voor mijn ontwikkeling van beginnend AIO naar een junior post-doc. Ik heb veel van je geleerd, zowel wetenschappelijk als persoonlijk. En volgens mij zijn er ook geen andere begeleiders die hun AIO's leren duiken, skieën, rotsklimmen, langlaufen, door grotten kruipen of golfen $(-)$ !

Ellen, door je aanstelling als professor ben je mijn promotor geworden, een rol die je met verve vervuld hebt. Ik heb onze discussies en je kritische blik erg gewaardeerd, het heeft me geholpen een eigen visie op type 2 diabetes te ontwikkelen. Dank ook dat je me meer bij jouw gezellige en enthousiaste 'vetstof'groep hebt betrokken.

Cees, het was een bijzonder genoegen om samen onderzoek te doen en dat - na enige moeite - te publiceren. Veel dank voor je kritische en waardevolle opmerkingen op de manuscripten en dit proefschrift, als co-auteur en promotor.

Ton en Wim, in de loop der jaren is jullie rol minder geworden, maar op de achtergrond waren jullie aanwezig en leverden jullie een belangrijke bijdrage aan dit proefschrift - door kritisch lezen van de manuscripten of door het stimuleren van een discussie over de onderzoeken. Dank daarvoor.

I would like to express my gratitude to the members of my thesis committee and/or opponents, Coen Stehouwer, Harm Kuipers, Michaela Diamant, Juleen Zierath, Marleen van Baak, Hans Sauerwein and Patrick Schrauwen for critical 
evaluation of the manuscript and/or their role as opponent during my thesis defense.

Sean McGee, Mark Hargreaves, Stephan Praet, Paul Smits, Cees Tack, Marlies Bosselaar, Petra van den Broek, Richard Jonkers, Ton Wagenmakers, Wim Saris, Hans Keizer, Maurice Pelsers and Trent Stellingwerff, thank you for your collaboration and contribution to the different chapters of this thesis, as well as the publications not included in this thesis.

Prof. Dr. Eric Ravussin, thank you for welcoming me to your lab as a MSc student. I truly enjoyed being involved in the top research projects in your HaPE group at the PBRC in Baton Rouge and I hope we will stay in touch.

Marlies, op het nippertje hebben we dan toch onze bron van frustratie, Chapter 4, gepubliceerd gekregen. Het was fijn om deze en andere vormen van AIOfrustratie af en toe met je te delen. Heel veel succes met de afronding van je eigen proefschrift, en geniet van je kids.

De proefpersonen uit de studies van dit proefschrift verdienen een enorm applaus, voor het geduldig doorstaan van de testen, het braaf volgen van protocollen, hun inzet en gezellige verhalen. Zonder hen zou dit onderzoek niet uitgevoerd kunnen worden.

Grote hulde ook aan mijn mede-M3'ers (Rene, Kristof, Ralph, Marika, Lex, Bart, Jan-Willem, Tim, Jodil, Letty, Milou, Dominique, Peter, Marlou, Joan, Antoine, Jos en Judith) en de dames van het SIRC (Annemie, Mia en Hanne) - altijd bereid op de meest onmogelijke tijden te helpen een infuus te zetten, te zoeken naar bioptnaalden, te passen op proefpersonen of samples te analyseren. Speciaal aan Jos, Joan, Jodil en Antoine, oneindige dank voor het analyseren van de eveneens eindeloze stroom plasma en spier!

Leden van het vetstof-overleg (Anneke v H, Anneke J, Chantalle, Cheryl, Eefje, Ellen, Gijs, Judith, Marleen, Yvonne, Johan, Nicole, Annemieke), pas in het laatste jaar ben ik meer bij jullie groep betrokken geraakt, maar ik heb de samenwerking en literatuurdiscussies zeer gewaardeerd.

Claudia, Larissa, Ilona, Kerstin en Desiree, wat zou de vakgroep zonder jullie moeten. Gesmijt met faxapparaten, onderzoekers wanhopig op zoek naar 
sleutels, geen post, geen printpapier en geen pepernoten met Sinterklaas. Het zou een chaos worden.

Loek en Paul, in mijn aanwezigheid weigeren Oxycons, Omnicals, computers (zelfs Apples!) en andere electronische apparaten met enige regelmaat te doen wat ze moeten doen. Gelukkig waren jullie daar dan altijd, en kon de geplande testdag gewoon doorgaan.

Dear fellow-ENLP'ers, the week we spent together was truly an unforgettable experience. I am sure we will stay connected.

Om even op adem te komen, een kop thee te drinken of een blokje om te wandelen was het fijn aan te kunnen kloppen bij het theekransje van de derde verdieping (Natalie, Annemiek, Kristel, Andrea's, Henrike, Steven, Freeha, Astrid, Marcel, Alberto, Ananda, Sanne, Jurriaan, Mieke, Sofie, Stijn, Femke, Anneke en Rick), Suus, Cheryl, Eefje of Annemieke. Marcel, je was een fijne kamergenoot, om mee te werken en te praten. Bovendien kan je heel hard mandarijntjes gooien.

Op weg naar een post-doc heb ik verder veel gehad aan de gesprekken en gedachtenwisselingen met Johan, Trent, Ralph, Annemieke, Margriet, Cheryl en Eefje. Dank voor de tips, suggesties, gedachten.

Tot slot een woord van algemene dank aan alle collega's van $\mathrm{HB}$ en BW die ik hier niet genoemd heb. Dank voor de gezellige werksfeer!

Dear Juleen Zierath, thank you for the warm welcome to your prestigious lab. It is an honour to work with you and your co-workers and am confident our collaboration will be successful.

Na ruim 2 pagina's is het nu tijd voor de mensen die misschien niets met de inhoudelijke aspecten van dit proefschrift te maken hebben gehad, maar zonder wie het me nooit gelukt was om de diepe dalen, puzzelstukjes en draken op mijn weg te verlaten, bij elkaar te leggen en te vermorzelen, en daarna dit proefschrift op papier te krijgen.

Onmisbaar is het mountainbiken en hardlopen geweest. Hypotheses opstellen, piekeren en over stenen of boomwortels knallen gaan nu eenmaal niet samen. Ook een aantal keer de St. Pietersberg op en af draven (al dan niet in de 
sneeuw, stortregen of brandende zon) schakelt de geest op een prettige manier uit. Lucie, Eugène, Roland, Irene, Jean H, Lara, Sybrand, Marc, Gerco, Eric, Inge, Jean B, Simone, Maas en andere loop- en MTB-idioten, dank voor de afleiding!

Suus, je bent een bijzonder mens, en stond altijd voor me klaar met een kop thee, zelfgebakken koekjes (cake, taart, muffins...) of de wandelschoenen.

Karin, ons contact is alles behalve regelmatig maar ik weet dat we aan elkaar denken, en af en toe lukt het toch om gezellig bij te kletsen...

Bianca, onze connectie was allereerst sportief maar bleek al na een paar dagen ook echt persoonlijk. Ik bewonder je sportieve prestaties enorm, net als je schijnbaar eindeloze bundel energie, voor je sport, werk, hond en vrienden. Wees voorzichtig met jezelf, zoals jij zijn er niet veel.

Miranda, ik was even bang dat mijn proefschrift je laptop om zeep ging helpen, maar hij heeft het uitgehouden. Volgende zomer misschien toch maar af en toe in de koelkast...? Heel veel dank voor de layout van dit boekje, zonder jou was het nooit zo mooi geworden. Maar het allerbelangrijkste, bedankt dat je zo'n mooi mens en lieve vriendin bent. Je bent wie je bent, en dat is iemand om trots op te zijn. I wish you and Lazaros a happy life together.

Eva, ik ben enorm trots dat jij mijn ' $1.5 x^{\prime}$ tweelingzusje bent. Diep respect voor wat je doet. Canada is niet alleen groter en verder weg dan Zweden, maar ook kouder, ze spreken er Frans en hebben er black flies die veel gemener zijn dan de Zweedse muggen. Maar je bent sterker, slimmer en groter dan ik, dus: je kan het zusje.

Niels, grote broer, harde werker en super MTB'er. Je luistert, denkt mee, geeft advies, precies wat een grote broer moet doen, en ik ben blij dat de rollen de laatste tijd ook wel eens omgekeerd zijn. Veel succes met zoeken naar die bergtop waar je op wilt zitten (fietsen).

Leen en Ria, ouders, we hebben ronduit zware tijden gekend, maar samen komen we er, dat weet ik zeker. Bedankt voor alles wat jullie voor me doen.

André, je betekent heel veel voor me. Je bent er altijd voor me, maar aarzelt ook niet om mijn gedachten in twijfel te trekken als je denkt dat dat nodig is. Zo heb je me enorm geholpen te zijn waar ik nu ben. 
Curriculum vitae 


\section{Curriculum vitae}

Hanneke Boon was born on July $24^{\text {th }} 1981$ in Rotterdam, the Netherlands. In 1999 she completed grammar school at the Erasmiaans Gymnasium in Rotterdam, the Netherlands. In the same year she started her studies in Health Sciences at the Maastricht University, Maastricht, the Netherlands. The focus of her specialisation was on exercise physiology and its role in the development of chronic metabolic disease. She was awarded a Dr. E. Dekker travel grant from the Netherlands Heart Foundation ('Hartstichting') to do a research internship at the prestigious Pennington Biomedical Research Center in Baton Rouge, Louisiana, USA, under supervision of Prof. Dr. Eric Ravussin. She graduated with distinction (cum laude) in February 2004, and started her PhD at the Department of Human Biology, Mastricht University, under supervision of Dr. L.J.C. van Loon and Prof. Dr. E.E. Blaak, funded by a grant from the Dutch Diabetes Research Foundation. In December 2007 she was nominated for the Young Physiologists Prize. In February 2008, she was selected to attend the European Nutritionist Leadership Program (ENLP) in Luxembourg and has since been a member of the ENLP network. From July to October 2009, she has been a visiting researcher at the Department of Molecular Medicine and Surgery, Section of Integrative Physiology, of the Karolinska Institute in Stockholm, Sweden, which is led by Prof. Dr. Juleen Zierath. After obtaining her PhD degree, she will continue her research at the Karolinska Institute as a post-doctoral researcher. 
List of publications 


\section{Full papers}

1. Bosselaar M, Boon $\mathbf{H}$, van Loon LJC, van den Broek PHH, Smits P, Tack CJ. Intra-arterial AICA-riboside administration induces NO-dependent vasodilation in vivo in human skeletal muscle. Am I Physiol Endocrinol Metab 2009; 297:E759-66.

2. Boon H, Bosselaar M, Praet SF, Blaak EE, Saris WHM, Wagenmakers AJ, McGee SL, Tack CJ, Smits P, Hargreaves M, van Loon LJC.

Intravenous AICAR administration reduces hepatic glucose output and inhibits whole body lipolysis in type 2 diabetic patients. Diabetologia 2008 Oct; 51(10): 1893-900.

3. Boon H, Blaak EE, Saris WHM, Keizer HA, Wagenmakers AJM, van Loon LJC. Substrate source utilisation in long-term diagnosed type 2 diabetes patients at rest, and during exercise and subsequent recovery. Diabetologia 2007 Jan; 50(1):103-12.

4. Boon H, Jonkers RAM, Koopman R, Blaak EE, Saris WHM, Wagenmakers AJM, van Loon LJC. Substrate source use in older, trained males after decades of endurance training. Medicine \& Science in Sports \& Exercise 2007 Dec; $39(12): 2160-70$.

5. Stellingwerff T, Boon $\mathbf{H}$, Gijsen AP, Stegen JH, Kuipers H, van Loon LJC. Carbohydrate supplementation during prolonged cycling exercise spares muscle glycogen but does not affect intramyocellular lipid use. Pflugers Arch Eur I Physiol 2007;454(4):635-47.

6. Stellingwerff T, Boon H, Jonkers RA, Senden JM, Spriet LL, Koopman R, van Loon RJ. Significant intramyocellular lipid use during prolonged cycling in endurance-trained males as assessed by three different methodologies. Am I Physiol Endocrinol Metab 2007;292(6):E1715-23.

7. Pelsers MMAL, Tsintzas $\mathrm{K}$, Boon $\mathrm{H}$, et al. Skeletal muscle fatty acid transporter protein expression in type 2 diabetes patients compared with overweight, sedentary men and age-matched, endurance-trained cyclists. Acta Physiologica 2007 Ju1;190(3):209-19. 


\section{Accepted abstracts for international scientific meetings}

2008 European Association for the Study of Diabetes (EASD)

H.Boon, M. Bosselaar, S.F.E. Praet, E.E. Blaak, W.H.M. Saris, A.J.M. Wagenmakers, S.L. McGee, C.J. Tack, P. Smits, M. Hargreaves, and L.J.C. van Loon. Intravenous AICAR administration reduces hepatic glucose output and inhibits whole body lipolysis in type 2 diabetic patients. Oral presentation.

\section{American Diabetes Association (ADA)}

H.Boon, E.E. Blaak, W.H.M. Saris, H.A. Keizer, A.J.M.Wagenmakers and L.J.C. van Loon. Substrate utilization in type 2 diabetes at rest, during exercise and subsequent recovery. Oral presentation.

\section{European Association for the Study of Diabetes (EASD)}

H. Boon, R.A.M. Jonkers, R. Koopman, E.E. Blaak, W.H.M. Saris, A.J.M. Wagenmakers and L.J.C. van Loon. Substrate source utilization in master athletes compared to healthy sedentary controls. Poster presentation.

2003 North American Association for the Study of Obesity (NAASO) H. Boon, M.I. Frisard, C.P. Brown, S.M. Jazwinski, J.P. DeLany and E. Ravussin. Validation of accelerometers to assess physical activity in elderly subjects. Oral presentation. 


\section{Abbreviations}

\begin{tabular}{|c|c|}
\hline $\mathrm{ACC}$ & acetyl-CoA carboxylase \\
\hline AICAR & 5-aminoimidazole-4-carboxamide riboside \\
\hline AMP & adenosine monophosphate \\
\hline AMPK & $5^{\prime}$-AMP-activated protein kinase \\
\hline Ar & acetate recovery factor \\
\hline AS160 & phospho-Akt Substrate of $160 \mathrm{kDa}$ \\
\hline AU & arbitrary unit \\
\hline DAG & diacylglycerol \\
\hline EN\% & energy percentage \\
\hline ENT & equilibrative nucleoside transporter \\
\hline ERK & extracellular signal-regulated protein kinase \\
\hline FFA/NEFA & free fatty acids/ non esterified fatty acids \\
\hline $\mathrm{FBF}$ & forearm blood flow \\
\hline $\mathrm{FGU}$ & forearm glucose uptake \\
\hline GSK & glycogen synthase kinase \\
\hline GC-(IR)MS & gas chromatograph (-isotope ratio) mass spectrometer \\
\hline HDAC5 & histone deacetylase 5 \\
\hline HPLC & high-performance liquid chromatography \\
\hline IMTG & intramyocellular triacylglycerol \\
\hline L-NMMA & $\mathrm{NG}_{\text {-monomethyl-L-arginine }}$ \\
\hline $\mathrm{Pr}^{13} \mathrm{CO}_{2}$ & production of ${ }^{13} \mathrm{CO}_{2}$ \\
\hline $\mathrm{Ra}$ & rate of appearance \\
\hline $\mathrm{Rd}$ & rate of disappearance \\
\hline RIA & radioimmunoassay \\
\hline Rox & rate of oxidation \\
\hline T2DM & type 2 diabetes mellitus \\
\hline TTR & tracer/tracee ratio, plasma enrichment \\
\hline $\mathrm{VO}_{2}$ & oxygen uptake \\
\hline $\mathrm{VCO}_{2}$ & $\mathrm{CO}_{2}$ production \\
\hline $\mathrm{VO}_{2} \max$ & maximal oxygen uptake capacity \\
\hline$W \max$ & maximal workload capacity \\
\hline
\end{tabular}




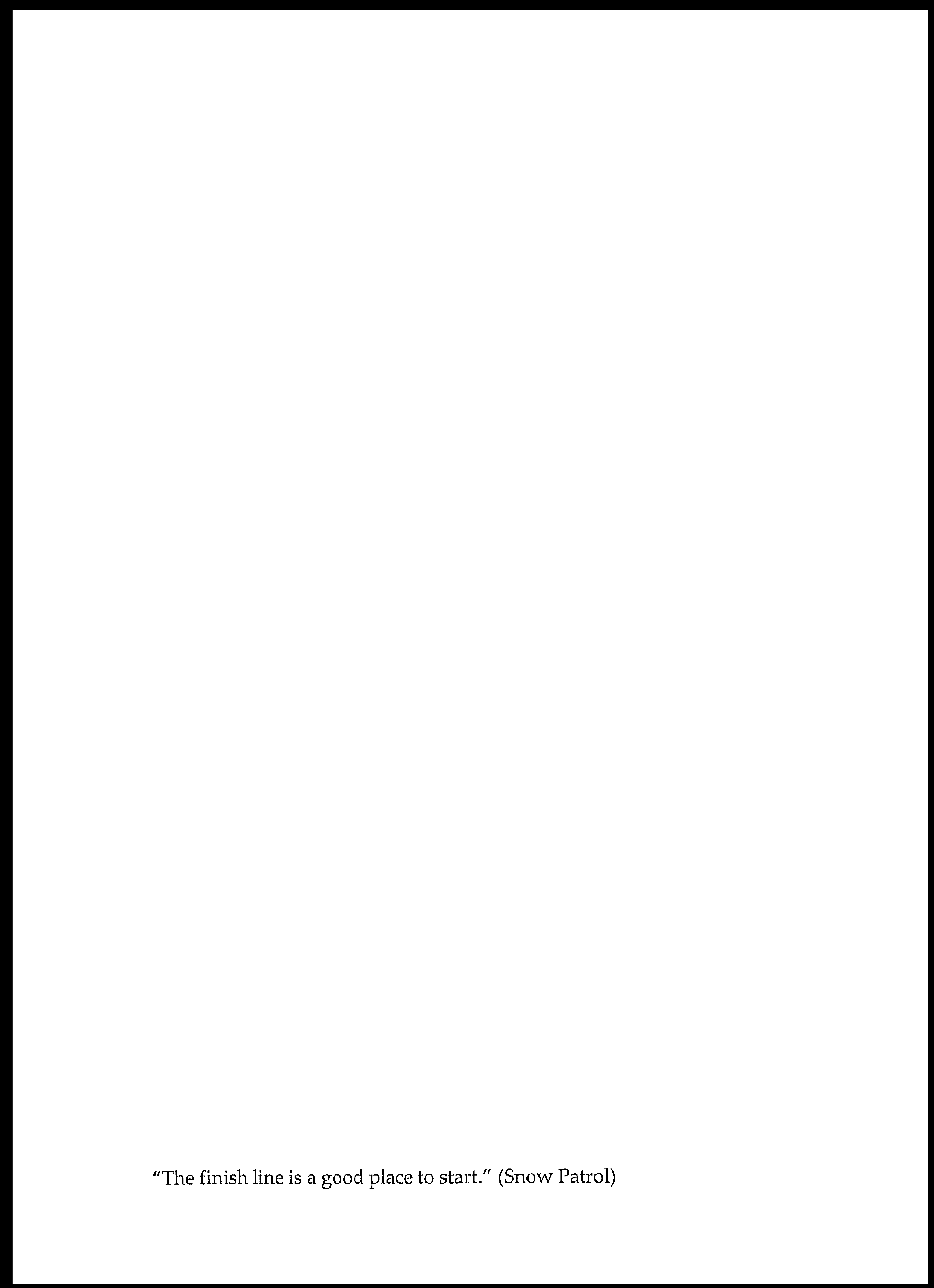

